Q norden

\title{
Waterbird Populations and Pressures in the Baltic Sea
}

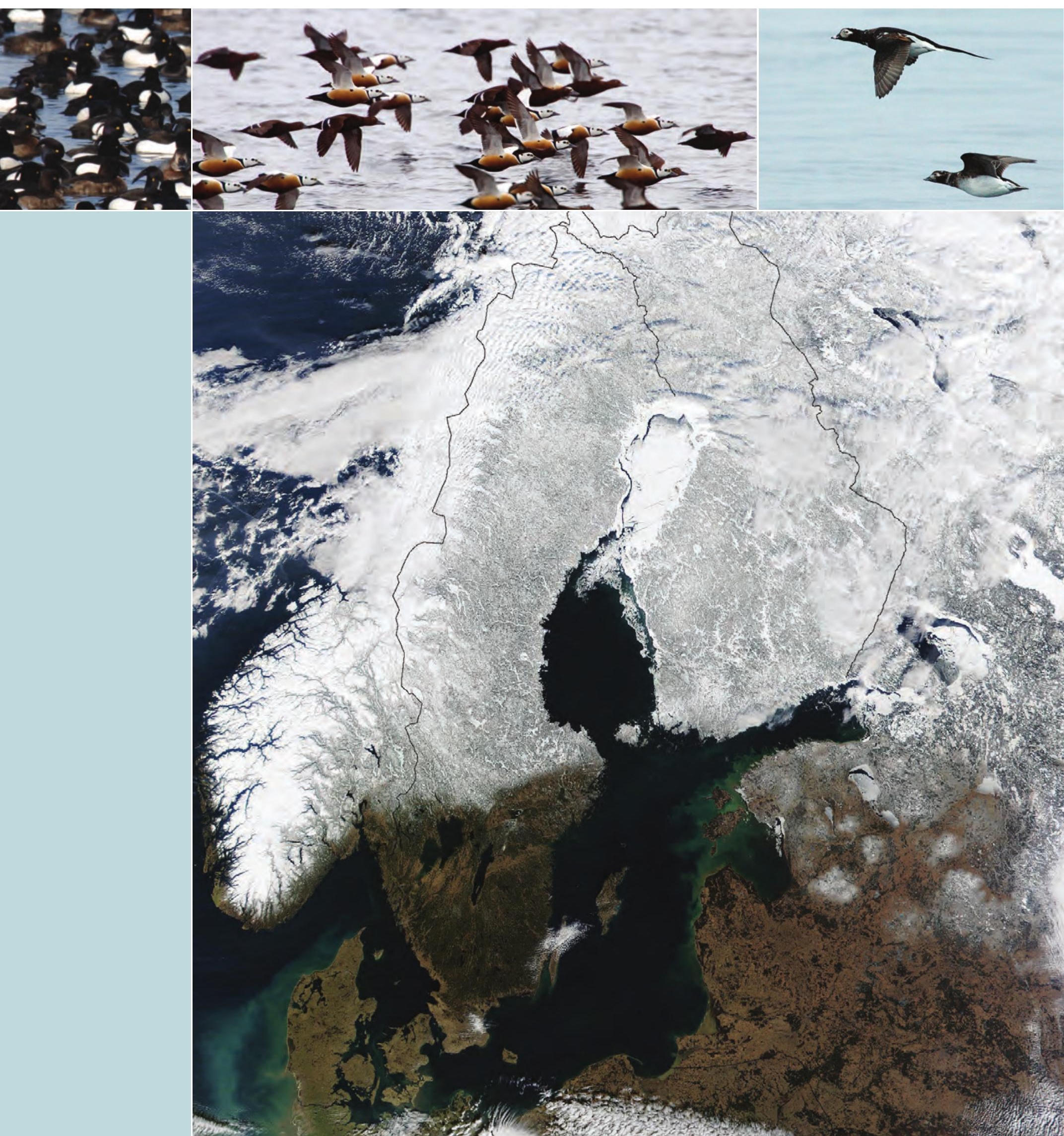


enorden 



\section{Waterbird Populations and Pressures in the Baltic Sea}

Henrik Skov, Stefan Heinänen, Ramūnas Žydelis, Jochen Bellebaum, Szymon Bzoma, Mindaugas Dagys, Jan Durinck, Stefan Garthe, Gennady Grishanov, Martti Hario, Jan Jacob Kieckbusch, Jan Kube, Andres Kuresoo, Kjell Larsson, Leho Luigujoe, Włodzimierz Meissner, Hans W. Nehls, Leif Nilsson, Ib Krag Petersen, Markku Mikkola Roos, Stefan Pihl, Nicole Sonntag, Andy Stock, Antra Stipniece and Johannes Wahl 
Waterbird Populations and Pressures in the Baltic Sea

TemaNord 2011:550

ISBN 978-92-893-2249-2

(C) Nordic Council of Ministers, Copenhagen 2011

Print: Rosendahls Bogtrykkeri AS

Copies: 430

Photos: Kjell Larsson, Thomas W. Johansen, Arthur Grosset, Minden Pictures

Printed in Denmark

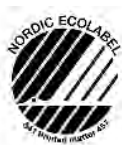

This publication has been published with financial support by the Nordic Council of Ministers But the contents of this publication do not necessarily reflect the views, policies or recommendations of the Nordic Council of Ministers.

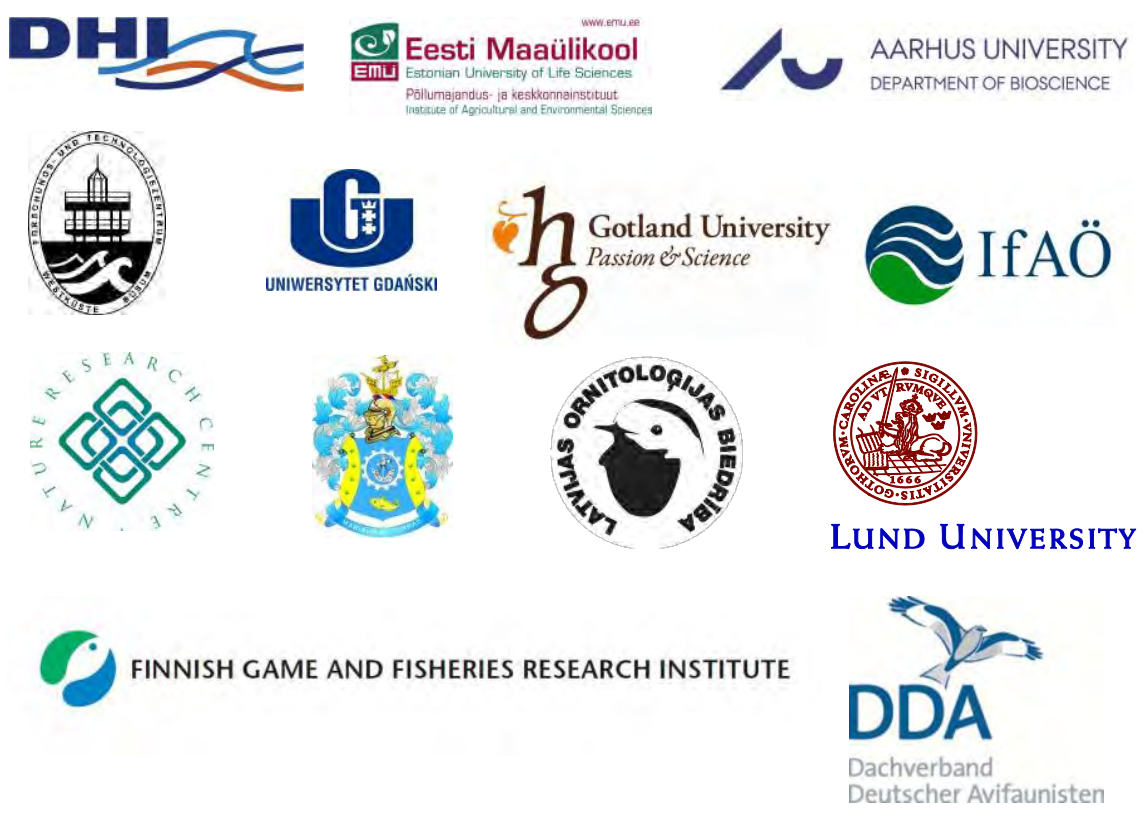

\section{Nordic co-operation}

Nordic co-operation is one of the world's most extensive forms of regional collaboration, involving Denmark, Finland, Iceland, Norway, Sweden, and Faroe Islands, Greenland, and Åland.

Nordic co-operation has firm traditions in politics, the economy, and culture. It plays an important role in European and international collaboration, and aims at creating a strong Nordic community in a strong Europe.

Nordic co-operation seeks to safeguard Nordic and regional interests and principles in the global community. Common Nordic values help the region solidify its position as one of the world's most innovative and competitive.

Nordic Council of Ministers

Ved Stranden 18

DK-1061 København K

Phone (+45) 33960200

www.norden.org 


\section{Content}

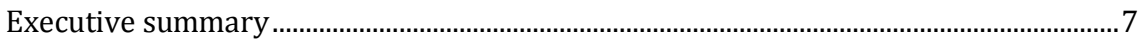

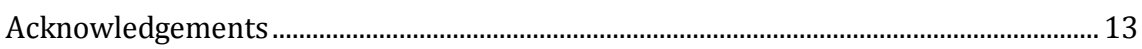

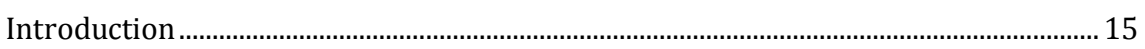

1. The Baltic Sea Environment........................................................................................ 19

1.1 Formation of the sea......................................................................................... 19

1.2 Hydrology of the Baltic Sea ......................................................................... 19

1.3 Diversity of marine species in the Baltic Sea................................................. 20

1.4 Marine habitats ............................................................................................. 20

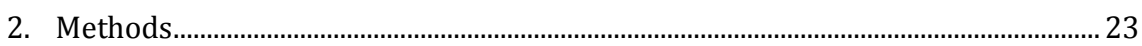

2.1 Study region .................................................................................................... 23

2.2 Selection of bird species and seasons ………............................................... 23

2.3 Coverage including comparisons with 1992/93 ............................................. 24

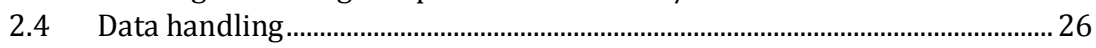

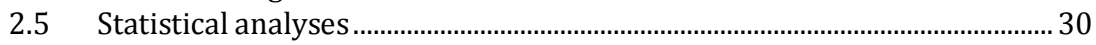

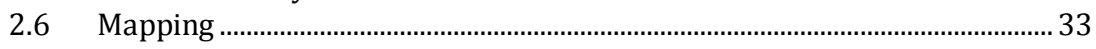

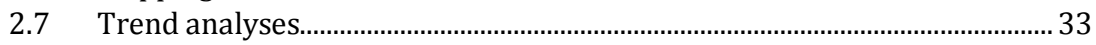

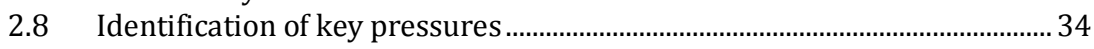

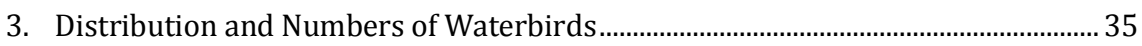

3.1 Red-throated Diver Gavia stellata and Black-throated Diver Gavia

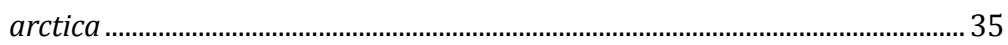

3.2 Great Crested Grebe Podiceps cristatus ............................................................. 38

3.3 Red-necked Grebe Podiceps grisegena ........................................................ 40

3.4 Slavonian Grebe Podiceps auritus ................................................................... 42

3.5 Great Cormorant Phalacrocorax carbo ............................................................. 44

3.6 Mute Swan Cygnus olor ................................................................................. 47

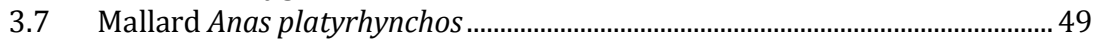

3.8 Common Pochard Aythya ferina ........................................................................ 51

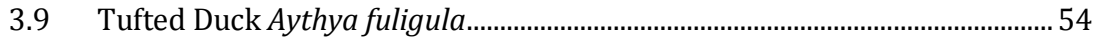

3.10 Greater Scaup Aythya marila ....................................................................... 57

3.11 Common Eider Somateria mollissima ................................................................ 59

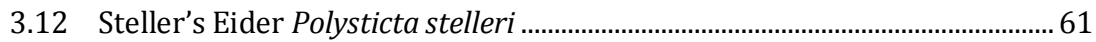

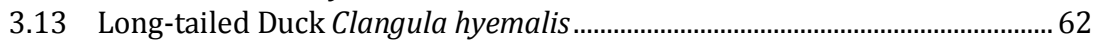

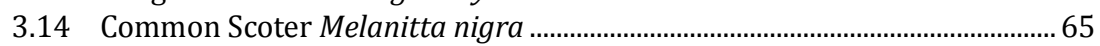

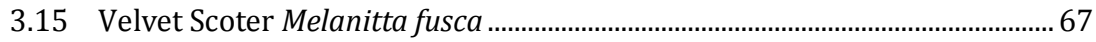

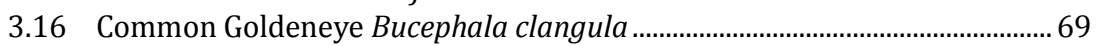

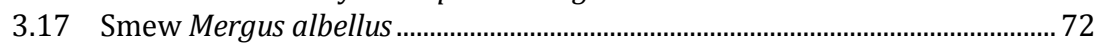

3.18 Red-breasted Merganser Mergus serrator....................................................... 75

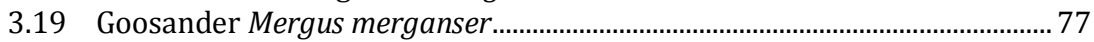

3.20 Common Coot Fulica atra ................................................................................ 80 
4. Changes in wintering populations of waterbirds in the Baltic Sea........................... 83

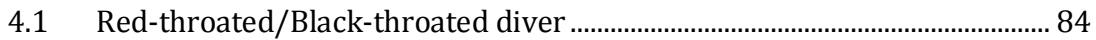

$4.2 \quad$ Great Crested Grebe ................................................................................... 84

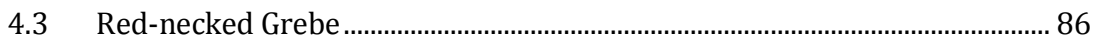

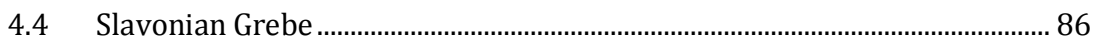

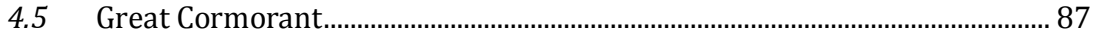

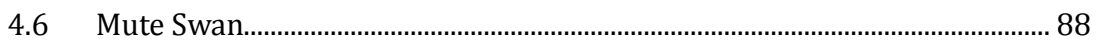

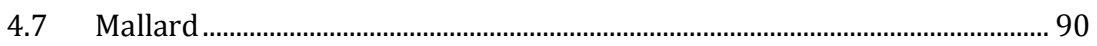

4.8 Common Pochard ............................................................................................... 91

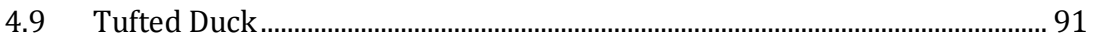

4.10 Greater Scaup........................................................................................... 92

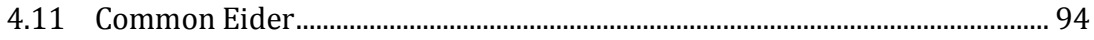

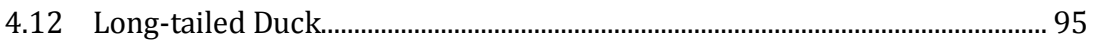

4.13 Common Scoter ................................................................................................ 96

4.14 Velvet Scoter ................................................................................................... 97

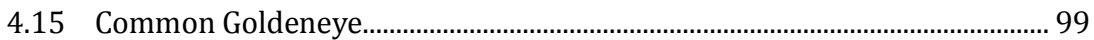

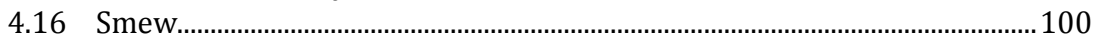

4.17 Red-breasted Merganser ............................................................................. 101

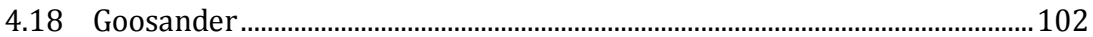

4.19 Common Coot .................................................................................................103

5. Conservation status of wintering waterbirds in the Baltic Sea...............................107

6. Interactions between human activities and waterbirds in the Baltic Sea.............109

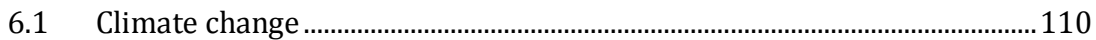

6.2 Meso-scale oceanographic oscillations ……...........................................114

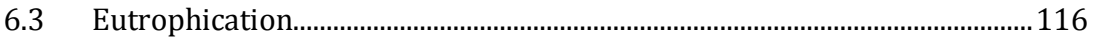

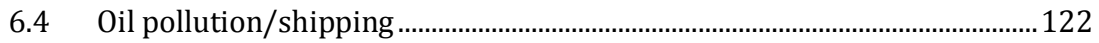

6.5 Hazardous substances.............................................................................124

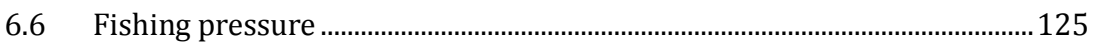

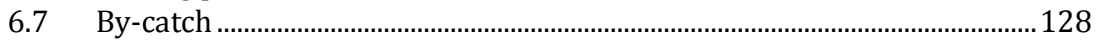

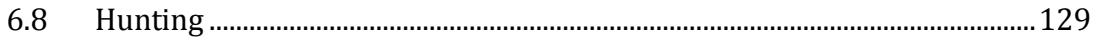

6.9 Fisheries discards.........................................................................................131

6.10 Predation by native and introduced predators .............................................132

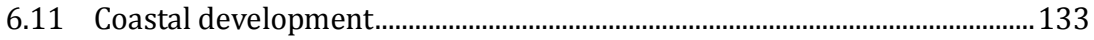

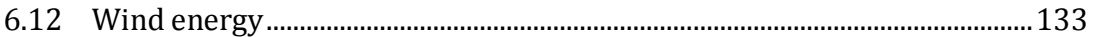

6.13 Sand and gravel extraction ...............................................................................134

6.14 Identification of key pressures.......................................................................134

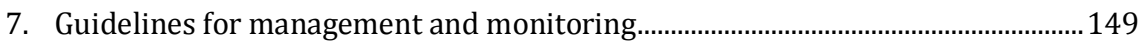

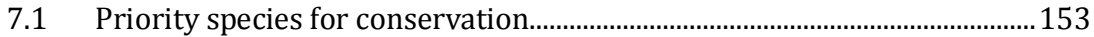

7.2 Performance indicators..................................................................................153

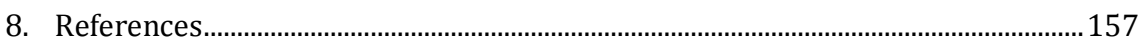

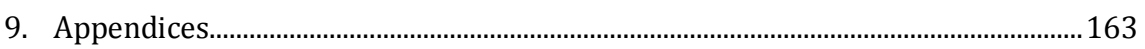

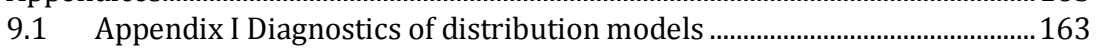

9.2 Appendix II Bansai 3 model complex............................................................191

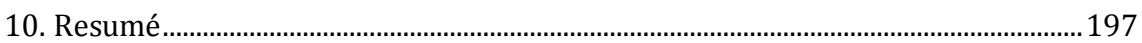




\section{Executive summary}

This report outlines the results of the coordinated census of wintering waterbirds in the Baltic Sea 2007-2009 undertaken under the SOWBAS project (Status of wintering Waterbird populations in the Baltic Sea). The international co-ordination and analyses of the waterbird census was funded by a grant from the Nordic Council of Ministers, and the surveys were funded by the regional and national authorities and organised by the involved governmental agencies, universities, NGOs and private consulting companies.

The hitherto only simultaneous census of the size of the wintering waterbird populations was carried out in 1992-1993, and documented population sizes of nine million birds which use the region. Although the results from this census have proven a major contribution to the designation of offshore Natura 2000 sites throughout the Baltic Sea, the knowledge of the recent status of the wintering waterbird populations has been inadequate to describe the conservation status and integrate waterbird protection within the wider marine management schemes being developed and implemented at regional and national levels.

The lacking information has seriously degraded the potential for implementing marine conservation goals listed in the HELCOM Baltic Sea Action Plan and the Nordic Council of Minister's Environmental Action Programme for 2005-2008 and 2009-2012, especially with respect to ecosystem-based management in the open waters of the Baltic Sea, and the assessment of impacts from eutrophication, anthropogenics, fisheries and climate change on the major biodiversity assets of the region. As a result, the ecological objectives of the Baltic Sea Action Plan (BSAP), which aims at restoring good ecological status of the Baltic marine environment by 2021, currently do not include targets and indicators for wintering waterbirds.

This report attempts to fill these gaps in our knowledge of the status and recent trends in the populations of wintering waterbirds in the Baltic Sea. The habitats and areas covered by this report are largely identical to the ones covered during the census in 1992-1993 (Durinck et al. 1994). Like the former census the census in 2007-2009 did not include freshwater habitats. The report is subdivided into a Methods chapter and five chapters covering the Results. Compared to the report covering the results from the 1992-1993 census the results for the offshore species in this report have been achieved through the application of spatial modelling rather than by application of interpolation techniques. Although both methods were constrained to cover the regions actualy cov- 
ered by the surveys interpolation techniques should be regarded as less robust than spatial modelling as they disregard the distribution of physical and biological habitat features.

The first part of the results covers the updated accounts of the status of species distributions, numbers and habitats. Here, for each species an updated overview of the importance of the Baltic Sea, the main wintering areas and patterns of distribution is provided, including comparisons with the situation in 1992/93. In the second part "Changes in wintering populations of waterbirds in the Baltic Sea" the changes in population sizes and distributions are further elaborated by trends from selected areas with intensive coverage over the 23-year period from 1987 to 2009 and by comparisons of distributions between 1992-93 and 20072009. The third part "Conservation status of wintering waterbirds in the Baltic Sea" summarises the results of the species-specific population assessments. The fourth part covers interactions between human activities and waterbirds in the Baltic Sea, and includes detailed reviews of regional trends of potential pressures to waterbirds and analyses of linkages between individual waterbird species and pressures and identification of key pressures per species. The fifth and conclusive chapter provides guidelines for management and monitoring, including a preliminary selection of Baltic-wide indicators for waterbirds.

Of the 20 species of waterbirds covered by this report the total population size has decreased between the two periods for 11 species; 7 of which have declined seriously by more than $30 \%$ over 16 years. The estimated total number of wintering waterbirds for the period 20072009 was 4.41 million compared to 7.44 million during 1992-1993; a reduction equivalent to $41 \%$. The sum of proportions of the biogeographic populations may be used as a proxy for total conservation status. A comparison between the two periods shows a reduction in total conservation status of $30 \%$.

Despite these overall large declines in the abundance of wintering waterbirds in the Baltic Sea the results of the surveys show variations to the general picture. Both the survey results and the trend data indicated stable or increasing populations of Mute Swans, Mallards and Common Coots in almost all areas of the Baltic Sea since the census 1992-1993. The trend analyses revealed that in fact numbers of Mute Swans in the Kattegat have declined since 1995 with an annual rate of $3 \%$, whereas in the central parts of the Baltic Sea numbers have generally increased annually by 2$4 \%$ and in the northern Baltic by $6 \%$. Despite overall positive population developments numbers of wintering Mallards have declined in SchleswigHolstein, Finland and Estonia and numbers of Common Coots have declined in Schleswig-Holstein. Negative correlations with nutrient concentrations are documented directly for Mallards in Estonia and Mute Swans in the Straits and in the German Central Baltic Coast, and indirectly by the positive relationship between Mallards and secchi depth in the German 
Central Baltic Coast and the same for Common Coot in the Straits. The general positive status of herbivorous waterbirds in the Baltic is thus seen as a response to the general improvement of water quality driven by the coordinated implementation since 1993 of politic action plans to combat eutrophication. In addition, positive correlations with winter sea temperature and the Baltic Sea Index are seen in all three species in the central and southern regions.

The surveys and trend analyses documented that benthic carnivores in coastal and offshore habitats have experienced different population developments since 1993. While benthic carnivores with a coastal distribution have either shown moderate declines, stable populations or population increases seaducks and mergansers with an offshore distribution have all declined seriously. Unfortunately, long time series of the abundance of seaducks and mergansers in the offshore parts of the Baltic Sea have not been available. Accordingly, despite steep declines in the concentration of nutrients and hence in benthic productivity which have coincided with the declines in all seaduck species the correlations with nutrient concentrations are generally weak. However, declines of more than $45 \%$ in the abundance of seaducks and mergansers wintering in the Baltic Sea since 1993 are documented. The offshore surveys for the Common Eider, Velvet Scoter and Long-tailed Duck documented declines in the overall abundance, and a relatively stronger decline taking place in the south and west. Consequently, as no northward shift has been observed the distribution of these species has contracted. The Longtailed Duck data documented ubiquitous declines of $65 \%$ of this the most numerous waterbird species wintering in the Baltic Sea. Similar declines were documented for the Steller's Eider and Velvet Scoter. The decline in Common Eider was 51\%, in Common Scoter 47\% and in Redbreasted Merganser 42\%.

In the coastal zone and lagoons, numbers of Common Pochards and Goosander have been stable since 1993, while Greater Scaup and Smew have declined moderately (by $25.9 \%$ and $13.0 \%$, respectively), and all four species have displayed a moderate northward shift in the distribution.

Tufted Ducks and Common Goldeneyes both displayed an overall large-scale increase in abundance, and a significant northward shift in distribution. Now, the largest concentrations of both species are found in the archipelagoes of the Swedish Baltic coast. The coastal time series of the Common Goldeneye show annual increases of 7-9\% in Estonia and Finland, and 2.8\% along the central Swedish coast, while Tufted Ducks have increased annually in Estonia by $18.9 \%$ and by $3.9 \%$ along the central Swedish coast.

The northward shift in the distribution of ducks of Aythya genus and Common Goldeneye may be interpreted as a response to climate change as reflected by positive correlations between the time series for these species and water temperature and the Baltic Sea Index. 
The development in the number of fish-eating species of waterbirds (divers, grebes and cormorants) wintering in the Baltic Sea differed to a large extent between the species. The estimates of Redthroated/Black-throated Divers indicate a serious decline of $85 \%$ since 1993. Numbers of Great Crested Grebe have declined moderately by $27 \%$, while Slavonian Grebes are now more abundant in the Baltic during winter, and have increased by $61 \%$. As no ship-based surveys were undertaken in Danish waters the population development for Rednecked Grebes is uncertain. With the exception of Kattegat, Great Cormorant showed large-scale increases throughout the Baltic. The largest increases have taken place in the Mecklenburg-Vorpommern and Poland (annual increases of $11 \%$ and 19\%).

Indicators are suggested both in terms of priority species for conservation and species which may be used as performance indicators in relation to the international and national actions taken to reduce the anthropogenic pressures in the Baltic Sea. Multiple pressures can be identified as playing an important (either negative or positive) role in the development of populations and distributions of most species of waterbirds. Teasing out the relative influence of each pressure on the health and conservation status of each species will require more detailed statistical analyses, which are outside the scope of this report. Thus, the suggested indicators should be seen as a first step in the direction of including targets and indicators for wintering waterbirds into the Baltic Sea Action Plan (BSAP).

The list of priority species for conservation has been proposed on the basis of species listed on Annex I to the EC Birds Directive (EC Birds Directive 1979) or on the basis of the importance of the Baltic Sea to the relevant bio-geographic population. With respect to the latter, species for which the Baltic Sea is of global significance in relation to the reference bio-geographic population ( $\geq 25 \%$ ) have been selected.

A wide range of waterbird ecotypes (herbivores, omnivores, molluscivores) may be used as indicators of climate change. Although the BSAP does not yet cover objectives related to climate changes it is worth noting that ubiquitous north-ward shifts in the distribution of wintering waterbirds have taken place over the last 15 years. The majority of northward distribution shifts may be coupled to reductions in ecosystem capacity in the southern Baltic as well as to increases in water temperature and the related increased availability of open water areas. Despite a lack of distributional change the trends of Mute swan, Mallard and Common Coot are also positively correlated with rising water temperatures in the Baltic Sea. This relationship is not surprising given the sensitivity of these species to cold winter and extensive ice cover.

Further studies are needed to investigate the geographical and habitat specific responses of bivalve-feeding seaducks to variable levels of reductions in nutrient load to the Baltic ecosystem. At this stage, howev- 
er, large-scale declines in the number of wintering seaducks and mergansers have been observed in parallel to similar declines in nutrient loads of coastal waters of the southern and central Baltic Sea. The results of this study stress the importance of eutrophication as a key driving factor for the spatio-temporal variability in food supply for and abundance of wintering waterbirds in the Baltic Sea. At the same time it should be stressed that several of the species of waterbirds which are declining in the Baltic Sea are recruited from breeding areas in the Siberian Arctic, sub-Arctic and tundra regions, and thus may be object of direct or indirect effects of climate-induced ecosystem changes in these regions. Indeed, recent monitoring of the Arctic migration in Estonia has revealed ubiquitous low proportions of juveniles among Arctic and tundra species of waterbirds (Ellermaa et al. 2009).

Indicators of oil pollution level can be developed from beached bird surveys and samples of net-drowned birds. Illegal discharges of oil pollution from ship traffic introduce significant extra mortality to wintering waterbirds in offshore Baltic waters. The scale and significance of the problem can not currently be assessed for all areas, but for Swedish offshore waters current mortality rates and proportions of oiled birds indicate that oil pollution possesses one of the most important threats to waterbirds, particularly to Long-tailed Ducks and Black Guillemots.

Despite the current lack of national or international monitoring programmes on incidental by-catches of waterbirds in the Baltic Sea bycatches have been reported in several areas and for several fisheries/waterbird scenarios in the Baltic Sea. In general, all diving species today experience extra-mortality due to by-catches in gill-nets. Without dedicated monitoring activities no reliable estimates of the scale of the problem can be obtained. 



\section{Acknowledgements}

The international co-ordination and analyses of the waterbird census was funded by a grant from the Nordic Council of Ministers. At the national level, the surveys were funded by the regional and national authorities and organised by the governmental agencies as part of their monitoring programmes or as targeted surveys.

The census and this publication would not have been possible without the efforts of the hundreds of observers, who carried out the counts from shore, aeroplanes and ships. Many of the observers participated in the annual International Midwinter Census organised by Wetlands International, while others took part in the counts which were specifically set up for this census. The pilots and ship crews are thanked for their kind support and collaboration.

The Swedish surveys were funded by Naturvårdsverket. The surveys on Hoburgs Bank during 2001-2003 were funded by WWF Sweden. Two surveys in 2007 and 2008 in the Pomeranian Bight were funded by Nord Stream AG. The surveys in Fehmarnbelt during 2009 were funded by Femern A/S. The surveys in Germany were funded by the Federal Agency for Nature Conservation (BfN).

Monitoring data from Kiel Bight were kindly provided by Landesamt für Landwirtschaft, Umwelt und ländliche Räume. 



\section{Introduction}

This report outlines the results of the coordinated census of wintering waterbirds in the Baltic Sea 2007-2009 undertaken under the SOWBAS project (Status of wintering Waterbird populations in the Baltic Sea).

The wintering waterbird populations constitute one of the most important and spectacular elements of the Baltic ecosystem. The hitherto only coordinated waterbird census of the size of the wintering waterbird populations of entire Baltic Sea was carried out in 1992-1993, and documented population sizes of nine million birds which use the region (Durinck et al. 1994). Although the results from this census have proven a major contribution to the designation of offshore Natura 2000 sites throughout the Baltic Sea, the knowledge of the recent status of the wintering waterbird populations has been inadequate to describe the conservation status and integrate waterbird protection within the wider marine management schemes being developed and implemented at regional and national levels. The lack of a recent update of Baltic waterbird populations has had negative consequences for the implementation of sustainable fisheries, energy and transport industries as well as for the international nature conservation commitments like the EC Birds Directive. The lacking information has also seriously degraded the potential for implementing marine conservation goals listed in the HELCOM Baltic Sea Action Plan (HELCOM 2007) and the Nordic Council of Minister's Environmental Action Programme for 2005-2008 and 2009-2012 (Nordic Council of Ministers 2005, 2008), especially with respect to ecosystem-based management in the open waters of the Baltic Sea, and the assessment of impacts from eutrophication, anthropogenics, fisheries and climate change on the major biodiversity assets of the region. As a result, the ecological objectives of the Baltic Sea Action Plan (BSAP), which aims at restoring the good ecological status of the Baltic marine environment by 2021, currently do not include targets and indicators for wintering waterbirds.

Further, the lack of updated censuses disenhances the establishment of a future Baltic-wide monitoring programme focused on waterbirds within HELCOM (as decided by HELCOM in 2002). After finalisation of the pilot project in 2003 and 2004, the HELCOM Waterbird Monitoring Programme was scheduled to start in 2006 following an implementation phase in 2005. The minimum requirements for the Baltic-wide monitoring programme for wintering waterbirds include the following key habitats, which may be regarded as holding significant proportions of the European wintering populations of waterbirds: 
- Lagoons and fjords;

- Sandy and muddy coastal areas to a depth of $10 \mathrm{~m}$;

- Archipelago areas of Estonia, Finland and Sweden;

- Sub-littoral soft and hard bottom areas between $10 \mathrm{~m}$ and $30 \mathrm{~m}$;

- Offshore banks.

Due to the Wetlands International Midwinter Census the monitoring of waterbirds wintering in the littoral zone of the Baltic Sea is regarded as adequate to resolve time trends for most regions and countries for coastal habitats, including most ice-free lagoons, fjords and coastal areas. As a contrast, the almost complete lack of quantitative data on waterbirds wintering in offshore areas has made it virtually impossible to track changes in populations of wintering seaducks, divers and grebes, including the numerically and ecologically dominating seaduck species accounting for $80 \%$ of the wintering waterbird fauna in the Baltic Sea, like Long-tailed Duck Clangula hyemalis, Velvet Scoter Melanitta fusca and Common Scoter Melanitta nigra.

This report attempts to fill these gaps in our knowledge of the status and recent trends in the populations of wintering waterbirds in the Baltic Sea. The report is subdivided into a Methods chapter and five chapters covering the Results. The Methods chapter deals with the coverage obtained during the 2007-2009 census, and includes comparisons with the coverage obtained during the 1992-1993 census. The survey methods are described, with technical details of land-based, aerial total counts as well as aerial and ship-based line transect surveys. An international census of this kind would not have been possible without coordination of databases, and a description of the national databases, quality assurance and assembly of the combined databases is provided, including issues like integration of data from multiple survey platforms, correction for distance bias and creation of geo-databases. Compared to the report covering the results from the 1992-1993 census (Durinck et al. 1994) the results for this report have been achieved through the application of spatial modelling. Hence, the Methods include detailed accounts of the development of conceptual models, applied geo-statistical analyses, spatial model design and model validation. The Methods also describe the projection and scale used for the mapping system and the analyses of change and trends in wintering waterbird populations and pressures between 1998-1993 and 2007-2009.

The first part of the results is entitled "Distribution and Numbers of Waterbirds" and takes the form of updated accounts of the status of species distributions, numbers and habitats. Here, for each species an updated overview of the importance of the Baltic Sea, the main wintering areas and patterns of distribution is provided, including comparisons with the situation in 1992/93. In the second part "Changes in wintering populations of waterbirds in the Baltic Sea" the changes in population 
sizes and distributions are further elaborated by trends from selected areas with intensive coverage over the 23-year period from 1987 to 2009 and by comparisons of distributions between 1992-93 and 20072009. The third part "Conservation status of wintering waterbirds in the Baltic Sea" summarises the results of the species-specific population assessments. The fourth part covers interactions between human activities and waterbirds in the Baltic Sea, and includes detailed reviews of regional trends of potential pressures to waterbirds and analyses of linkages between individual waterbird species and pressures and identification of key pressures per species. The fifth and conclusive chapter provides guidelines for management and monitoring, including a preliminary selection of indicators. 



\section{The Baltic Sea Environment}

\subsection{Formation of the sea}

The Baltic Sea is a brackish non-tidal sea covering about $415,000 \mathrm{~km}^{2}$ (including the Kattegat, the Danish straits, the Bothnian Bay, the Bothnian Sea andthe Gulf of Finland). The Baltic Sea was created after the lce Age. 10,000 years ago, a milder climate caused the ice in Sweden to melt, and the Baltic Ice Lake found an outlet to the ocean over central Sweden. Subsequently, this outlet was blocked due to the progressing uplift of mainland Sweden. As a result, the Baltic Sea basin became again an isolated lake. Because the land uplift was greater in the north than in the south, the floor of the Baltic Sea basin slowly tilted. About 7,500 years ago, a new contact with the ocean was established through the Danish sounds and straits. Since then, this outlet has been the only connection between the Baltic Sea and the North Atlantic.

\subsection{Hydrology of the Baltic Sea}

The limited connection of the Baltic Sea with the open sea and the large input of fresh water from rivers have resulted in water masses consisting of an upper layer with continuous flow of brackish water and a lower layer of higher salinity. In the lower layer, the water is renewed in an oscillatory manner through salt water intrusions from the North Sea. Accordingly, the salinity varies from 15 to $30 \%$ in the Kattegat, to 5-6\% in the central parts of the Baltic proper, to about $3 \%$ in the Bothnian Bay. Although the maximum depth of the Baltic Sea is $459 \mathrm{~m}$, it is a relatively shallow sea with a mean depth of about 55 metres. Furthermore, large parts are less than $25 \mathrm{~m}$ deep, especially in Danish, German and Polish waters, and a number of large very shallow semi-open lagoons with water depths of just 1 to 2 meters are found here. The water of the lagoons is much more brackish than that of the open Baltic. The exchange of water between the lagoons and the open sea takes place only through a few inlets. Consequently, inflowing river water remains in the lagoons, which function as buffers to the Baltic Sea. 
The duration and extend of ice-cover are of crucial importance for the ecosystem of the Baltic Sea. In general, ice covers most of the Bothnian Bay for 5-6 months. Frequently, the ice covers the shallow parts of the Bothnian Sea, the Gulf of Finland and the Gulf of Riga. However, the central part of the Baltic proper is always ice-free.

\subsection{Diversity of marine species in the Baltic Sea}

The number of species in the Baltic Sea is low compared to fully marine systems. As compared to the North Sea, the Baltic Sea holds a very poor flora and fauna. The number of marine species decreases dramatically as one goes through the Danish straits into the Baltic proper and continues to decrease up to the Gulf of Finland and the Bothnian Bay. The continuously decreasing salt concentration is the main reason for the poverty of species. However, temperature also has an impact on life in the Baltic Sea. Because of six months of ice cover. The relatively low salinity results in a short productive season of only $4-5$ months in the Bothnian Bay.

\subsection{Marine habitats}

Basically, the coastal and offshore zone of the Baltic Sea comprises three types of plant and animal habitats: hard bottom, soft bottom and the pelagic community. Hard bottom communities close to the coast are the most species-rich in the Baltic Sea. A typical zone is usually found on rocky shores. Below the upper zone of green algae, a very conspicuous belt of the brown Fucus algae and the red Furcellaria algae grows. This community is inhabited by an exceptionally rich fauna including mussels, snails and crustaceans. The fish community of the area is a mixture of marine species such as Herring Clupea harengus, Sprat Sprattus sprattus, Gobies Gobius spp. and fresh-water species like Common Perch Perca fluviatilis, Bream Abramis brama, Three-spined Stickleback Gasterosteus aculeutus, etc. Many fish species, including Herring, pass their larval stages in the Fucus/Furcellaria belt.

In water depths where scarcity of light does not allow further algae growth the Blue Mussel Mytilus edulis, predominates entirely. Normally, the mussel belt starts at a few meters of depth and often extends to 30 meters. In the Baltic proper blue mussels represent more than $90 \%$ of the total animal biomass. Soft bottom communities make up the largest part of the sea floor and consist of muddy and sandy sediments. In shallow protected bays on the coast Eelgras Zostera marina is found. Freshwater from rivers has a strong impact on the fauna in shallow bays. Insect larvae are numerous and both freshwater and marine fish live together. 
Away from the coast at depths between 50 and 150 meters, soft bottom dominates the sea floor. The animal community found here is dominated by the Baltic Tellinn Macoma balthica. This community is also found in the deeper parts of the Gulf of Riga. Cod Gadus morhua is a common fish in the soft-bottom parts of the Baltic Sea as well as in hard bottom areas. The pelagic communities are habitat for the main fish species of the Baltic Sea. The most important fish of the Baltic Sea are the Herring and Sprat. Sandeels Ammodytes tobianus, Greater Sandeel Hypperoplus lanceolatus and the Fifteen-spined Stickleback Spinachia spinachia are also important as a food resource for seabirds. 



\section{Methods}

\subsection{Study region}

The present atlas includes the entire ice-free areas of the Baltic Sea during the winters of 2007, 2008 and 2009, and is bounded by the coastlines of Sweden, Finland, Estonia, Latvia, Lithuania, Russia (Kaliningrad), Poland, Germany and Denmark (Map 1). It includes all coastal, territorial and EEZ waters, as well as all bays and semi-enclosed brackish-water lagoons and fjords along the Baltic coasts. Limfjorden (Denmark) is not included in the present atlas.

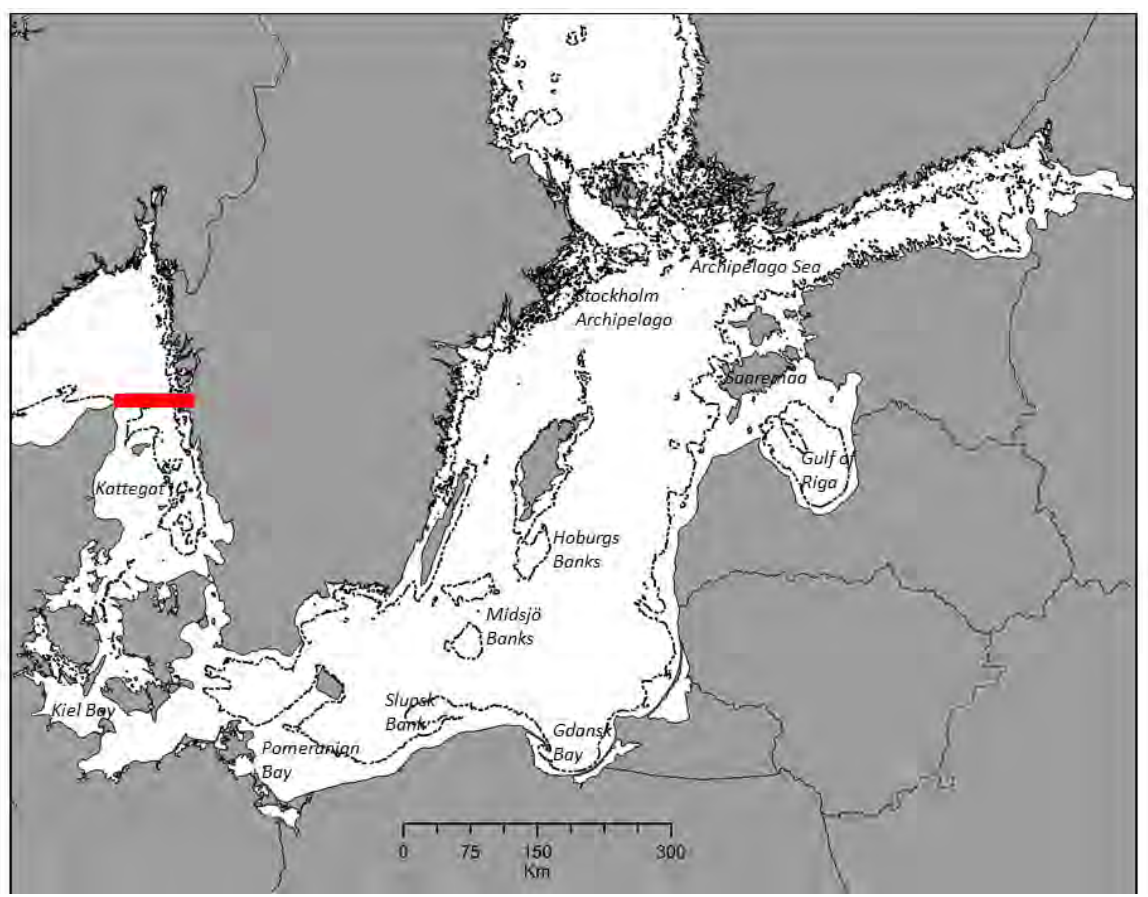

Map 1. Study region with the boundary between the Baltic Sea and the North Sea marked in red. The $30 \mathrm{~m}$ depth contour and key areas are indicated.

\subsection{Selection of bird species and seasons}

The winter distribution and abundance of 20 bird species has been analysed. Except for the Swedish coastal areas where data from 2004 were used, data from the period from November $15^{\text {th }}$ to March $15^{\text {th }} 2007-$ 2009 have been used. Compared to Durinck et al. (1994) this atlas mainly contains information on benthivorous species, while the more pelagic species like gulls and auks have been omitted due to insufficient cover- 
age of the open parts of the Baltic Sea (see below). Each of the 20 species selected has a population in the study region of at least $1 \%$ of the species' biogeographic (breeding or non-breeding) population during parts of the year. In the selection of data from specific survey platforms we have generally followed the recommendations from Pihl et al. (1992) and used only the best observation platform as the major source of data for each species. Information gained by other methods was used to supplement that from the best platform.

\subsection{Coverage including comparisons with 1992/93}

Compared to the Atlas of wintering waterbirds in 1994 the co-ordinated census reported in this Atlas covered a comparatively equal area of shallow water $(<20 \mathrm{~m})$, but a smaller area of waters deeper than $20 \mathrm{~m}$ (Maps 2 and 3). Due to extensive ice cover, the major parts of the Gulf of Finland, the Bothnian Sea and the Bothnian Bay were not covered. The coastal areas, including lagoons, archipelagoes and fjords, received an almost equal coverage in 2007-2009 as compared to 1992-1993. The proportion of offshore line-transect surveys undertaken from aircraft in 2007-2009 was greater than in 1992-1993, and a comparatively lower proportion of ship-based surveys was undertaken. Offshore areas which were mainly covered by ship in 1992-1993, and mainly by aircraft in 2007-2009 were the Inner Danish, Swedish and Estonian waters.

\subsubsection{Survey methods}

Four sampling methods have been employed to collect the data analysed in this report; counts from land, aerial total counts, aerial transect counts and ship transect counts.

\subsubsection{Aerial and ship-based total counts}

Birds in inshore waters were recorded from aircraft flying at a speed of 100-140 kilometers per hour and at a height of 60 to 100 meters. Only data from aircraft, collected with methods comparable to those of Pihl \& Frikke (1992), have been used. When conducting a total survey, the plane flew along survey lines which enabled a full count of all birds present in the survey area. In Finland (Åland) ship-based total counts were undertaken.

\subsubsection{Land-based counts}

Within predefined stretches of coastline, birds were recorded from the shore to an undefined distance. For Sweden, the complete coastal census data from 2004 were used. 


\subsubsection{Transect surveys from ship and airplane}

Only ship-based data collected by methods comparable to the standard description of Tasker et al. (1984) and Webb \& Durinck (1992) have been included. Most surveys were made from dedicated ships following a standard grid of transect lines. Dedicated ship-based surveys were undertaken in the following EEZs: Russia, Sweden (Gotland), Estonia, Latvia, Lithuania, Poland and Germany. Observations from ships of opportunity were collected by DHI from the Swedish fishery research vessel Argos in the Kattegat. The observations from ships were made by two observers from platforms 5-8 meters above sea-level using $300 \mathrm{~m}$ wide transects. The birds were recorded with various spatial resolution from 1-10-minute intervals and grouped into transect "bands" according to their distance from the track line. These bands were: a) $0-50$ meters, b) $50-100 \mathrm{~m}, \mathrm{c}) 100-200 \mathrm{~m}$ and d) $200-300 \mathrm{~m}$.

Transect counts from aeroplanes have been used by the Danish, Swedish and Estonian teams, largely following the recommendations of Camphuysen et al. (2004). The survey methodology followed line transect survey techniques using a high-winged, twin-engine air-craft (e.g. Partenavia P-68 and CESSNA-337), equipped with "bubble windows", at an altitude of 250 feet $(76 \mathrm{~m}$ ) and with a cruising speed of ca. 100 knots (ca. $185 \mathrm{~km} / \mathrm{h}$ ). Each survey was carried out by two experienced observers.

A binned perpendicular distance from the survey track line was recorded, using either three bins or transect bands or a trip transect. Directly underneath the aircraft was a blind strip extending out to $44 \mathrm{~m}$ either side of the track line where the observer was unable to effectively detect birds. The three-band system consisted of an inner transect band extending from 44 to $163 \mathrm{~m}$, a middle band from 163 to $432 \mathrm{~m}$, and a distant band from 432 to $1000 \mathrm{~m}$. In Sweden, counts were only undertaken in a main belt extending $200 \mathrm{~m}$ on either side of the plane. Flocks noted further away were entered as additional information.

Due to limited spatial resolution the data collected during the Finnish aerial and ship-based transect counts had to be treated as total counts.

\begin{tabular}{lccccc}
\multicolumn{5}{l}{ Table 1. Overview of survey effort distributed across participating countries and survey methods. } \\
\hline $\begin{array}{c}\text { Land-based } \\
\text { counts }\end{array}$ & $\begin{array}{c}\text { Aerial total } \\
\text { counts }\end{array}$ & $\begin{array}{c}\text { Aerial transect } \\
\text { counts }\end{array}$ & $\begin{array}{c}\text { Ship-based } \\
\text { total counts }\end{array}$ & $\begin{array}{c}\text { Ship-based } \\
\text { transect counts }\end{array}$ \\
\hline $\begin{array}{l}\text { Sweden } \\
\text { Finland }\end{array}$ & $\mathrm{X}$ & $\mathrm{X}$ & $\mathrm{X}$ & $\mathrm{X}$ & $\mathrm{X}$ \\
Russia & $\mathrm{X}$ & $\mathrm{X}$ & & $\mathrm{X}$ & \\
Estonia & $\mathrm{X}$ & $\mathrm{X}$ & $\mathrm{X}$ & & \\
Latvia & $\mathrm{X}$ & & & & $\mathrm{X}$ \\
Lithuania & $\mathrm{X}$ & & & $\mathrm{X}$ \\
Poland & $\mathrm{X}$ & $\mathrm{X}$ & $\mathrm{X}$ & $\mathrm{X}$ \\
Germany & $\mathrm{X}$ & $\mathrm{X}$ & $\mathrm{X}$ & $\mathrm{X}$ \\
Denmark & & & &
\end{tabular}




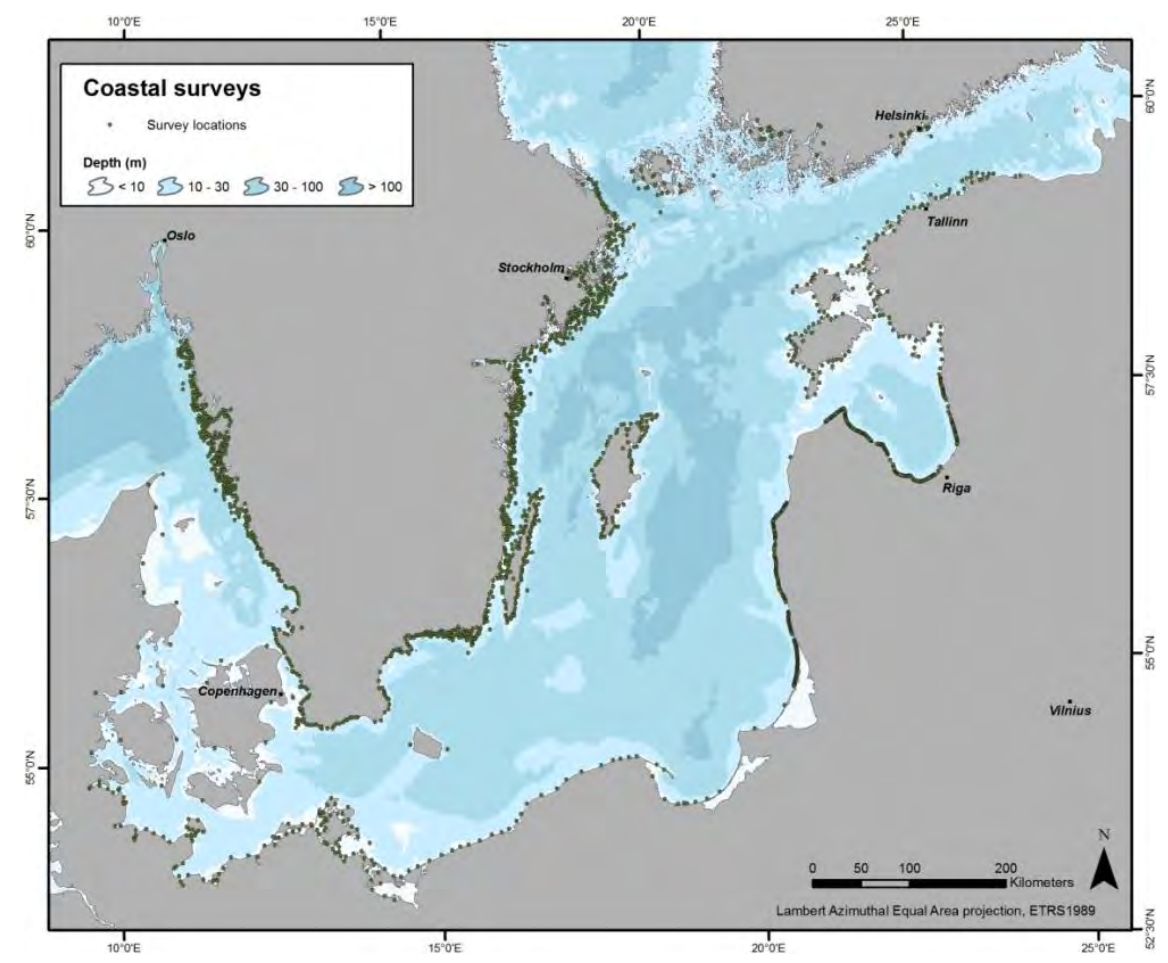

Map 2. Location of aerial and ship-based total counts and land-based counts. The dots represents the centre co-ordinate of each coastal segment.

\subsection{Data handling}

\subsubsection{National databases}

Survey data were collated and quality assured at the national (regional) level before entering analysis. Only data sets which were suitable for linking with geographical information systems (GIS) were used. Data gathered during adverse weather conditions ( $>$ sea state 3 ) have been removed prior to analysis. In most cases the formats of the national (regional) databases for coastal surveys conformed to the standard used for the midwinter census of waterbirds co-ordinated by Wetlands International. The format of the databases of offshore surveys varied between countries.

\subsubsection{Assembly of combined databases}

The strategy for processing of data differed between strictly coastal species like Mute swan Cygnus olor, Mallard Anas platyrhynchos and Common Coot Fulica atra and species with wider distributions (coastal and offshore) like Red-necked Grebe Podiceps grisegena and Long-tailed duck Clangula hyemalis. For most of the widely distributed species a modelling strategy was applied using Baltic-wide habitat variables within a spatial modelling framework as a basis for integration and prediction of densities 
throughout the Baltic Sea. The data on coastal species were processed as actual observed numbers for specific sites. Due to the restricted range of their distribution results for Steller's eiders Polysticta stellerii were obtained in the same way. The use of actual observed numbers for the coastal counts conforms to the procedures used for the 1992-93 census, apart from the fact that numbers observed were transferred into densities in Durinck et al. (1994). The coastal counts were aggregated into 57 standard stretches of coastline, which to a large degree corresponded to the 53 standard areas used in Durinck et al. (1994).

The spatial modelling framework allowed for an un-biased comparison of the results from surveys across countries and survey techniques and further allowed for integration between coastal and offshore sites. Data from land-based and aerial and ship-based total counts were averaged for standard stretches of coasts and shallow grounds. By using average counts for several smaller segments of coast, information on differences between sites has sometimes been lost. Yet, for the purpose of this report it was found relevant to describe and classify areas at a scale which facilitates a direct comparison of areas and habitats across the Baltic Sea. Thus, the bird numbers describe comparable values for different stretches of the coast.

The distribution range of bird concentrations in wider areas was measured by using GIS. All estimates (modelled species) and totals below 100 were rounded off to the nearest five, estimates/totals between 100 and 10,000 to the nearest ten, estimates/totals between 10,000 and 100,000 to the nearest 100 and those exceeding 100,000 to the nearest 1000 .

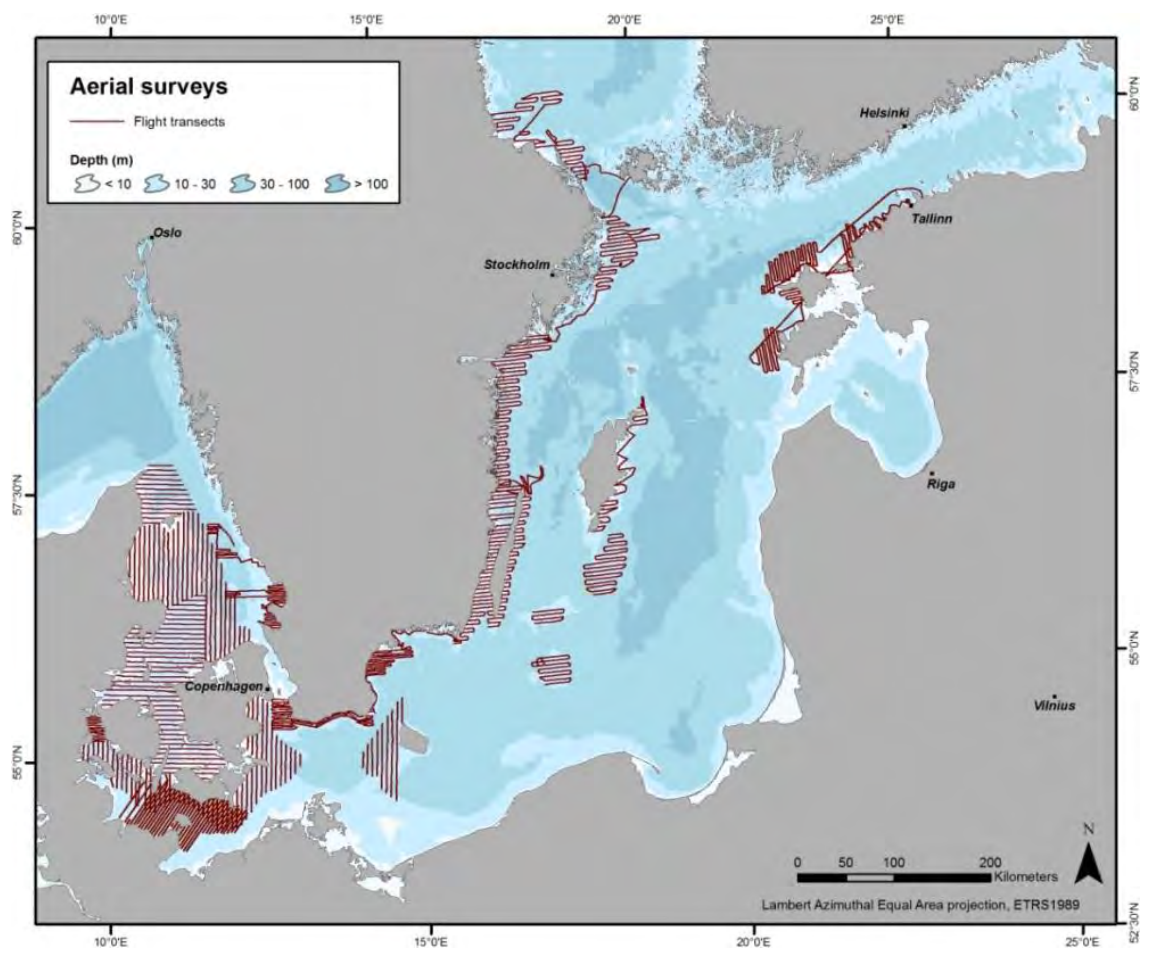

Map 3. Location of aerial transects. 


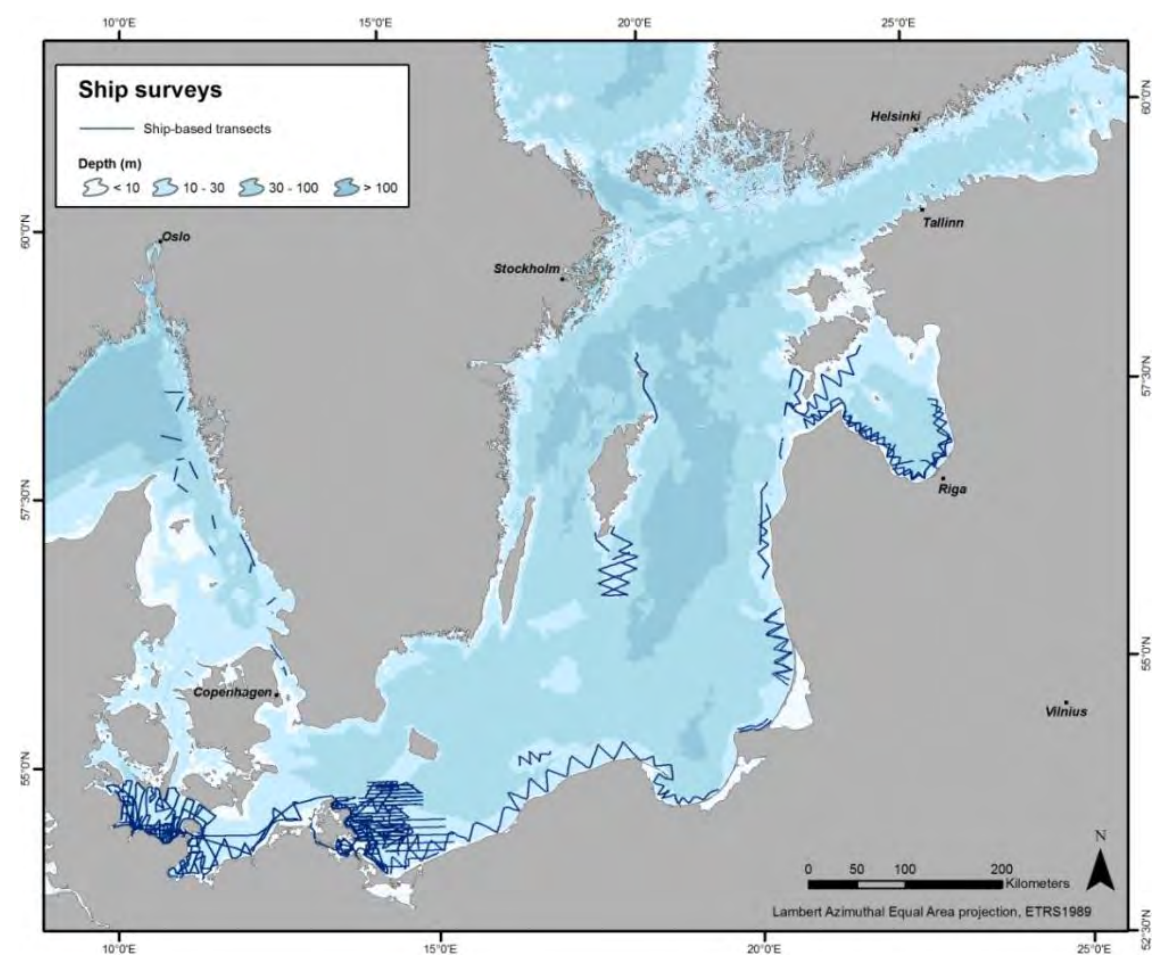

Map 4. Location of ship-based transects.

\subsubsection{Distance error correction}

An ideal count within a transect would include all birds on the water. However, in reality the probability of missing a bird increases with distance to the observer. We therefore determined a correction factor to allow for birds missed while making transect counts of birds on the water using key functions, adjustment terms and variance estimators available through the software package DISTANCE ver. 6.2 (Laake et al. 1991, Buckland et al. 1993). Numbers of counted birds on the water were corrected using these factors. The distance functions applied for the different species/regions are listed in Appendix I. The analysis of the survey data based on the three innermost perpendicular distance bands from the aircrafts and the four distance bands from ships and using exact sizes of clusters. Key functions were evaluated with cosines and simple polynomials for adjustment terms: uniform, half-normal and hazard rate, or the best function was chosen on the basis of minimum AIC values. The data were not post-stratified by wave height. In order to minimise the impact of increasing wave heights on the detectability of the birds only data collected in wave heights equal to or lower than Beaufort 3 were retained for estimation of detection probabilities.

Even with relatively low sample sizes the application of line transect theory allows for precise estimation of $p$ - the probability of observation within a transect, and the correction factor $1 / p$. Numbers of birds counted flying in a transect could not be corrected in this way. The average 
density of birds in transects surveyed from ships and aeroplanes was calculated by dividing the sum of the corrected numbers of sitting birds and (uncorrected) numbers of flying birds per count unit by the area covered during each count.

\subsubsection{Creation of geo-databases}

The three databases with total counts (land-based, aerial total counts, ship-based total counts) were combined into one database and the aerial transect counts and ship-based transect counts of sampled densities of waterbirds were combined into another database. The latter was integrated with co-variables needed for modelling the distribution of the offshore species waterbirds. The co-variables were both hydrodynamic and water quality parameters taken from DHI's BANSAI 3 model, and static data on landscape and topographic variables (Table 2). Details of the Bansai 3 model complex are provided in Appendix II.

Table 2. List of static and semi-dynamic co-variables integrated with the survey data into the geodatabases used as inputs for spatial modelling.

\begin{tabular}{|c|c|c|c|c|}
\hline Variable & $\begin{array}{l}\text { Static/ } \\
\text { dynamic }\end{array}$ & Raw parameter & Model parameter & Source \\
\hline Bathymetry & Static & Water depth in $\mathrm{m}$ & Water depth in $\mathrm{m}$ & $\mathrm{DHI}$ \\
\hline Bottom relief & Static & $\begin{array}{l}\text { Tangent of angle with } \\
\text { max downhill slope }\end{array}$ & $\begin{array}{l}\text { Tangent of angle with } \\
\text { max downhill slope }\end{array}$ & $\mathrm{DHI}$ \\
\hline Benthic complexity & Static & $\begin{array}{l}\text { Kernel of } x \text { pixels }=(n- \\
\text { 1)/(c-1)1 }\end{array}$ & $\begin{array}{l}\text { Kernel of } x \text { pixels }= \\
(n-1) /(c-1) 1\end{array}$ & $\mathrm{DHI}$ \\
\hline Distance to land & Static & Distance in km & Distance in km & $\mathrm{DHI}$ \\
\hline $\begin{array}{l}\text { Distance to shipping } \\
\text { lanes }\end{array}$ & Static & $\begin{array}{l}\text { Distance based on AIS } \\
\text { data }\end{array}$ & $\begin{array}{l}\text { Distance based on } \\
\text { AIS data }\end{array}$ & $\begin{array}{l}\text { Danish Maritime } \\
\text { Authority }\end{array}$ \\
\hline $\begin{array}{l}\text { Temperature and } \\
\text { salinity }\end{array}$ & Dynamic & $\begin{array}{l}\text { 3-D hourly model data } \\
\text { in } 5 \mathrm{~km} \text { resolution }\end{array}$ & $\begin{array}{l}\text { Mean values } \\
2000-2008\end{array}$ & $\mathrm{DHI}$ \\
\hline Depth of pycnocline & Dynamic & $\begin{array}{l}\text { 3-D hourly model data } \\
\text { in } 5 \mathrm{~km} \text { resolution }\end{array}$ & $\begin{array}{l}\text { Mean values } \\
2000-2008\end{array}$ & $\mathrm{DHI}$ \\
\hline $\begin{array}{l}\text { Stratification } \\
\text { parameter }\end{array}$ & Dynamic & $\begin{array}{l}\text { 3-D hourly model data } \\
\text { in } 5 \mathrm{~km} \text { resolution }\end{array}$ & $\begin{array}{l}\text { Mean values } \\
\text { 2000-2008 }\end{array}$ & $\mathrm{DHI}$ \\
\hline Current velocity & Dynamic & $\begin{array}{l}\text { 3-D hourly model data } \\
\text { in } 5 \mathrm{~km} \text { resolution }\end{array}$ & $\begin{array}{l}\text { Mean values } \\
2000-2008\end{array}$ & $\mathrm{DHI}$ \\
\hline Frontal index & Dynamic & $\begin{array}{l}\text { 3-D hourly model data } \\
\text { in } 5 \mathrm{~km} \text { resolution }\end{array}$ & $\begin{array}{l}\text { Mean values } \\
2000-2008\end{array}$ & $\mathrm{DHI}$ \\
\hline Filter-feeder index & Dynamic & $\begin{array}{l}\text { 3-D hourly model data } \\
\text { in } 5 \mathrm{~km} \text { resolution }\end{array}$ & $\begin{array}{l}\text { Mean values } \\
2000-2008\end{array}$ & $\mathrm{DHI}$ \\
\hline
\end{tabular}




\subsection{Statistical analyses}

\subsubsection{Geo-statistical analyses}

Spatial prediction models have been applied for the target waterbird species using landscape, topographic, hydrographic and prey predictor variables available for the entire survey area (Table 2). The response variable is spatially resolved distance corrected densities of coastal counts and of each segment of the aerial and ship-based line transects. The statistical models have been established through an iterative process, which was initiated by an analysis of the spatial structure of the transect data as a means for selecting the scale of controlling parameters. The spatial structure was analysed by means of geo-statistical analysis and variography which determined the scale and structure of autocorrelations in the sampled data. The geostatistical analyses were undertaken on the sampled densities from the aerial and ship-based transects. The analyses aimed at defining the aggregative response (Schneider \& Duffy 1985) using the range of the variogram, and predictor variables were subsequently selected with spatial dimensions matching the variogram range. Obviously, the selected predictor variables constituted a compromise between ranges identified across several species. In this process, the spatial structure of the data collected on benthivorous carnivores which dominate the waterbird community in the Baltic Sea during winter was given high priority.

\subsubsection{Conceptual models}

Based on experience from the development of spatial prediction models for waterbirds in Danish waters, different concepts for the spatial models were developed for benthic and pelagic carnivorous species. Benthic carnivores are here covered mainly by diving ducks and mergansers, whereas pelagic carnivores are covered by divers, grebes and cormorants. Prediction models for benthic carnivores were developed by combining patterns of potential prey density, as reflected by an index of modelled filter-feeder carrying capacity, with water temperature, water depth, seabed terrain and distances to coastal areas and shipping lanes. The filter-feeder index describes the average carrying capacity using an arbitrary scale based on DHI's hydrodynamic and geo-biochemical model complex BANSAI 3. Details of the BANSAI 3 model are given in Appendix II. The carrying capacity index combines a physiology-based growth model for a standard individual with an advection term that replenishes the food ingested by filter-feeders. On a large scale the index depends on the local primary production and on a smaller scale current speed plays an increasing role. The average carrying capacity index for 2007-2009 validated by Skov et al. (in Press) was used. For seaducks which typically display avoidance patterns in relation to areas with high anthro- 
pogenic pressure the spatial models included variables describing the distance to shoreline and shipping lanes.

Prediction models for pelagic carnivores were developed by combining patterns of hydrodynamics with water depth, seabed terrain and distances to coastal areas and shipping lanes. Hydrodynamic parameters included temperature and salinity and current velocities reflecting water masses, and eddy activity, water column structure (pycnocline depth) and horizontal fronts, and were all calculated from the BANSAI 3 model using average values for 2007-2009.

\subsubsection{Spatial modelling}

The distance-corrected densities formed the basis for estimating the local density of birds in the whole region. Statistical models were developed using Generalised Additive Models (GAMs). It should be noted that the abundance estimates published by Durinck et al. (1994) for the census period 1992-1993 were based on interpolation techniques rather than statistical models. One feature which is immediately apparent when viewing the maps is the difference in coverage of non-surveyed areas between the two reports. The interpolation techniques used by Durinck et al. (1994) did not allow for inclusion of areas with a distance exceeding 15 nautical miles to survey transects, while the statistical modelling techniques used in this report allowed for estimation of densities at further distances from the survey transects. Regions in which no transect surveys, or very few surveys, were undertaken (e.g. parts of the archipelagos) were, however, excluded from the modelled areas, as model results for these regions could not be considered sufficiently reliable.

GAMs are able to relate predictor variables to data that can be nonnormally distributed (Hastie \& Tibshirani 1990). Data may be assumed to be from several families of probability distributions, including the normal, binomial, Poisson, negative binomial, or gamma distribution, many of which better fit the non-normal error structures of most ecological data. Thus, GAMs are flexible and well suited for analysing ecological relationships, which can be poorly represented by classical Gaussian distributions. We used a two-step GAM approach (in literature also called a hurdle model or a delta model) to deal with zero inflation (an excess of zeros) in our data set (Stefánsson 1996, Barry \& Welsh 2002, Potts and Elith 2006). In the first part a binomial model (with a logit link) were fitted which predicts the probability of presence or absence. In the second step only positive values (densities) were fitted using a gamma distribution with a log link, which predicts the density (see e.g. Stefánsson 1996). The two model parts were finally combined by multiplying the predictions from both steps.

GAMs were fitted in R version 2.9.0 (R Development Core Team, 2004) using the MGCV library (Wood 2006a), in which the degree of smoothness 
(or degrees of freedom) of the smooth functions of the predictor variables is determined as part of the model fitting process. The default smoothing spline used in MGCV is a thin plate regression spline, which allows a smooth function to be estimated with multiple predictor variables in noisy data, without knowledge of the knot locations (where the different splines join) being required. This method removes the subjectivity that is introduced by estimating knot locations, which is required for other smoothing methods. In MGCV, the default dimension ( $\mathrm{k}=$ equivalent to setting the maximum number of degrees of freedom for each smooth function) is 10 for single covariate smooth functions.

To reduce potential overfitting of the GAMs, the smooth functions for each of the environmental variables were limited to $4(\mathrm{k}=4)$ or less estimated degrees of freedom. Geographical co-ordinates were usually allowed to have higher degree of smoothing. Variables were selected based on expert opinion. The predictor variables were chosen for each species based on the ecological knowledge we have. A "full model" including all, in our opinion, relevant predictors available were fitted, where after unimportant variables were dropped. Variables were considered unimportant if the UBRE/GCV score dropped when the variable were dropped, and if the plotted confidence band included zeros everywhere and the estimated degree of freedom was close to zero at the same time. Variables contributing very little to the model fit (contributes with a very little change in UBRE/GCV) were also removed (Wood and Augustin 2002). We also inspected the response curves and the final predictions visually. If the models resulted in non-logic responses or prediction maps the models were calibrated further (Austin 2002; Wintle et al. 2005).

Line transect data usually display a high degree of spatial autocorrelation and if strong spartial autocorrelation remains in the model residuals the significance values might be inflated and hence lead to unreliable explanatory and predictive power (Segurado et al. 2006). The autocorrelation effects were reduced by aggregating data into a $1235 \mathrm{~m}$ grid before analysis. The effect of autocorrelation was further reduced by incorporating geographical co-ordinates as predictor variables. Spatial autocorrelation in model residuals was checked by using an autocorrelogram displaying Moran's I values over 10 lags. For the calculations of Moran's I the R package "spdep" (Bivand 2009) was used. The correlograms are shown in Appendix I.

The models were validated by withdrawing $30 \%$ of the data for evaluation while fitting the models on the remaining $70 \%$. The presence/absence part of the models was evaluated by using the area under the receiver operating characteristic curve (AUC), which is a threshold independent method. AUC describes the models capability of distinguishing between presence and absence. An AUC value of 0.5 indicates the model is no better than random and a value of 0.8 means the model is capable of distinguishing presence from absence $80 \%$ of the time 
(Fielding \& Bell 1997). The final combined model was evaluated by measuring Spearman's rank correlation between observed and predicted values (Potts \& Elith 2006). The model results and evaluation statistics are shown in Appendix I.

Prediction models were developed for the entire Baltic Sea.

\subsubsection{Estimation of population size}

Estimates of population sizes were made by integrating density estimates for discrete areas of different density levels. Areas of different density levels were identified visually based on the mapped final spatial models. The density levels generally followed Durinck et al. (1994). Estimated population sizes were tabulated for areas of high abundance as for residual areas of lower abundance.

\subsection{Mapping}

All maps have been prepared by using Lambert Azimuth Equal Area projection. Each map occupies half of a page.

\subsection{Trend analyses}

Analyses of historic trends in wintering waterbirds and selected pressures to waterbirds in the Baltic Sea were undertaken for the 22 year period from 1987 to 2009. The trend data on waterbirds were taken from selected sites or combination of sites, which have been monitored regularly for the whole or extended parts of this period (Table 3). Except for Germany, due to heterogeneity of survey data sources and methods no imputation of time series to correct for missing data was undertaken. The imputation of the German data was undertaken by the Federation of German Avifaunists (DDA).

Combined trends in the numbers of wintering waterbirds were plotted per species, country and region. The significance of the trends was estimated using linear regression over the entire time series.

Pressures were selected reflecting fishing intensity, oil transport/production, eutrophication, climatic and oceanographic changes (Table 4). 
Table 3. Selected sites, regional coverage and survey methods used for estimation of trends.

\begin{tabular}{|c|c|c|c|c|c|}
\hline Sites & Survey methods & Baltic Proper & Gulf of Riga & Straits & Kattegat \\
\hline Sweden coastal & Land-based & $x$ & & & $x$ \\
\hline \multirow[t]{3}{*}{ Finland coastal } & Land-based & $x$ & & & \\
\hline & Ship-based transects & $x$ & & & \\
\hline & Aerial transects & $x$ & & & \\
\hline Sgt. Petersburg & No data & & & & \\
\hline Estonia coastal & Land-based & $x$ & $x$ & & \\
\hline Latvia coastal & No data & & & & \\
\hline Lithuania coastal & No data & & & & \\
\hline Kaliningrad coastal & No data & & & & \\
\hline Poland coastal & Land-based & $\mathrm{x}$ & & & \\
\hline Germany coastal & Land-based & $x$ & & $x$ & \\
\hline Germany lagoons & Land-based & $x$ & & $x$ & \\
\hline Sweden offshore & Ship-based transects & $x$ & & & \\
\hline Germany offshore & Ship-based transects & $x$ & & $x$ & \\
\hline Denmark coastal & No data & & & & \\
\hline Denmark offshore & No data & & & & \\
\hline
\end{tabular}

Table 4. Selected pressure variables and sources.

\begin{tabular}{ll}
\hline Pressure variable & Source \\
\hline Dissolved inorganic nitrogen & HELCOM BSEP 115B \\
Dissolved inorganic phosphorous & HELCOM BSEP 115B \\
Total petroleum hydrocarbons & ICES oceanographic database \\
Oil records from systematic patrols & HELCOM \\
Salinity (PSU) surface & ICES oceanographic database \\
Salinity (PSU) bottom & ICES oceanographic database \\
Temperature at 40 m & ICES oceanographic database \\
Maximum ice coverage & ICES WGIAB \\
Baltic Sea Index & ICES WGIAB \\
Secchi depth & DHI \\
Bottom oxygen concentration summer & ICES WGIAB \\
Spawning stock biomass of cod, sprat and herring & ICES WGIAB, WGIBTS
\end{tabular}

\subsection{Identification of key pressures}

Following the trend analyses we quantified the linkage between selected pressures and waterbirds using correlation analysis (Pearson) of factors affecting the abundance of herbivores, piscivores, benthivores and omnivores in the different regions. The results of the correlation analyses were used to develop interpretations of the documented differences in the abundance and distribution of waterbirds between the survey results from 1992-1993 and 2007-2009. 


\section{Distribution and Numbers of Waterbirds}

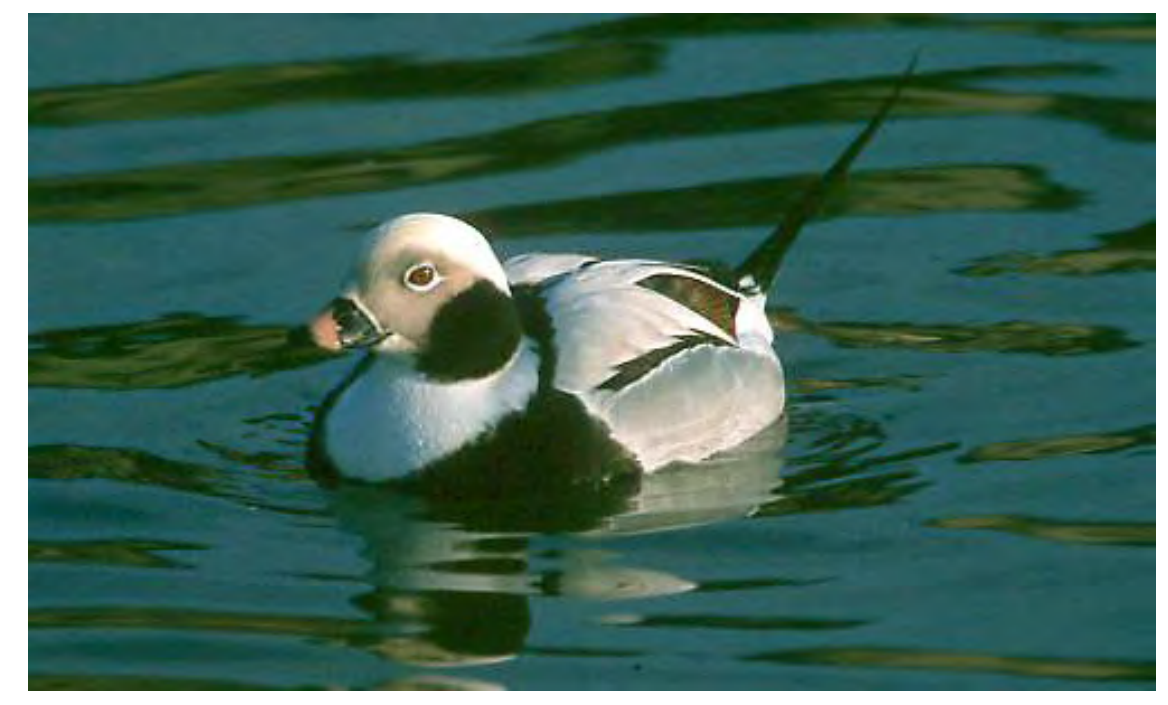

\subsection{Red-throated Diver Gavia stellata and Black- throated Diver Gavia arctica}

\subsubsection{Importance of the Baltic Sea}

The north-west European winter population of Red-throated Divers is estimated at 150,000-450,000 birds, while the population of Blackthroated Divers is estimated at 250,000-500,000 birds (Delany \& Scott 2006). The results of the present study indicate a massive decline from 56,500 birds in the Baltic Sea during 1988-1993 to 8,575 in 2007-2009, equivalent of $84.1 \%$. As the estimated sizes of the total populations of both species of divers have been completely revised since the 1994 status report it is not possible to assess whether the decline in the Baltic winter population is a reflection a large-scale or just regional population declines. Assuming that the estimates in Delany \& Scott (2006) are correct the current status indicates that between $0.9 \%$ and $2.1 \%$ of the north-west European winter populations of both species winter in the Baltic Sea. The range of the proportion of birds wintering in the Baltic Sea is caused by uncertainties regarding the sizes of recruiting populations in Russia (Delany \& Scott 2006). 


\subsubsection{Main wintering areas in the Baltic Sea}

The Irbe Strait and the Gulf of Riga were the most important areas to wintering divers during 1988-1993. During the recent counts less than 1,000 birds were estimated Gulf of Riga, while the largest concentrations of divers were found in a continuous area extending from the Irbe Strait and along the coasts of Lithuania, Latvia and southern Estonia as well as in the Pomeranian Bay. In the former area numbers were estimated at 3,900 , equivalent of $46 \%$ of the total number in the Baltic Sea, and in the Pomeranian Bay numbers estimated were 1,270, equivalent of $15 \%$. In both areas, the numbers present in 2007-2009 still represent a decline of approximately $50 \%$ as compared to $1988-1993$.

\subsubsection{Distribution in the Baltic Sea}

Despite significantly smaller numbers of divers as compared to 19921993, especially in the region around the Gulf of Riga, and differences in estimation techniques between Durinck et al. (1994) and this publication, overall distribution patterns in the Baltic Sea have not changed since mid 1990 'es, and the highest densities are still found in a narrow band along the mainland coast north of Rügen within the water depth zone of 5 to 30 $m$. In this high-density area the vast majority of identified divers are Redthroated. South of this area the proportion of Black-throated Divers appears to be higher. Mean densities above 10 birds per $\mathrm{km}^{2}$ were rarely recorded. The core areas boast mean densities between 3 and 5 birds per $\mathrm{km}^{2}$, and are found in the eastern parts of the Pomeranian Bay and off the Latvian coast. Dispersed populations in densities below 0.5 birds per $\mathrm{km}^{2}$ were found in all other areas with sandy sediments and a water depth shallower than $30 \mathrm{~m}$. Very low densities of divers are estimated to winter north of a line between Saaremaa and Stockholm.

\subsubsection{Phenology}

Both species begin to arrive to the Baltic Sea in September, and during the following months their numbers gradually increase. Some divers only rest in the Baltic Sea for a few weeks before they move on to winter quarters in the North Sea, the coasts of the East Atlantic and the Black Sea. Red-throated Diver moults its flight feathers from September to December, whereas in Black-throated Diver moults in spring.

In mild winters, return movements to the Baltic Sea begin in January. In the Kattegat the number of divers usually increases in February and March. Subsequently, the divers move to the central and eastern Baltic Sea and to the breeding grounds. Between mid-April and mid-May the divers leave the Baltic Sea. 


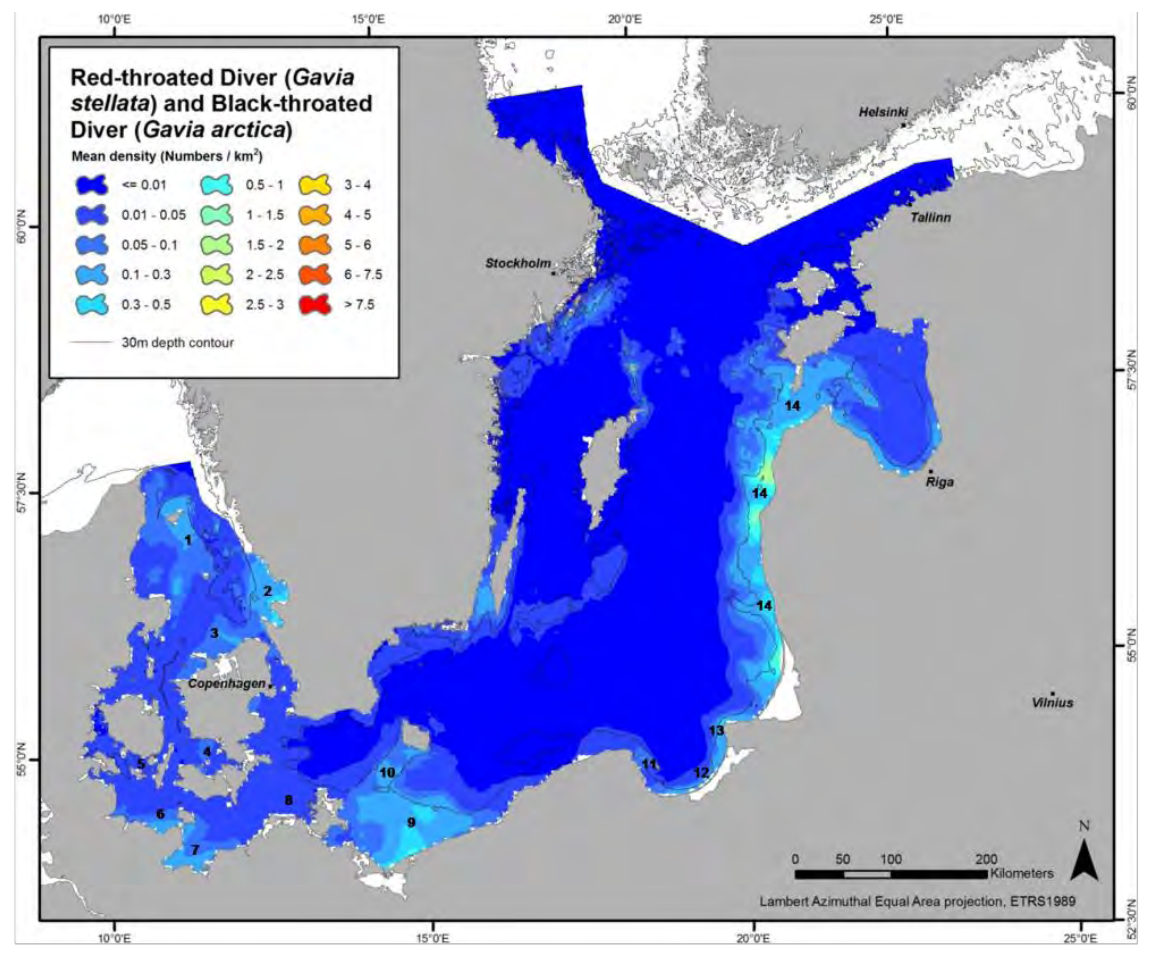

Map 5. Distribution and density of wintering Red-throated Divers Gavia stellata and Black-throated Divers Gavia arctica in the Baltic Sea, 2007-2009.

Table 5. The average number of wintering Red-throated Divers Gavia stellata and Black-throated Divers Gavia arctica estimated by spatial modeling for key areas of the Baltic Sea, 2007-2009

\begin{tabular}{llrrrrr}
\hline Id & Locality & Area & Number & Mean density & Std density & \% \\
\hline 1 & NW Kattegat & 6,440 & 430 & 0.068 & 0.033 & 5.01 \\
2 & Skåne NW & 1,784 & 400 & 0.223 & 0.066 & 4.66 \\
3 & S Kattegat & 2,606 & 160 & 0.060 & 0.026 & 1.87 \\
4 & Smålandsfarvandet & 841 & 40 & 0.045 & 0.011 & 0.47 \\
5 & South Funen & 852 & 35 & 0.041 & 0.008 & 0.41 \\
6 & Kiel Bay & 703 & 65 & 0.095 & 0.044 & 0.76 \\
7 & Mecklenburg Bay & 1,553 & 160 & 0.103 & 0.039 & 1.87 \\
8 & Darss & 2,475 & 65 & 0.026 & 0.007 & 0.76 \\
9 & Pomeranian Bay & 5,865 & 1,270 & 0.215 & 0.093 & 14.81 \\
10 & Rønne Bank & 721 & 50 & 0.067 & 0.038 & 0.58 \\
11 & Hel Peninsula & 991 & 40 & 0.042 & 0.017 & 0.47 \\
12 & Gulf of Gdansk & 1,163 & 95 & 0.083 & 0.074 & 1.11 \\
13 & Kaliningrad & 475 & 95 & 0.197 & 0.067 & 1.11 \\
14 & Lithuania-Latvia-Estonia & 14,349 & 3,900 & 0.272 & 0.258 & 45.48 \\
15 & Key areas & & 6,805 & & & 79.36 \\
16 & Residual & 1,770 & & & & \\
& Total & $\mathbf{8 , 5 7 5}$ & & & & \\
\end{tabular}

Area indicates the size of the area in $\mathrm{km}^{2}$, Number is the average estimated number of birds, mean density is the mean density of birds per $\mathrm{km}^{2}$ within the area, Std density is the standard deviation of the density within the area and \% compares the percentage of birds within the area with the total estimated number in the Baltic Sea. 


\subsection{Great Crested Grebe Podiceps cristatus}

\subsubsection{Importance of the Baltic Sea}

The north-west European winter population of Great Crested Grebes is estimated at 290,000-420,000 birds (Delany \& Scott 2006). The results of the present study indicate a decrease from 11,325 birds in the Baltic Sea during 1988-1993 to 8,300 in 2007-2009, equivalent of $26.7 \%$. Due to lack of survey data on this species from Danish waters the density of Great Crested Grebe was not modeled for these areas, and hence the total estimate for the Baltic Sea may have been higher than reported. The number of wintering Great Crested Grebes in marine habitats is known to fluctuate as a response to the winter climate with higher numbers occurring offshore when lagoons and lakes freeze over. The surveyed winters of 20072009, however, were characterised by high temperatures and open coastal and inland waters. As the estimated sizes of the total population wintering in north-west Europe have been completely revised since the 1994 status report it is not possible to assess whether the increase in the Baltic winter population is a reflection of a large-scale or just regional population increases. Assuming that the estimates in Delany \& Scott (2006) are correct the current status indicates that between $2.3 \%$ and $3.3 \%$ of the north-west European winter population of Great Crested Grebe wintered in the Baltic Sea during 2007-2009. During colder winters the number of wintering Great Crested Grebes most likely increases. The range of the proportion of birds wintering in the Baltic Sea is caused by uncertainties both regarding the extent of habitat displacement from icecovered lakes and regarding the sizes of recruiting populations in Fennoscandia and Russia (Delany \& Scott 2006).

\subsubsection{Main wintering areas in the Baltic Sea}

The geographical distribution of Great Crested Grebes have changed slightly since the 1994 status report both due to actual changes in recorded numbers between surveyed areas and changes in the estimation technique (spatial modeling) which has allowed for the estimation of potential populations in non-surveyed areas. On the other hand, numbers of birds in coastal lagoons have not been available for this report. During 1988-1993 most grebes were found in German waters, and the highest concentrations were recorded in Pomeranian Bay-Greifswalder Lagoon and in Kiel Bay. Observations from the lagoons in Germany were missing, and estimated numbers were $75 \%$ below the estimates for 1988-1993. During the current census most birds were found inshore along the coastal strip from Flensburg Fjord to the Lithuanian-Latvian central coast with 6,730 birds or $81 \%$. Numbers along the LithuanianLatvian central coast were estimated at 2,170 compared to less than 500 
during 1988-1993. The increase along the northern mainland coast may indicate a northward shift in the distribution.

\subsubsection{Distribution in the Baltic Sea}

The species winters in all coastal habitats shallower than $5 \mathrm{~m}$. Areas with medium-higher densities are characterized as sandy or muddy substrates, while rocky habitats support lower densities.

\subsubsection{Phenology}

After the breeding season, large numbers of grebes gather in lakes and in lagoons to moult. Autumn migration mainly takes place in September and October where most birds leave the Baltic Sea. After mid winters, return movements begin in February in the western part of the Baltic Sea. However, in the central Baltic Sea, spring migration takes place in March and April.

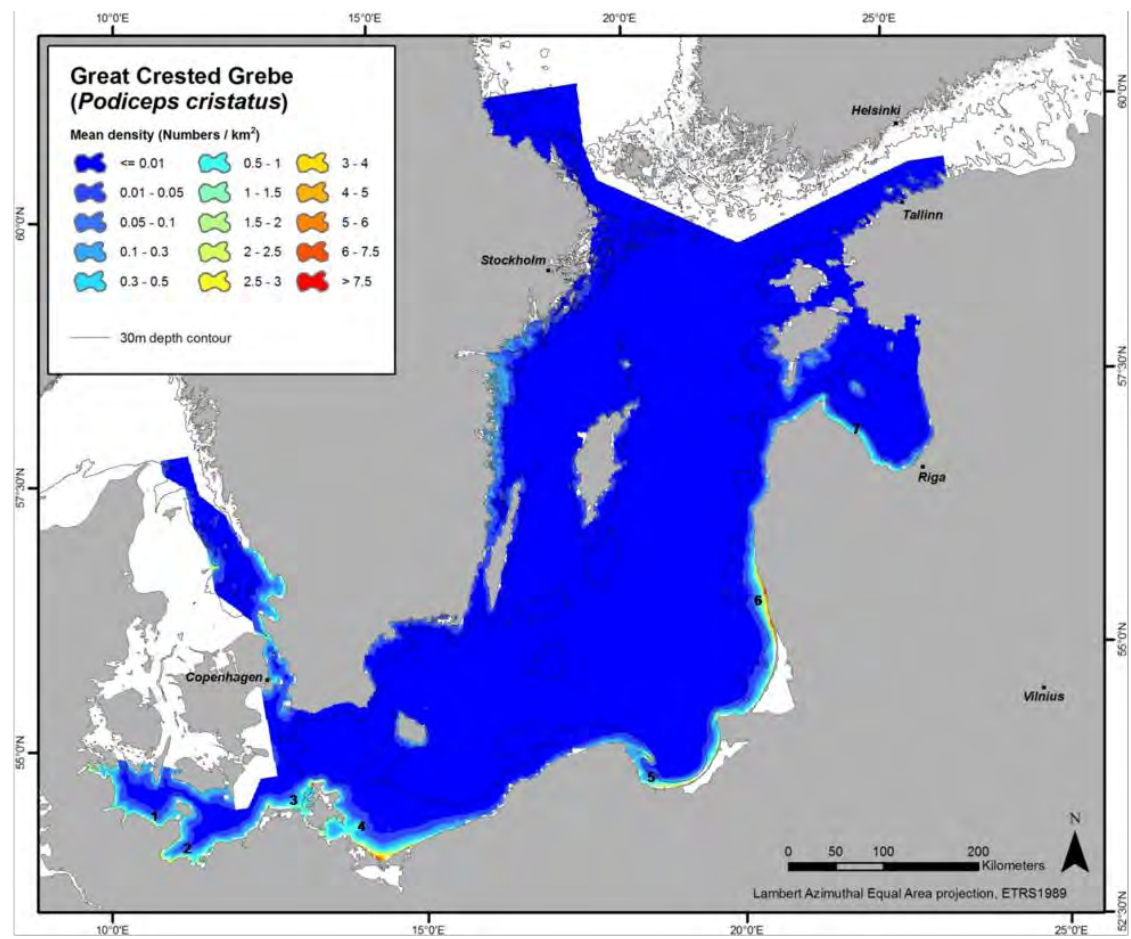

Map 6. Distribution and density of wintering Great Crested Grebe Podiceps cristatus in the Baltic Sea, 2007-2009. 
Table 6. The average number of wintering Great Crested Grebe Podiceps cristatus estimated by spatial modeling for key areas of the Baltic Sea, 2007-2009.

\begin{tabular}{llrrrrr}
\hline Id & Locality & Area & Number & Mean density & Std density & $\%$ \\
\hline 1 & Kiel Bay & 1,268 & 950 & 0.750 & 0.671 & 11.45 \\
2 & Mecklenburg Bay & 1,381 & 900 & 0.649 & 0.644 & 10.84 \\
3 & Darss & 1,026 & 670 & 0.657 & 0.838 & 8.07 \\
4 & Pomeranian Bay & 1,324 & 1,470 & 1.110 & 1.193 & 17.71 \\
5 & Gulf of Gdansk & 934 & 570 & 0.614 & 0.695 & 6.87 \\
6 & Lithuania-Latvia central coast & 2,398 & 2,170 & 0.904 & 1.354 & 26.14 \\
7 & Irbe Strait - Gulf of Riga & 1,344 & 350 & 0.258 & 0.314 & 4.22 \\
& Key areas & & 7,080 & & & 85.30 \\
& Residual & & 1,220 & & & 14.70 \\
& Total & & $\mathbf{8 , 3 0 0}$ & & & 100.00
\end{tabular}

Area indicates the size of the area in $\mathrm{km}^{2}$, Number is the average estimated number of birds, mean density is the mean density of birds per $\mathrm{km}^{2}$ within the area, Std density is the standard deviation of the density within the area and \% compares the percentage of birds within the area with the total estimated number in the Baltic Sea.

\subsection{Red-necked Grebe Podiceps grisegena}

\subsubsection{Importance of the Baltic Sea}

The north-west European winter population of Red-necked Grebes is estimated at 42,000-60,000 birds (Delany \& Scott 2006). The results of the present study generated significantly smaller numbers of wintering Red-necked Grebes in the Baltic Sea (770) as compared to the 5,500 birds estimated during 1988-1993, equivalent to a decrease of $86 \%$. Due to lack of survey data on this species from Danish waters the density of Red-necked Grebe was not modeled for these areas, and hence the total estimate for the Baltic Sea most certainly has been higher than reported. As the estimated sizes of the total population wintering in north-west Europe has been completely revised since the 1994 status report it is not possible to assess whether the decrease in the Baltic winter population is a reflection of a large-scale or just regional population decreases. Part of this decline is caused by the lack of available data from several important Danish areas as no ship-based surveys, which are necessary to cover this species, were undertaken. Most importantly, the northwestern Kattegat where more than 2,300 birds were found in 19881993 was not covered. Assuming that the estimates in Delany \& Scott (2006) are correct the current status indicates that between $1.3 \%$ and $1.8 \%$ of the north-west European winter population of Red-necked Grebe winter in the surveyed part of the Baltic Sea. The range of the proportion of birds wintering in the Baltic Sea is caused by uncertainties regarding the sizes of recruiting populations in Fennoscandia and Russia (Delany \& Scott 2006). 


\subsubsection{Main wintering areas in the Baltic Sea}

The resolution of the distribution of this species requires the use of shipbased surveys. Thus, only the distribution in German and Polish waters can be estimated for the current period. During 1988-1993 some birds were also found in the Gulf of Riga, but none were recorded here during 2007-2009. During the latter period the main wintering area was Pomeranian Bay with estimated 310 birds.

\subsubsection{Distribution in the Baltic Sea}

Birds were dispersed in German and Polish waters shallower than $20 \mathrm{~m}$.

\subsubsection{Phenology}

After the breeding season, Red-necked Grebes move to the sea in order to moult. Autumn migration to the winter quarters in the Baltic Sea peaks in October while spring migration takes place from March to the beginning of May.

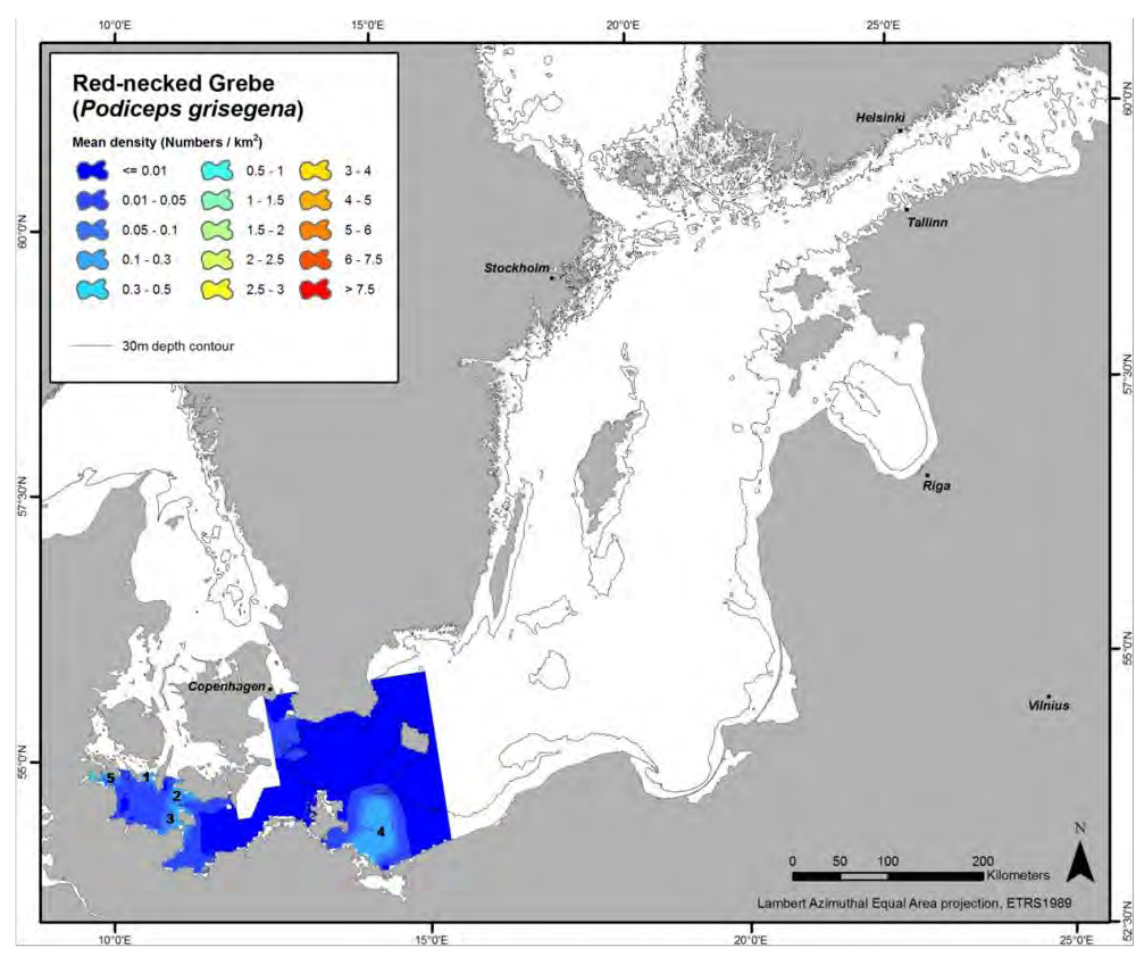

Map 7. Distribution and density of wintering Red-necked Grebe Podiceps grisegena in the Baltic Sea, 2007-2009. 
Table 7. The average number of wintering Red-necked Grebe Podiceps grisegena estimated by spatial modeling for key areas of the Baltic Sea, 2007-2009.

\begin{tabular}{llrrrrr}
\hline Id & Locality & Area & Number & Mean density & Std density & $\%$ \\
\hline 1 & South Funen & 186 & 20 & 0.113 & 0.037 & 2.74 \\
2 & Lolland SW & 430 & 50 & 0.113 & 0.054 & 6.32 \\
3 & Kiel Bay & 885 & 80 & 0.092 & 0.058 & 10.52 \\
4 & Pomeranian Bay & 2,540 & 310 & 0.122 & 0.049 & 40.26 \\
5 & Flensborg Fjord & 339 & 60 & 0.178 & 0.159 & 7.82 \\
& Key areas & & 520 & & & 67.66 \\
& Residual & 250 & & & 100.00 \\
& Total & 770 & & & 10.34 \\
\end{tabular}

Area indicates the size of the area in $\mathrm{km}^{2}$, Number is the average estimated number of birds, mean density is the mean density of birds per $\mathrm{km}^{2}$ within the area, Std density is the standard deviation of the density within the area and \% compares the percentage of birds within the area with the total estimated number in the Baltic Sea.

\subsection{Slavonian Grebe Podiceps auritus}

\subsubsection{Importance of the Baltic Sea}

The north-west European winter population of Slavonian Grebes is estimated at 14,200-26,000 birds (Delany \& Scott 2006). The results of the present study indicate an increase in the numbers wintering in the Baltic Sea from 1,800 birds during 1988-1993 to 2,890 in 2007-2009, equivalent of $60.6 \%$. As the estimated sizes of the total population wintering in north-west Europe has been completely revised since the 1994 status report it is not possible to assess whether the increase in the Baltic winter population is a reflection of a large-scale or just regional population increases. Assuming that the estimates in Delany \& Scott (2006) are correct the current status indicates that between $11.1 \%$ and $20.4 \%$ of the north-west European winter population of Slavonian Grebe winter in the Baltic Sea. The range of the proportion of birds wintering in the Baltic Sea is caused by uncertainties regarding the sizes of recruiting populations in Russia (Delany \& Scott 2006).

\subsubsection{Main wintering areas in the Baltic Sea}

The birds were only recorded in east German and Polish waters. Surprisingly, no birds were observed in Russian, Lithuanian and Latvian waters. As found in the last status report the main area in the Baltic Sea is the Pomeranian Bay with estimated 2,410 (1,690 estimated by Durinck et al. 1994). Some birds are also wintering in the western part of the Gulf of Gdansk. 


\subsubsection{Distribution in the Baltic Sea}

The birds are found exclusively in areas shallower than $20 \mathrm{~m}$ with sandy sediments.

\subsubsection{Phenology}

After the breeding season, most Slavonian Grebes leave fresh-water localities to move to inshore seas. Autumn migration to the Baltic Sea begins in late August and peaks from October to November. Spring migration begins in March but some birds remain in the northern Baltic Sea until May, depending on when thaw is setting in.

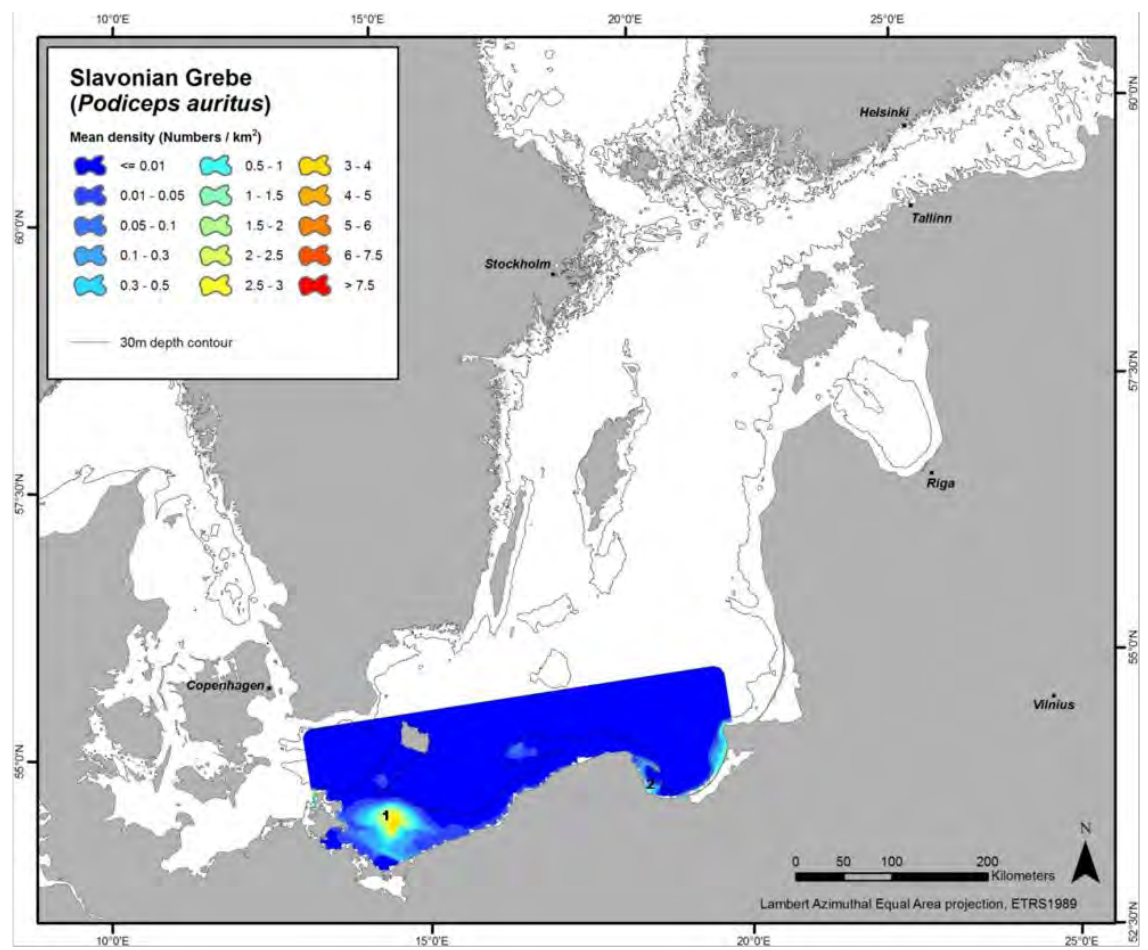

Map 8. Distribution and density of wintering Slavonian Grebe Podiceps auritus in the Baltic Sea, 2007-2009.

Table 8. The average number of wintering Slavonian Grebe Podiceps auritus estimated by spatial modeling for key areas of the Baltic Sea, 2007-2009.

\begin{tabular}{llrrrrr}
\hline Id & Locality & Area & Number & Mean density & Std density & $\%$ \\
\hline 1 & Pomeranian Bay & 3,161 & 2,410 & 0.762 & 0.894 & 83.39 \\
2 & Gulf of Gdansk & 1,583 & 330 & 0.210 & 0.280 & 11.42 \\
& Key areas & & 2,740 & & & 94.81 \\
& Residual & 150 & & & 5.19 \\
& Total & $\mathbf{2 , 8 9 0}$ & & & $\mathbf{1 0 0 . 0 0}$
\end{tabular}

Area indicates the size of the area in $\mathrm{km} 2$, Number is the average estimated number of birds, mean density is the mean density of birds per $\mathrm{km}^{2}$ within the area, Std density is the standard deviation of the density within the area and \% compares the percentage of birds within the area with the total estimated number in the Baltic Sea. 


\subsection{Great Cormorant Phalacrocorax carbo}

\subsubsection{Importance of the Baltic Sea}

The north-west European breeding populations of two Great Cormorant subpopulations (P.c.carbo and P.c.sinensis) are 500,000-525,000 birds (Delany \& Scott 2006). The current wintering numbers in the Baltic Sea of 54,000 birds constitute $10.3-10.8 \%$ of these populations, - a large increase from the 19,400 birds recorded during 1988-1993. The estimated sizes of the total breeding populations are relatively accurate, and the large increase in the Baltic winter population is undoubtedly a result of the increase of the breeding populations and prolonged period of mild winters.

\subsubsection{Main wintering areas in the Baltic Sea}

The largest concentrations of Great Cormorants were recorded in five regions: Danish waters, the Mecklenburg region of Germany, the southern part of Bohuslän and Gdansk Bay and the Sound. During 2007-2009 $31 \%$ of the Great Cormorants were found in Danish waters compared to approximately half of the birds during the former census period. The proportion wintering in the Mecklenburg region of Germany has increased since the first status report from $9 \%$ to $24 \%$, while the proportion in the Åland Archipelago has increased from 1.3\% to 3.6\%. The Gdansk Bay was only used by few birds during 1992-1993, while the region supported $11 \%$ during 2007-2009. 


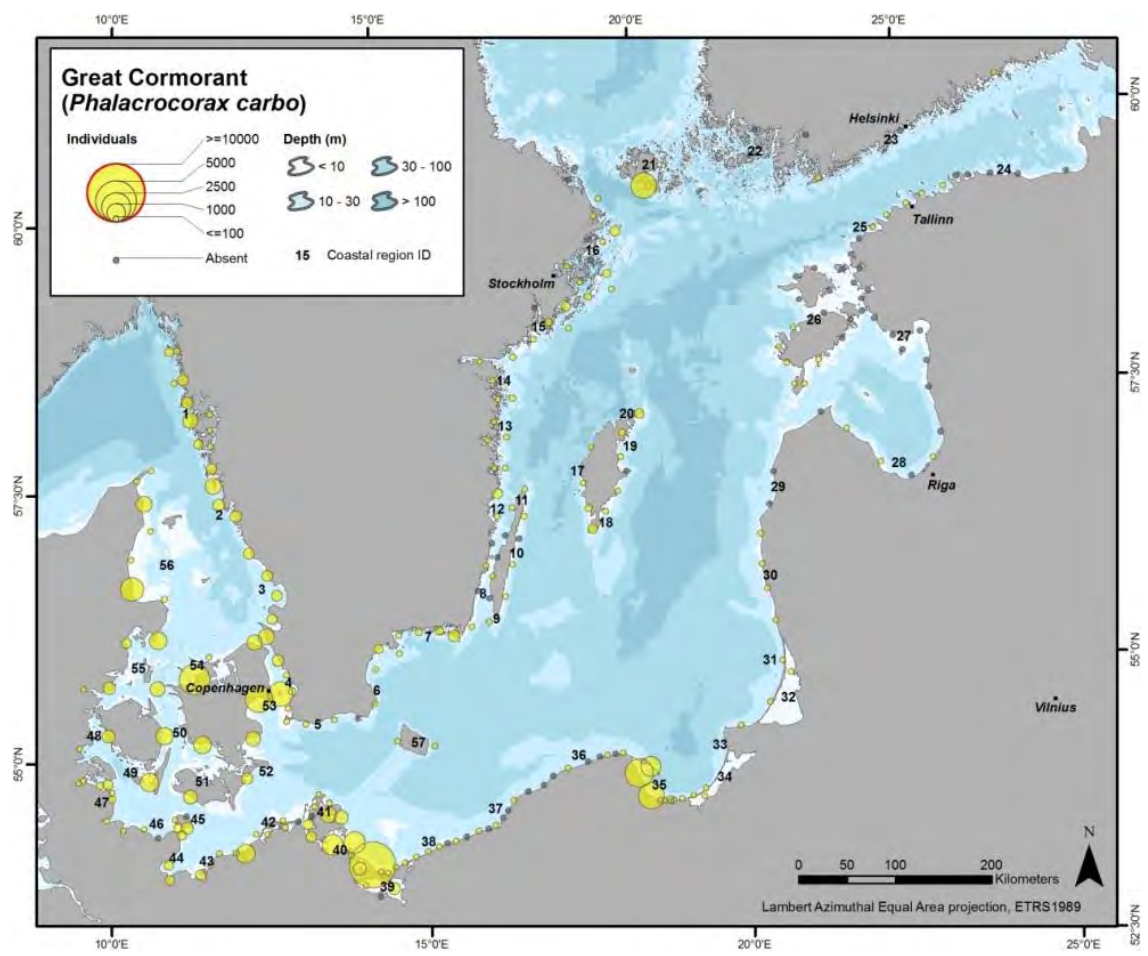

Map 9. Distribution and numbers of wintering Great Cormorant Phalacrocorax carbo in the Baltic Sea, 2007-2009.

\subsubsection{Distribution in the Baltic Sea}

The winter distribution of the Great Cormorant seems to have changed only slightly over the 15 year period since the last status report. Cormorants chiefly used waters with sandy and rocky bottoms shallower than $5 \mathrm{~m}$. In regions where areas shallower than $8 \mathrm{~m}$ extend offshore medium numbers of cormorants are found tens of kilometers at sea, and single birds can be recorded in areas as deep as $20 \mathrm{~m}$.

\subsubsection{Phenology}

The breeding population in Denmark and southern Sweden belongs to the subspecies P.c.sinensis. This population is mainly migratory, and moved to the Mediterranean from August to September. In autumn, migrants of the subspecies P.c.carbo that breed in Norway arrive to the Danish waters to winter. Cormorants that winter in southern Europe return to Danish waters in February and March; at the same time, cormorants from Norway move north toward their breeding grounds. 
Table 9. The average number of wintering Great Cormorant Phalacrocorax carbo in key areas of the Baltic Sea, 2007-2009.

\begin{tabular}{|c|c|c|c|}
\hline Id & Locality & Number & $\%$ \\
\hline 1 & Bohüslän S & 3,438 & 6.38 \\
\hline 2 & Halland & 806 & 1.50 \\
\hline 3 & Skåne NW & 1,346 & 2.50 \\
\hline 4 & The Sound, Sweden & 1,382 & 2.57 \\
\hline 5 & Skåne south coast & 176 & 0.33 \\
\hline 6 & Hanö Bay & 374 & 0.69 \\
\hline 7 & Blekinge archipelago & 873 & 1.62 \\
\hline 8 & S Kalmar Sound & 36 & 0.07 \\
\hline 9 & Öland south coast & 42 & 0.08 \\
\hline 10 & Öland east coast & 184 & 0.34 \\
\hline 11 & Öland north coast \& N Ground & 31 & 0.06 \\
\hline 12 & N Kalmar Sound & 426 & 0.79 \\
\hline 13 & N Kalmar Län archipelago & 63 & 0.12 \\
\hline 14 & Östergötland archipelago & 326 & 0.61 \\
\hline 15 & Södermanlands archipelago & 223 & 0.41 \\
\hline 16 & Stockholm archipelago & 970 & 1.80 \\
\hline 17 & Gotland west coast & 290 & 0.54 \\
\hline 18 & Gotland S coast & 306 & 0.57 \\
\hline 19 & Gotland NE coast & 167 & 0.31 \\
\hline 20 & Gotland N coast, Fårön \& Gotska Sandön & 265 & 0.49 \\
\hline 21 & Åland Archipelago & 1,937 & 3.60 \\
\hline 22 & Archipelago Sea & 0 & 0.00 \\
\hline 23 & Gulf of Finland & 4 & 0.01 \\
\hline 24 & Estonia $\mathrm{N}$ coast & 7 & 0.01 \\
\hline 25 & Estonia NW coast & 81 & 0.15 \\
\hline 26 & Hiiumaa-Saaremaa coasts & 75 & 0.14 \\
\hline 27 & Estonian $\mathrm{S}$ coast & 0 & 0.00 \\
\hline 28 & Gulf of Riga & 7 & 0.01 \\
\hline 29 & Latvia W coast & 8 & 0.01 \\
\hline 30 & Latvia SW coast & 115 & 0.21 \\
\hline 31 & Lithuanian and northern Kaliningrad coast & 9 & 0.02 \\
\hline 32 & Curonian Lagoon & 11 & 0.02 \\
\hline 33 & S Kaliningrad coast & 79 & 0.15 \\
\hline 34 & Vistula Lagoon & 12 & 0.02 \\
\hline 35 & Gdansk Bay & 5,840 & 10.84 \\
\hline 36 & Pomorskie coast & 13 & 0.02 \\
\hline 37 & N Zachodniopomorskie coast & 10 & 0.02 \\
\hline 38 & S Zachodniopomorskie coast & 309 & 0.57 \\
\hline 39 & Szczecin Lagoon & 445 & 0.83 \\
\hline 40 & Usedomer coast and Greifswalder Lagoon & 9,985 & 18.53 \\
\hline 41 & Rügen coast & 1,776 & 3.30 \\
\hline 42 & Darss coast & 1,088 & 2.02 \\
\hline 43 & Wismar Bay & 371 & 0.69 \\
\hline 44 & Fehmarn Belt & 762 & 1.41 \\
\hline 45 & Fehmarn coast & 734 & 1.36 \\
\hline 46 & Propstei coast & 109 & 0.20 \\
\hline 47 & Schleswig-Holstein coast & 765 & 1.42 \\
\hline 48 & Little Belt & 595 & 1.10 \\
\hline 49 & N Kiel Bay & 1,024 & 1.90 \\
\hline 50 & Great Belt & 900 & 1.67 \\
\hline 51 & Lolland coast & 1,487 & 2.76 \\
\hline 52 & SE Denmark coast & 1,013 & 1.88 \\
\hline 53 & The Sound, Danish coast & 4,636 & 8.60 \\
\hline 54 & NW Sealand & 2,810 & 5.22 \\
\hline 55 & SW Kattegat & 2,358 & 4.38 \\
\hline 56 & NW Kattegat & 2,642 & 4.90 \\
\hline \multirow[t]{2}{*}{57} & Bornholm coast & 138 & 0.26 \\
\hline & Total & 54,000 & 100.00 \\
\hline
\end{tabular}

Number is the average estimated number of birds, and \% compares the percentage of birds within the area with the total estimated number in the Baltic Sea. 


\subsection{Mute Swan Cygnus olor}

\subsubsection{Importance of the Baltic Sea}

The north-west European winter population of Mute Swan has increased by $62 \%$ from 180,000 in the early 1990 'es to 292,000 birds in 2006 (Delany \& Scott 2006). The current Baltic winter population is estimated at 132,000 birds, equivalent to an increase of $22.2 \%$ since $1988-1993$, and a decline in the proportion of the fly-way population using the Baltic Sea for wintering from $61 \%$ to $45 \%$.

\subsubsection{Main wintering areas in the Baltic Sea}

The location of the main wintering areas has remained stable since the last status report. The coasts of Hiiumaa and Saaremaa, the lagoons on Rügen and southeastern Denmark are still the main areas used by this species. The numbers wintering in Danish waters have been stable around 50,000, and so the proportion wintering here has decreased from $46 \%$ to $37 \%$ since 1993 . The proportion wintering in eastern German waters has remained at $23 \%$ and the proportion wintering around Hiiumaa and Saaremaa has increased from $8 \%$ to $10 \%$.

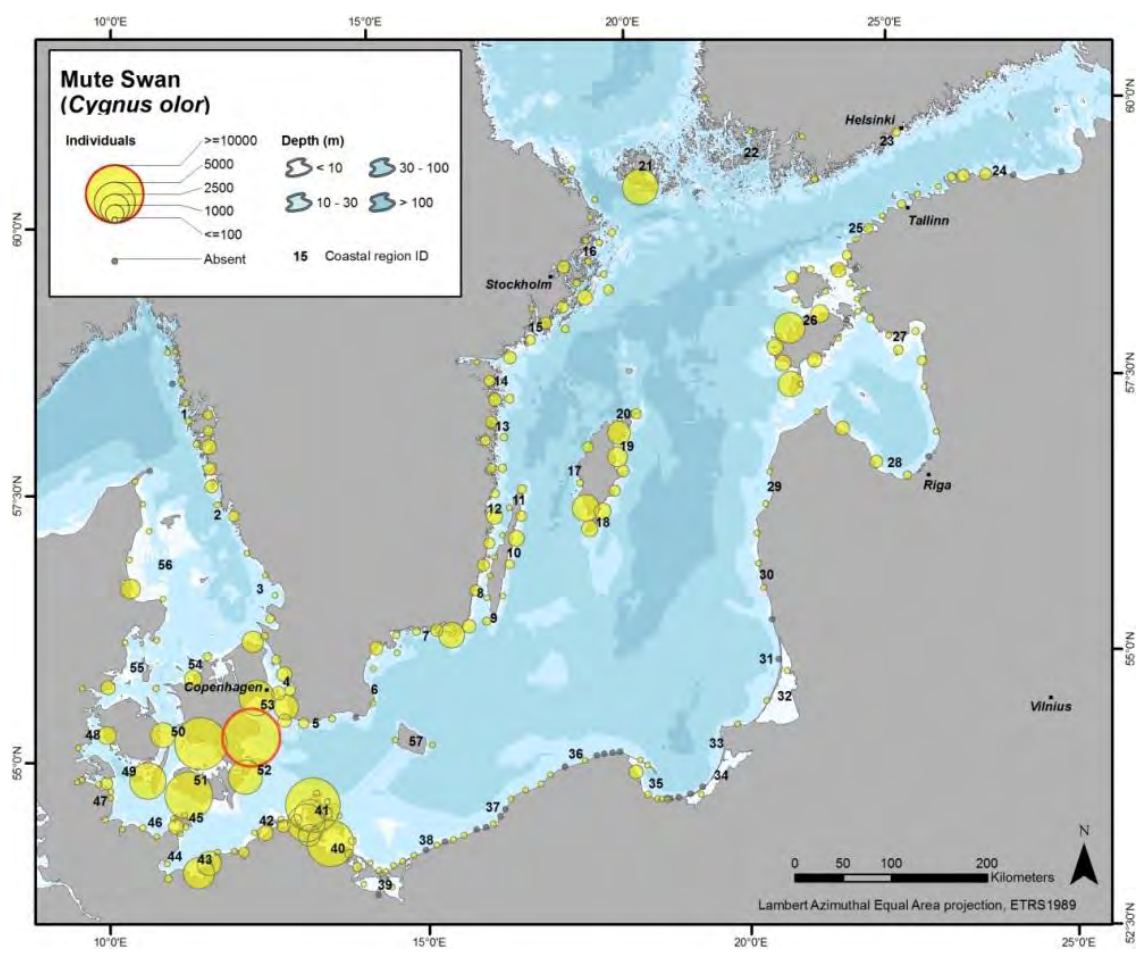

Map 10. Distribution and numbers of wintering Mute Swan Cygnus olor in the Baltic Sea, 2007-2009. 


\subsubsection{Distribution in the Baltic Sea}

Mute Swans winter in fresh and brackish waters however, during hard winters almost all birds move to marine areas. The most important habitats are sheltered lagoons and fjords. Most birds are found in southeastern Denmark, the Sound, the shallow waters around Rügen and the coastal areas around Hiiumaa and Saaremaa. In winter, Mute Swans feed almost exclusively on aquatic plant material in areas of less than 2 meters water depth. During cold spells, distribution patterns may be altered as birds are forced to leave ice-covered areas.

\subsubsection{Phenology}

Large numbers of young, non-breeding swans spend their first years in the south-western part of the Baltic Sea, notably in Danish waters. From July to August they move to undisturbed shallow waters in order to moult in large flocks. Mute swans return to their breeding areas when thaw is setting in, but most birds move inland in February and March.

Table 10. The average number of wintering Mute Swan Cygnus olor in key areas of the Baltic Sea, 2007-2009.

\begin{tabular}{|c|c|c|c|}
\hline Id & Locality & Number & $\%$ \\
\hline 1 & Bohüslän S & 2,771 & 2.11 \\
\hline 2 & Halland & 467 & 0.35 \\
\hline 3 & Skåne NW & 341 & 0.26 \\
\hline 4 & The Sound, Sweden & 3,271 & 2.49 \\
\hline 5 & Skåne south coast & 998 & 0.76 \\
\hline 6 & Hanö Bay & 601 & 0.46 \\
\hline 7 & Blekinge archipelago & 2,821 & 2.14 \\
\hline 8 & S Kalmar Sound & 1,447 & 1.10 \\
\hline 9 & Öland south coast & 203 & 0.15 \\
\hline 10 & Öland east coast & 1,394 & 1.06 \\
\hline 11 & Öland north coast \& N Ground & 242 & 0.18 \\
\hline 12 & N Kalmar Sound & 1,841 & 1.40 \\
\hline 13 & N Kalmar Län archipelago & 883 & 0.67 \\
\hline 14 & Östergötland archipelago & 1,621 & 1.23 \\
\hline 15 & Södermanlands archipelago & 762 & 0.58 \\
\hline 16 & Stockholm archipelago & 2,923 & 2.22 \\
\hline 17 & Gotland west coast & 2,676 & 2.03 \\
\hline 18 & Gotland $S$ coast & 1,997 & 1.52 \\
\hline 19 & Gotland NE coast & 3,159 & 2.40 \\
\hline 20 & Gotland N coast, Fårön \& Gotska Sandön & 313 & 0.24 \\
\hline 21 & Åland Archipelago & 3,820 & 2.90 \\
\hline 22 & Archipelago Sea & 57 & 0.04 \\
\hline 23 & Gulf of Finland & 341 & 0.26 \\
\hline 24 & Estonia $\mathrm{N}$ coast & 1,262 & 0.96 \\
\hline 25 & Estonia NW coast & 782 & 0.59 \\
\hline 26 & Hiiumaa-Saaremaa coasts & 9,779 & 7.43 \\
\hline 27 & Estonian $S$ coast & 922 & 0.70 \\
\hline 28 & Gulf of Riga & 1,303 & 0.99 \\
\hline 29 & Latvia W coast & 22 & 0.02 \\
\hline 30 & Latvia SW coast & 16 & 0.01 \\
\hline 31 & Lithuanian and northern Kaliningrad coast & 3 & 0.00 \\
\hline 32 & Curonian Lagoon & 35 & 0.03 \\
\hline 33 & S Kaliningrad coast & 41 & 0.03 \\
\hline 34 & Vistula Lagoon & 99 & 0.08 \\
\hline 35 & Gdansk Bay & 860 & 0.65 \\
\hline 36 & Pomorskie coast & 84 & 0.06 \\
\hline 37 & N Zachodniopomorskie coast & 21 & 0.02 \\
\hline 38 & S Zachodniopomorskie coast & 112 & 0.09 \\
\hline
\end{tabular}




\begin{tabular}{rlrr}
\hline Id & Locality & Number & $\%$ \\
\hline 39 & Szczecin Lagoon & 82 & 0.06 \\
40 & Usedomer coast and Greifswalder Lagoon & 8,673 & 6.59 \\
41 & Rügen coast & 16,576 & 12.60 \\
42 & Darss coast & 1,920 & 1.46 \\
43 & Wismar Bay & 4,752 & 3.61 \\
44 & Fehmarn Belt & 253 & 0.19 \\
45 & Fehmarn coast & 815 & 0.62 \\
46 & Propstei coast & 164 & 0.12 \\
47 & Schleswig-Holstein coast & 746 & 0.57 \\
48 & Little Belt & 1,003 & 0.76 \\
49 & N Kiel Bay & 3,988 & 3.03 \\
50 & Great Belt & 1,850 & 1.41 \\
51 & Lolland coast & 14,998 & 11.40 \\
52 & SE Denmark coast & 16,371 & 12.44 \\
53 & The Sound, Danish coast & 5,712 & 4.34 \\
54 & NW Sealand & 1,216 & 0.92 \\
55 & SW Kattegat & 795 & 0.60 \\
56 & NW Kattegat & 1,314 & 1.00 \\
57 & Bornholm coast & 70 & 0.05 \\
& Total & 132,000 & 100.00
\end{tabular}

Number is the average estimated number of birds, and \% compares the percentage of birds within the area with the total estimated number in the Baltic Sea.

\subsection{Mallard Anas platyrhynchos}

\subsubsection{Importance of the Baltic Sea}

The north-west European winter population of Mallard has recently been estimated at 4.5 million birds, - a decrease by $10 \%$ since the early 1990 'es (Delany \& Scott 2006). The current Baltic winter population is estimated at 254,000 birds, equivalent to an increase of $11.9 \%$ since $1988-1993$, and a $1.2 \%$ increase in the proportion of the fly-way population using the Baltic Sea for wintering.

\subsubsection{Main wintering areas in the Baltic Sea}

Both the distribution and the numbers of birds have remained stable over the period since the last status. The lagoons around Rügen Greifswald still hold the largest concentration of Mallards in The Baltic Sea with approximately 54,000 birds. Otherwise, larger concentrations are found in south-eastern Denmark, the south coast of Sweden, Gotland and Hiiumaa and Saaremaa. 


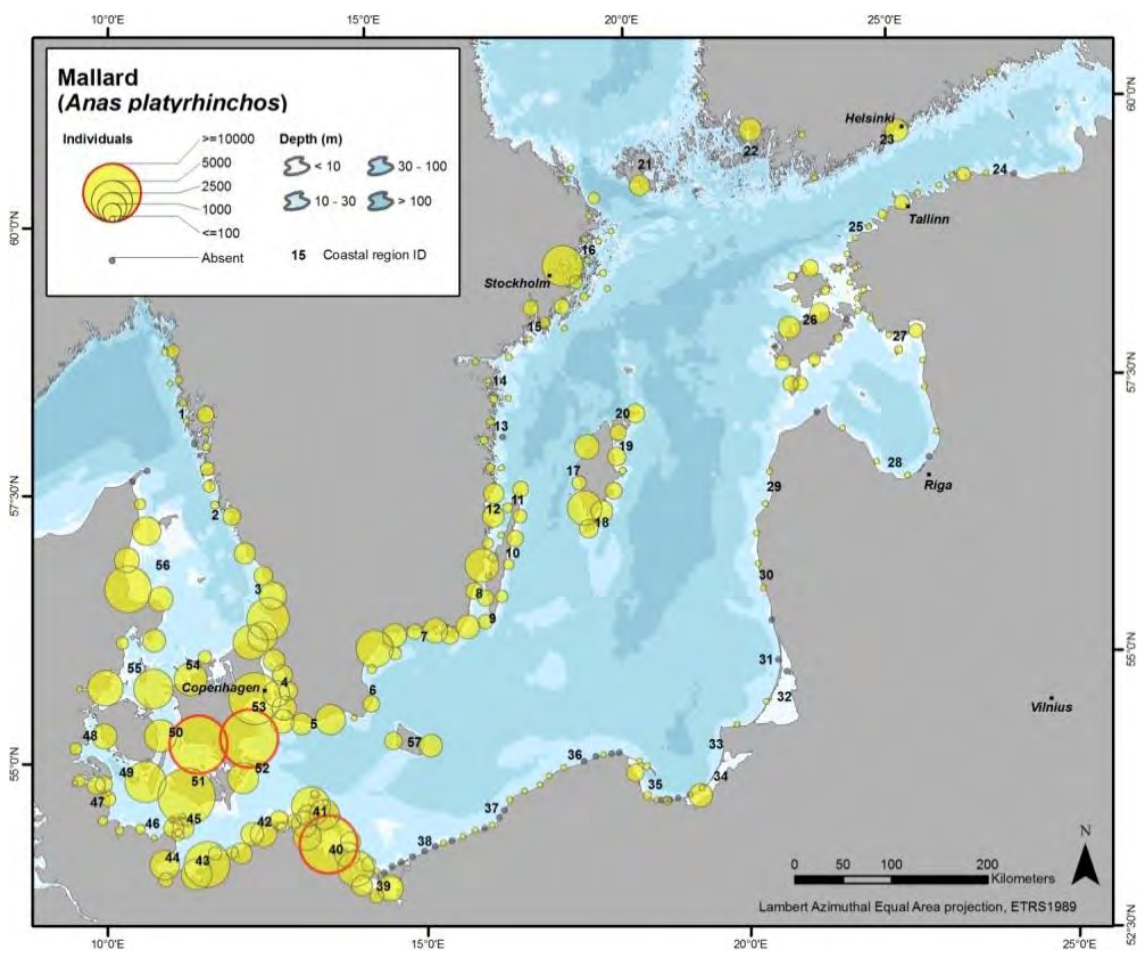

Map 11. Distribution and numbers of wintering Mallard Anas platyrhynchos in the Baltic Sea, 2007-2009.

\subsubsection{Distribution in the Baltic Sea}

The species is mainly an inland species associated with freshwater localities. The species is fairly widespread along all Baltic coasts and across all coastal habitats types shallower than $5 \mathrm{~m}$ depth.

\subsubsection{Phenology}

Movements to the Baltic Sea take place from August to November. During cold spells, large numbers of Mallards take to the sea, but in years with extensive ice cover most birds leave the Baltic region. Spring migration takes place from February to early May depending on the timing of inland thaw.

Table 11. The average number of wintering Mallard Anas platyrhynchos in key areas of the Baltic Sea, 2007-2009.

\begin{tabular}{llrr}
\hline Id & Locality & Number & $\%$ \\
\hline 1 & Bohüslän S & 3,117 & 1.23 \\
2 & Halland & 1,134 & 0.45 \\
3 & Skåne NW & 9,972 & 3.93 \\
4 & The Sound, Sweden & 7,982 & 3.14 \\
5 & Skåne south coast & 5,775 & 2.27 \\
6 & Hanö Bay & 5,230 & 2.06 \\
7 & Blekinge archipelago & 5,559 & 2.19 \\
8 & S Kalmar Sound & 7,001 & 2.76 \\
9 & Öland south coast & 626 & 0.25 \\
10 & Öland east coast & 2,165 & 0.85
\end{tabular}




\begin{tabular}{|c|c|c|c|}
\hline Id & Locality & Number & $\%$ \\
\hline 11 & Öland north coast \& N Ground & 749 & 0.29 \\
\hline 12 & N Kalmar Sound & 3,667 & 1.44 \\
\hline 13 & N Kalmar Län archipelago & 357 & 0.14 \\
\hline 14 & Östergötland archipelago & 613 & 0.24 \\
\hline 15 & Södermanlands archipelago & 1,041 & 0.41 \\
\hline 16 & Stockholm archipelago & 7,284 & 2.87 \\
\hline 17 & Gotland west coast & 5,922 & 2.33 \\
\hline 18 & Gotland S coast & 3,293 & 1.30 \\
\hline 19 & Gotland NE coast & 1,939 & 0.76 \\
\hline 20 & Gotland N coast, Fårön \& Gotska Sandön & 1,060 & 0.42 \\
\hline 21 & Åland Archipelago & 1,238 & 0.49 \\
\hline 22 & Archipelago Sea & 1,628 & 0.64 \\
\hline 23 & Gulf of Finland & 1,556 & 0.61 \\
\hline 24 & Estonia $\mathrm{N}$ coast & 933 & 0.37 \\
\hline 25 & Estonia NW coast & 949 & 0.37 \\
\hline 26 & Hiiumaa-Saaremaa coasts & 6,753 & 2.66 \\
\hline 27 & Estonian $\mathrm{S}$ coast & 860 & 0.34 \\
\hline 28 & Gulf of riga & 246 & 0.10 \\
\hline 29 & Latvia W coast & 43 & 0.02 \\
\hline 30 & Latvia SW coast & 14 & 0.01 \\
\hline 31 & Lithuanian and northern Kaliningrad coast & 12 & 0.00 \\
\hline 32 & Curonian Lagoon & 0 & 0.00 \\
\hline 33 & S Kaliningrad coast & 72 & 0.03 \\
\hline 34 & Vistula Lagoon & 1,632 & 0.64 \\
\hline 35 & Gdansk Bay & 1,477 & 0.58 \\
\hline 36 & Pomorskie coast & 256 & 0.10 \\
\hline 37 & N Zachodniopomorskie coast & 170 & 0.07 \\
\hline 38 & S Zachodniopomorskie coast & 81 & 0.03 \\
\hline 39 & Szczecin Lagoon & 3,867 & 1.52 \\
\hline 40 & Usedomer coast and Greifswalder Lagoon & 27,130 & 10.68 \\
\hline 41 & Rügen coast & 10,893 & 4.29 \\
\hline 42 & Darss coast & 6,892 & 2.71 \\
\hline 43 & Wismar Bay & 10,045 & 3.95 \\
\hline 44 & Fehmarn Belt & 3,626 & 1.43 \\
\hline 45 & Fehmarn coast & 2,529 & 1.00 \\
\hline 46 & Propstei coast & 522 & 0.21 \\
\hline 47 & Schleswig-Holstein coast & 3,245 & 1.28 \\
\hline 48 & Little Belt & 2,272 & 0.89 \\
\hline 49 & N Kiel Bay & 5,018 & 1.98 \\
\hline 50 & Great Belt & 3,103 & 1.22 \\
\hline 51 & Lolland coast & 19,828 & 7.81 \\
\hline 52 & SE Denmark coast & 19,280 & 7.59 \\
\hline 53 & The Sound, Danish coast & 13,646 & 5.37 \\
\hline 54 & NW Sealand & 8,438 & 3.32 \\
\hline 55 & SW Kattegat & 5,814 & 2.29 \\
\hline 56 & NW Kattegat & 12,987 & 5.11 \\
\hline \multirow[t]{2}{*}{57} & Bornholm coast & 2,472 & 0.97 \\
\hline & Total & 254,000 & 100.00 \\
\hline
\end{tabular}

Number is the average estimated number of birds, and \% compares the percentage of birds within the area with the total estimated number in the Baltic Sea.

\subsection{Common Pochard Aythya ferina}

\subsubsection{Importance of the Baltic Sea}

The north-west European winter population of Common Pochard is 350,000 birds, and the population seems stable (Delany \& Scott 2006). The Baltic winter population has remained stable, and has only declined by $1.8 \%$ since 1994 , and the proportion of the fly-way population using the Baltic Sea for wintering is $8.7 \%$ or almost the same as in 1993 (8.9\%). 


\subsubsection{Main wintering areas in the Baltic Sea}

The Szczecin-Rügen Lagoons and Wismar Bay comprise the key wintering area in the Baltic Sea supporting 33\% of the total, while the southern Danish coasts support approximately $20 \%$.

\subsubsection{Distribution in the Baltic Sea}

The distribution of Common Pochard has not changed much since mid 1990 'es, although some extension of their wintering range to the north is noticeable with birds now being observed regularly north of Kalmar Sound, on Gotland, and along Latvia and Estonian coasts. During mild winters, Common Pochard occur in fairly large numbers in the southern and eastern parts of the Baltic Sea, with the majority of birds concentrated in lagoons and sheltered bays in northern Germany and adjacent Poland. Obviously, fewer birds occur in these areas during prolonged periods of mild winters like the current. During cold weather many birds leave the Baltic Sea in order to move south and west to Western and Central Europe.

\subsubsection{Phenology}

In autumn, migrants arrive to the Baltic Sea, while spring migration takes place in March and April.

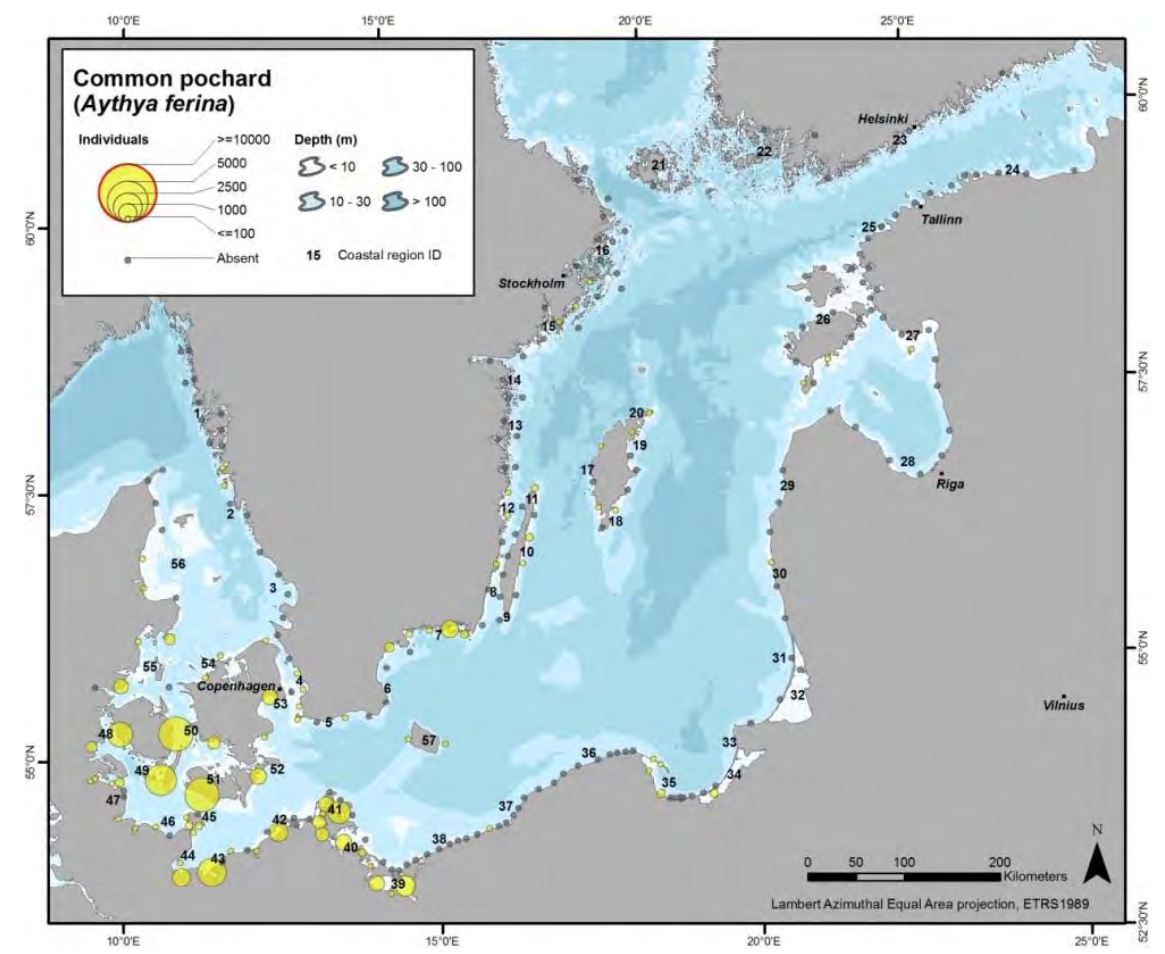

Map 12. Distribution and numbers of wintering Common Pochard Aythya ferina in the Baltic Sea, 2007-2009. 
Table 12. The average number of wintering Common Pochard Aythya ferina in key areas of the Baltic Sea, 2007-2009.

\begin{tabular}{|c|c|c|c|}
\hline Id & Locality & Number & $\%$ \\
\hline 1 & Bohüslän S & 3 & 0.01 \\
\hline 2 & Halland & 0 & 0.00 \\
\hline 3 & Skåne NW & 0 & 0.00 \\
\hline 4 & The Sound, Sweden & 221 & 0.73 \\
\hline 5 & Skåne south coast & 64 & 0.21 \\
\hline 6 & Hanö Bay & 279 & 0.92 \\
\hline 7 & Blekinge archipelago & 1,359 & 4.46 \\
\hline 8 & S Kalmar Sound & 112 & 0.37 \\
\hline 9 & Öland south coast & 0 & 0.00 \\
\hline 10 & Öland east coast & 187 & 0.61 \\
\hline 11 & Öland north coast \& N Ground & 142 & 0.47 \\
\hline 12 & N Kalmar Sound & 51 & 0.17 \\
\hline 13 & N Kalmar Län archipelago & 0 & 0.00 \\
\hline 14 & Östergötland archipelago & 0 & 0.00 \\
\hline 15 & Södermanlands archipelago & 11 & 0.04 \\
\hline 16 & Stockholm archipelago & 146 & 0.48 \\
\hline 17 & Gotland west coast & 6 & 0.02 \\
\hline 18 & Gotland S coast & 9 & 0.03 \\
\hline 19 & Gotland NE coast & 69 & 0.23 \\
\hline 20 & Gotland N coast, Fårön \& Gotska Sandön & 1 & 0.00 \\
\hline 21 & Åland Archipelago & 0 & 0.00 \\
\hline 22 & Archipelago Sea & 0 & 0.00 \\
\hline 23 & Gulf of Finland & 0 & 0.00 \\
\hline 24 & Estonia $\mathrm{N}$ coast & 0 & 0.00 \\
\hline 25 & Estonia NW coast & 0 & 0.00 \\
\hline 26 & Hiiumaa-Saaremaa coasts & 13 & 0.04 \\
\hline 27 & Estonian $\mathrm{S}$ coast & 1 & 0.00 \\
\hline 28 & Gulf of riga & 0 & 0.00 \\
\hline 29 & Latvia W coast & 0 & 0.00 \\
\hline 30 & Latvia SW coast & 13 & 0.04 \\
\hline 31 & Lithuanian and northern Kaliningrad coast & 0 & 0.00 \\
\hline 32 & Curonian Lagoon & 0 & 0.00 \\
\hline 33 & S Kaliningrad coast & 0 & 0.00 \\
\hline 34 & Vistula Lagoon & 200 & 0.66 \\
\hline 35 & Gdansk Bay & 329 & 1.08 \\
\hline 36 & Pomorskie coast & 0 & 0.00 \\
\hline 37 & N Zachodniopomorskie coast & 65 & 0.21 \\
\hline 38 & S Zachodniopomorskie coast & 0 & 0.00 \\
\hline 39 & Szczecin Lagoon & 1,989 & 6.53 \\
\hline 40 & Usedomer coast and Greifswalder Lagoon & 1,578 & 5.18 \\
\hline 41 & Rügen coast & 2,743 & 9.01 \\
\hline 42 & Darss coast & 1,157 & 3.80 \\
\hline 43 & Wismar Bay & 2,451 & 8.05 \\
\hline 44 & Fehmarn Belt & 1,020 & 3.35 \\
\hline 45 & Fehmarn coast & 324 & 1.06 \\
\hline 46 & Propstei coast & 33 & 0.11 \\
\hline 47 & Schleswig-Holstein coast & 369 & 1.21 \\
\hline 48 & Little Belt & 2,198 & 7.22 \\
\hline 49 & N Kiel Bay & 2,894 & 9.50 \\
\hline 50 & Great Belt & 3,553 & 11.67 \\
\hline 51 & Lolland coast & 3,983 & 13.08 \\
\hline 52 & SE Denmark coast & 821 & 2.70 \\
\hline 53 & The Sound, Danish coast & 767 & 2.52 \\
\hline 54 & NW Sealand & 112 & 0.37 \\
\hline 55 & SW Kattegat & 1,134 & 3.72 \\
\hline 56 & NW Kattegat & 8 & 0.03 \\
\hline \multirow[t]{2}{*}{57} & Bornholm coast & 42 & 0.14 \\
\hline & Total & 30,450 & 100.00 \\
\hline
\end{tabular}

Number is the average estimated number of birds, and \% compares the percentage of birds within the area with the total estimated number in the Baltic Sea. 


\subsection{Tufted Duck Aythya fuligula}

\subsubsection{Importance of the Baltic Sea}

The north-west European winter population of Tufted Ducks has recently been estimated at 1.2 million birds, as compared to 750,000 estimated during the early 1990'es (Delany \& Scott 2006). The current Baltic winter population may be estimated at 476,000 birds, equivalent to an increase of $49.5 \%$ since $1988-1993$. The Baltic Sea now supports $39.7 \%$ of the north-west European winter population of Tufted Ducks, or more or less the same as during the former census period. Thus, the increase in the total number wintering in the Baltic Sea may be seen as mainly a result of the increase in the overall population size.

\subsubsection{Main wintering areas in the Baltic Sea}

A re-location of Tufted Ducks has taken place since mid 1990'es, as the distribution which used to have its center in the shallow bays and lagoons along the north-east coast of Germany and in west Poland as well as in southeast Denmark is now split between these regions in the southwestern Baltic and the east coast of Sweden. In the area from the Wismar Bay in Germany to the Szczecin Lagoon in Poland, 130,000 Tufted Ducks were recorded during the survey period from 1988 to 1993. During 2007-2009 half of this number or 65,000 birds were recorded here. In southeastern Denmark 80,000 Tufted Ducks were recorded during the former census period as compared to 143,000 during the present census, - an increase by $80 \%$. Similarly, numbers in the Blekinge Archipelago have increased by $60 \%$ from 22,000 to 33,000 between the two periods. Further north along the Swedish east coast numbers have increased dramatically. This has especially taken place between Kalmar Sound and Stockholm Archipelago, where numbers have increased from 48,000 to 143,500 ; equivalent of $200 \%$. 


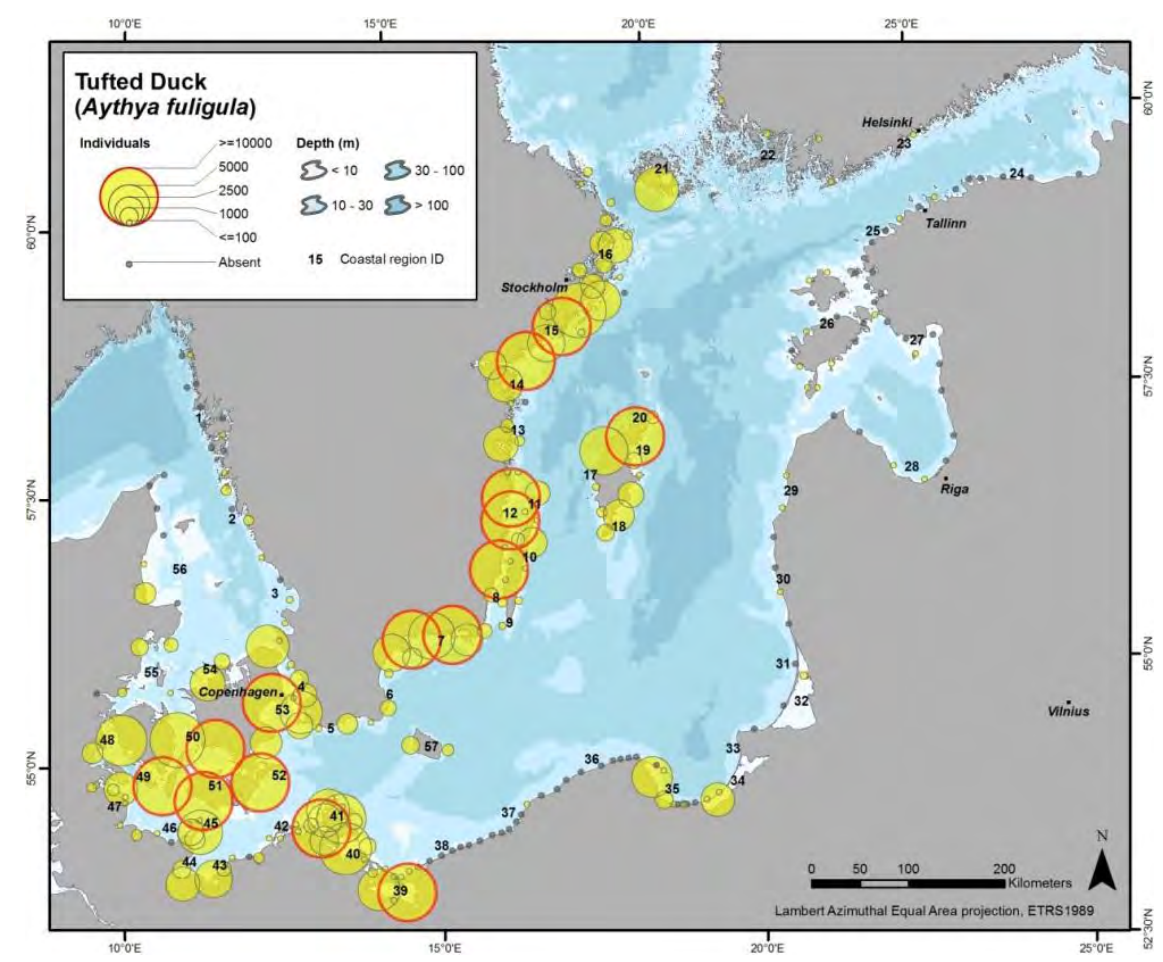

Map 13. Distribution and numbers of wintering Tufted Duck Aythya fuligula in the Baltic Sea, 2007-2009.

\subsubsection{Distribution in the Baltic Sea}

As described above the distribution of the species shifted northwestwards in the Baltic over the past 15 years. Most birds are found in enclosed bays, lagoons and archipelago areas, with lower densities scattered in more exposed areas with a water depth less than $5 \mathrm{~m}$. The birds utilize both areas with rocky and sandy substrates. It should be noted that in the southern part of the Baltic large flocks of Tufted Ducks roost in coastal lakes not covered by this census, and use marine habitats for feeding during the night.

\subsubsection{Phenology}

Birds breeding in Russia begin to join local breeding birds in October to winter in the Baltic Sea. Usually, numbers increase during autumn and peak in January and February. In hard winters, some birds leave the Baltic Sea in order to winter in the Netherlands and the British Isles. Return movements start in March and the last departures take place in late April. 
Table 13. The average number of wintering Tufted Duck Aythya fuligula in key areas of the Baltic Sea, 2007-2009.

\begin{tabular}{|c|c|c|c|}
\hline Id & Locality & Number & $\%$ \\
\hline 1 & Bohüslän S & 328 & 0.07 \\
\hline 2 & Halland & 285 & 0.06 \\
\hline 3 & Skåne NW & 169 & 0.04 \\
\hline 4 & The Sound, Sweden & 8,138 & 1.71 \\
\hline 5 & Skåne south coast & 3,473 & 0.73 \\
\hline 6 & Hanö Bay & 5,160 & 1.08 \\
\hline 7 & Blekinge archipelago & 33,555 & 7.05 \\
\hline 8 & S Kalmar Sound & 26,169 & 5.49 \\
\hline 9 & Öland south coast & 154 & 0.03 \\
\hline 10 & Öland east coast & 2,982 & 0.63 \\
\hline 11 & Öland north coast \& N Ground & 1,800 & 0.38 \\
\hline 12 & N Kalmar Sound & 39,045 & 8.20 \\
\hline 13 & N Kalmar Län archipelago & 4,400 & 0.92 \\
\hline 14 & Östergötland archipelago & 18,835 & 3.95 \\
\hline 15 & Södermanlands archipelago & 31,658 & 6.65 \\
\hline 16 & Stockholm archipelago & 23,486 & 4.93 \\
\hline 17 & Gotland west coast & 7,350 & 1.54 \\
\hline 18 & Gotland S coast & 5,758 & 1.21 \\
\hline 19 & Gotland NE coast & 11,838 & 2.49 \\
\hline 20 & Gotland N coast, Fårön \& Gotska Sandön & 464 & 0.10 \\
\hline 21 & Åland Archipelago & 5,762 & 1.21 \\
\hline 22 & Archipelago Sea & 147 & 0.03 \\
\hline 23 & Gulf of Finland & 102 & 0.02 \\
\hline 24 & Estonia $\mathrm{N}$ coast & 34 & 0.01 \\
\hline 25 & Estonia NW coast & 2 & 0.00 \\
\hline 26 & Hiiumaa-Saaremaa coasts & 138 & 0.03 \\
\hline 27 & Estonian $\mathrm{S}$ coast & 4 & 0.00 \\
\hline 28 & Gulf of riga & 4 & 0.00 \\
\hline 29 & Latvia W coast & 8 & 0.00 \\
\hline 30 & Latvia SW coast & 7 & 0.00 \\
\hline 31 & Lithuanian and northern Kaliningrad coast & 0 & 0.00 \\
\hline 32 & Curonian Lagoon & 180 & 0.04 \\
\hline 33 & S Kaliningrad coast & 0 & 0.00 \\
\hline 34 & Vistula Lagoon & 3,350 & 0.70 \\
\hline 35 & Gdansk Bay & 6,035 & 1.27 \\
\hline 36 & Pomorskie coast & 0 & 0.00 \\
\hline 37 & N Zachodniopomorskie coast & 58 & 0.01 \\
\hline 38 & S Zachodniopomorskie coast & 5 & 0.00 \\
\hline 39 & Szczecin Lagoon & 17,791 & 3.74 \\
\hline 40 & Usedomer coast and Greifswalder Lagoon & 11,649 & 2.45 \\
\hline 41 & Rügen coast & 29,682 & 6.23 \\
\hline 42 & Darss coast & 1,046 & 0.22 \\
\hline 43 & Wismar Bay & 4,885 & 1.03 \\
\hline 44 & Fehmarn Belt & 5,602 & 1.18 \\
\hline 45 & Fehmarn coast & 7,999 & 1.68 \\
\hline 46 & Propstei coast & 444 & 0.09 \\
\hline 47 & Schleswig-Holstein coast & 4,207 & 0.88 \\
\hline 48 & Little Belt & 9,035 & 1.90 \\
\hline 49 & N Kiel Bay & 15,239 & 3.20 \\
\hline 50 & Great Belt & 8,963 & 1.88 \\
\hline 51 & Lolland coast & 31,604 & 6.64 \\
\hline 52 & SE Denmark coast & 48,455 & 10.17 \\
\hline 53 & The Sound, Danish coast & 29,834 & 6.26 \\
\hline 54 & NW Sealand & 4,446 & 0.93 \\
\hline 55 & SW Kattegat & 1,712 & 0.36 \\
\hline 56 & NW Kattegat & 1,449 & 0.30 \\
\hline \multirow[t]{2}{*}{57} & Bornholm coast & 1,334 & 0.28 \\
\hline & Total & 476,000 & 100.00 \\
\hline
\end{tabular}

Number is the average estimated number of birds, and \% compares the percentage of birds within the area with the total estimated number in the Baltic Sea. 


\subsection{Greater Scaup Aythya marila}

\subsubsection{Importance of the Baltic Sea}

The estimate of the north-west European winter population of Greater Scaup has remained at 310,000 birds for the last 15 years (Delany \& Scott 2006). The current Baltic winter population is estimated at 127,000 birds, equivalent to a decrease of $13.0 \%$ since $1988-1993$. The Baltic Sea now supports $41.0 \%$ of the north-west European winter population of Greater Scaup, as compared to 47.1\% during 1988-1993.

\subsubsection{Main wintering areas in the Baltic Sea}

The main wintering area in the Baltic Sea is the Szczecin Lagoon, where 27,869 were counted, and Usedomer and Greifswalder Lagoon, where 54,195 were counted. In both areas 26,000 were counted during $1988-$ 1993. Reductions were noted in the lagoons and enclosed bays further west along the German coast, where areas like Wismar Bay and Traveförde held much lower numbers than 15 years ago. Numbers in Danish waters, however, were much at the same level as in 1988-1993.

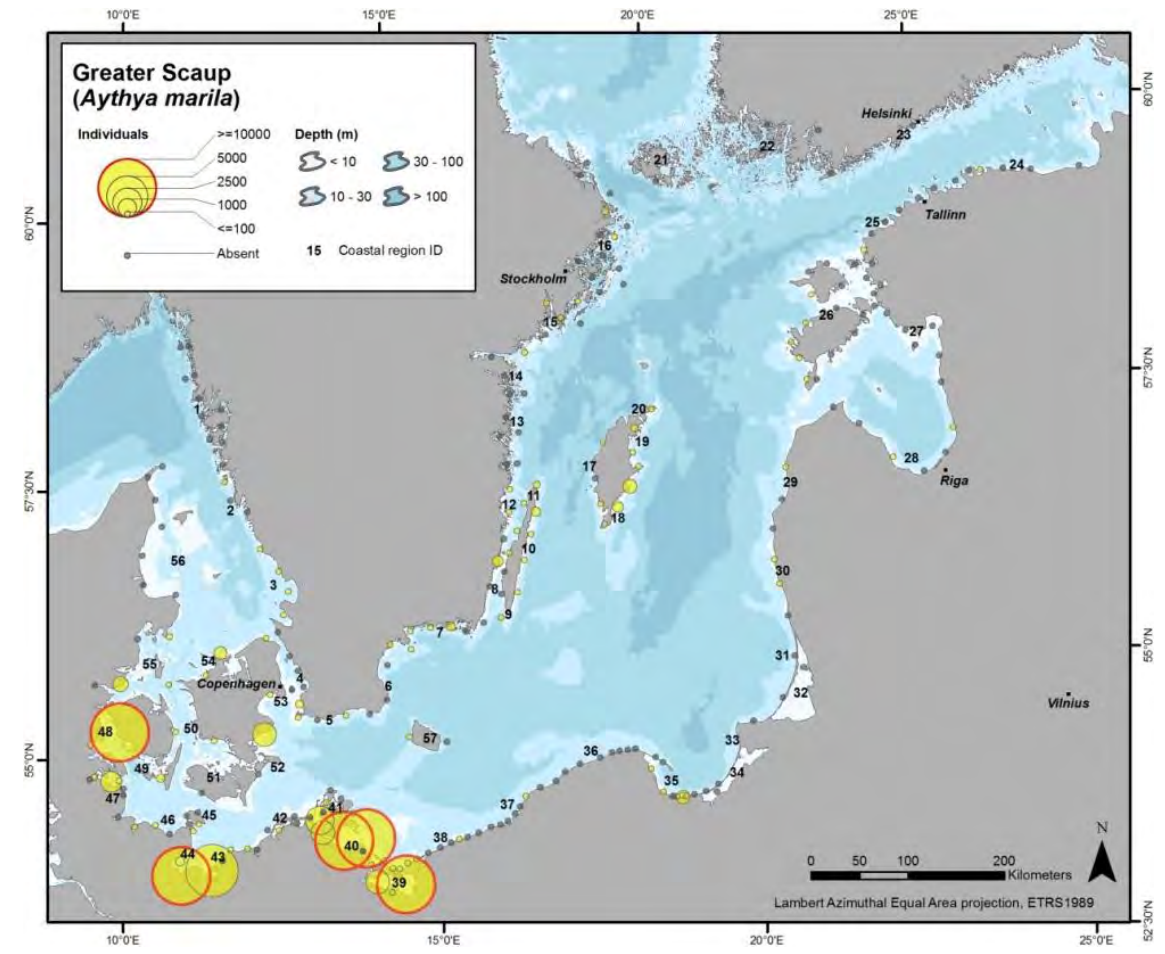

Map 14. Distribution and numbers of wintering Greater Scaup Aythya marila in the Baltic Sea, 2007-2009. 


\subsubsection{Distribution in the Baltic Sea}

As described above the distribution of the species along the mainland coast of the Baltic shifted slightly east-wards over the past 15 years. Most birds are found in enclosed bays, lagoons and archipelago areas, with lower densities scattered in more exposed areas with a water depth less than $8 \mathrm{~m}$. The birds utilize both areas with rocky and sandy substrates. It should be noted that like the Tufted Duck flocks of Greater Scaup may roost in coastal lakes not covered by this census, and use marine habitats for feeding during the night. During cold winters, some Greater Scaup probably leave the Baltic Sea, to winter in Netherlands and France.

\subsubsection{Phenology}

Autumn migration of the Russian breeding population to the Baltic Sea begins in September, but the majority of Greater Scaup arrive in October and November. In mild winters, return movements begin in late February but the spring migration takes place in March and April. Large concentrations are found in the northern part of the Gulf of Riga in early May.

Table 14. The average number of wintering Greater Scaup Aythya marila in key areas of the Baltic Sea, 2007-2009.

\begin{tabular}{|c|c|c|c|}
\hline Id & Locality & Number & $\%$ \\
\hline 1 & Bohüslän S & 10 & 0.01 \\
\hline 2 & Halland & 0 & 0.00 \\
\hline 3 & Skåne NW & 22 & 0.02 \\
\hline 4 & The Sound, Sweden & 208 & 0.16 \\
\hline 5 & Skåne south coast & 108 & 0.08 \\
\hline 6 & Hanö Bay & 103 & 0.08 \\
\hline 7 & Blekinge archipelago & 329 & 0.26 \\
\hline 8 & S Kalmar Sound & 339 & 0.27 \\
\hline 9 & Öland south coast & 2 & 0.00 \\
\hline 10 & Öland east coast & 348 & 0.27 \\
\hline 11 & Öland north coast \& N Ground & 150 & 0.12 \\
\hline 12 & N Kalmar Sound & 78 & 0.06 \\
\hline 13 & N Kalmar Län archipelago & 0 & 0.00 \\
\hline 14 & Östergötland archipelago & 110 & 0.09 \\
\hline 15 & Södermanlands archipelago & 16 & 0.01 \\
\hline 16 & Stockholm archipelago & 163 & 0.13 \\
\hline 17 & Gotland west coast & 10 & 0.01 \\
\hline 18 & Gotland S coast & 990 & 0.78 \\
\hline 19 & Gotland NE coast & 163 & 0.13 \\
\hline 20 & Gotland N coast, Fårön \& Gotska Sandön & 4 & 0.00 \\
\hline 21 & Åland Archipelago & 0 & 0.00 \\
\hline 22 & Archipelago Sea & 0 & 0.00 \\
\hline 23 & Gulf of Finland & 0 & 0.00 \\
\hline 24 & Estonia $\mathrm{N}$ coast & 1 & 0.00 \\
\hline 25 & Estonia NW coast & 2 & 0.00 \\
\hline 26 & Hiiumaa-Saaremaa coasts & 42 & 0.03 \\
\hline 27 & Estonian $S$ coast & 0 & 0.00 \\
\hline 28 & Gulf of riga & 15 & 0.01 \\
\hline 29 & Latvia W coast & 1 & 0.00 \\
\hline 30 & Latvia SW coast & 12 & 0.01 \\
\hline 31 & Lithuanian and northern Kaliningrad coast & 0 & 0.00 \\
\hline 32 & Curonian Lagoon & 0 & 0.00 \\
\hline 33 & S Kaliningrad coast & 0 & 0.00 \\
\hline 34 & Vistula Lagoon & 0 & 0.00 \\
\hline 35 & Gdansk Bay & 609 & 0.48 \\
\hline
\end{tabular}




\begin{tabular}{llrr}
\hline Id & Locality & Number & $\%$ \\
\hline 36 & Pomorskie coast & 0 & 0.00 \\
37 & N Zachodniopomorskie coast & 4 & 0.00 \\
38 & S Zachodniopomorskie coast & 7 & 0.01 \\
39 & Szczecin Lagoon & 27,869 & 21.89 \\
40 & Usedomer coast and Greifswalder Lagoon & 54,195 & 42.56 \\
41 & Rügen coast & 2,556 & 2.01 \\
42 & Darss coast & 1 & 0.00 \\
43 & Wismar Bay & 8,217 & 6.45 \\
44 & Fehmarn Belt & 13,308 & 10.45 \\
45 & Fehmarn coast & 50 & 0.04 \\
46 & Propstei coast & 20 & 0.02 \\
47 & Schleswig-Holstein coast & 1,369 & 1.08 \\
48 & Little Belt & 12,629 & 9.92 \\
49 & N Kiel Bay & 213 & 0.17 \\
50 & Great Belt & 11 & 0.01 \\
51 & Lolland coast & 45 & 0.04 \\
52 & SE Denmark coast & 1,675 & 1.32 \\
53 & The Sound, Danish coast & 21 & 0.02 \\
54 & NW Sealand & 484 & 0.38 \\
55 & SW Kattegat & 821 & 0.64 \\
56 & NW Kattegat & 0 & 0.00 \\
57 & Bornholm coast & 3 & 0.00 \\
& Total & 127,000 & 100.00 \\
\hline
\end{tabular}

Number is the average estimated number of birds, and \% compares the percentage of birds within the area with the total estimated number in the Baltic Sea.

\subsection{Common Eider Somateria mollissima}

\subsubsection{Importance of the Baltic Sea}

The north-west European winter population of Common Eiders has recently been estimated at between 1.82 and 2.38 million, of which 760,000 were estimated for the Wadden Sea and the Baltic Sea (Delany \& Scott 2006). The results of the present study indicate that between $21.6 \%$ and $28.3 \%$ of the north-west European winter population presently winter in the Baltic Sea, - compared to $35 \%$ for $1988-1993$. The total number wintering in the Baltic Sea has declined from 1,048,000 to 515,000 - equivalent to $50.8 \%$. The uncertainties regarding the size of the fly-way population are mainly due to inexact estimates of the breeding populations in NW Russia and Iceland.

\subsubsection{Main wintering areas in the Baltic Sea}

A relocation of wintering Common Eiders has taken place since 1993. The north-west Kattegat used to be the most important wintering area in the Baltic Sea with $32.5 \%$ of the birds estimated for 1988-1993, or 341,000 . The importance of this area has declined dramatically to just $4.5 \%$. Similarly, the south-western Kattegat now supports considerably fewer birds, and the proportion wintering here has dropped from $18.4 \%$ to $8 \%$. The Kiel Bay-Little Belt-South Funen region, on the other hand, 
has increased its importance with a proportion of $53.5 \%$ as compared to $25 \%$ in 1988-1993, and an estimated 275,000 birds.

\subsubsection{Distribution in the Baltic Sea}

On the basis of the documented relocation of wintering eiders, and the lack of obvious extensions of the distribution range to the north it is obvious that that a contraction of the distribution of Common Eiders to the southwest corner of the Baltic Sea has taken place since 1993. The habitat use of Common Eiders in the Baltic is sill areas of a water depth between 5 and $15 \mathrm{~m}$.

\subsubsection{Phenology}

Most adult males leave the breeding grounds in May and June to form flocks with non-breeding juveniles. In August, the males become flightless for some weeks when they moult flight feathers. Autumn migration from the breeding grounds in the northern and central parts of the Baltic Sea to Danish and German waters begins in late September and early October and lasts through December. Some of these Common Eiders pass Jutland to spend the first part of the winter in the Wadden Sea. Most of these birds return to the sea between Funen and Germany from mid-February to mid-March. Spring migration to the breeding grounds begins in late March and mid-April. Only local breeders remain in the Danish and German waters.

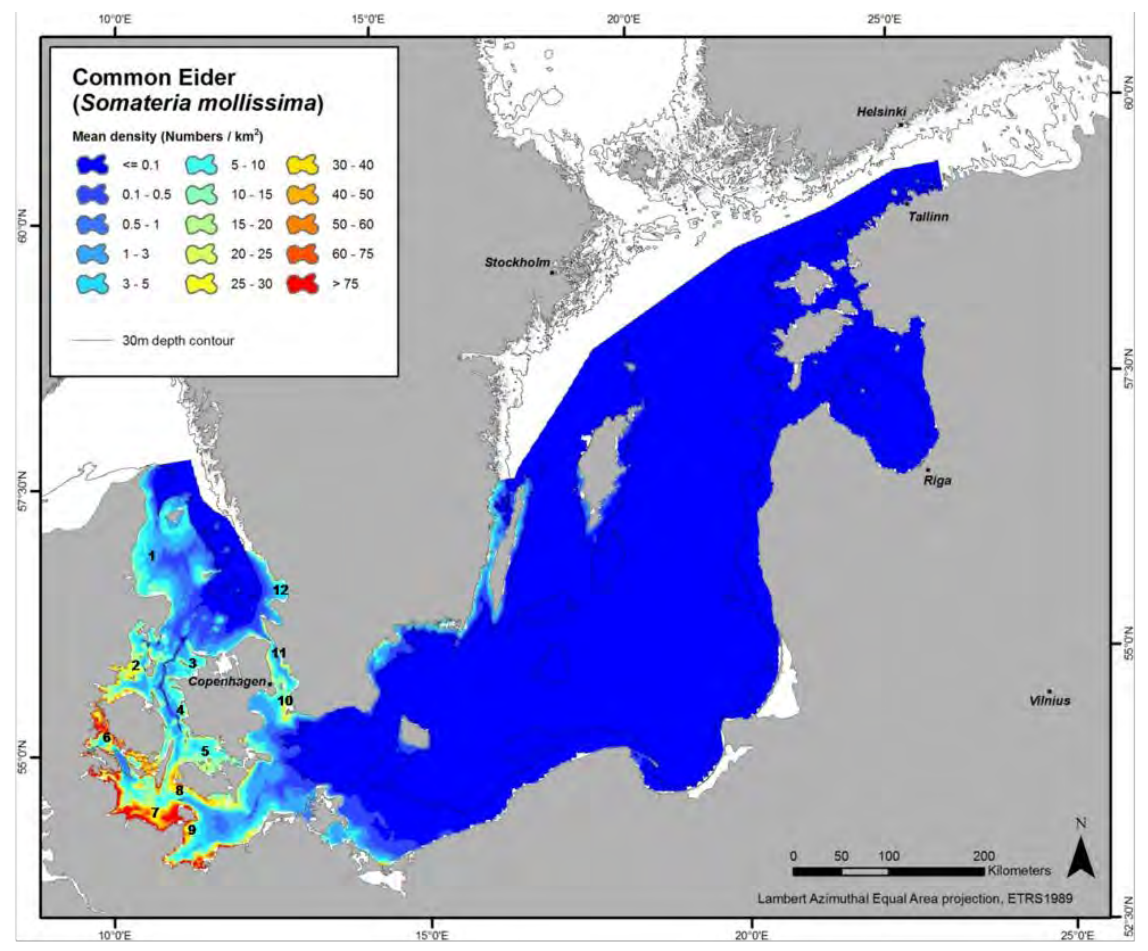

Map 15. Distribution and density numbers per $\mathrm{km}^{2}$ of wintering Common Eider Somateria mollissima in the Baltic Sea, 2007-2009. 
Table 15. The average number of wintering Common Eider Somateria mollissima estimated by spatial modeling for key areas of the Baltic Sea, 2007-2009.

\begin{tabular}{|c|c|c|c|c|c|c|}
\hline Id & Locality & Area & Number & Mean density & Std density & $\%$ \\
\hline 1 & NW Kattegat & 5,810 & 23,400 & 4.03 & 3.54 & 4.54 \\
\hline 2 & SW Kattegat & 2,750 & 41,100 & 14.96 & 13.03 & 7.98 \\
\hline 3 & Sejerø Bay & 515 & 3,450 & 6.69 & 4.66 & 0.67 \\
\hline 4 & Great Belt & 1,812 & 24,600 & 13.59 & 12.26 & 4.78 \\
\hline 5 & Smålandsfarvandet & 1,438 & 17,100 & 11.88 & 6.11 & 3.32 \\
\hline 6 & Little Belt \& Sydfynske Öhav & 1,861 & 83,800 & 44.99 & 35.79 & 16.27 \\
\hline 7 & Kiel bay & 3,781 & 191,800 & 50.72 & 60.93 & 37.23 \\
\hline 8 & Lolland $\mathrm{S}$ coast & 556 & 13,400 & 24.08 & 12.65 & 2.60 \\
\hline 9 & Lübeck Bay and Sagas Bank & 1,389 & 51,400 & 37.02 & 35.78 & 9.98 \\
\hline 10 & The Sound S & 1,389 & 11,700 & 8.39 & 7.78 & 2.27 \\
\hline 11 & The Sound N & 1,535 & 9,800 & 6.40 & 8.42 & 1.90 \\
\hline \multirow[t]{4}{*}{12} & Sweden Kattegat coast & 1,026 & 4,660 & 4.53 & 5.99 & 0.90 \\
\hline & Key areas & & 476,210 & & & 92.45 \\
\hline & Residual & & 38,900 & & & 7.55 \\
\hline & Total & & 515,000 & & & 100.00 \\
\hline
\end{tabular}

Area indicates the size of the area in $\mathrm{km}^{2}$, Number is the average estimated number of birds, mean density is the mean density of birds per $\mathrm{km}^{2}$ within the area, Std density is the standard deviation of the density within the area and \% compares the percentage of birds within the area with the total estimated number in the Baltic Sea.

\subsection{Steller's Eider Polysticta stelleri}

\subsubsection{Importance of the Baltic Sea}

The number of Steller's Elders wintering in North-west Europe has been estimated at 10,000 - 15,000 birds (Delany \& Scott 2006). The population has been in decline since the early 1990 'es, with an annual rate of $15 \%$ (Zydelis et al. 2006) between 1996 and 2003. The total number estimated for the Baltic Sea $(2,300)$ represents a decline by $66 \%$ since $1988-1993$.

\subsubsection{Main wintering areas in the Baltic Sea}

Steller's Eiders were only recorded in three locations during the coordinated counts 2007-2009: west coasts of Saaremaa and Hiiumaa Islands $(2,250)$, Palanga (40) and in the Archipelago Sea (13). It should be noted that the latter area covers observations from both the Archipelago Sea (8 birds), Helsinki, Pori and Rauma. The reduction in numbers is especially evident at the Palanga and in the Archipelago Sea/Åland site, but the absence of sightings outside these three main locations, e.g. on Gotland, is also striking.

\subsubsection{Distribution in the Baltic Sea}

Unlike most other species of seaducks, Steller's Eiders prefer to winter in shallow areas close to the coast, in areas of less than $10 \mathrm{~m}$ water depth. 


\subsubsection{Phenology}

Steller's Eiders arrive to the Baltic Sea in November and leave in mid April - early May.

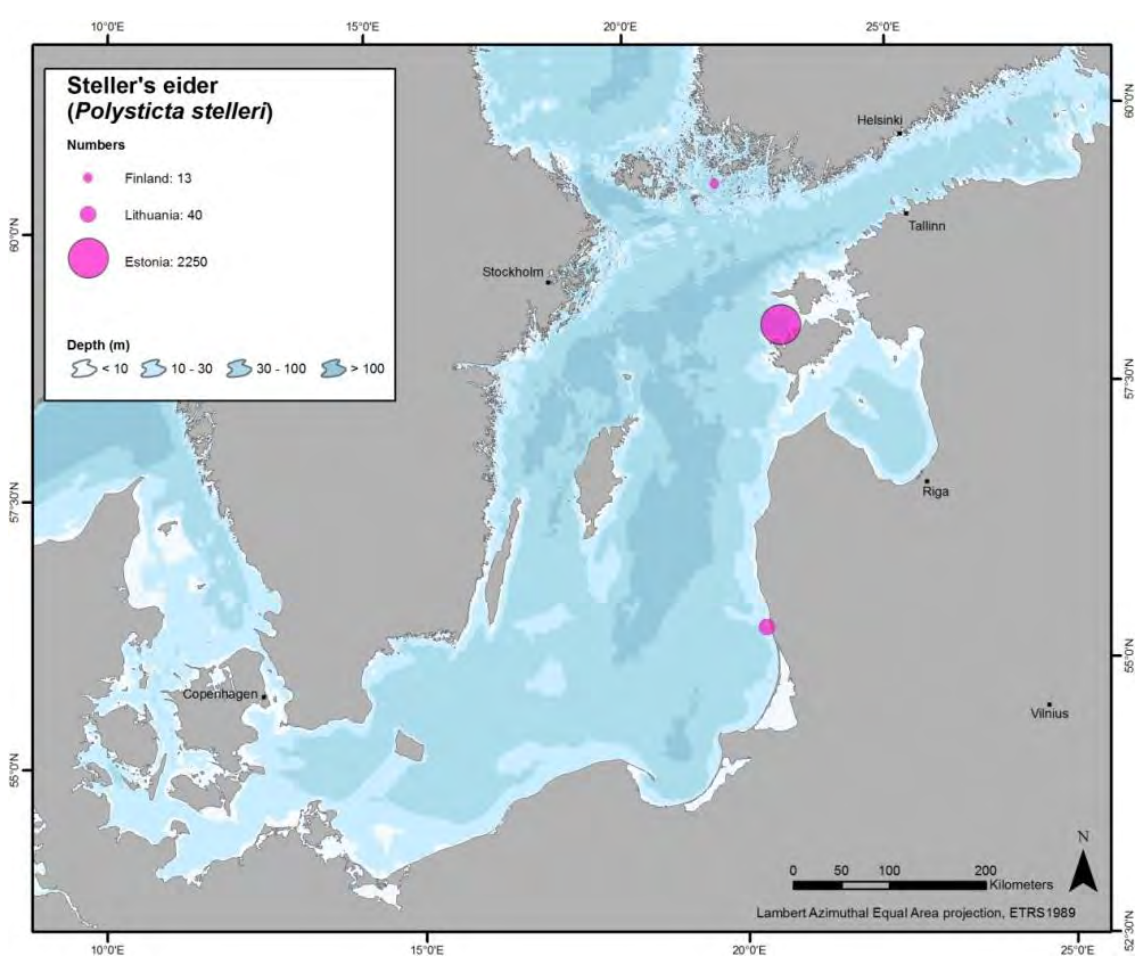

Map 16. Distribution and numbers of wintering Steller's Eider Polysticta stelleri in the Baltic Sea, 2007-2009.

Table 16. The average number of wintering Steller's Eider Polysticta stelleri in key areas of the Baltic Sea, 2007-2009.

\begin{tabular}{lrr}
\hline Locality & Number & $\%$ \\
\hline Saaremaa & 2,250 & 97.7 \\
Palanga & 40 & 1.7 \\
Archipelago Sea & 13 & 0.6 \\
Total & $\mathbf{2 , 3 0 0}$ & $\mathbf{1 0 0 . 0}$
\end{tabular}

Area indicates the size of the area in $\mathrm{km}^{2}$, Number is the average estimated number of birds, and \% compares the percentage of birds within the area with the total estimated number in the Baltic Sea.

\subsection{Long-tailed Duck Clangula hyemalis}

\subsubsection{Importance of the Baltic Sea}

Following the Baltic co-ordinated surveys in 1992-1993, the estimate of the north-west European winter population of Long-tailed Ducks was updated to 4.7 million birds, and this is still the only available estimate of the size of this population (Delany \& Scott 2006). The results of the present study indi- 
cate that at least the winter population in the Baltic Sea has declined dramatically from 4,272,000 birds to 1,482,000 birds during the period up until 2007-2009. This represents $65.3 \%$, or an annual decline of $4.4 \%$. If the north-west European winter population of Long-tailed Ducks is unchanged this means that $31.5 \%$ of the north-west European winter population presently winter in the Baltic Sea, - compared to 91\% in 1988-1993.

\subsubsection{Main wintering areas in the Baltic Sea}

In spite of the steep population decline since 1993 the vast majority of the population of wintering Long-tailed Ducks in the Baltic Sea still stay within three areas: the Pomeranian Bay, The Irbe Strait - Gulf of Riga and Hoburgs Bank - Midsjö Banks. The decline has affected all three regions. In the Pomeranian Bay numbers have declined from 803,000 to $186,000(77 \%)$. In the Irbe Strait - Gulf of Riga numbers have declined from 1,095,000 to 182,000 (83\%) and on Hoburgs Bank - Midsjö Banks numbers have declined from 1,007,000 to 361,300 (64\%). In the Pomeranian Bay, the spatial trend in densities shows an increase from the periphereral to the central parts, and in the Gulf of Riga zones of high densities of Long-tailed Ducks were estimated around the two islands Kihnu and Ruhnu. No change is obvious in the numbers of long-tailed Ducks wintering in the northern archipelagoes.

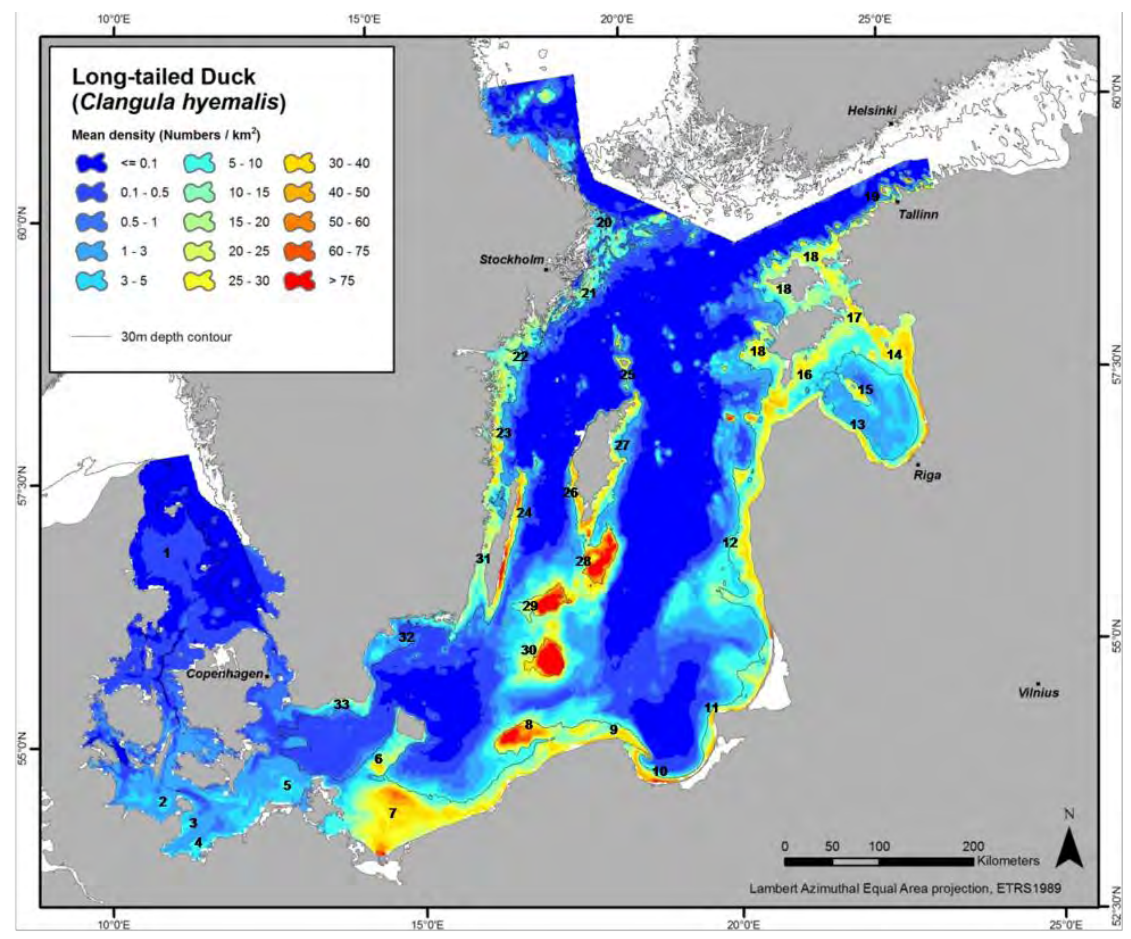

Map 17. Distribution and density of wintering Long-tailed Duck Clangula hyemalis in the Baltic Sea, 2007-2009. 


\subsubsection{Distribution in the Baltic Sea}

The distribution range and the location of higher densities of Long-tailed Ducks are largely identical to the situation 15 years ago, although general density levels are lower. The main depth range of Long-tailed Ducks in the Baltic Sea remains 10-35 m.

\subsubsection{Phenology}

Long-tailed Ducks do not moult in the Baltic Sea, but arrive from moulting areas in Russia from October to December. Return movements begin in March, and in early May large concentrations can be seen in the northern part of the Gulf of Riga, and during the second part of this month, the majority of the birds pass over-land by the lakes Ladoga and Onega towards the White Sea.

Table 17. The average number of wintering Long-tailed Duck Clangula hyemalis estimated by spatial modeling for key areas of the Baltic Sea, 2007-2009.

\begin{tabular}{|c|c|c|c|c|c|c|}
\hline & Locality & Area & Number & $\begin{array}{r}\text { Mean } \\
\text { density }\end{array}$ & $\begin{array}{r}\text { Std } \\
\text { density }\end{array}$ & $\%$ \\
\hline 1 & NW Kattegat & 3,353 & 440 & 0.13 & 0.05 & 0.03 \\
\hline 2 & Kiel Bay & 2,537 & 4,970 & 1.96 & 1.12 & 0.33 \\
\hline 3 & Sagas Bank & 267 & 890 & 3.34 & 1.07 & 0.06 \\
\hline 4 & Wismar Bay & 434 & 1,980 & 4.55 & 1.57 & 0.13 \\
\hline 5 & Darss \& Plantagenet Ground & 1,642 & 5,550 & 3.38 & 1.16 & 0.37 \\
\hline 6 & Rønne Bank \& Adler Ground & 722 & 12,000 & 16.60 & 9.83 & 0.81 \\
\hline 7 & Pomeranian Bay & 7,316 & 186,000 & 25.45 & 11.54 & 12.51 \\
\hline 8 & Slupsk Bank & 1,402 & 61,200 & 43.67 & 24.16 & 4.12 \\
\hline 9 & Central Polish coast & 2,628 & 51,500 & 19.58 & 10.34 & 3.47 \\
\hline 10 & Gulf of Gdansk & 1,053 & 26,000 & 24.73 & 19.62 & 1.75 \\
\hline 11 & Kaliningrad - Lithuania S & 1,314 & 22,900 & 17.44 & 10.58 & 1.54 \\
\hline 12 & Lithuania N - Latvia S & 1,317 & 35,800 & 27.18 & 8.92 & 2.41 \\
\hline 13 & Gulf of Riga, southwest & 1,751 & 30,800 & 17.58 & 11.49 & 2.07 \\
\hline 14 & Kihnu offshore & 3,316 & 73,300 & 22.09 & 12.22 & 4.93 \\
\hline 15 & Ruhnu offshore & 615 & 8,160 & 13.27 & 10.31 & 0.55 \\
\hline 16 & Gulf of Riga, northwest & 2,982 & 60,700 & 20.36 & 12.64 & 4.08 \\
\hline 17 & Muhu Strait & 375 & 9,710 & 25.86 & 7.65 & 0.65 \\
\hline 18 & Hiiumaa \& Saaremaa coast & 4,973 & 69,000 & 13.89 & 9.59 & 4.64 \\
\hline 19 & Estonia $\mathrm{N}$ coast & 1,524 & 15,000 & 9.99 & 12.15 & 1.01 \\
\hline 20 & Stockholm archipelago $\mathrm{N}$ & 3,349 & 20,700 & 6.18 & 5.06 & 1.39 \\
\hline 21 & Stockholm archipelago S and Södermanland Archipelago & 1,248 & 10,700 & 8.57 & 7.51 & 0.72 \\
\hline 22 & Östergötland Archipelago & 1,515 & 22,300 & 14.70 & 7.87 & 1.50 \\
\hline 23 & N Kalmar Archipelago & 1,130 & 21,000 & 18.56 & 11.81 & 1.41 \\
\hline 24 & Öland E & 1,486 & 43,600 & 29.35 & 22.16 & 2.93 \\
\hline 25 & Fårö \& Gotska Sandøn & 720 & 6,100 & 8.42 & 10.55 & 0.41 \\
\hline 26 & Gotland SW & 630 & 16,000 & 25.47 & 15.36 & 1.08 \\
\hline 27 & Gotland E & 1,896 & 28,000 & 14.95 & 11.27 & 1.88 \\
\hline 28 & Hoburgs Bank & 3,198 & 113,800 & 35.58 & 30.60 & 7.66 \\
\hline 29 & N Midsjö Bank & 2,767 & 93,600 & 33.81 & 42.25 & 6.30 \\
\hline 30 & S Midsjö Bank & 2,428 & 153,900 & 63.38 & 80.96 & 10.35 \\
\hline 31 & Kalmar Sound & 2,292 & 27,100 & 11.83 & 6.84 & 1.82 \\
\hline 32 & Hanö Bay & 1,937 & 6,980 & 3.60 & 3.13 & 0.47 \\
\hline \multirow[t]{4}{*}{33} & Skåne $S$ coast & 913 & 6,570 & 7.19 & 4.90 & 0.44 \\
\hline & Key areas & & $1,246,000$ & & & 83.85 \\
\hline & Residual & & 240,000 & & & 16.15 \\
\hline & Total & & $1,486,000$ & & & 100.00 \\
\hline
\end{tabular}

Area indicates the size of the area in $\mathrm{km}^{2}$, Number is the average estimated number of birds, mean density is the mean density of birds per $\mathrm{km}^{2}$ within the area, Std density is the standard deviation of the density within the area and \% compares the percentage of birds within the area with the total estimated number in the Baltic Sea. 


\subsection{Common Scoter Melanitta nigra}

\subsubsection{Importance of the Baltic Sea}

The recent estimate of the north-west European winter population of Common Scoters is $1,600,000$ birds (Delany \& Scott 2006). The results of the present study indicate a decline by $47.5 \%$ of the total number wintering in the Baltic Sea from 783,000 during 1988-1993 to 412,000 in 2007-2009. This means that $26 \%$ of the north-west European winter population presently winter in the Baltic Sea, - compared to at least $49 \%$ for 1988-1993. The range of the proportion of birds wintering in the Baltic Sea is caused by variations in the breeding success of recruiting populations in Russia (Durinck et al. 1994).

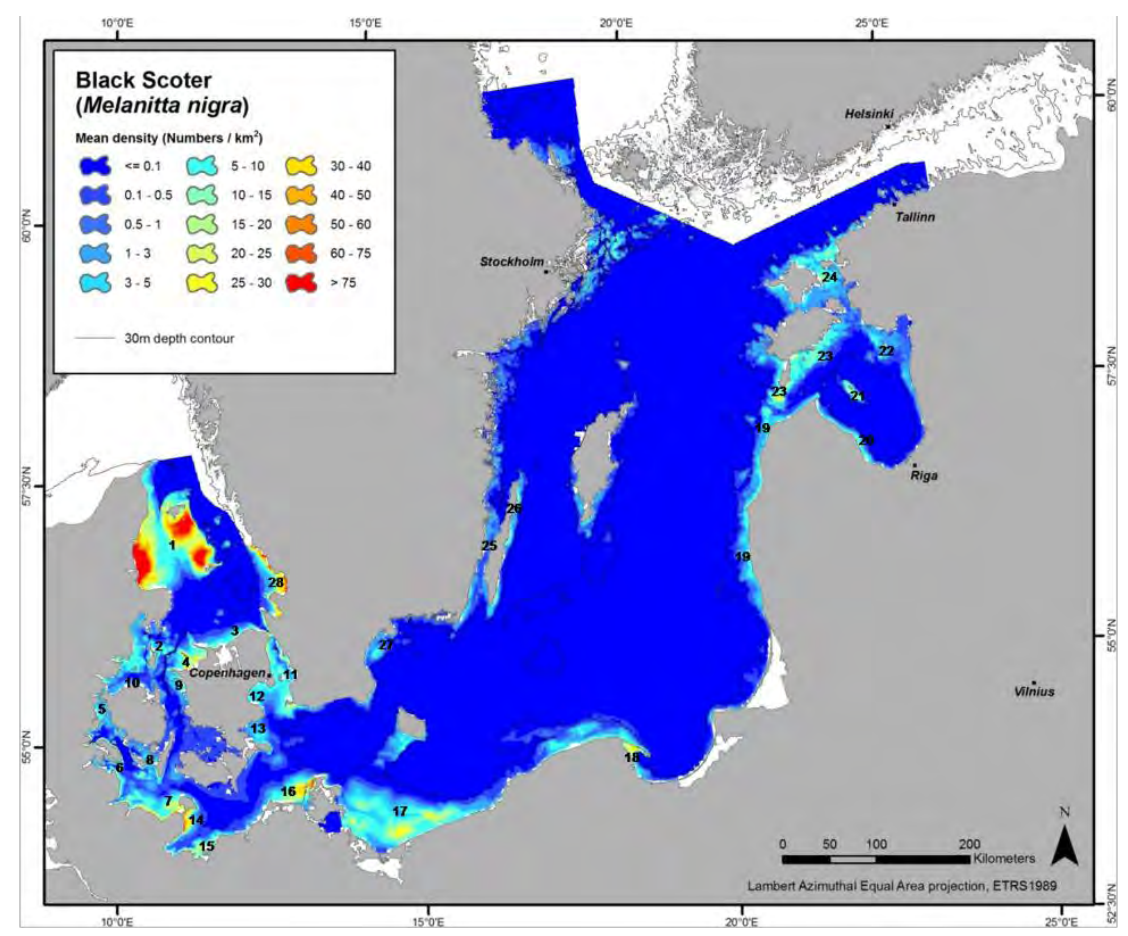

Map 18. Distribution and density of wintering Common Scoter Melanitta nigra in the Baltic Sea, 2007-2009.

\subsubsection{Main wintering areas in the Baltic Sea}

The unique importance of the north-west Kattegat as a key wintering area in the Baltic Sea has deteriorated markedly since 1988-1993, although the area still boasts the largest number of Common Scoters in Europe. The estimated total number of wintering Common Scoters in the north-west Kattegat has declined from 494,000 equivalent of $63 \%$ of the Baltic winter population to 190,000 equivalent of $46 \%$. A similar decline has been noted in the Kiel Bay - Little Belt region from 9.8\% to 4.8\%. In the central part of the Baltic Sea the importance of the Pomeranian Bay, including Odra Bank, 
is at the level of 1988-1993, yet numbers have dropped from 91,000 to 42,000 . Further north, more birds are now using Gulf of Gdansk and the mainland coasts of Lithuania and Latvia, the shallows of the Gulf of Riga and east of Saaremaa and Hiiumaa. On the northern mainland coast numbers have increased from 3,500 to 8,770. In the Gulf of Riga and east of Saaremaa and Hiiumaa numbers have increased from almost 5,000 to 28,000 . On the Swedish Kattegat coast numbers have increased from few hundred birds to estimated 20,000 birds.

\subsubsection{Distribution in the Baltic Sea}

The distribution patterns in the southern part of the Baltic Sea resemble the patterns estimated during 1988-1993, showing a preference for areas with water depths between 5 and $15 \mathrm{~m}$. The estimated densities in Køge and Faxe Bays, eastern Denmark, in Skälderviken and Laholmsbugten, western Sweden and also along the southeastern coast of Sweden are higher than during the former period. The numbers in Skälderviken and Laholmsbugten may be overestimated due to limited effort. Numbers in Hanö Bay, Kalmar Sound and Öland were much higher in winter 2007 as compared to 2009 with a total exceeding 35,000 birds. The area of high densities in north-west Kattegat and Kiel Bay is smaller than during 1992-1993. The high densities in the Pomeranian Bay were found southeast of the Odra Bank, which also held the highest densities in 1988-1993. The slight relocation of wintering common scoters to the north has evidently changed the distributions along the mainland coasts. Common Scoters were also distributed along the entire mainland coast during 1988-1993, yet densities were lower. Densities along the coast of Halland (Sweden) have increased markedly. The range of water depth used by common scoters in the northern parts is the same (5-15 m) as in the southern parts.

\subsubsection{Phenology}

From late June to August, migration of males and immatures takes place from the Baltic Sea to German and Danish waters. In August and September, the males become flightless for some weeks when they moult flight feathers. Females and juveniles arrive to the area in September and October. In April and May, the scoters migrate from the winter quarters in the Baltic Sea, and large numbers concentrate in the Riga Bay in the beginning of May before the Common Scoters fly overland to the breeding grounds in Russia. 
Table 18. The average number of wintering Common Scoter Melanitta nigra estimated by spatial modeling for key areas of the Baltic Sea, 2007-2009.

\begin{tabular}{|c|c|c|c|c|c|c|}
\hline Id & Locality & Area & Number & $\begin{array}{r}\text { Mean } \\
\text { density }\end{array}$ & $\begin{array}{r}\text { Std } \\
\text { density }\end{array}$ & $\%$ \\
\hline 1 & NW Kattegat & 6,517 & 190,000 & 29.09 & 36.56 & 46.24 \\
\hline 2 & SW Kattegat & 1,736 & 7,000 & 4.05 & 3.45 & 1.70 \\
\hline 3 & Sealand $N$ coast & 328 & 2,250 & 6.85 & 2.73 & 0.55 \\
\hline 4 & Sejerø Bay & 538 & 8,720 & 16.19 & 8.34 & 2.12 \\
\hline 5 & Little Belt & 716 & 2,960 & 4.13 & 4.57 & 0.72 \\
\hline 6 & Als and Flensburg Fjords & 436 & 2,100 & 4.81 & 5.72 & 0.51 \\
\hline 7 & Kiel Bay & 2,360 & 14,600 & 6.18 & 7.77 & 3.55 \\
\hline 8 & Sydfynske $\varnothing$ hav & 1,163 & 1,620 & 1.40 & 1.40 & 0.39 \\
\hline 9 & Great Belt & 565 & 1,550 & 2.74 & 2.77 & 0.38 \\
\hline 10 & North Funen & 384 & 710 & 1.86 & 1.10 & 0.17 \\
\hline 11 & The Sound, incl. Falsterbo & 1,435 & 11,200 & 7.80 & 5.46 & 2.73 \\
\hline 12 & Køge Bay & 459 & 2,120 & 4.62 & 1.93 & 0.52 \\
\hline 13 & Faxe Bay & 452 & 1,340 & 2.97 & 1.50 & 0.33 \\
\hline 14 & Sagas Bank & 354 & 6,070 & 17.15 & 17.84 & 1.48 \\
\hline 15 & Wismar Bay & 444 & 4,350 & 9.80 & 6.76 & 1.06 \\
\hline 16 & Darss - Plantagenet Ground & 755 & 13,310 & 17.64 & 12.51 & 3.24 \\
\hline 17 & Pomeranian Bay & 4,957 & 41,600 & 8.39 & 5.71 & 10.12 \\
\hline 18 & Gulf of Gdansk & 1,351 & 7,640 & 5.66 & 8.19 & 1.86 \\
\hline 19 & Lithuania-Latvia & 2,129 & 8,770 & 4.12 & 2.98 & 2.13 \\
\hline 20 & Gulf of Riga, southwest & 928 & 2,270 & 2.45 & 3.02 & 0.55 \\
\hline 21 & Ruhnu & 341 & 1,880 & 5.52 & 6.26 & 0.46 \\
\hline 22 & Kihnu Strait & 2,206 & 3,020 & 1.37 & 1.53 & 0.73 \\
\hline 23 & Gulf of Riga, northwest & 2,617 & 14,450 & 5.52 & 4.88 & 3.52 \\
\hline 24 & Hiumaa NE & 844 & 6,010 & 7.12 & 3.51 & 1.46 \\
\hline 25 & Kalmar Sound & 2797 & 2,230 & 0.80 & 1.03 & 0.54 \\
\hline 26 & Öland E \& N & 1203 & 2,570 & 2.14 & 3.11 & 0.62 \\
\hline 27 & Hanö Bay & 2277 & 1,650 & 0.73 & 1.36 & 0.40 \\
\hline \multirow[t]{4}{*}{28} & Skälderviken and Laholmsbugten & 657 & 20,750 & 31.61 & 20.42 & 5.05 \\
\hline & Key areas & & 383,000 & & & 91.58 \\
\hline & Residual & & 29,000 & & & 8.42 \\
\hline & Total & & 412,000 & & & 100.00 \\
\hline
\end{tabular}

Area indicates the size of the area in $\mathrm{km}^{2}$, Number is the average estimated number of birds, mean density is the mean density of birds per $\mathrm{km}^{2}$ within the area, Std density is the standard deviation of the density within the area and \% compares the percentage of birds within the area with the total estimated number in the Baltic Sea.

\subsection{Velvet Scoter Melanitta fusca}

\subsubsection{Importance of the Baltic Sea}

Following the Baltic co-ordinated surveys in 1992-1993, the estimate of north-west European winter population of Velvet Scoters was updated to 1 million birds, and this is still the only available estimate of the size of the size of this population (Delany \& Scott 2006). Since 1993, the Baltic winter population has declined steeply to 373,000 birds, equivalent to $60 \%$, or an annual decline of $3.7 \%$. If the north-west European winter population of Velvet Scoters is unchanged this means that $37 \%$ of the north-west European winter population presently winter in the Baltic Sea, - compared to 93\% in 1988-1993. 


\subsubsection{Main wintering areas in the Baltic Sea}

During the surveys in 1992-93 three quarters of the north-west European winter population of Velvet Scoters were found in two areas in the Baltic Sea: Pomeranian Bay and the Irbe Strait - Gulf of Riga. Numbers in both areas have declined dramatically during the intervening period between the two censuses, while numbers wintering off the mainland coasts of Lithuania and Latvia seemingly have increased; Pomeranian Bay from 357,200 birds to 125,100 birds (65\%) and Irbe Strait - Gulf of Riga from 342,200 to 46,900 birds (86\%). The numbers estimated for the coastal area off Lithuania and Latvia has increased significantly from 33,000 to 147,900 birds. Numbers wintering in areas further to the west have declined at the same rate as the Gulf of Riga, like the Northwestern Kattegat which has declined from 76,300 birds to 660 birds (99\%). Not included in the estimated numbers are 2,500 Velvet Scoters which were counted on the Swedish Kattegat coast. The Central Polish coast has declined from 54,000 birds to 24,900 birds (52\%).

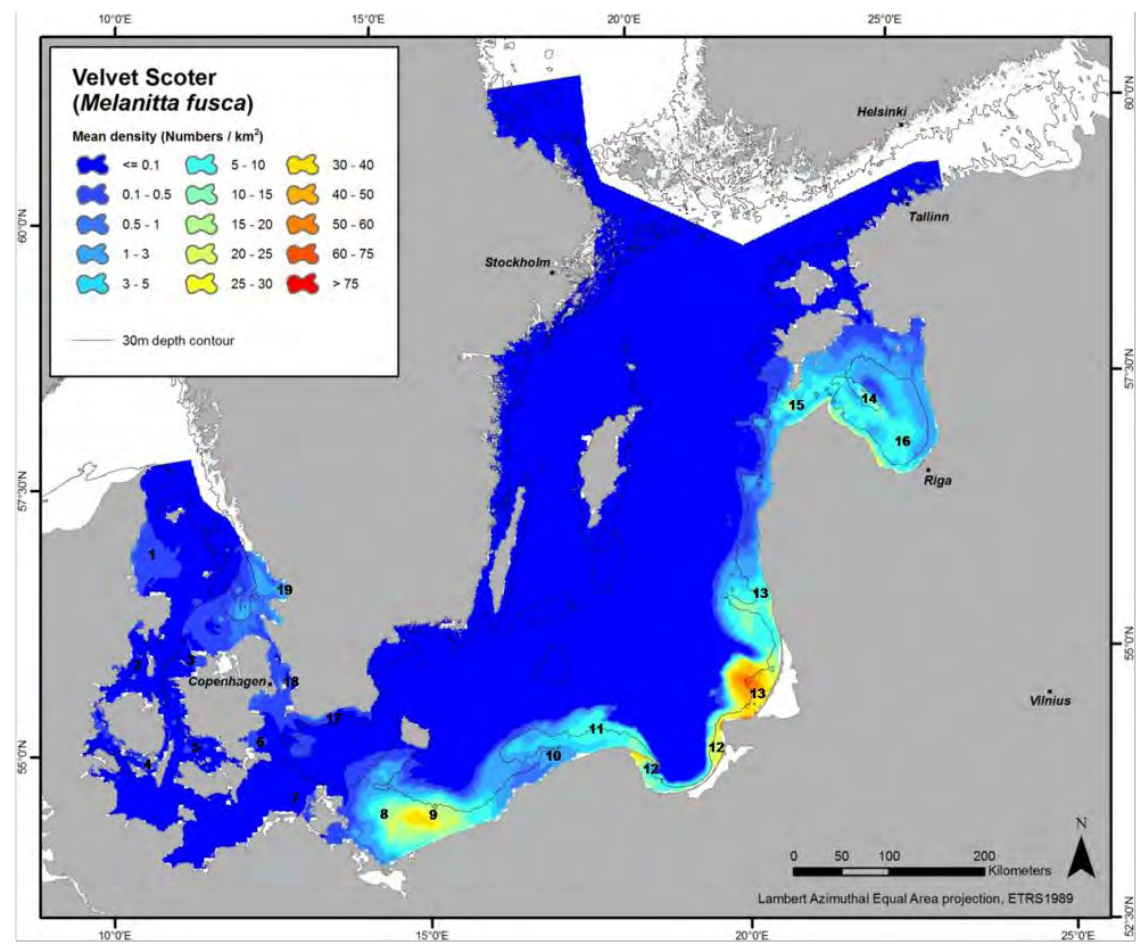

Map 19. Distribution and density of wintering Velvet Scoter Melanitta fusca in the Baltic Sea, 2007-2009.

\subsubsection{Distribution in the Baltic Sea}

The depth range of Velvet Scoters does not seem to have changed since the 1992-1993 census and the vast majority of birds are still found in areas with a water depth between 10 and $30 \mathrm{~m}$. 


\subsubsection{Phenology}

In June, most male scoters leave the breeding grounds to moult mainly along the north coast of Russia. In autumn, the main migration to the Baltic Sea takes place in September and October. Spring migration begins in March. In May, scoters concentrate in the northern part of the Gulf of Riga before they move overland to the breeding areas. By midMay, only the local breeders remain in the area.

Table 19. The average number of wintering Velvet Scoter Melanitta fusca estimated by spatial modeling for key areas of the Baltic Sea, 2007-2009.

\begin{tabular}{|c|c|c|c|c|c|c|}
\hline Id & Locality & Area & Number & $\begin{array}{r}\text { Mean } \\
\text { density }\end{array}$ & $\begin{array}{r}\text { Std } \\
\text { density }\end{array}$ & $\%$ \\
\hline 1 & NW Kattegat & 5531 & 655 & 0.12 & 0.14 & 0.16 \\
\hline 2 & SW Kattegat & 1895 & 55 & 0.03 & 0.03 & 0.01 \\
\hline 3 & Sejerø Bay & 546 & 55 & 0.10 & 0.07 & 0.01 \\
\hline 4 & Sydfynske $\varnothing$ hav & 295 & 40 & 0.13 & 0.06 & 0.01 \\
\hline 5 & Smålandsfarvandet & 1265 & 85 & 0.07 & 0.03 & 0.02 \\
\hline 6 & Faxe Bay & 519 & 65 & 0.12 & 0.06 & 0.02 \\
\hline 7 & Wismar Bay - Darss & 1467 & 55 & 0.04 & 0.06 & 0.01 \\
\hline 8 & Pomeranian Bay, medium & 6135 & 49,535 & 8.07 & 8.63 & 11.94 \\
\hline 9 & Pomeranian Bay, high & 4854 & 75,565 & 15.57 & 7.72 & 18.22 \\
\hline 10 & Central Polish Coast, medium & 7011 & 22,065 & 3.15 & 2.25 & 5.32 \\
\hline 11 & Central Polish Coast, high & 510 & 4,090 & 8.02 & 4.26 & 0.99 \\
\hline 12 & Gdansk Bay & 1301 & 12,315 & 9.46 & 8.71 & 2.97 \\
\hline 13 & Lithuania-Latvia coast & 7679 & 147,925 & 19.26 & 14.84 & 35.66 \\
\hline 14 & Ruhnu & 731 & 4,820 & 6.60 & 4.02 & 1.16 \\
\hline 15 & Gulf of Riga, west & 3935 & 25,840 & 6.57 & 3.57 & 6.23 \\
\hline 16 & Gulf of Riga, medium & 12966 & 16,200 & 1.25 & 3.51 & 3.91 \\
\hline 17 & South Skåne & 2037 & 900 & 0.44 & 0.91 & 0.22 \\
\hline 18 & The Sound & 1061 & 575 & 0.54 & 0.90 & 0.14 \\
\hline \multirow[t]{4}{*}{19} & Skälderviken - Laholmsbugten & 377 & 260 & 0.69 & 0.95 & 0.06 \\
\hline & Key areas & & 361,000 & & 4.27 & 97.03 \\
\hline & Residual & & 12,000 & & & 2.97 \\
\hline & Total & & 373,000 & & & 100.00 \\
\hline
\end{tabular}

Area indicates the size of the area in $\mathrm{km}^{2}$, Number is the average estimated number of birds, mean density is the mean density of birds per $\mathrm{km}^{2}$ within the area, Std density is the standard deviation of the density within the area and \% compares the percentage of birds within the area with the total estimated number in the Baltic Sea

\subsection{Common Goldeneye Bucephala clangula}

\subsubsection{Importance of the Baltic Sea}

The estimate of the north-west European winter population of Common Goldeneyes has recently been updated to between 1 million and 1.3 million birds (Delany \& Scott 2006). The current Baltic winter population may be estimated at 174,000 birds, equivalent to an increase of $41.5 \%$ since 1988-1993. The Baltic Sea now supports between 13 and 17\% of the north-west European winter population of Common Goldeneyes. 


\subsubsection{Main wintering areas in the Baltic Sea}

The main wintering areas in the Baltic Sea have not changed their status, although certain changes have happened and new important areas have appeared due to a north-ward shift in the distribution of the Common Goldeneye. The largest concentrations of Common Goldeneyes are now found in the northern archipelago areas of Sweden. A total of 26,800 birds were counted in the Swedish archipelagoes north of Kalmar Sound; a very large increase from 2,320 birds found here during 19881993. The north-ward shift has also augmented the importance of the coasts around Gotland which now support 12,980 birds, an increase of 135\%. The lagoons and sheltered coasts around Rügen now hold 73\% more birds $(15,645)$, while the Gulf of Gdansk has remained stable at 5,300 birds. The numbers wintering in the coastal areas of SchleswigHolstein, on the other hand, have decreased from 8,610 to 7,355 birds, equivalent of $15 \%$.

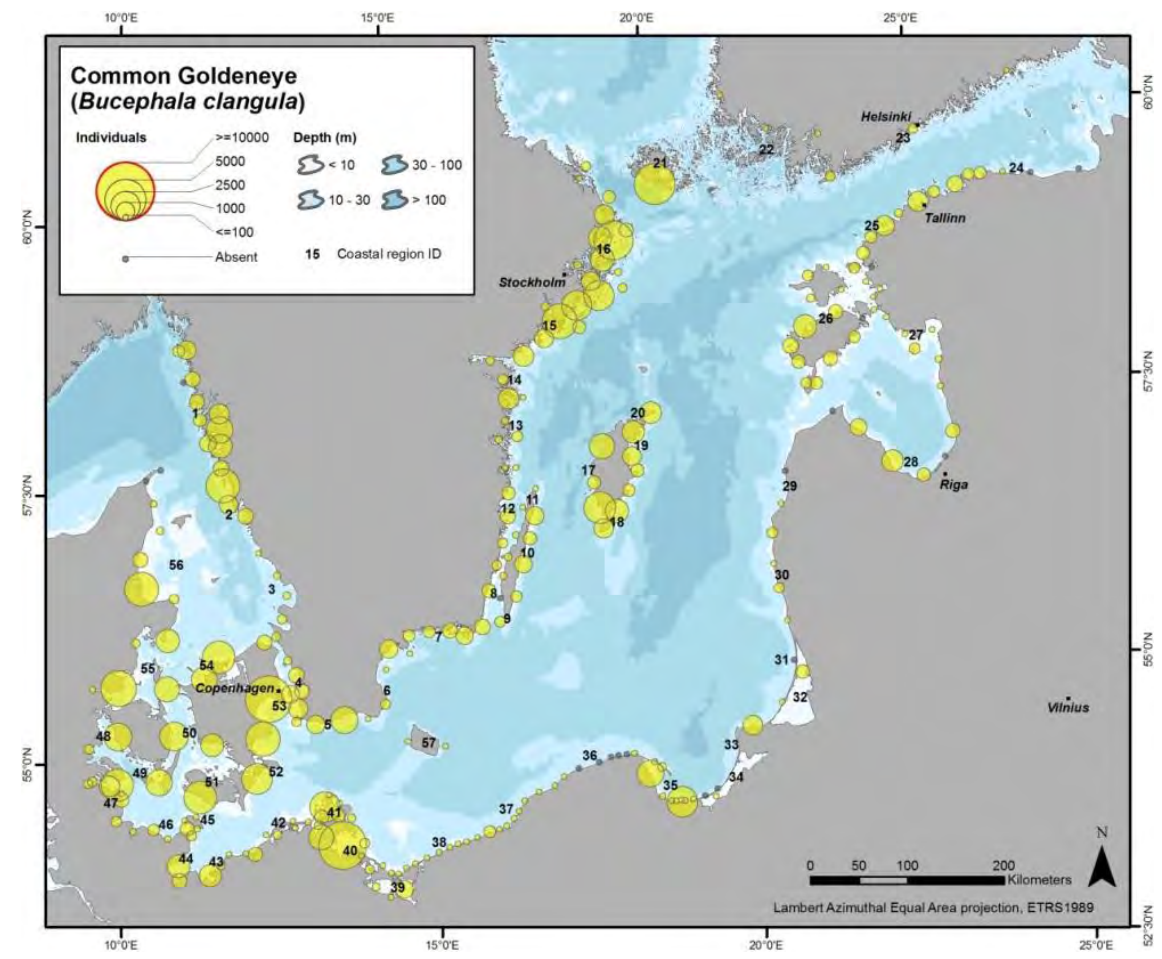

Map 20. Distribution and numbers of wintering Common Goldeneye Bucephala clangula in the Baltic Sea, 2007-2009.

\subsubsection{Distribution in the Baltic Sea}

Common Goldeneyes are wide distributed along all coastal habitats shallower than $5 \mathrm{~m}$, and they occur in fresh, brackish and salt water. A relocation of birds from the south to the north has taken place since 1993, which means that a larger proportion of the birds now winter in rocky 
habitats. Further north, along the coastal areas of Bothnian Sea appreciable numbers were also counted in these normally ice-covered areas (L. Nilsson pers. comm.).

\subsubsection{Phenology}

Autumn migration to the Baltic Sea begins in late August, rising to a peak in November. In hard winters, many Common Goldeneyes move to West and Central Europe. Migration to the breeding grounds - begins in late February and the majority of goldeneyes have left the winter quarters in mid-April.

Table 20. The average number of wintering Common Goldeneye Bucephala clangula in key areas of the Baltic Sea, 2007-2009.

\begin{tabular}{|c|c|c|c|}
\hline Id & Locality & Number & $\%$ \\
\hline 1 & Bohüslän S & 13,161 & 7.58 \\
\hline 2 & Halland & 1,742 & 1.00 \\
\hline 3 & Skåne NW & 668 & 0.38 \\
\hline 4 & The Sound, Sweden & 2,891 & 1.67 \\
\hline 5 & Skåne south coast & 3,454 & 1.99 \\
\hline 6 & Hanö Bay & 1,427 & 0.82 \\
\hline 7 & Blekinge archipelago & 2,480 & 1.43 \\
\hline 8 & S Kalmar Sound & 1,923 & 1.11 \\
\hline 9 & Öland south coast & 334 & 0.19 \\
\hline 10 & Öland east coast & 2,783 & 1.60 \\
\hline 11 & Öland north coast \& N Ground & 76 & 0.04 \\
\hline 12 & N Kalmar Sound & 1,875 & 1.08 \\
\hline 13 & N Kalmar Län archipelago & 658 & 0.38 \\
\hline 14 & Östergötland archipelago & 3,020 & 1.74 \\
\hline 15 & Södermanlands archipelago & 4,857 & 2.80 \\
\hline 16 & Stockholm archipelago & 17,773 & 10.24 \\
\hline 17 & Gotland west coast & 5,356 & 3.08 \\
\hline 18 & Gotland S coast & 3,173 & 1.83 \\
\hline 19 & Gotland NE coast & 3,058 & 1.76 \\
\hline 20 & Gotland N coast, Fårön \& Gotska Sandön & 1,395 & 0.80 \\
\hline 21 & Åland Archipelago & 4,956 & 2.85 \\
\hline 22 & Archipelago Sea & 107 & 0.06 \\
\hline 23 & Gulf of Finland & 549 & 0.32 \\
\hline 24 & Estonia $\mathrm{N}$ coast & 2,084 & 1.20 \\
\hline 25 & Estonia NW coast & 3,504 & 2.02 \\
\hline 26 & Hiiumaa-Saaremaa coasts & 6,522 & 3.76 \\
\hline 27 & Estonian $S$ coast & 697 & 0.40 \\
\hline 28 & Gulf of riga & 3,493 & 2.01 \\
\hline 29 & Latvia W coast & 368 & 0.21 \\
\hline 30 & Latvia SW coast & 360 & 0.21 \\
\hline 31 & Lithuanian and northern Kaliningrad coast & 55 & 0.03 \\
\hline 32 & Curonian Lagoon & 550 & 0.32 \\
\hline 33 & S Kaliningrad coast & 1,170 & 0.67 \\
\hline 34 & Vistula Lagoon & 27 & 0.02 \\
\hline 35 & Gdansk Bay & 5,322 & 3.07 \\
\hline 36 & Pomorskie coast & 20 & 0.01 \\
\hline 37 & N Zachodniopomorskie coast & 617 & 0.36 \\
\hline 38 & S Zachodniopomorskie coast & 455 & 0.26 \\
\hline 39 & Szczecin Lagoon & 1,094 & 0.63 \\
\hline 40 & Usedomer coast and Greifswalder Lagoon & 9,244 & 5.32 \\
\hline 41 & Rügen coast & 4,304 & 2.48 \\
\hline 42 & Darss coast & 1,005 & 0.58 \\
\hline 43 & Wismar Bay & 1,700 & 0.98 \\
\hline 44 & Fehmarn Belt & 2,475 & 1.43 \\
\hline 45 & Fehmarn coast & 821 & 0.47 \\
\hline 46 & Propstei coast & 664 & 0.38 \\
\hline 47 & Schleswig-Holstein coast & 5,872 & 3.38 \\
\hline 48 & Little Belt & 2,550 & 1.47 \\
\hline
\end{tabular}




\begin{tabular}{llrr}
\hline Id & Locality & Number & $\%$ \\
\hline 49 & N Kiel Bay & 2,044 & 1.18 \\
50 & Great Belt & 2,444 & 1.41 \\
51 & Lolland coast & 4,700 & 2.71 \\
52 & SE Denmark coast & 6,292 & 3.62 \\
53 & The Sound, Danish coast & 8,012 & 4.61 \\
54 & NW Sealand & 6,980 & 4.02 \\
55 & SW Kattegat & 5,729 & 3.30 \\
56 & NW Kattegat & 4,660 & 2.68 \\
57 & Bornholm coast & $\mathbf{7 3}$ & 0.04 \\
& Total & $\mathbf{1 7 4 , 0 0 0}$ & $\mathbf{1 0 0 . 0 0}$ \\
\hline
\end{tabular}

Number is the average estimated number of birds, and \% compares the percentage of birds within the area with the total estimated number in the Baltic Sea.

\subsection{Smew Mergus albellus}

\subsubsection{Importance of the Baltic Sea}

The estimate of the north-west European winter population of Smews has recently been updated to 40,000 birds (Delany \& Scott 2006). The current Baltic winter population may be estimated at 12,600 birds, equivalent to a decrease of $25.9 \%$ since $1988-1993$. The Baltic Sea now supports $31.5 \%$ of the north-west European winter population of Smews compared to $68 \%$ during $1988-1993$.

\subsubsection{Main wintering areas in the Baltic Sea}

The distribution of Smew in the Baltic Sea has changed since 1993, as the importance of the main area for Smew in the southeast has now deteriorated, while more birds are using western and northern sectors. The Szczecin Lagoon which held 9,200 birds during 1988-1993 used to be the most important area in the Baltic Sea. However, during the counts 2007-2009 only 870 birds were recorded here, - a decline of $91 \%$. In comparison, the numbers wintering in the neighbouring lagoons of Usedom and around Rügen have remained stable; 4,285/4,350 birds. No counts were undertaken in the Wistula Lagoon, where 1,430 were observed during the former census. The second most important areas to Smew are now the coasts of Lolland $(1,060)$ and Blekinge Archipelago $(1,015)$. In general, more birds now use the Swedish coastal areas as compared to 1988-1993, and a ten-fold increase has been noted here from 375 to 3,715 birds. 


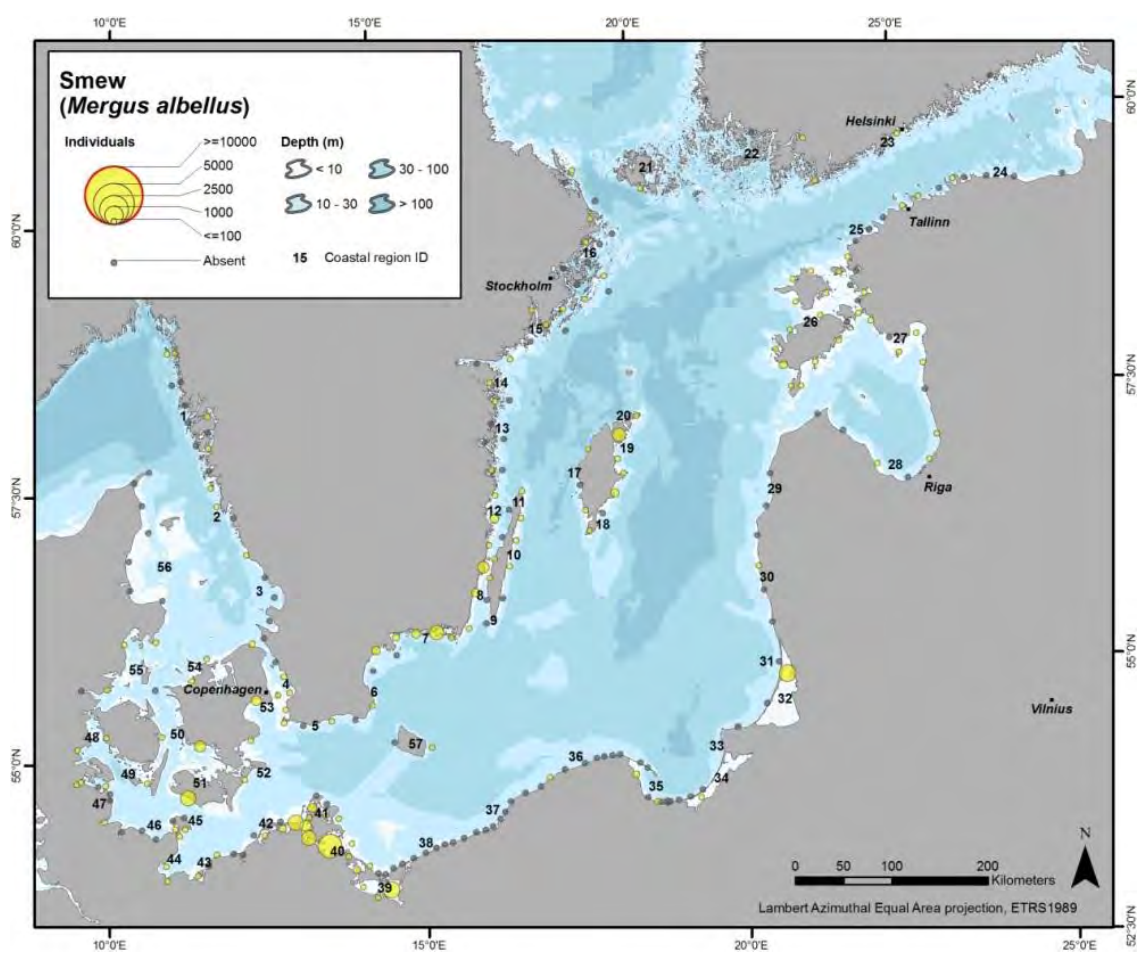

Map 21. Distribution and numbers of wintering Smew Mergus albellus in the Baltic Sea, 2007-2009.

\subsubsection{Distribution in the Baltic Sea}

The shift in the distribution from the southeast to the north and west means that Smews no longer have sheltered bays and lagoons as their primary habitat in the Baltic Sea, but use a wide range of habitats, including rocky coasts and archipelagoes.

\subsubsection{Phenology}

In autumn, Smews begin to arrive to the Baltic Sea in mid-October, but the main arrival is usually not until December or even January. Return movements begin in March and most Smews have left the region by mid-April. 
Table 21. The average number of wintering Smew Mergus albellus in key areas of the Baltic Sea, 2007-2009.

\begin{tabular}{|c|c|c|c|}
\hline Id & Locality & Number & $\%$ \\
\hline 1 & Bohüslän S & 52 & 0.41 \\
\hline 2 & Halland & 24 & 0.19 \\
\hline 3 & Skåne NW & 1 & 0.01 \\
\hline 4 & The Sound, Sweden & 10 & 0.08 \\
\hline 5 & Skåne south coast & 31 & 0.25 \\
\hline 6 & Hanö Bay & 226 & 1.79 \\
\hline 7 & Blekinge archipelago & 1,017 & 8.07 \\
\hline 8 & S Kalmar Sound & 685 & 5.44 \\
\hline 9 & Öland south coast & 0 & 0.00 \\
\hline 10 & Öland east coast & 130 & 1.03 \\
\hline 11 & Öland north coast \& N Ground & 1 & 0.01 \\
\hline 12 & N Kalmar Sound & 333 & 2.64 \\
\hline 13 & N Kalmar Län archipelago & 0 & 0.00 \\
\hline 14 & Östergötland archipelago & 78 & 0.62 \\
\hline 15 & Södermanlands archipelago & 100 & 0.79 \\
\hline 16 & Stockholm archipelago & 157 & 1.25 \\
\hline 17 & Gotland west coast & 83 & 0.66 \\
\hline 18 & Gotland S coast & 222 & 1.76 \\
\hline 19 & Gotland NE coast & 563 & 4.47 \\
\hline 20 & Gotland N coast, Fårön \& Gotska Sandön & 1 & 0.01 \\
\hline 21 & Åland Archipelago & 43 & 0.34 \\
\hline 22 & Archipelago Sea & 4 & 0.03 \\
\hline 23 & Gulf of Finland & 2 & 0.02 \\
\hline 24 & Estonia $\mathrm{N}$ coast & 5 & 0.04 \\
\hline 25 & Estonia NW coast & 5 & 0.04 \\
\hline 26 & Hiiumaa-Saaremaa coasts & 447 & 3.55 \\
\hline 27 & Estonian $\mathrm{S}$ coast & 59 & 0.47 \\
\hline 28 & Gulf of riga & 7 & 0.06 \\
\hline 29 & Latvia W coast & 0 & 0.00 \\
\hline 30 & Latvia SW coast & 12 & 0.10 \\
\hline 31 & Lithuanian and northern Kaliningrad coast & 0 & 0.00 \\
\hline 32 & Curonian Lagoon & 840 & 6.67 \\
\hline 33 & S Kaliningrad coast & 0 & 0.00 \\
\hline 34 & Vistula Lagoon & 70 & 0.56 \\
\hline 35 & Gdansk Bay & 156 & 1.24 \\
\hline 36 & Pomorskie coast & 2 & 0.02 \\
\hline 37 & N Zachodniopomorskie coast & 0 & 0.00 \\
\hline 38 & S Zachodniopomorskie coast & 0 & 0.00 \\
\hline 39 & Szczecin Lagoon & 872 & 6.92 \\
\hline 40 & Usedomer coast and Greifswalder Lagoon & 2,622 & 20.81 \\
\hline 41 & Rügen coast & 786 & 6.24 \\
\hline 42 & Darss coast & 943 & 7.49 \\
\hline 43 & Wismar Bay & 8 & 0.06 \\
\hline 44 & Fehmarn Belt & 81 & 0.64 \\
\hline 45 & Fehmarn coast & 24 & 0.19 \\
\hline 46 & Propstei coast & 0 & 0.00 \\
\hline 47 & Schleswig-Holstein coast & 64 & 0.51 \\
\hline 48 & Little Belt & 38 & 0.30 \\
\hline 49 & N Kiel Bay & 21 & 0.17 \\
\hline 50 & Great Belt & 26 & 0.21 \\
\hline 51 & Lolland coast & 1,061 & 8.42 \\
\hline 52 & SE Denmark coast & 109 & 0.87 \\
\hline 53 & The Sound, Danish coast & 431 & 3.42 \\
\hline 54 & NW Sealand & 80 & 0.64 \\
\hline 55 & SW Kattegat & 64 & 0.51 \\
\hline 56 & NW Kattegat & 0 & 0.00 \\
\hline \multirow[t]{2}{*}{57} & Bornholm coast & 2 & 0.02 \\
\hline & Total & 12,600 & 100.00 \\
\hline
\end{tabular}

Number is the average estimated number of birds, and \% compares the percentage of birds within the area with the total estimated number in the Baltic Sea. 


\subsection{Red-breasted Merganser Mergus serrator}

\subsubsection{Importance of the Baltic Sea}

The estimate of the north-west European winter population of Redbreasted Merganser has recently been updated to 170,000 birds (Delany \& Scott 2006). The current Baltic winter population is estimated at 25,700 birds, equivalent to a significant decrease of $41.6 \%$ since $1988-$ 1993. The Baltic Sea now supports $15 \%$ of the north-west European winter population of Red-breasted Mergansers.

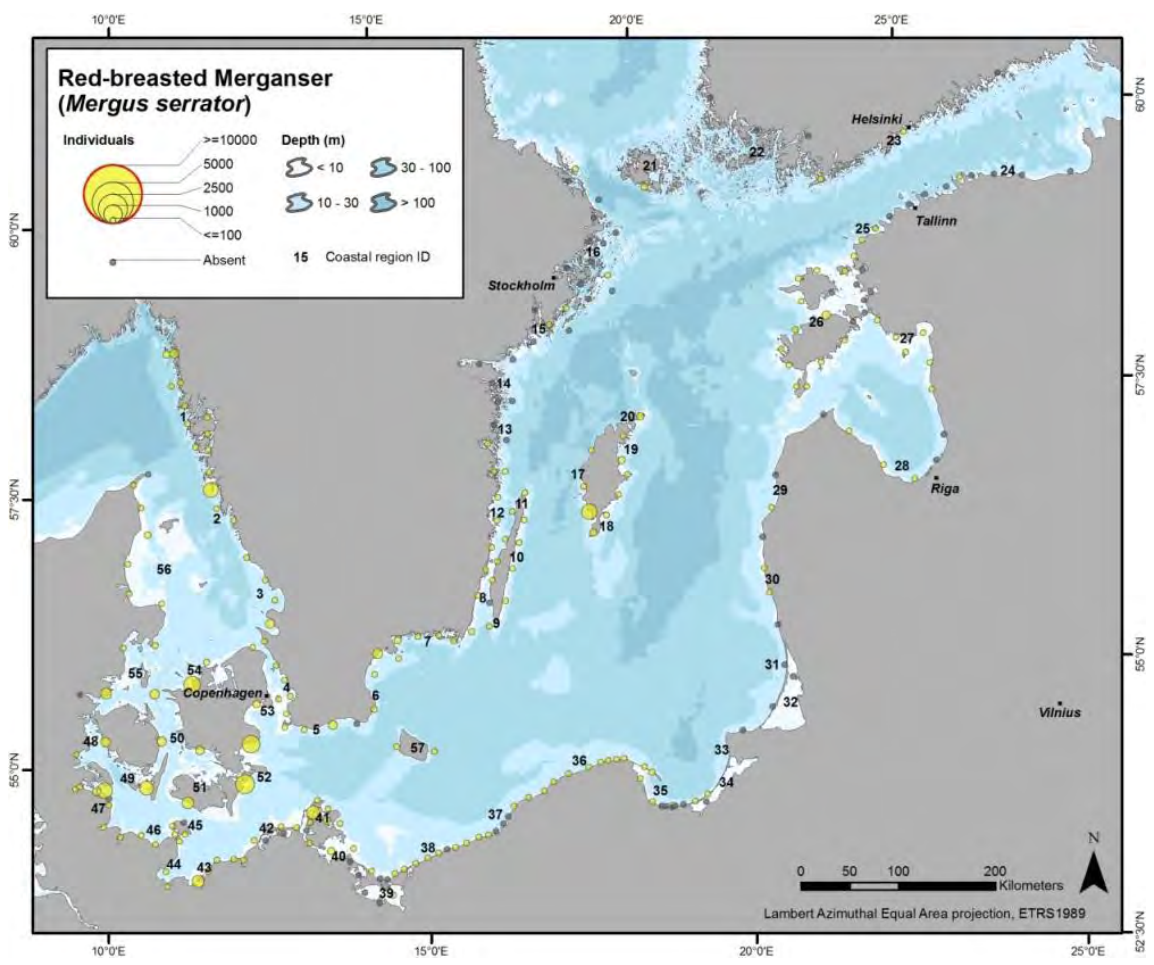

Map 22. Distribution and numbers of wintering Red-breasted Merganser Mergus serrator in the Baltic Sea, 2007-2009.

\subsubsection{Main wintering areas in the Baltic Sea}

During 1988-1993 the bulk (60\%) of the Red-breasted Merganser population in the Baltic Sea was recorded within one region between southeast Denmark and the lagoons in eastern Germany and north-west Poland. This region now supports $37 \%$ of the mergansers. However, the numbers of wintering Red-breasted Mergansers along the eastern German coast have declined by $87 \%$ from 13,715 to 1,800 since 1993 . In an area like Greifswalder Lagoon numbers have declined from 5,335 to 415 birds. In Danish waters numbers have declined by approximately $58 \%$ since 1988-1993. Numbers in Polish, Russian, Lithuanian, Latvian and Estonian waters have declined by $78 \%$. In contrast much more Red- 
breasted Mergansers were recorded during this survey period in Swedish waters as compared to 1988-1993; equivalent to an increase of $221 \%$. The most important area to the species is now the east coast of Gotland with 8,200 birds (estimated from line transect surveys).

\subsubsection{Distribution in the Baltic Sea}

Red-breasted Mergansers use a wide range of shallow $(<20 \mathrm{~m})$ habitats, including rocky coasts and archipelagos for wintering in the Baltic Sea.

\subsubsection{Phenology}

During autumn, most Red-breasted Mergansers leave freshwater localities, and move to the coast. In September, migrants from north and east begin to arrive to the Baltic Sea. In October-November, the numbers of birds rise to a peak. Some mergansers stay for the winter while others continue to the Netherlands and Britain. Spring return depends on when thaw is setting in, but main movements are usually in March and April.

Table 22. The average number of wintering Red-breasted Merganser Mergus serrator in key areas of the Baltic Sea, 2007-2009.

\begin{tabular}{|c|c|c|c|}
\hline Id & Locality & Number & $\%$ \\
\hline 1 & Bohüslän S & 1,313 & 8.18 \\
\hline 2 & Halland & 51 & 0.32 \\
\hline 3 & Skåne NW & 344 & 2.14 \\
\hline 4 & The Sound, Sweden & 218 & 1.36 \\
\hline 5 & Skåne south coast & 300 & 1.87 \\
\hline 6 & Hanö Bay & 504 & 3.14 \\
\hline 7 & Blekinge archipelago & 342 & 2.13 \\
\hline 8 & S Kalmar Sound & 267 & 1.66 \\
\hline 9 & Öland south coast & 58 & 0.36 \\
\hline 10 & Öland east coast & 212 & 1.32 \\
\hline 11 & Öland north coast \& N Ground & 68 & 0.42 \\
\hline 12 & N Kalmar Sound & 142 & 0.89 \\
\hline 13 & N Kalmar Län archipelago & 45 & 0.28 \\
\hline 14 & Östergötland archipelago & 0 & 0.00 \\
\hline 15 & Södermanlands archipelago & 2 & 0.01 \\
\hline 16 & Stockholm archipelago & 5 & 0.03 \\
\hline 17 & Gotland west coast & 812 & 5.06 \\
\hline 18 & Gotland S coast & 291 & 1.81 \\
\hline 19 & Gotland NE coast & 185 & 1.15 \\
\hline 20 & Gotland N coast, Fårön \& Gotska Sandön & 157 & 0.98 \\
\hline 21 & Åland Archipelago & 140 & 0.87 \\
\hline 22 & Archipelago Sea & 0 & 0.00 \\
\hline 23 & Gulf of Finland & 9 & 0.06 \\
\hline 24 & Estonia $\mathrm{N}$ coast & 1 & 0.01 \\
\hline 25 & Estonia NW coast & 81 & 0.50 \\
\hline 26 & Hiiumaa-Saaremaa coasts & 622 & 3.88 \\
\hline 27 & Estonian $S$ coast & 17 & 0.11 \\
\hline 28 & Gulf of riga & 78 & 0.49 \\
\hline 29 & Latvia W coast & 3 & 0.02 \\
\hline 30 & Latvia SW coast & 3 & 0.02 \\
\hline 31 & Lithuanian and northern Kaliningrad coast & 0 & 0.00 \\
\hline 32 & Curonian Lagoon & 0 & 0.00 \\
\hline 33 & S Kaliningrad coast & 0 & 0.00 \\
\hline 34 & Vistula Lagoon & 0 & 0.00 \\
\hline 35 & Gdansk Bay & 241 & 1.50 \\
\hline 36 & Pomorskie coast & 74 & 0.46 \\
\hline 37 & N Zachodniopomorskie coast & 28 & 0.17 \\
\hline
\end{tabular}




\begin{tabular}{llrr}
\hline Id & Locality & Number & $\%$ \\
\hline 38 & S Zachodniopomorskie coast & 292 & 1.82 \\
39 & Szczecin Lagoon & 1 & 0.01 \\
40 & Usedomer coast and Greifswalder Lagoon & 414 & 2.58 \\
41 & Rügen coast & 854 & 5.32 \\
42 & Darss coast & 67 & 0.42 \\
43 & Wismar Bay & 463 & 2.89 \\
44 & Fehmarn Belt & 54 & 0.34 \\
45 & Fehmarn coast & 147 & 0.92 \\
46 & Propstei coast & 23 & 0.14 \\
47 & Schleswig-Holstein coast & 1,084 & 6.76 \\
48 & Little Belt & 285 & 1.78 \\
49 & N Kiel Bay & 586 & 3.65 \\
50 & Great Belt & 246 & 1.53 \\
51 & Lolland coast & 623 & 3.88 \\
52 & SE Denmark coast & 1,943 & 12.11 \\
53 & The Sound, Danish coast & 284 & 1.77 \\
54 & NW Sealand & 1,173 & 7.31 \\
55 & SW Kattegat & 497 & 3.10 \\
56 & NW Kattegat & 374 & 2.33 \\
57 & Bornholm coast & 21 & 0.13 \\
& Estimated Falsterbo Peninsula & 2,300 & \\
& Estimated Gotland E & 8,200 & 25,700 \\
\end{tabular}

Number is the average estimated number of birds, and \% compares the percentage of birds within the area with the total estimated number in the Baltic Sea. For the Faltserbo Peninsula and the east coast of Gotland numbers estimated from transect surveys have been added.

\subsection{Goosander Mergus merganser}

\subsubsection{Importance of the Baltic Sea}

The estimate of the north-west European winter population of Goosander has recently been updated to 266,000 birds (Delany \& Scott 2006). The current Baltic winter population is estimated at 66,000 birds, equivalent to a decline of $9.6 \%$ since 1988-1993. The Baltic Sea now supports $24.8 \%$ of the north-west European winter population of Goosanders.

\subsubsection{Main wintering areas in the Baltic Sea}

The distribution of wintering Goosanders in the Baltic Sea has not changed markedly since 1988-1993, and the species still has its geographical centers in the lagoons in eastern Germany and west Poland, the Curonian Lagoon, Estonian waters and the Swedish east coast. However, the proportion of birds wintering in the latter area has increased. The population wintering in the lagoons in eastern Germany and west Poland have declined dramatically from 33,000 to 11,175 since $1993,-a$ decline of $66 \%$, of which a large part is due to the deterioration of the Szczecin Lagoon as the most important area in the Baltic Sea to this species. Today, only 5,530 Goosanders winter here. Numbers further north, in the Curonian Lagoon, have declined less steeply, from 12,000 birds in 
1988-1993 to 8,200 birds in 2007-2009. Further north, even, numbers of Goosanders have increased by 24\% since 1993 from 4,425 birds to 5,495 birds. Total numbers along the east Swedish coast have increased even more, and today the region boasts 19,700 Goosanders as compared to 11,000 during $1988-1993$. The main area on this coastline is the Kalmar Sound $(5,000)$ and the Stockholm Archipelago $(3,800)$.

\section{Distribution in the Baltic Sea}

Goosanders winter in freshwater, brackish waters and saltwater. However, in cold winters most Goosanders occur in estuaries, lagoons and sheltered sea coasts in areas of less than $10 \mathrm{~m}$ water depth. Goosanders winter along most of the coasts of the Baltic Sea, yet the change in the distribution towards the north and west now means that a higher proportion of Goosanders use rocky coasts and archipelagoes rather enclosed bays and lagoons with sandy or muddy substrates. Most Goosanders are found in areas with a water depth less than $5 \mathrm{~m}$.

\subsubsection{Phenology}

In the Baltic region most movements from inland waters to the coast take place from mid-October to December. In the same period, migrants from the north and east arrive to the Baltic Sea. Return migration begins very early. Except for hard winters, many Goosanders leave Danish waters in late-January while in other parts of the Baltic Sea most movements take place in March. 


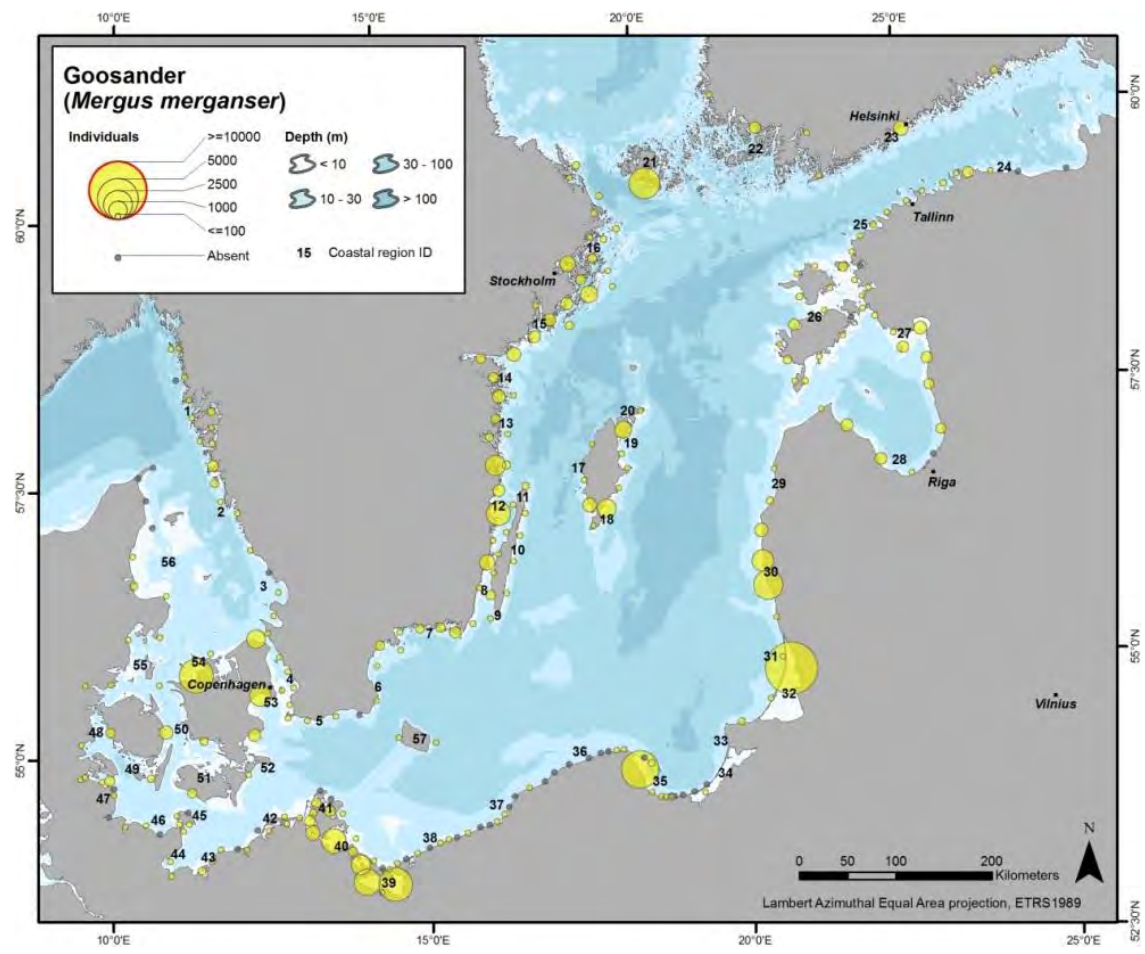

Map 23. Distribution and numbers of wintering Goosander Mergus merganser in the Baltic Sea, 2007-2009.

Table 23. The average number of wintering Goosander Mergus merganser in key areas of the Baltic Sea, 2007-2009.

\begin{tabular}{|c|c|c|c|}
\hline Id & Locality & Number & $\%$ \\
\hline 1 & Bohüslän S & 1,020 & 1.55 \\
\hline 2 & Halland & 20 & 0.03 \\
\hline 3 & Skåne NW & 60 & 0.09 \\
\hline 4 & The Sound, Sweden & 106 & 0.16 \\
\hline 5 & Skåne south coast & 179 & 0.27 \\
\hline 6 & Hanö Bay & 270 & 0.41 \\
\hline 7 & Blekinge archipelago & 1,005 & 1.52 \\
\hline 8 & S Kalmar Sound & 1,256 & 1.91 \\
\hline 9 & Öland south coast & 45 & 0.07 \\
\hline 10 & Öland east coast & 323 & 0.49 \\
\hline 11 & Öland north coast \& N Ground & 164 & 0.25 \\
\hline 12 & N Kalmar Sound & 3,719 & 5.64 \\
\hline 13 & N Kalmar Län archipelago & 525 & 0.80 \\
\hline 14 & Östergötland archipelago & 1,679 & 2.55 \\
\hline 15 & Södermanlands archipelago & 991 & 1.50 \\
\hline 16 & Stockholm archipelago & 3,821 & 5.80 \\
\hline 17 & Gotland west coast & 632 & 0.96 \\
\hline 18 & Gotland S coast & 1,175 & 1.78 \\
\hline 19 & Gotland NE coast & 972 & 1.47 \\
\hline 20 & Gotland N coast, Fårön \& Gotska Sandön & 91 & 0.14 \\
\hline 21 & Åland Archipelago & 2,850 & 4.32 \\
\hline 22 & Archipelago Sea & 488 & 0.74 \\
\hline 23 & Gulf of Finland & 885 & 1.34 \\
\hline 24 & Estonia $\mathrm{N}$ coast & 615 & 0.93 \\
\hline 25 & Estonia NW coast & 360 & 0.55 \\
\hline 26 & Hiiumaa-Saaremaa coasts & 1,728 & 2.62 \\
\hline 27 & Estonian $S$ coast & 1,455 & 2.21 \\
\hline 28 & Gulf of riga & 1,536 & 2.33 \\
\hline 29 & Latvia W coast & 733 & 1.11 \\
\hline 30 & Latvia SW coast & 3,972 & 6.03 \\
\hline 31 & Lithuanian and northern Kaliningrad coast & 38 & 0.06 \\
\hline 32 & Curonian Lagoon & 8,200 & 12.44 \\
\hline
\end{tabular}




\begin{tabular}{llrr}
\hline Id & Locality & Number & $\%$ \\
\hline 33 & S Kaliningrad coast & 151 & 0.23 \\
34 & Vistula Lagoon & 22 & 0.03 \\
35 & Gdansk Bay & 4,439 & 6.73 \\
36 & Pomorskie coast & 4 & 0.01 \\
37 & N Zachodniopomorskie coast & 53 & 0.08 \\
38 & S Zachodniopomorskie coast & 185 & 0.28 \\
39 & Szczecin Lagoon & 5,530 & 8.39 \\
40 & Usedomer coast and Greifswalder Lagoon & 3,867 & 5.87 \\
41 & Rügen coast & 1,173 & 1.78 \\
42 & Darss coast & 219 & 0.33 \\
43 & Wismar Bay & 201 & 0.30 \\
44 & Fehmarn Belt & 16 & 0.02 \\
45 & Fehmarn coast & 48 & 0.07 \\
46 & Propstei coast & 54 & 0.08 \\
47 & Schleswig-Holstein coast & 405 & 0.61 \\
48 & Little Belt & 355 & 0.54 \\
49 & N Kiel Bay & 172 & 0.26 \\
50 & Great Belt & 539 & 0.82 \\
51 & Lolland coast & 459 & 0.70 \\
52 & SE Denmark coast & 563 & 0.85 \\
53 & The Sound, Danish coast & 2,492 & 3.78 \\
54 & NW Sealand & 3,561 & 5.40 \\
55 & SW Kattegat & 188 & 0.29 \\
56 & NW Kattegat & 287 & 0.44 \\
57 & Bornholm coast & 24 & 0.04 \\
\hline & Total & 66,000 & $\mathbf{1 0 0 . 0 0}$ \\
\hline & isthe average estimated & & $\%$ \\
\hline
\end{tabular}

Number is the average estimated number of birds, and \% compares the percentage of birds within the area with the total estimated number in the Baltic Sea.

\subsection{Common Coot Fulica atra}

\subsubsection{Importance of the Baltic Sea}

The estimate of the north-west European winter population of Common Coots has recently been estimated at 1,750,000 birds (Delany \& Scott 2006). The current Baltic winter population is estimated at 248,000 birds, equivalent to an increase of $17 \%$ since 1988-1993. The Baltic Sea now supports $14.2 \%$ of the north-west European winter population of Common Coots.

\subsubsection{Main wintering areas in the Baltic Sea}

The location of the main areas has not changed since the last census period. Numbers in Schleswig-Holstein have declined by 67\% from 45,000 during 1988 to 1993 to 15,196 during 2007-2009, while numbers in Mecklenburg-Vorpommern have remained relatively stable. Numbers in the Gulf of Gdansk, along the southern part of the Swedish east coast and in the shallows of southeastern Denmark have increased during the period. 


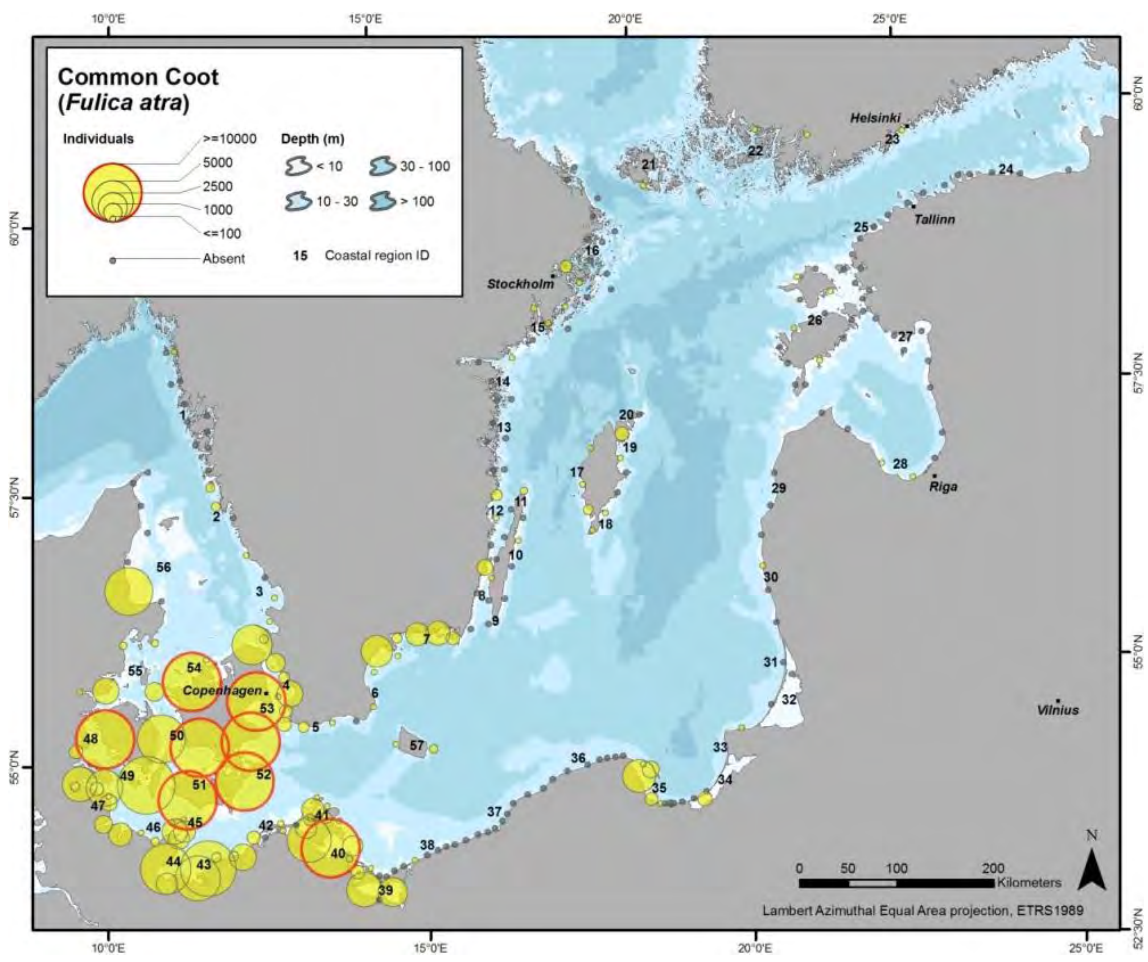

Map 24. Distribution and numbers of wintering Common Coot Fulica atra in the Baltic Sea, 2007-2009.

\subsubsection{Distribution in the Baltic Sea}

Common Coot mainly winters in fresh and brackish waters. Usually, it prefers lakes, lagoons, estuaries and sheltered coasts and is nearly always found in very shallow waters less than $3 \mathrm{~m}$ deep. Historically, the wintering range of Common Coot in the Baltic Sea has been centered in the south-western part. Despite declines in the densities sustained by the southern-most areas, the wintering range has not been significantly altered.

\subsubsection{Phenology}

In mild winters, some Coots of the northern and eastern Baltic Sea population remain in the coastal areas while almost the entire population breeding in southern Sweden, Denmark and Germany is sedentary. In cold winters, nearly all Common Coots leave the Baltic Sea while about one third of Danish Coots remain in the area. Common Coots begin to move to the coast in August, and, during the same period, migrants from the east and north start to arrive to the area. In Danish and German waters, the number usually rises to a peak in October-November. After this period coots wintering outside the Baltic Sea move on. Spring migration from West and Central Europe begins in March, and, in the beginning of May, all Coots have left the Baltic Sea. 
Table 24. The average number of wintering Common Coot Fulica atra in key areas of the Baltic Sea, 2007-2009.

\begin{tabular}{|c|c|c|c|}
\hline Id & Locality & Number & $\%$ \\
\hline 1 & Bohüslän S & 235 & 0.09 \\
\hline 2 & Halland & 238 & 0.10 \\
\hline 3 & Halland south coast & 50 & 0.02 \\
\hline 4 & The Sound, Sweden & 4,122 & 1.66 \\
\hline 5 & Skåne south coast & 983 & 0.40 \\
\hline 6 & Hanö Bay & 2,967 & 1.20 \\
\hline 7 & Blekinge archipelago & 4,155 & 1.68 \\
\hline 8 & S Kalmar Sound & 747 & 0.30 \\
\hline 9 & Öland south coast & 0 & 0.00 \\
\hline 10 & Öland east coast & 5 & 0.00 \\
\hline 11 & Öland north coast \& N Ground & 155 & 0.06 \\
\hline 12 & N Kalmar Sound & 349 & 0.14 \\
\hline 13 & N Kalmar Län archipelago & 0 & 0.00 \\
\hline 14 & Östergötland archipelago & 4 & 0.00 \\
\hline 15 & Södermanlands archipelago & 146 & 0.06 \\
\hline 16 & Stockholm archipelago & 525 & 0.21 \\
\hline 17 & Gotland west coast & 347 & 0.14 \\
\hline 18 & Gotland S coast & 49 & 0.02 \\
\hline 19 & Gotland NE coast & 542 & 0.22 \\
\hline 20 & Gotland N coast, Fårön \& Gotska Sandön & 0 & 0.00 \\
\hline 21 & Åland Archipelago & 121 & 0.05 \\
\hline 22 & Archipelago Sea & 35 & 0.01 \\
\hline 23 & Gulf of Finland & 7 & 0.00 \\
\hline 24 & Estonia $\mathrm{N}$ coast & 0 & 0.00 \\
\hline 25 & Estonia NW coast & 0 & 0.00 \\
\hline 26 & Hiiumaa-Saaremaa coasts & 10 & 0.00 \\
\hline 27 & Estonian $\mathrm{S}$ coast & 0 & 0.00 \\
\hline 28 & Gulf of riga & 12 & 0.00 \\
\hline 29 & Latvia W coast & 0 & 0.00 \\
\hline 30 & Latvia SW coast & 41 & 0.02 \\
\hline 31 & Lithuanian and northern Kaliningrad coast & 0 & 0.00 \\
\hline 32 & Curonian Lagoon & 0 & 0.00 \\
\hline 33 & S Kaliningrad coast & 14 & 0.01 \\
\hline 34 & Vistula Lagoon & 600 & 0.24 \\
\hline 35 & Gdansk Bay & 4,576 & 1.84 \\
\hline 36 & Pomorskie coast & 0 & 0.00 \\
\hline 37 & N Zachodniopomorskie coast & 0 & 0.00 \\
\hline 38 & S Zachodniopomorskie coast & 3 & 0.00 \\
\hline 39 & Szczecin Lagoon & 6,156 & 2.48 \\
\hline 40 & Usedomer coast and Greifswalder Lagoon & 20,689 & 8.34 \\
\hline 41 & Rügen coast & 3,674 & 1.48 \\
\hline 42 & Darss coast & 2,753 & 1.11 \\
\hline 43 & Wismar Bay & 15,676 & 6.32 \\
\hline 44 & Fehmarn Belt & 10,180 & 4.10 \\
\hline 45 & Fehmarn coast & 3,333 & 1.34 \\
\hline 46 & Propstei coast & 1,871 & 0.75 \\
\hline 47 & Schleswig-Holstein coast & 9,992 & 4.03 \\
\hline 48 & Little Belt & 11,431 & 4.61 \\
\hline 49 & N Kiel Bay & 9,765 & 3.94 \\
\hline 50 & Great Belt & 6,840 & 2.76 \\
\hline 51 & Lolland coast & 48,456 & 19.53 \\
\hline 52 & SE Denmark coast & 26,015 & 10.49 \\
\hline 53 & The Sound, Danish coast & 27,821 & 11.22 \\
\hline 54 & NW Sealand & 12,925 & 5.21 \\
\hline 55 & SW Kattegat & 2,447 & 0.99 \\
\hline 56 & NW Kattegat & 6,749 & 2.72 \\
\hline \multirow[t]{2}{*}{57} & Bornholm coast & 241 & 0.10 \\
\hline & Total & 248,000 & 100.00 \\
\hline
\end{tabular}

Number is the average estimated number of birds, and \% compares the percentage of birds within the area with the total estimated number in the Baltic Sea. 


\section{Changes in wintering populations of waterbirds in the Baltic Sea}

On the following pages the results of the analysis of trends in the numbers of wintering waterbirds in selected regions with comparable yearly coverage between 1987 and 2008 are presented species by species. The purpose of the trend analyses has mainly been to allow for an interpretation of the differences observed in the distribution and abundance of several species between 1992-1993 and 2007-2009. To that end, the trends in the waterbirds would also allow us to link numbers of individual species per region with trends in the selected pressures. With the exception of the trends which have been established for the Long-tailed Ducks on Hoburgs Bank the trend data stem from counts in coastal areas. These coastal counts have to a large degree been undertaken as part of the Wetlands International Midwinter Census.

The results are combined for sites in the Kattegat, the Straits (Germany and Sweden), Central Baltic Sea (Germany, Sweden, Poland and Finland) and Estonia.

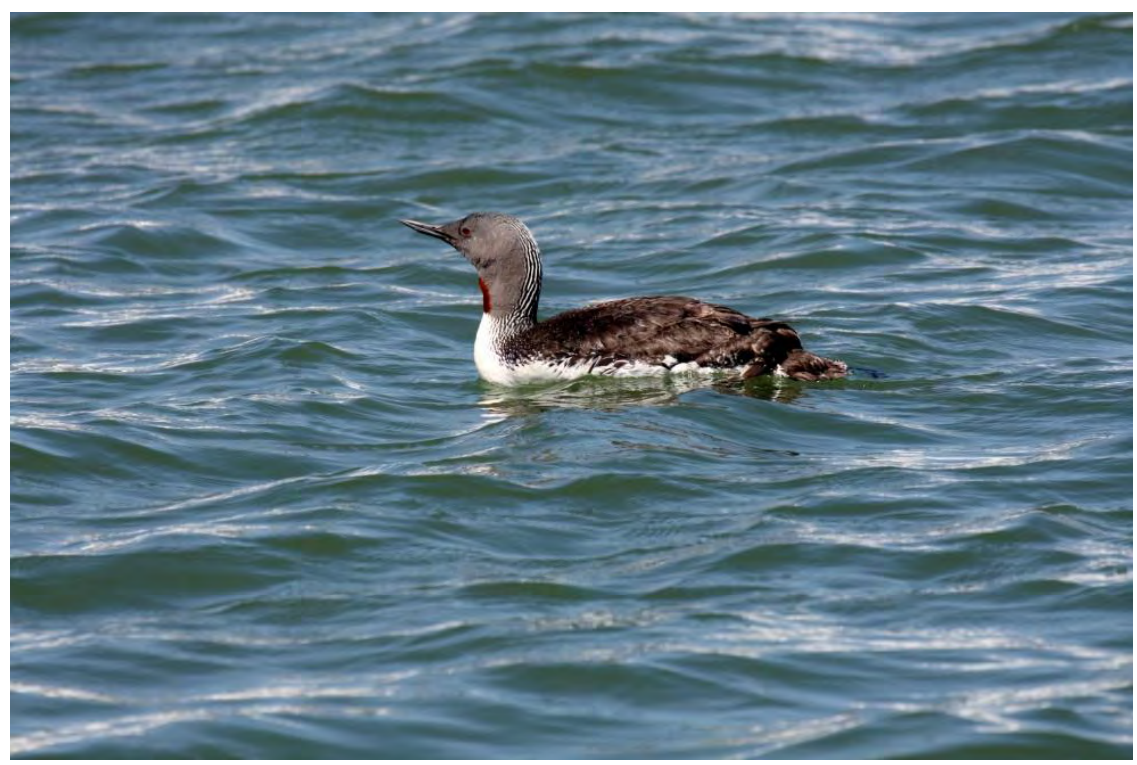




\subsection{Red-throated/Black-throated diver}

As the divers are primarily offshore species it is not known to what degree coastal counts provide a reliable picture of the overall trends in the Baltic. The surveys indicated that the population of wintering divers have declined ubiquitously between the two census periods. This is to some extent reflected by the coastal counts from 1987 to 2003, during which period steep declines were observed along the Swedish coast. After 2003, numbers in most coastal areas have increased slightly. The trend along the Swedish coast of the Central Baltic Sea was significant (Table 26).

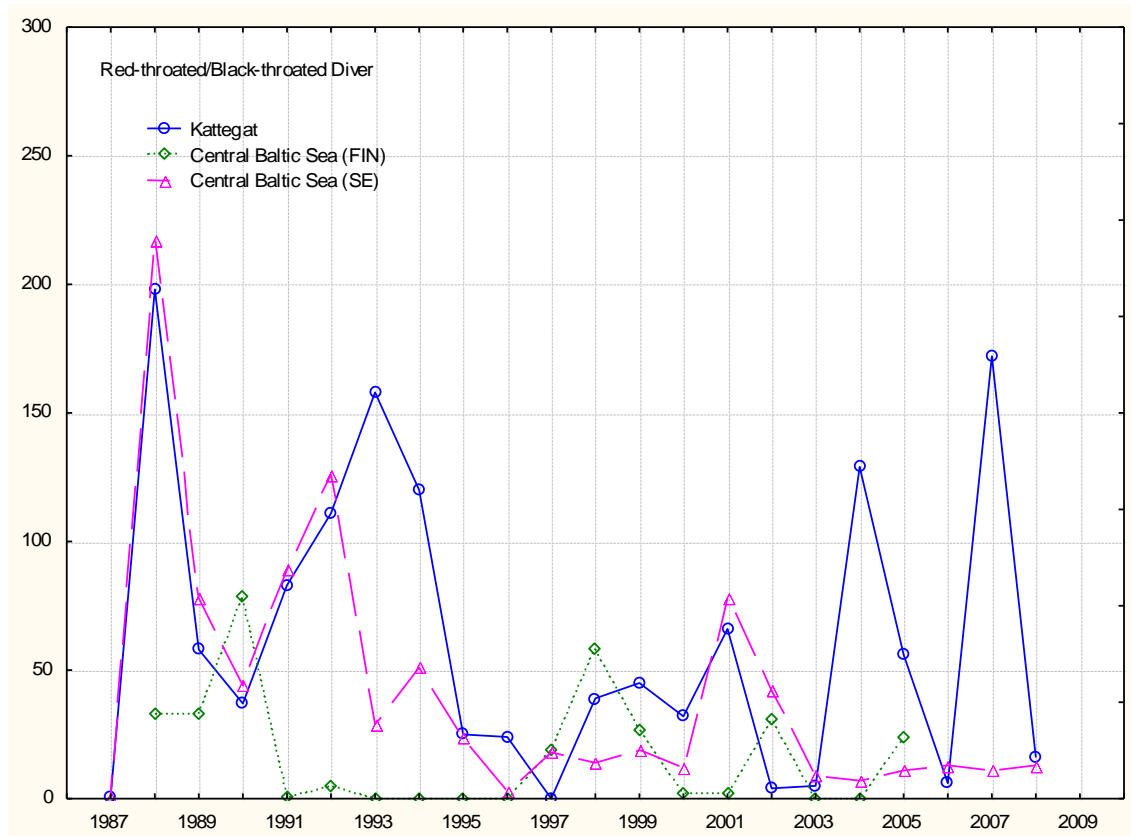

Figure 1. Trends in Red-throated/Black-throated diver numbers during winter counts 1987-2008 in selected coastal areas in the Kattegat, the Straits, the Central Baltic Sea. Y-axis shows total numbers seen per region.

\subsection{Great Crested Grebe}

The trend shown by the coastal counts are in agreement with the results of the surveys, which indicated a population increase in Great Crested Grebes along the northern mainland coast between the two survey periods (Figure 2). Additionally, Figure 2 indicates increases over the same period along all other coasts. The trends in all areas but SchleswigHolstein are significant $(\mathrm{p}<0.1$, Table 26$)$. Within the overall trends large year-to-year fluctuations are observed, possibly induced by variations in winter temperature and the availability of ice-free fresh-water habitats. 

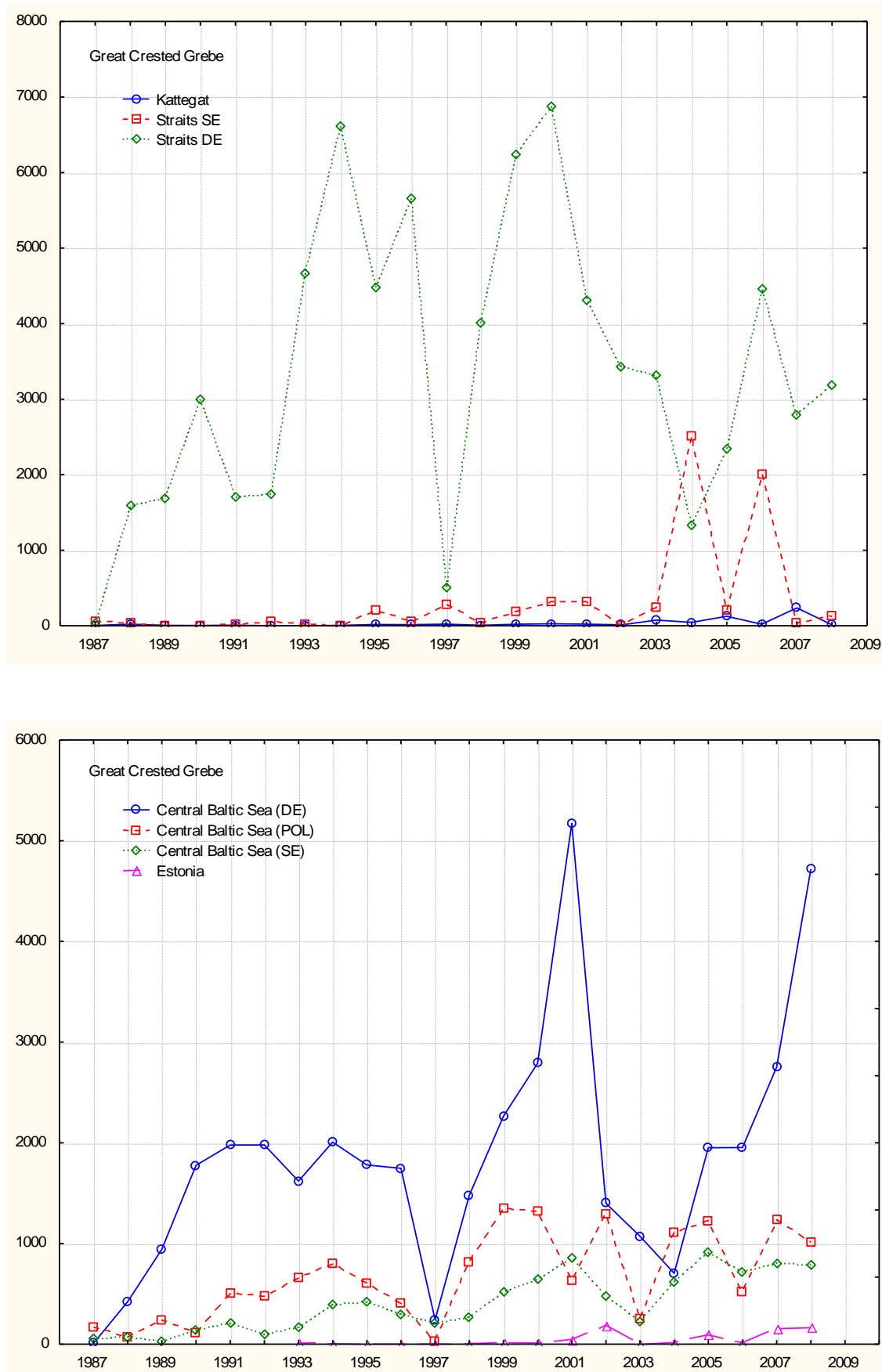

Figure 2. Trends in Great Crested Grebe numbers during winter counts 1987 2008 in selected coastal areas in the Kattegat, the Straits, the Central Baltic Sea and Estonia. Y-axis shows total numbers seen per region. 


\subsection{Red-necked Grebe}

The coastal trends shed more light on the development of the wintering population of Red-necked grebes. In Estonia, the trend has been positive with an annual increase of 5.6\% (Table 26).

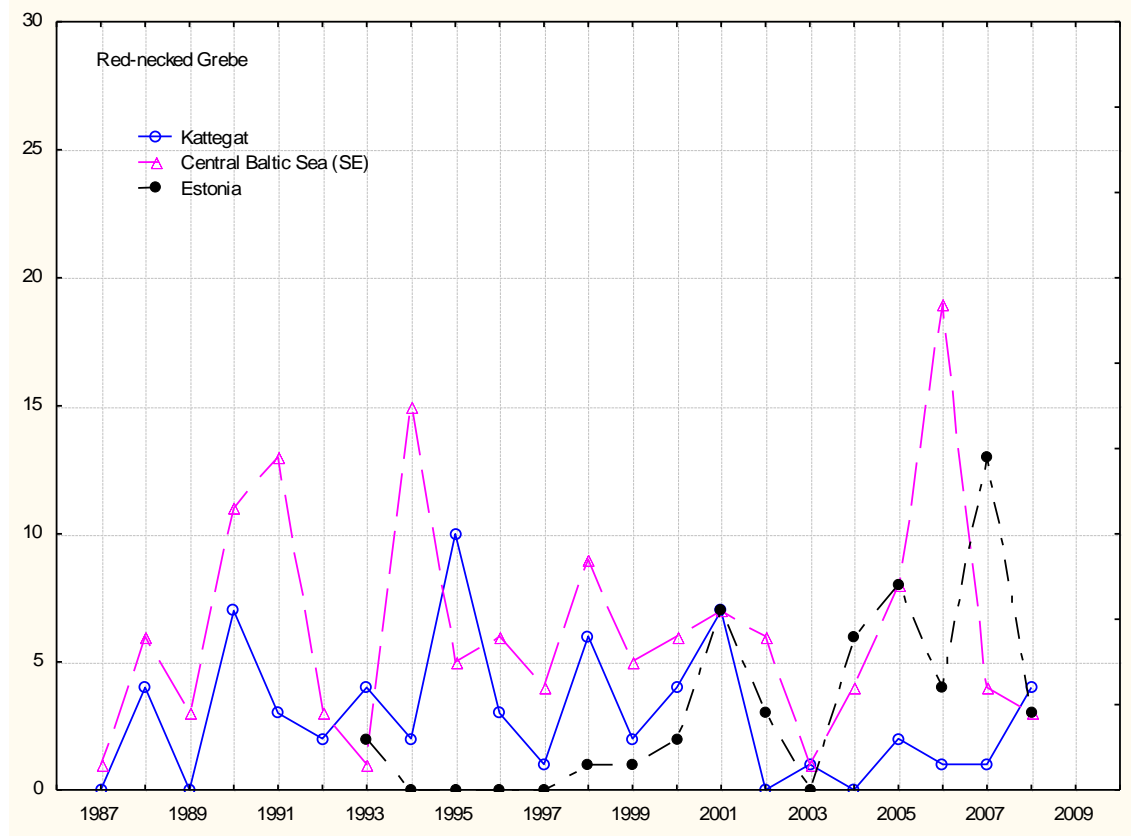

Figure 3. Trends in Red-necked Grebe numbers during winter counts 1987-2008 in selected coastal areas in the Kattegat, the Central Baltic Sea and Estonia. Yaxis shows total numbers seen per region.

\subsection{Slavonian Grebe}

Only sample sizes from the Kattegat were sufficient to allow for the calculation of a trend. The surveys indicated that numbers wintering in the main region off Germany and Poland have been increasing over the period. The coastal counts in the Kattegat reveal a significant positive trend with annual increases of 7.7\% (Table 26). 


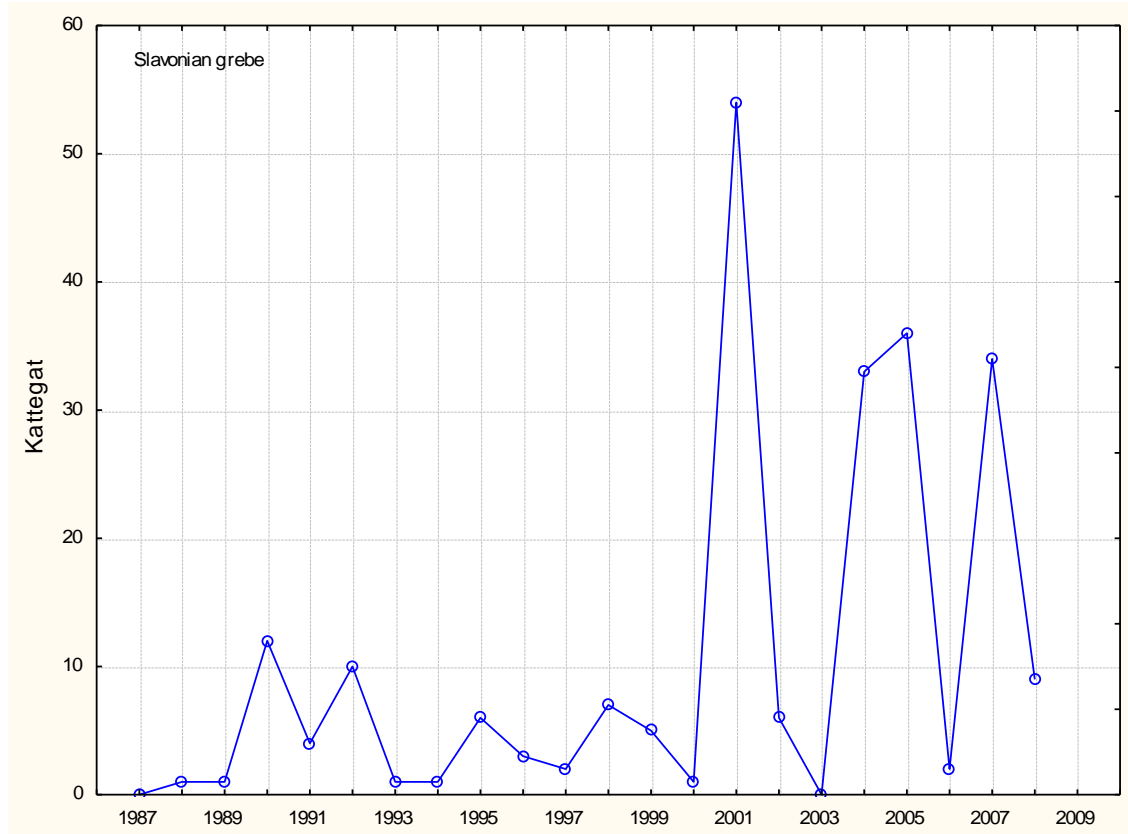

Figure 4. Trends in Slavonian Grebe numbers during winter counts 1987-2008 in selected coastal areas in the Kattegat. Y-axis shows total numbers seen per region.

\subsection{Great Cormorant}

The trends reflected in the coastal counts agree with the results of the surveys (Figure 5). In the Kattegat numbers of wintering cormorants increased until 1993, followed by a general decrease (mean annual decrease 3\%). In this area wintering Cormorants are made up of a mixture of P.c.carbo and P.c.sinensis. In all other areas reported numbers have been significantly increasing. The largest increases have taken place in the Mecklenburg-Vorpommern and Poland (annual increases of $11 \%$ and $19.2 \%$, respectively - Table 26 ). 

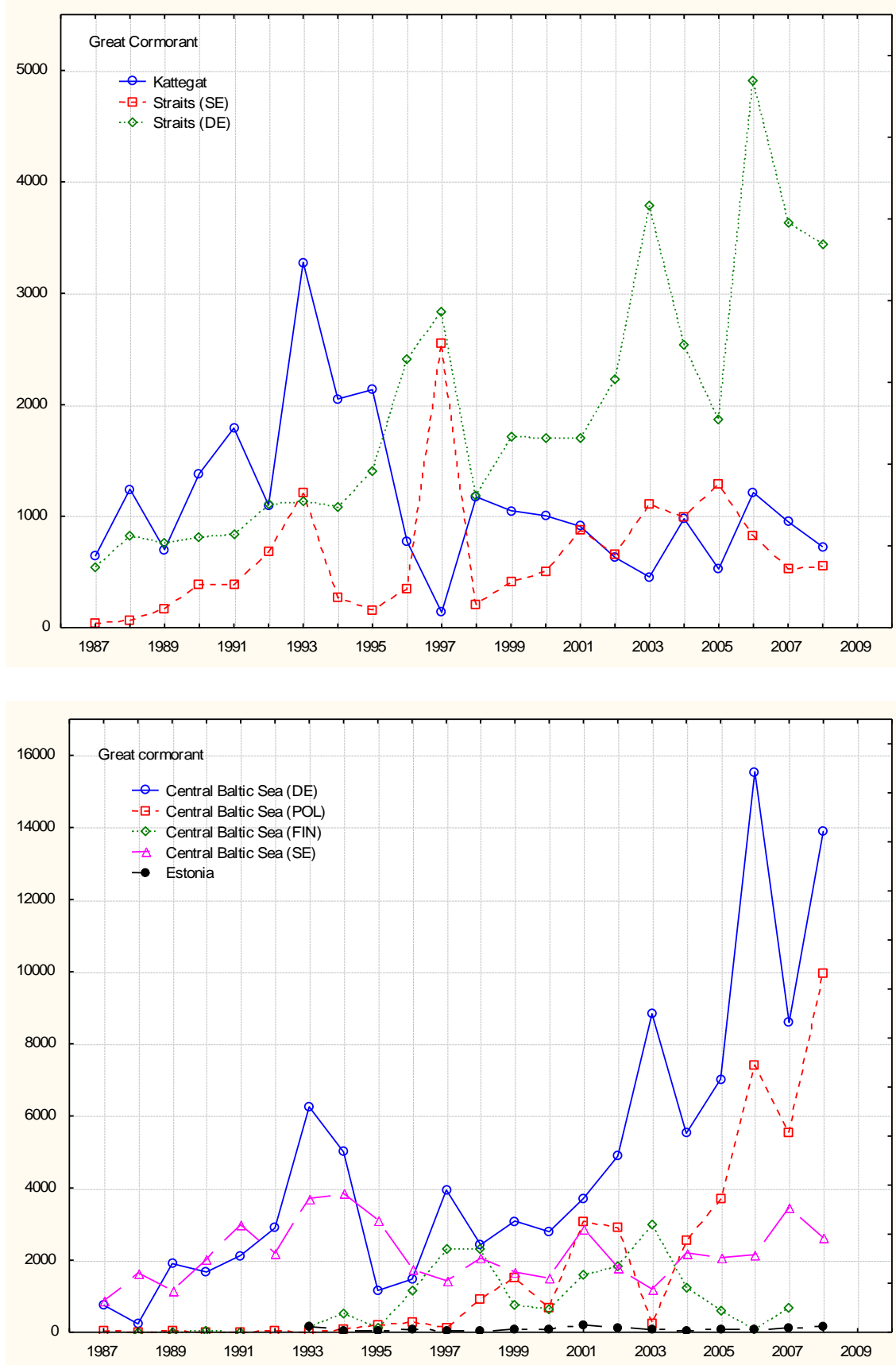

Figure 5. Trends in Great Cormorant numbers during winter counts 1987-2008 in selected coastal areas in the Kattegat, the Straits, the Central Baltic Sea and Estonia. Y-axis shows total numbers seen per region.

\subsection{Mute Swan}

The survey results indicated stable or increasing numbers of Mute Swans in almost all areas of the Baltic Sea since the census period 1992-1993. The trend analyses reveal that numbers in the Kattegat have declined 
since 1995 with an annual decline of 3\% (Figure 6, Table 26). In the central parts of the Baltic Sea numbers have generally increased annually by $2-4 \%$, while in the north counts indicate an annual increase of $6 \%$ (Table 26). Except for Poland and Germany all trends are significant $(\mathrm{p}<0.1)$.
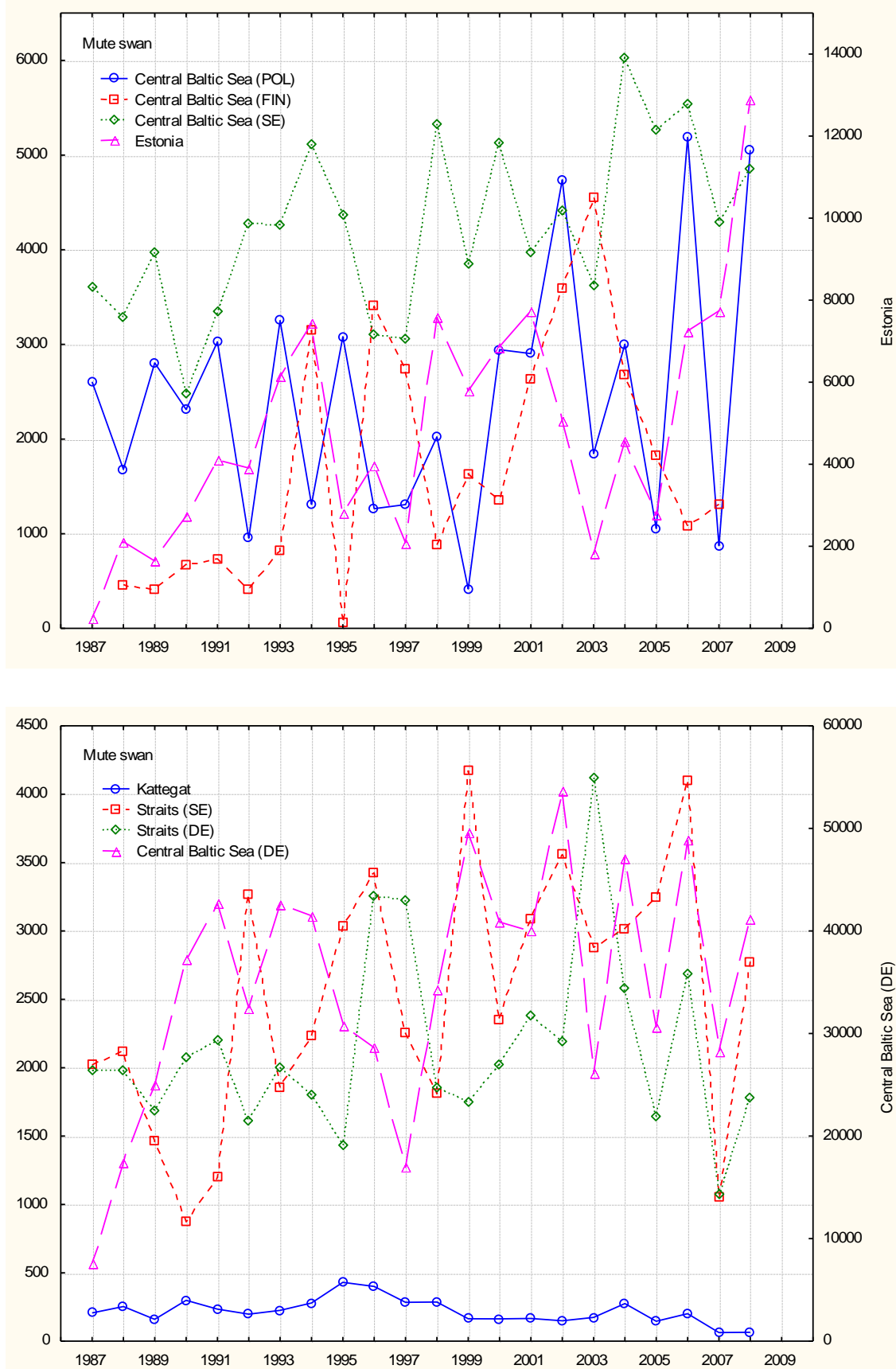

Figure 6. Trends in Mute Swan numbers during winter counts 1987-2008 in selected coastal areas in the Kattegat, the Straits, the Central Baltic. Y-axis shows total numbers seen per region. 


\subsection{Mallard}

The survey results indicated stable or slightly increasing numbers in the Baltic Sea since the census 1992-1993. The trend analyses reveal quite large year-to-year fluctuations with few general tendencies. However, a positive trend is observed in Öresund, while declines have been recorded in Schleswig-Holstein, Finland and Estonia (Table 26, Figure 7).
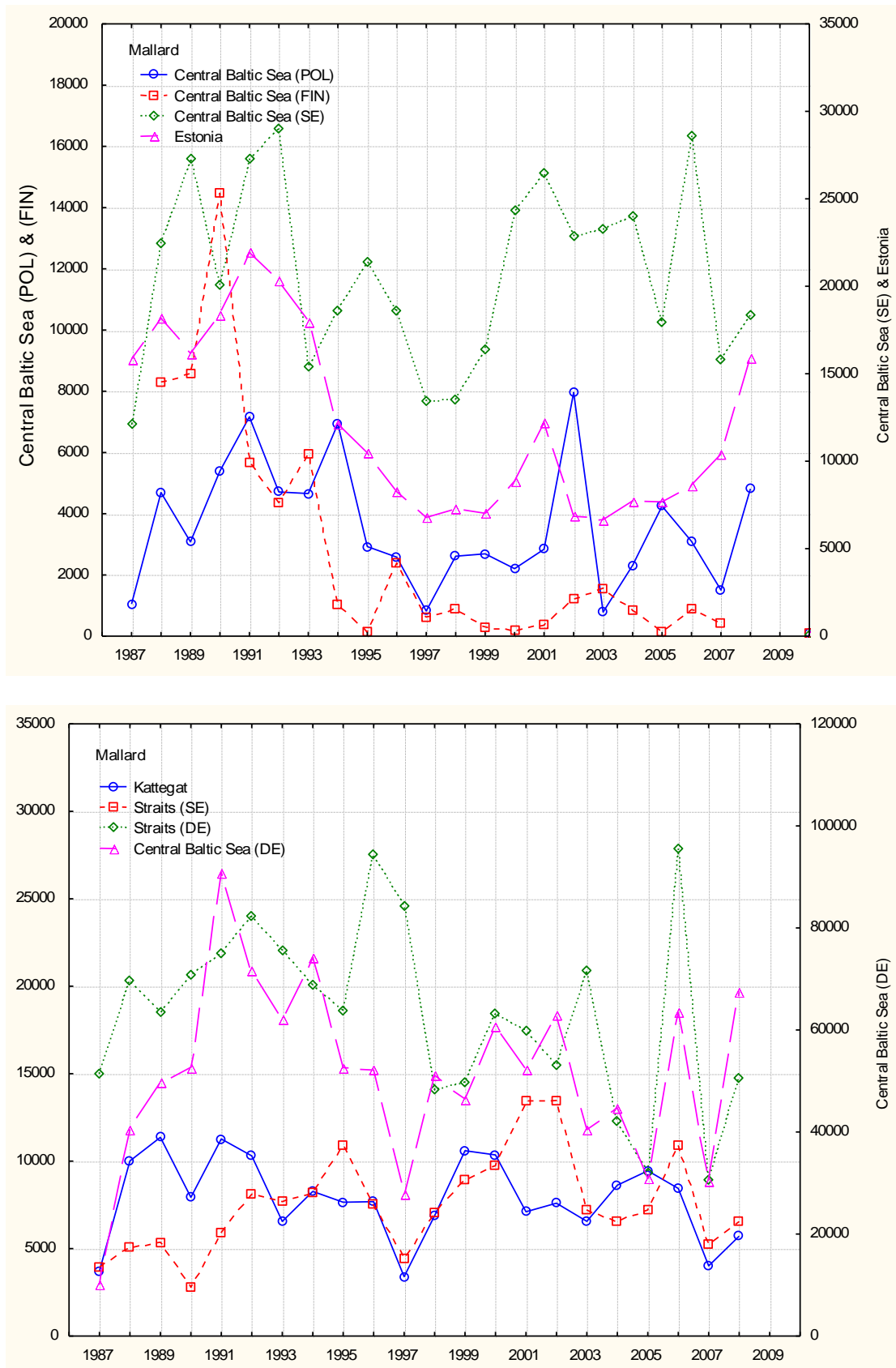

Figure 7. Trends in Mallard numbers during winter counts 1987-2008 in selected coastal areas in the Kattegat, the Straits, the Central Baltic. Y-axis shows total numbers seen per region. 


\subsection{Common Pochard}

Numbers of Common Pochard in coastal habitats vary in response to the severity of the winter. Measured over the entire trend period an increasing trend has been noted along the Swedish coast of the central Baltic Sea with an annual increase of $3.1 \%$.

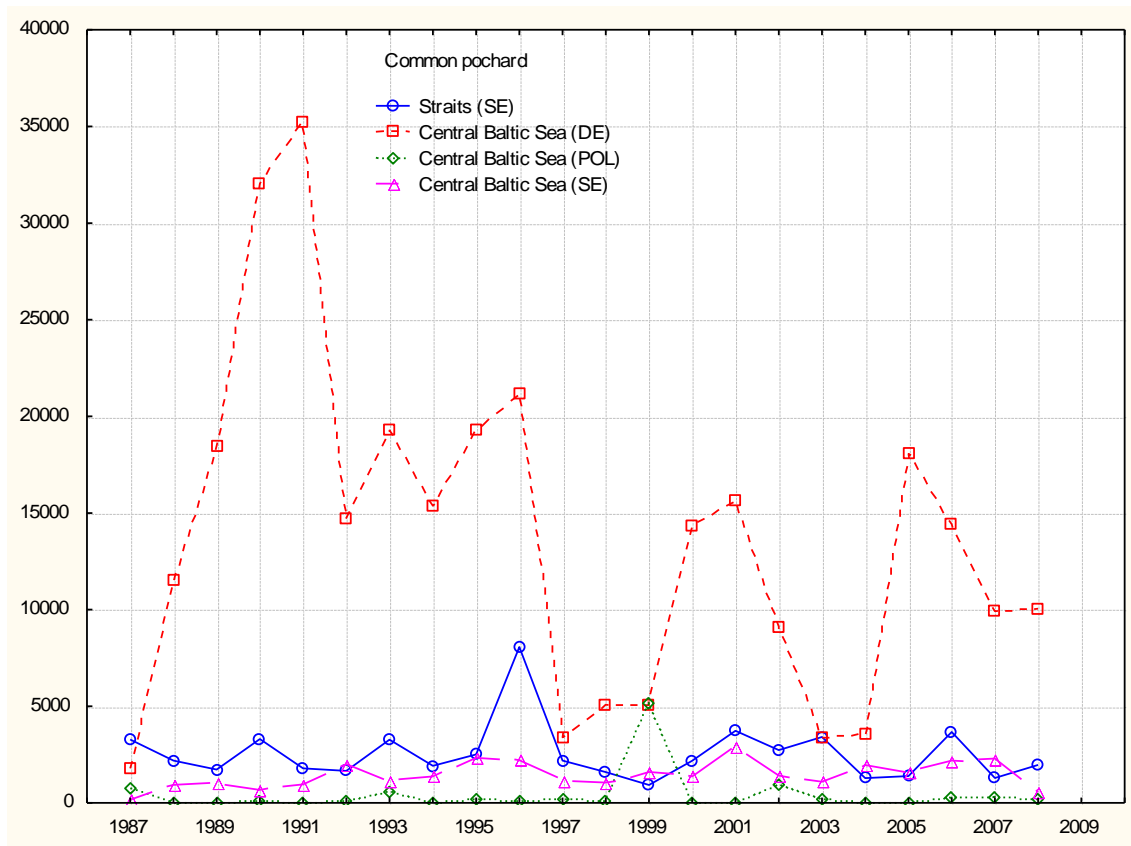

Figure 8. Trends in Common Pochard numbers during winter counts 1987-2008 in selected coastal areas in the Straits and the Central Baltic Sea. Y-axis shows total numbers seen per region.

\subsection{Tufted Duck}

In all regions numbers have been either stable or increasing. As seen in the survey results, the largest relative increases have taken place in the north, with trends in Estonia and along the central Swedish coast being significant $(\mathrm{p}<0.1$, Table 26). The annual increase in Estonia has been $18.9 \%$ and $3.9 \%$ along the central Swedish coast (Table 26). 

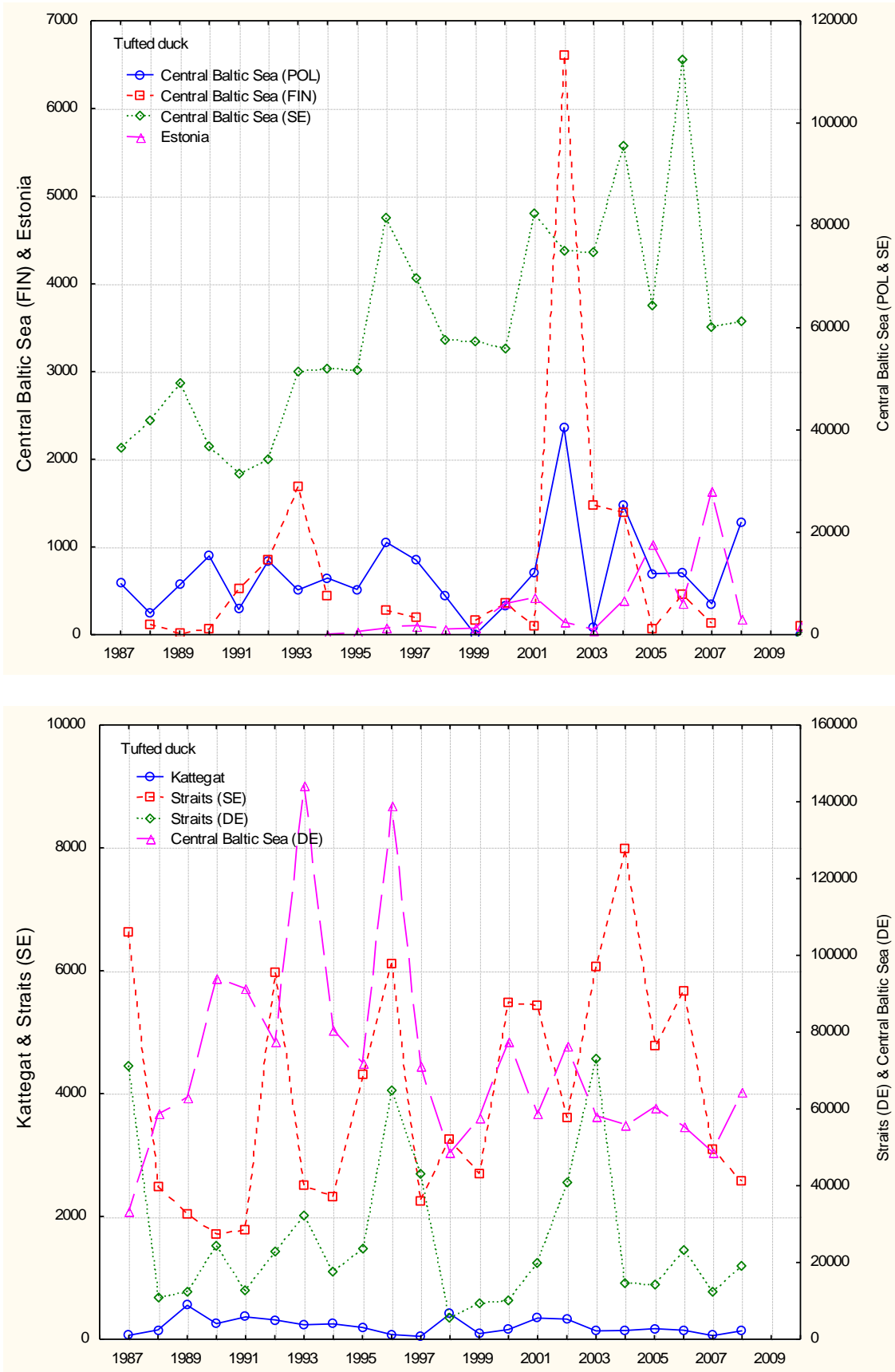

Figure 9. Trends in Tufted Duck numbers during winter counts 1987-2008 in selected coastal areas in the Kattegat, the Straits, the Central Baltic. Y-axis shows total numbers seen per region.

\subsection{Greater Scaup}

The trend analyses indicate annual increases in the Sound of $7.4 \%$ and an annual decrease in Mecklenburg-Vorpommern of 11.8\% (Table 26). The results of the coastal counts further stress the high degree of varia- 
bility in the numbers counted from year to year, which most likely can be explained by variations in winter severity and ice cover on lakes and lagoons.
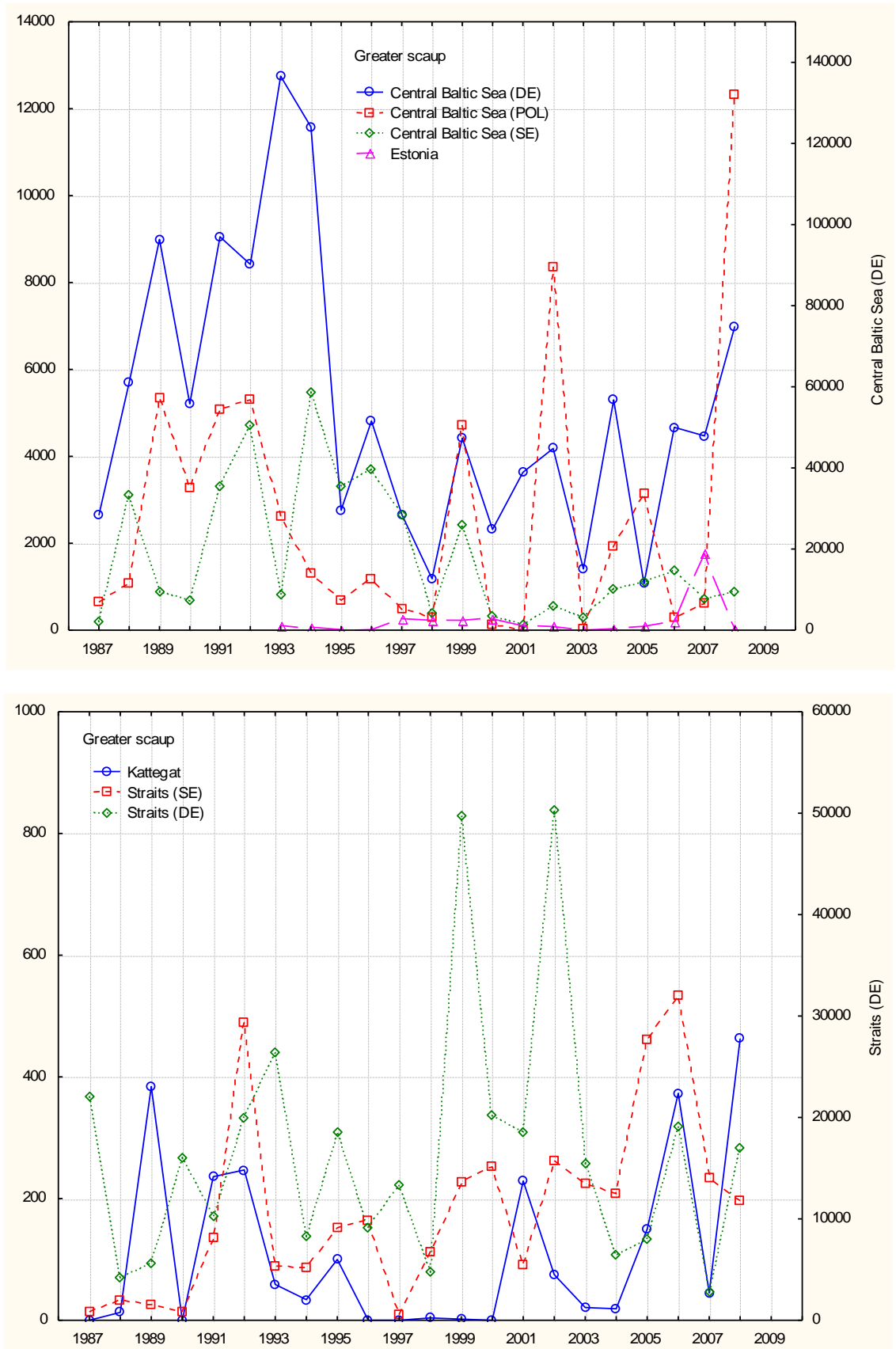

Figure 10. Trends in Greater Scaup numbers during winter counts 1987-2008 in selected coastal areas in the Kattegat, the Straits, the Central Baltic Sea. Y-axis shows total numbers seen per region. 


\subsection{Common Eider}

Numbers of this offshore species counted during coastal surveys may not reflect the true development of the wintering population. The surveys documented large-scale declines in the primary regions in the western Baltic. Along the Swedish Kattegat and Central Baltic coasts and in Öresund numbers have increased (Figure 11).
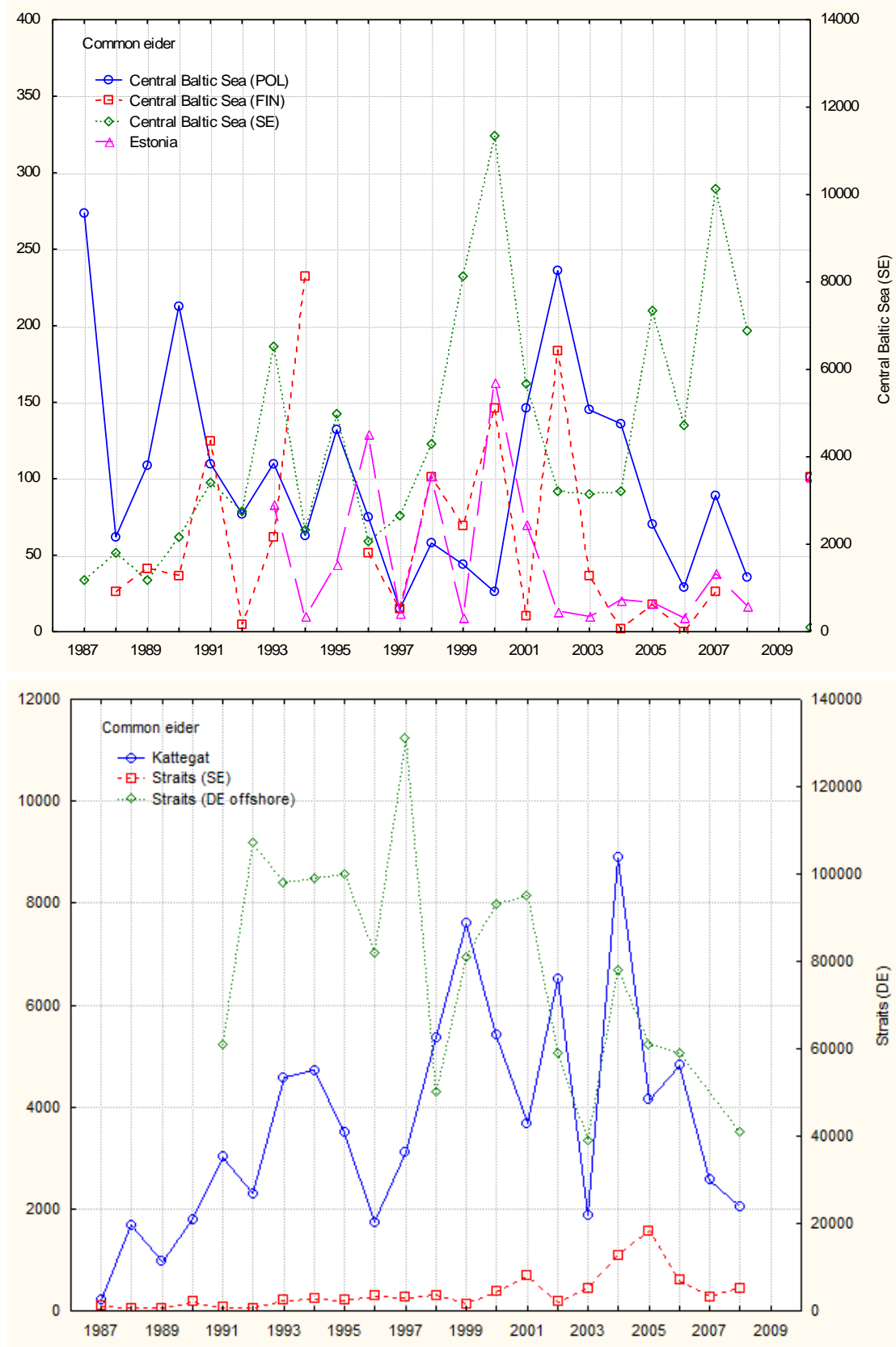

Figure 11. Trends in Common Eider numbers during winter counts 1987-2008 in selected coastal areas in the Kattegat, the Central Baltic Sea. Y-axis shows total numbers seen per region. 


\subsection{Long-tailed Duck}

To an even greater extent than for the Common Eider the numbers of Longtailed Ducks counted during coastal surveys do not reflect the true development of the wintering population. The surveys documented large-scale declines in all parts of the Baltic Sea. The large-scale decline was $65 \%$, or an annual decline of $4.4 \%$ since 1993 . This trend is mainly reflected by the coastal counts in Poland, Finland and Sweden (Kattegat, Figure 12).
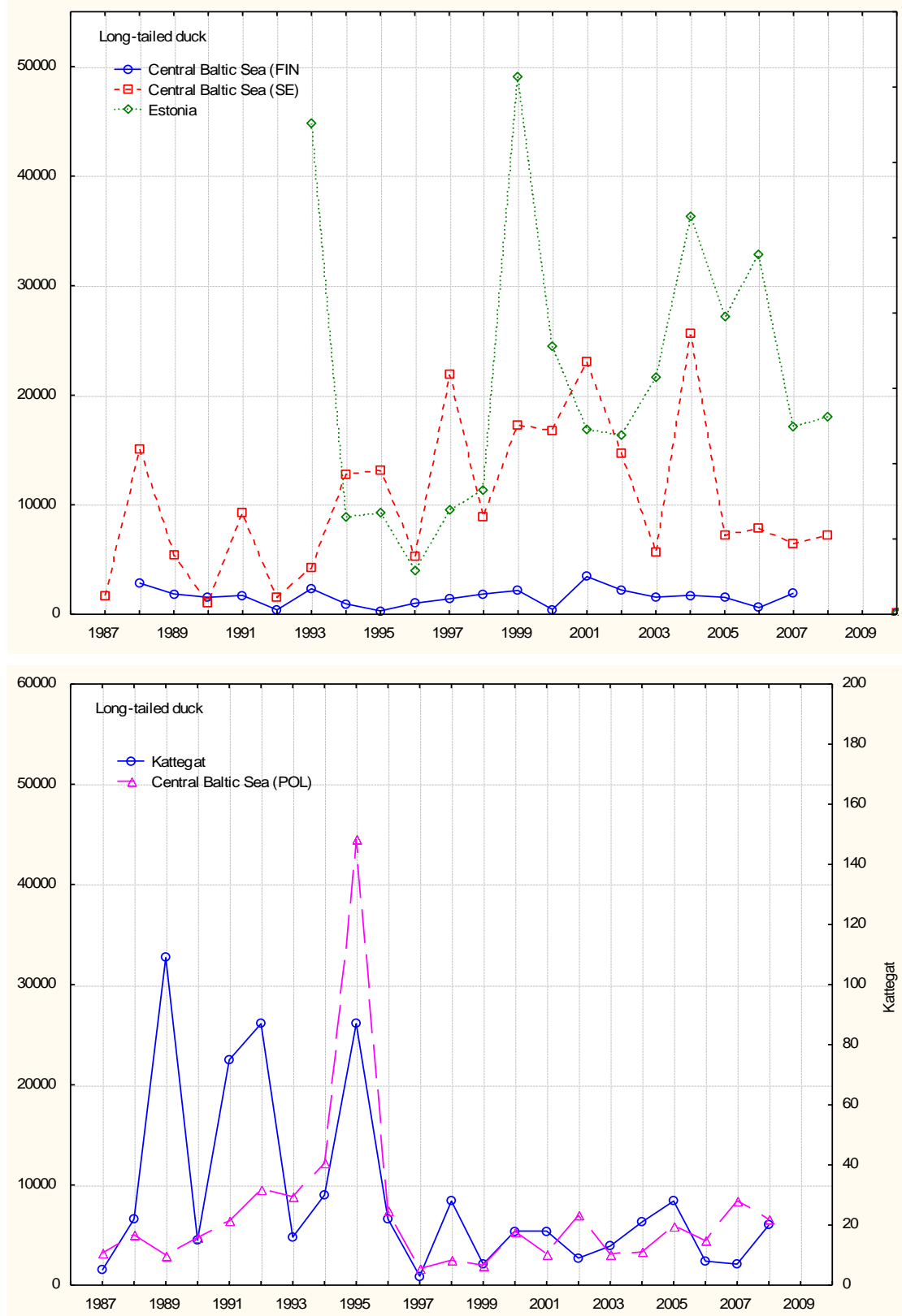

Figure 12. Trends in Long-tailed Duck numbers during winter counts 1987-2008 in selected coastal areas in the Kattegat, the Central Baltic Sea. Y-axis shows total numbers seen per region. 
Only the latter trend was significant $(\mathrm{p}<0.1$, Table 26). From the main areas trend data are only available for the Hoburgs Bank which corroborate the large-scale decline of $64 \%$ seen in this region (Figure 13).

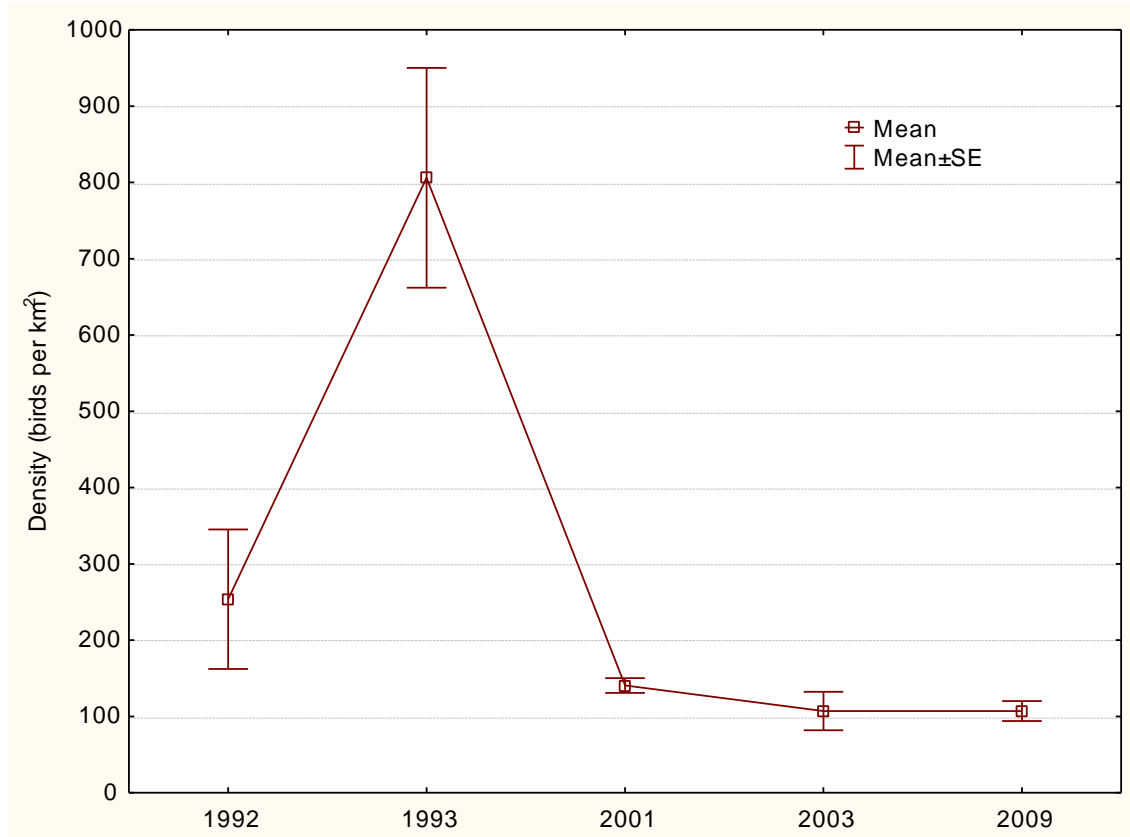

Figure 13. Trends in Long-tailed Duck numbers during winter surveys 19872008 on Hoburgs Bank. The graph shown mean densities and standard errors estimated for the surveys in 1992, 1993, 2001, 2003 and 2009. Y-axis shows total numbers seen per region.

\subsection{Common Scoter}

Although the same limitations regarding the use of coastal surveys may hold for this seaduck species the coastal counts actually reflect several of the trends indicated by the surveys. The surveys documented large declines in the main areas, and increases in the northeast and along the Swedish Kattegat coast. The trends in the coastal counts also show an increase along the Swedish Kattegat coast, in Estonia and Finland. The annual increases in the latter two areas are $12.5 \%$ and $16.1 \%$, respectively (Table 26). 

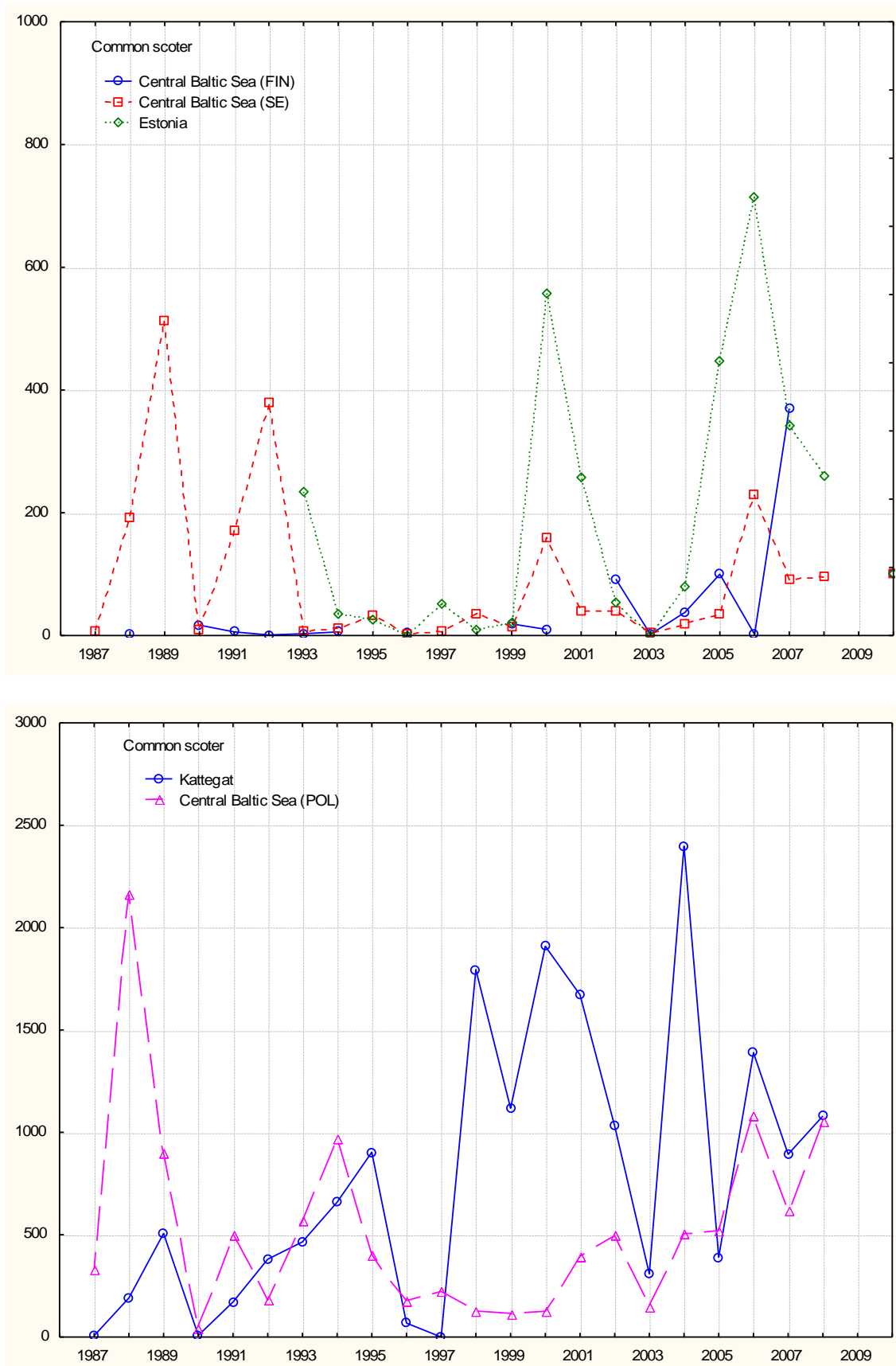

Figure 14. Trends in Common Scoter numbers during winter counts 1987-2008 in selected coastal areas in the Kattegat, the Central Baltic Sea. Y-axis shows total numbers seen per region.

\subsection{Velvet Scoter}

The coastal surveys may not reflect the true development of the wintering population, which is mainly found in three offshore areas. The surveys documented huge declines in all three main areas, from where no 
trends are available. An annual decline of $17.6 \%$ has been observed along the Swedish coast of the Central Baltic Sea. An annual increase of $17 \%$ in Finland indicates that numbers now wintering in Finnish waters may have been underestimated.
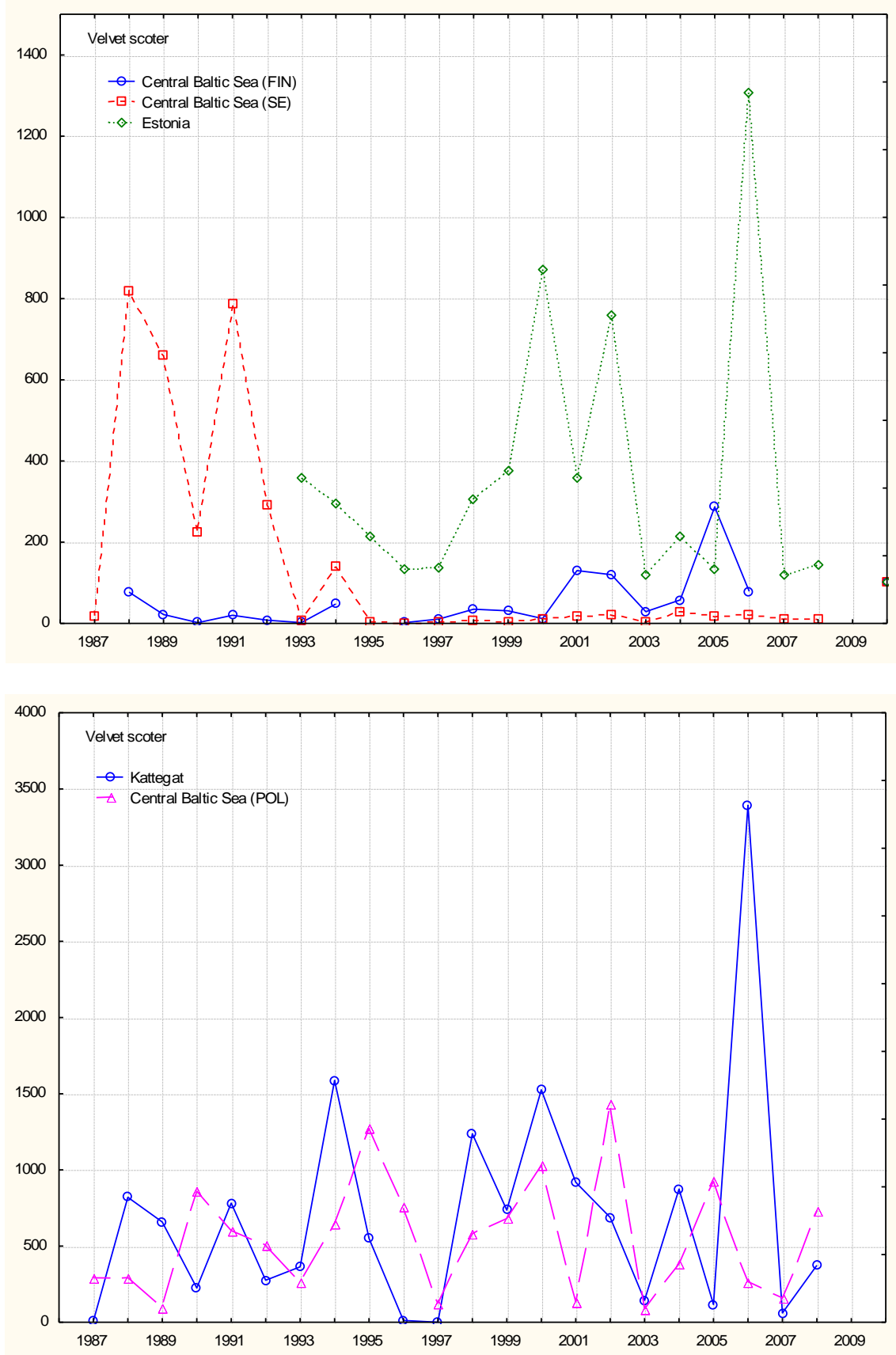

Figure 15. Trends in Velvet Scoter numbers during winter counts 1987-2008 in selected coastal areas in the Kattegat, the Central Baltic Sea. Y-axis shows total numbers seen per region. 


\subsection{Common Goldeneye}

The survey results indicated a large overall increase, most prominent in the northern parts, while decreases were observed locally in the south. This is corroborated by the coastal time series which show an annual decrease of $2.9 \%$ in the Kattegat and annual increases of 7-9\% in Estonia and Finland and 2.8\% along the Swedish coast of the Central Baltic Sea.
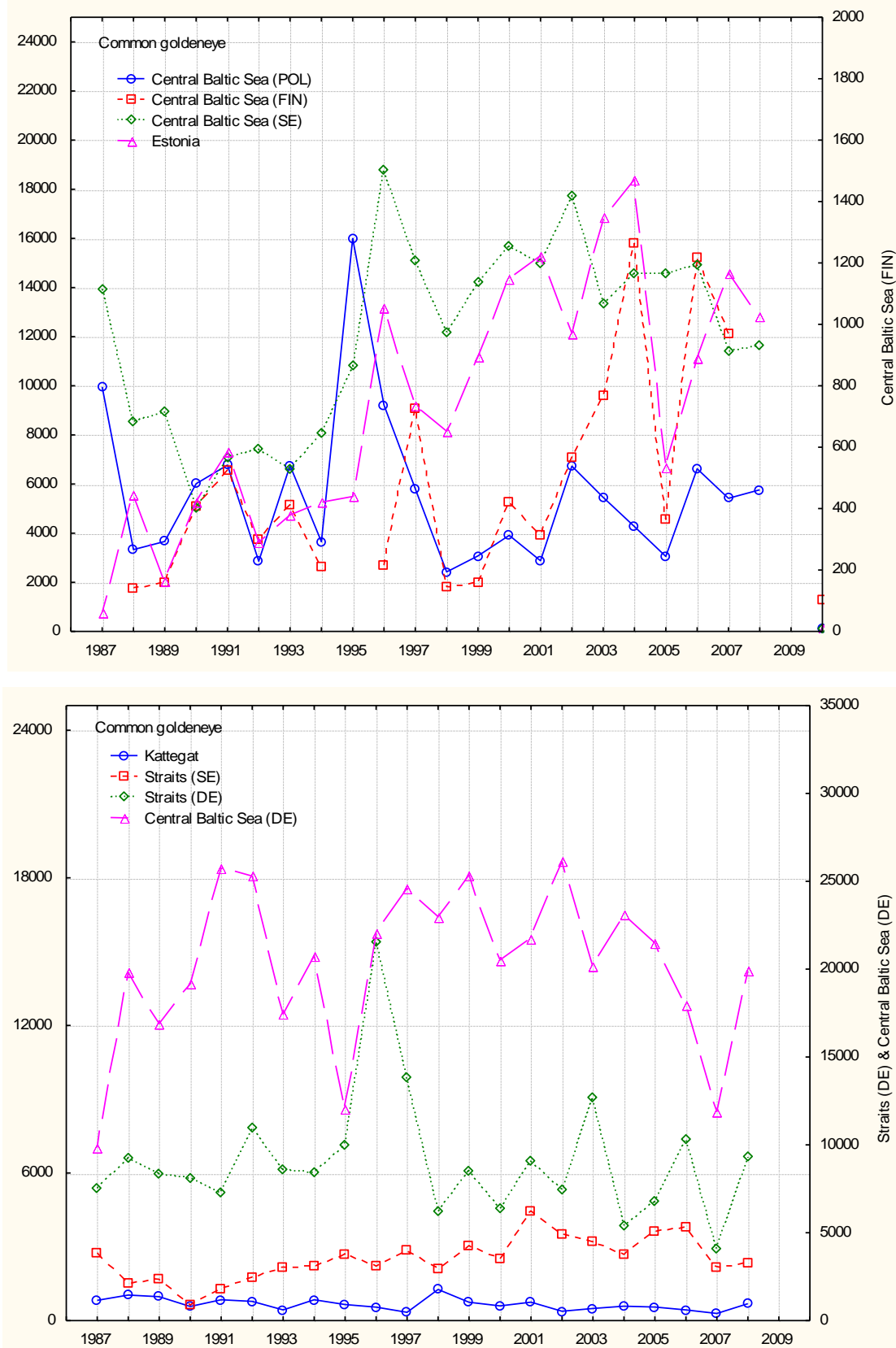

Figure 16. Trends in Common Goldeneye numbers during winter counts 19872008 in selected coastal areas in the Kattegat, the Straits, the Central Baltic Sea $Y$-axis shows total numbers seen per region. 


\subsection{Smew}

The trends in the coastal counts corroborate the survey results with respect to increases in numbers of wintering Smew along the northern mainland coast and in Sweden (Figure 17, Table 26). The trends further indicate that the numbers wintering in the lagoons of Usedom and around Rügen have increased slightly since 1988-1993. The large-scale decline of Smew in the Szczecin Lagoon is not reflected in the coastal time series.
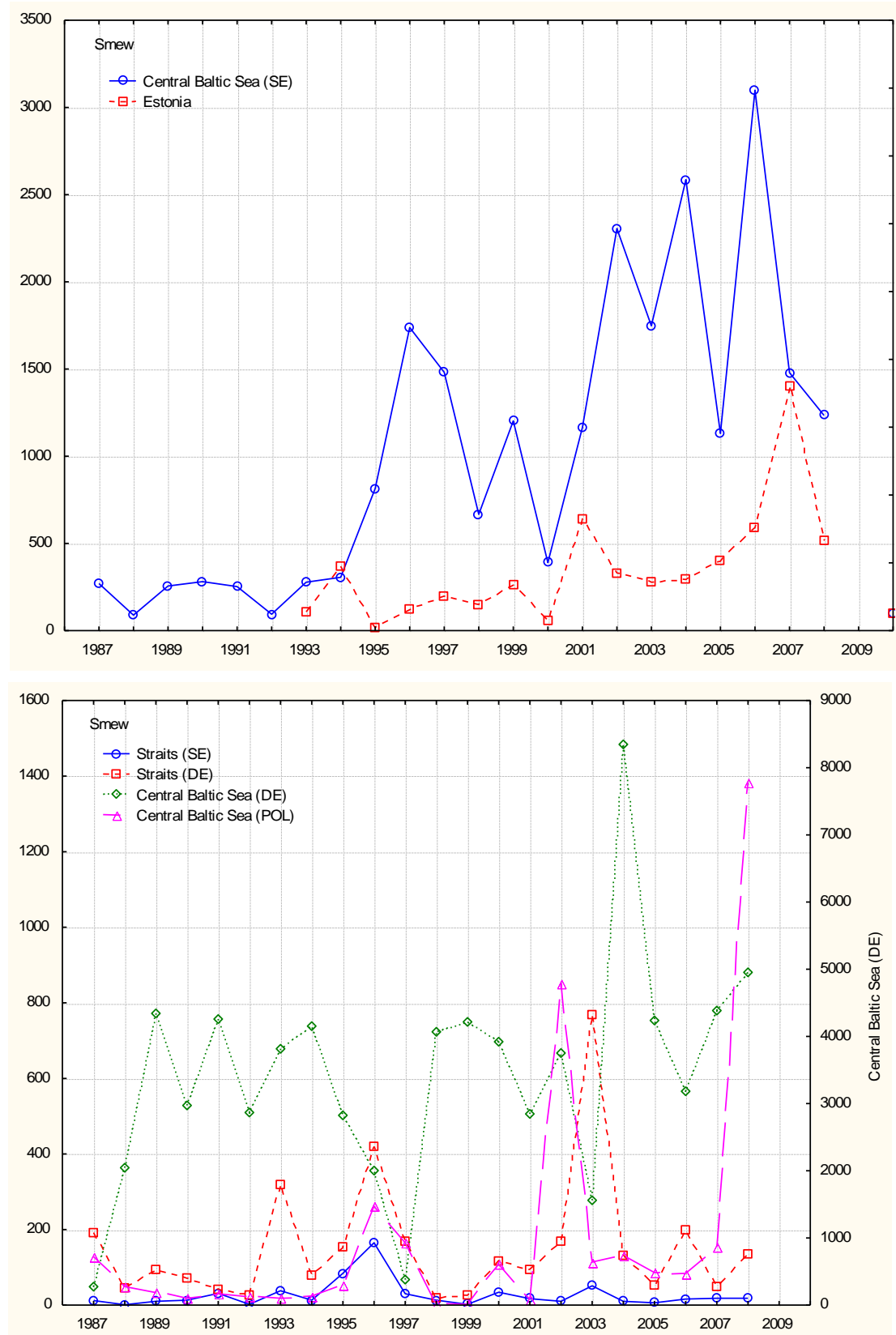

Figure 17. Trends in Smew numbers during winter counts 1987-2008 in selected coastal areas in the Kattegat, the Straits, the Central Baltic Sea. Y-axis shows total numbers seen per region. 


\subsection{Red-breasted Merganser}

The survey results indicated large-scale declines in the number of Redbreasted Mergansers, except in Swedish waters, and the trend analyses corroborates these findings exactly (Table 26 ).
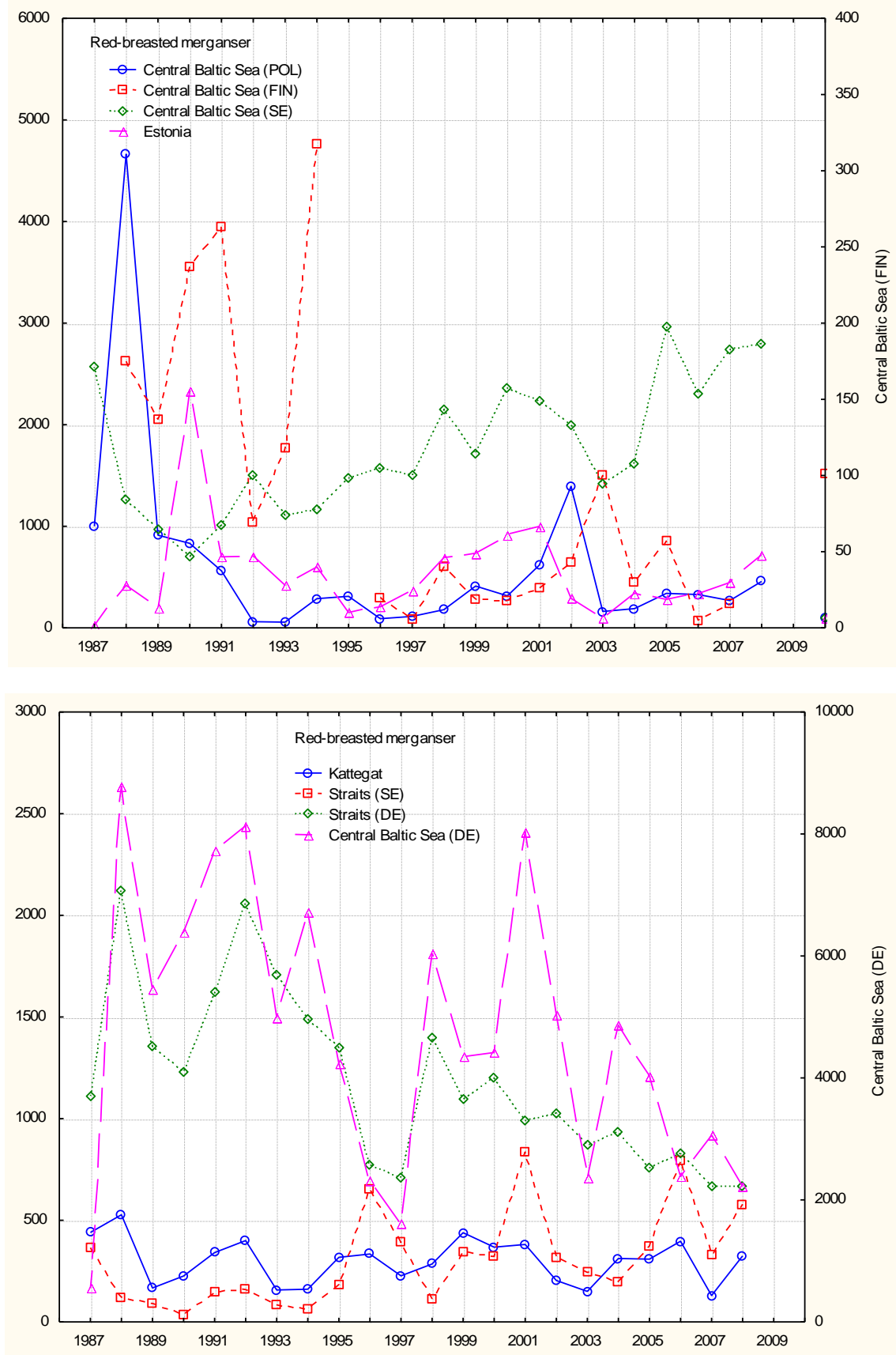

Figure 18. Trends in Red-breasted Merganser numbers during winter counts 1987-2008 in selected coastal areas in the Kattegat, the Straits, the Central Baltic Sea. Y-axis shows total numbers seen per region. 


\subsection{Goosander}

The surveys of Goosanders revealed a slight change in their winter distribution in the Baltic Sea with relatively more birds wintering in the north and northeast. The trends in the coastal counts do not reflect these changes very well. This is principally due to the fact that the coastal counts on which the trends were calculated didn't cover the large concentrations found in lagoons and archipelagoes. An additional factor is the large fluctuation between years induced by changes in the availability of ice-free lakes.
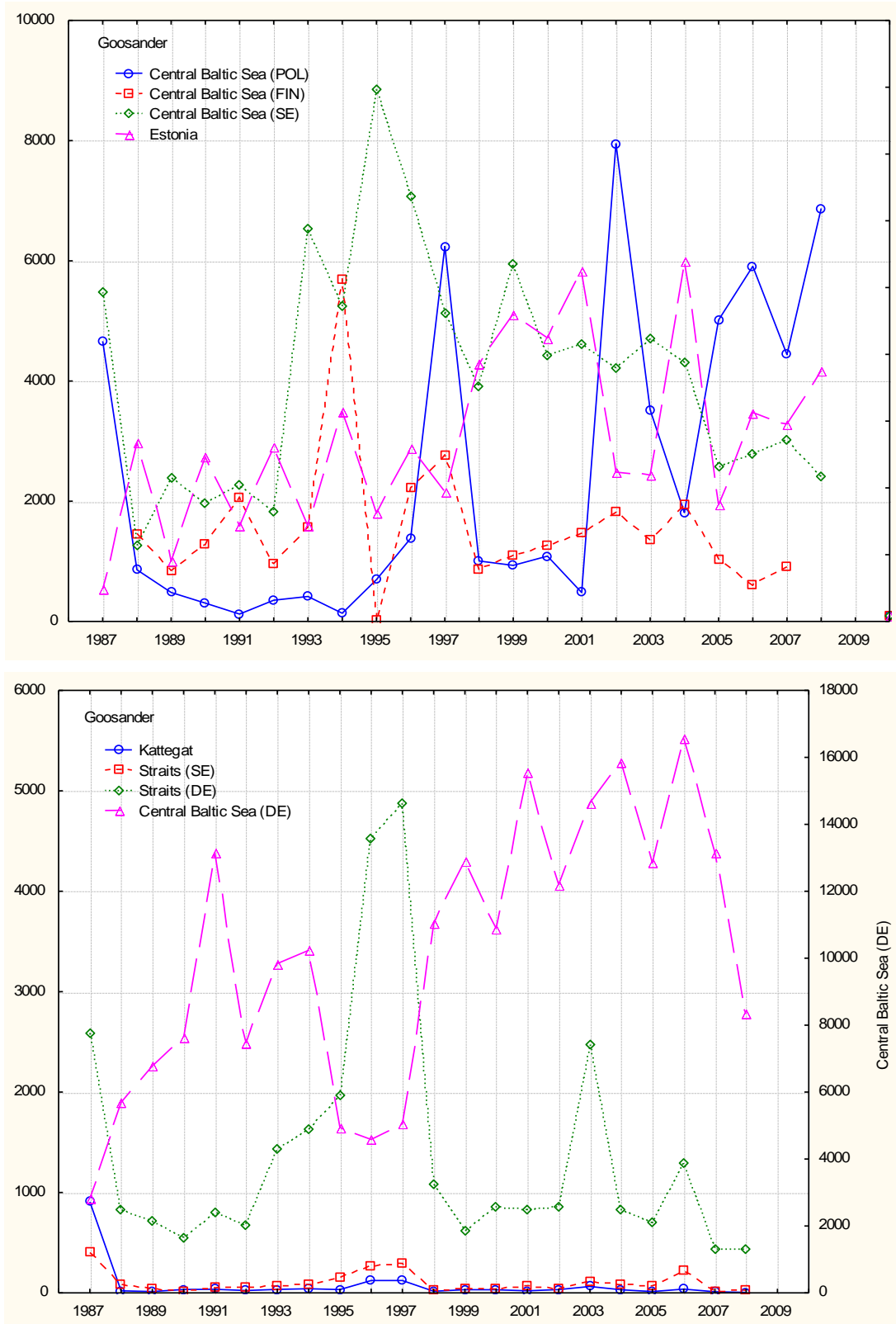

Figure 19. Trends in Goosander numbers during winter counts 1987-2008 in selected coastal areas in the Kattegat, the Straits, the Central Baltic Sea. Y-axis shows total numbers seen per region. 
The reduction in numbers in the south-east, e.g. in the Szczecin Lagoon, is not mirrored by the coastal counts (Table 26). Significant declines were recorded along the coasts of Kattegat and in Estonia, while significant increases were recorded Mecklenburg-Vorpommern and Poland (Table 26).

\subsection{Common Coot}

Compared to several other waterbird species the changes in the distribution of Common Coots wintering in the Baltic Sea displayed by the surveys are relatively complex, and hence the grouped trends in the coastal counts can only be used as general reference points to the trends of this species. Overall, the trends are either stable or positive for all regions but Schleswig-Holstein.

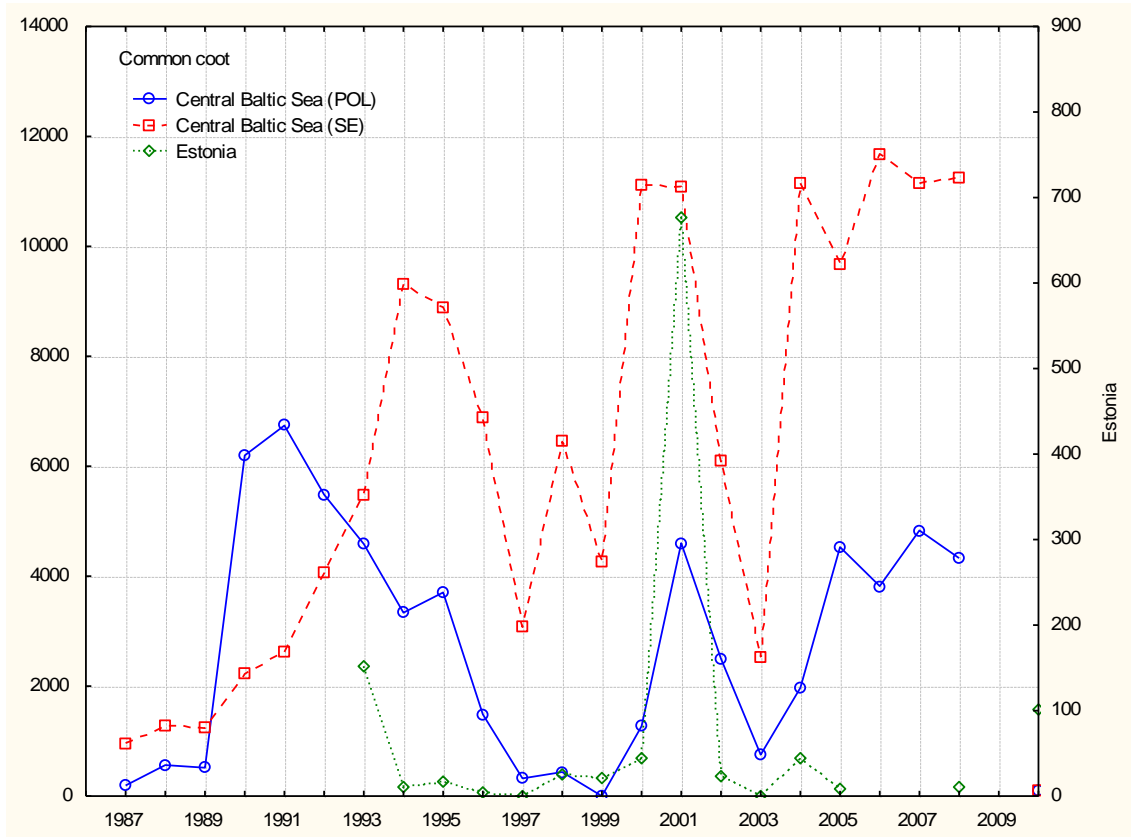




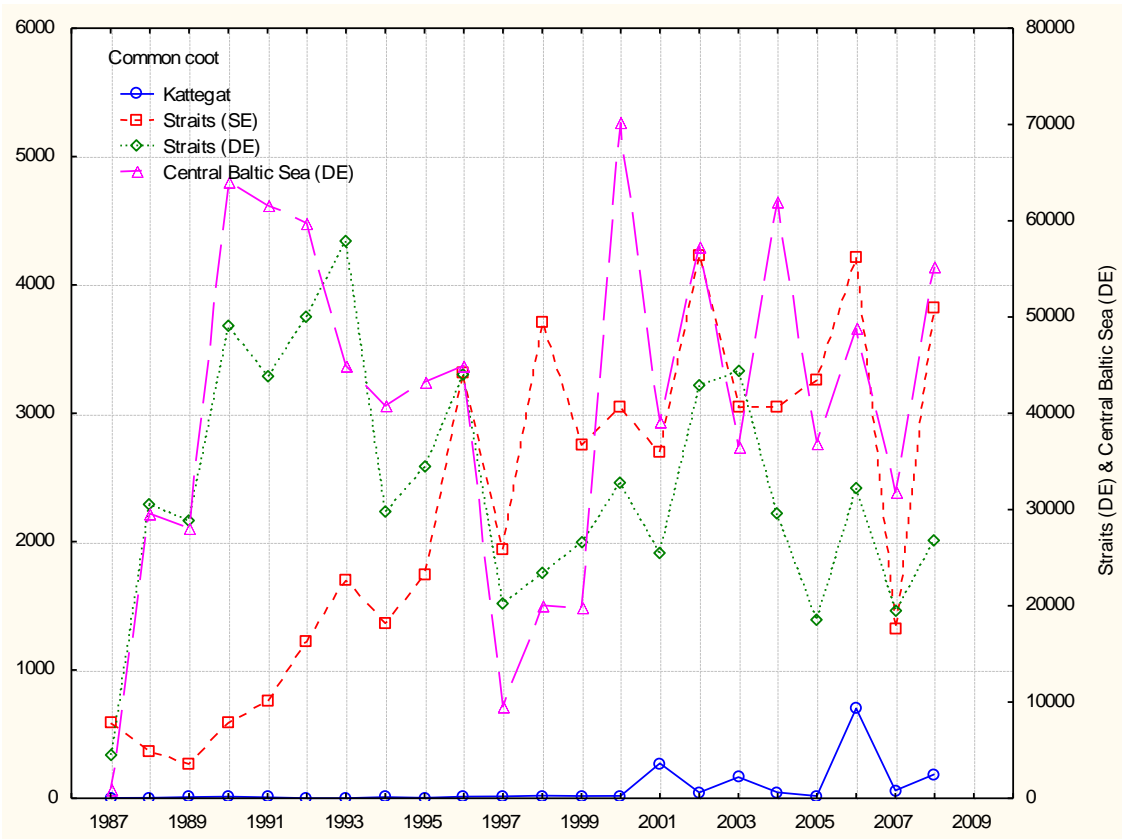

Figure 20. Trends in Common Coot numbers during winter counts 1987-2008 in selected coastal areas in the Kattegat, the Straits, the Central Baltic Sea. Y-axis shows total numbers seen per region. 
Table 26. Size and significance of population trends in selected areas/regions (displayed in Figures 1-20).

\begin{tabular}{|c|c|c|c|c|c|c|c|c|c|c|c|c|c|c|c|c|c|c|c|c|}
\hline & $\begin{array}{l}\text { Region/ } \\
\text { Species }\end{array}$ & Divers & $\begin{array}{r}\text { Great } \\
\text { Crested } \\
\text { Grebe }\end{array}$ & $\begin{array}{r}\text { Red- } \\
\text { necked } \\
\text { Grebe }\end{array}$ & $\begin{array}{r}\text { Slavonian } \\
\text { Grebe }\end{array}$ & $\begin{array}{r}\text { Cormo- } \\
\text { rant }\end{array}$ & $\begin{array}{l}\text { Mute } \\
\text { Swan }\end{array}$ & Mallard & $\begin{array}{r}\text { Common } \\
\text { Pochard }\end{array}$ & $\begin{array}{r}\text { Tufted } \\
\text { Duck }\end{array}$ & $\begin{array}{r}\text { Greater } \\
\text { Scaup }\end{array}$ & $\begin{array}{r}\text { Common } \\
\text { Eider }\end{array}$ & $\begin{array}{c}\text { Long- } \\
\text { tailed } \\
\text { Duck }\end{array}$ & $\begin{array}{l}\text { Com- } \\
\text { mon } \\
\text { Scoter }\end{array}$ & $\begin{array}{l}\text { Velvet } \\
\text { Scoter }\end{array}$ & $\begin{array}{r}\text { Common } \\
\text { Golden- } \\
\text { eye }\end{array}$ & Smew & $\begin{array}{l}\text { Goos- } \\
\text { ander }\end{array}$ & $\begin{array}{r}\text { Red- } \\
\text { breasted } \\
\text { Merganser }\end{array}$ & $\begin{array}{r}\text { Common } \\
\text { Coot }\end{array}$ \\
\hline \multirow[t]{3}{*}{ Kattegat } & Size & -1.7 & 4.5 & -0.1 & 1.1 & -34.5 & -6.46 & -83.3 & & -6.484 & 4.6 & 151.3 & -2 & 60.4 & 25.1 & -18.7 & 0 & -10.8 & 3 & 12.1 \\
\hline & Size \% & -2.6 & 12.8 & -1.4 & 7.7 & -3.2 & -3.0 & -1.1 & & -3.1 & 4.1 & 4.3 & -6.1 & 8.0 & 3.7 & -2.9 & & -13.9 & 1.0 & 16.0 \\
\hline & $\mathrm{p}$ & 0.42 & 0.01 & 0.50 & 0.03 & 0.14 & 0.03 & 0.30 & & 0.14 & 0.36 & 0.04 & 0.05 & 0.01 & 0.34 & 0.02 & 0.00 & 0.09 & 0.43 & 0.02 \\
\hline \multirow[t]{3}{*}{ Straits (SE) } & Size & & 42.8 & & & 31.2 & 65.1 & 172.7 & & 81.2 & 13.2 & 35.4 & & & & 83.7 & -0.2 & -3.3 & 19.2 & 159.4 \\
\hline & Size \% & & 14.4 & & & 5.0 & 2.7 & 2.4 & & 2.1 & 7.4 & 10.3 & & & & 3.5 & -0.7 & -3.2 & 6.4 & 7.5 \\
\hline & $\mathrm{p}$ & & 0.05 & & & 0.10 & 0.04 & 0.07 & & 0.20 & 0.01 & 0.00 & & & & 0.00 & 0.91 & 0.35 & 0.01 & 0.00 \\
\hline \multirow[t]{3}{*}{ Straits (DE) } & Size & & 72.5 & & & 149.1 & 13.7 & -294.5 & -24.7 & -359 & 160.6 & & & & & -69.5 & 3.9 & -29.6 & -47.2 & -349.1 \\
\hline & Size \% & & 2.2 & & & 7.9 & 0.7 & -2.0 & -1.1 & -1.6 & 1.1 & & & & & -0.9 & 2.3 & -2.3 & -5.9 & -1.4 \\
\hline & $\mathrm{p}$ & & 0.27 & & & 0.00 & 0.56 & 0.09 & 0.63 & 0.61 & 0.72 & & & & & 0.58 & 0.50 & 0.49 & 0.00 & 0.35 \\
\hline \multirow{3}{*}{$\begin{array}{l}\text { Central Baltic } \\
\text { Sea (DE) }\end{array}$} & Size & & 92.8 & & & 478.1 & 805.7 & -68.3 & -470 & -1040.2 & -2003.5 & & & & & 89.6 & 105.5 & 415.3 & -136.1 & 33.1 \\
\hline & Size \% & & 7.4 & & & 11.0 & 3.8 & -0.2 & -8.8 & -2.8 & -11.8 & & & & & 0.6 & 4.2 & 4.7 & -4.8 & 0.1 \\
\hline & $\mathrm{p}$ & & 0.02 & & & 0.00 & 0.04 & 0.91 & 0.11 & 0.25 & 0.09 & & & & & 0.57 & 0.06 & 0.00 & 0.08 & 0.66 \\
\hline \multirow[t]{3}{*}{ Poland } & Size & & 44.3 & & & 328.9 & 50.4 & -59.4 & 9 & 346 & 56.1 & -3.3 & -128.4 & 5.9 & 5.2 & 75.7 & 22.2 & 225.7 & -56.8 & 56 \\
\hline & Size \% & & 6.8 & & & 19.2 & 2.2 & -1.7 & 2.2 & 3.0 & 2.2 & -3.2 & -1.9 & 1.2 & 1.0 & 1.4 & 13.3 & 9.5 & -9.6 & 2.1 \\
\hline & $\mathrm{p}$ & & 0.00 & & & 0.00 & 0.27 & 0.40 & 0.81 & 0.26 & 0.01 & 0.17 & 0.67 & 0.73 & 0.70 & 0.48 & 0.04 & 0.01 & 0.08 & 0.73 \\
\hline \multirow[t]{3}{*}{ Finland } & Size & -1.1 & & & & 68.1 & 102.4 & -482.1 & & 50.1 & & -3.1 & -3.7 & 7.8 & 6.2 & 37.1 & & -31.6 & -10.4 & \\
\hline & Size \% & -5.0 & & & & 7.9 & 6.2 & -17.3 & & 6.3 & & -3.7 & -0.2 & 16.1 & 11.0 & 7.9 & & -2.1 & -11.6 & \\
\hline & $p$ & 0.32 & & & & 0.06 & 0.04 & 0.00 & & 0.42 & & 0.48 & 0.91 & 0.05 & 0.03 & 0.00 & & 0.49 & 0.00 & \\
\hline \multirow{3}{*}{$\begin{array}{l}\text { Central Baltic } \\
\text { Sea (SE) }\end{array}$} & Size & -4.1 & 38 & 0.1 & & 20.3 & 80.9 & 11 & 43.6 & 2249.6 & -87.7 & 261.7 & 311.9 & -5.3 & -24.5 & 321.9 & 99.4 & -5.2 & 66.2 & 458.2 \\
\hline & Size \% & -18.8 & 9.7 & 1.0 & & 1.0 & 2.0 & 0.1 & 3.1 & 3.9 & -5.3 & 6.1 & 3.1 & -5.6 & -17.6 & 2.8 & 10.0 & -0.1 & 3.9 & 7.4 \\
\hline & $\mathrm{p}$ & 0.01 & 0.00 & 0.76 & & 0.48 & 0.01 & 0.95 & 0.05 & 0.00 & 0.10 & 0.00 & 0.20 & 0.25 & 0.00 & 0.01 & 0.00 & 0.94 & 0.00 & 0.00 \\
\hline \multirow[t]{3}{*}{ Estonia } & Size & & 8.6 & 0.5 & & 3.7 & 267.6 & -496.7 & 0.2 & 59.9 & 30 & -3.6 & 453 & 23.4 & 9.9 & 600.4 & 44.8 & -120.1 & -9.8 & 31 \\
\hline & Size \% & & 17.7 & 5.6 & & 4.1 & 5.7 & -4.3 & 2.0 & 18.9 & 14.1 & -7.2 & 2.2 & 12.5 & 2.8 & 6.8 & 13.1 & -4.1 & -1.9 & 17.4 \\
\hline & $\mathrm{p}$ & & 0.01 & 0.01 & & 0.19 & 0.00 & 0.00 & 0.40 & 0.02 & 0.20 & 0.18 & 0.55 & 0.05 & 0.60 & 0.00 & 0.01 & 0.01 & 0.56 & 0.09 \\
\hline
\end{tabular}

Size is the mean yearly change in numbers, Size\% is the mean yearly change in percentage and $p$ is the $p$ value of the trend (linear regression). Significant trends ( $p<0.1$ ) are marked in italic. 



\section{Conservation status of wintering waterbirds in the Baltic Sea}

In table 27 an overview is given of the population estimates for all wintering waterbirds covered by this status report. In addition to listing the estimated totals for the surveys during the two periods 2007-2009 and 1992-1993 the table also gives proportions of the total bio-geographic populations wintering in the Baltic Sea during these two periods. Of the 20 species of waterbirds covered the total population size has decreased between the two periods for 11 species; 7 of which have declined seriously by more than $30 \%$ in 16 years.

The estimated total number of wintering waterbirds for the period 2007-2009 was 4.41 millions compared to 7.44 million during 19921993; a reduction equivalent to $41 \%$. The sum of proportions of the biogeographic populations may be used as a proxy for total conservation status. A comparison between the two periods shows a reduction in total conservation status of $30 \%$. It should be noted, however, that the size of the relevant bio-geographic populations has not been updated since 1996.

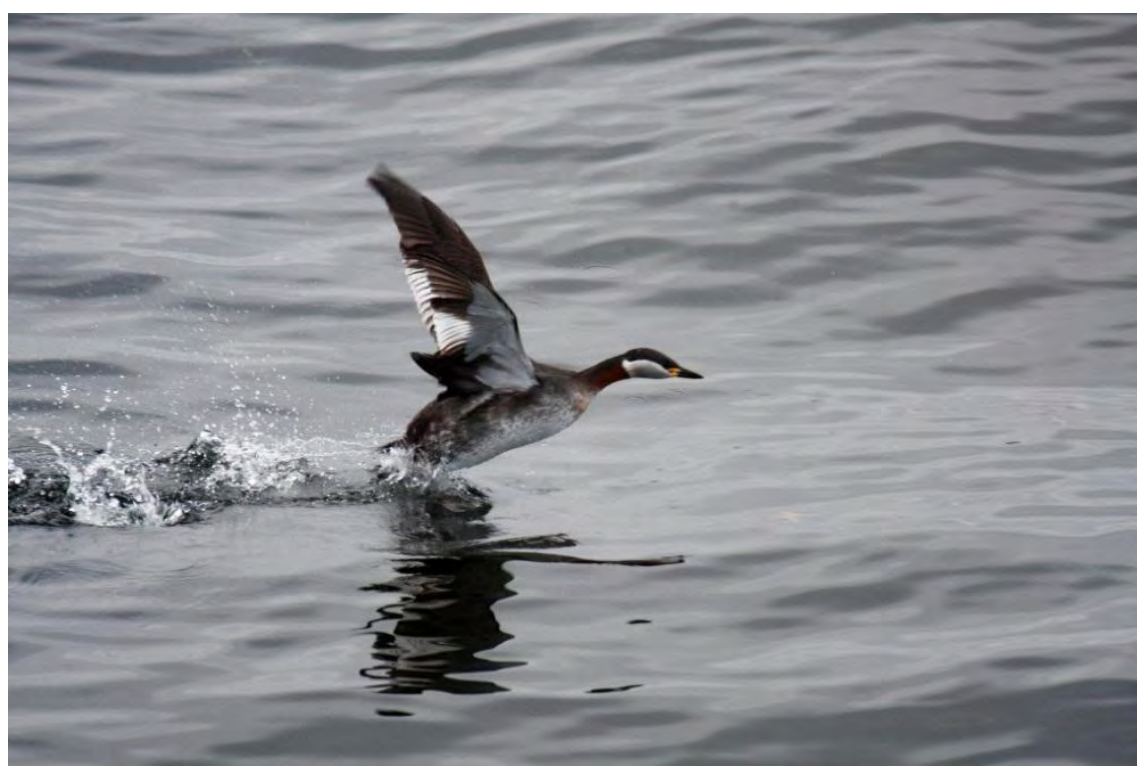


Table 27. Overview of population estimates. The table shows the total wintering populations estimated for the period 2007-2009 and 1992-1993, the percentage change between the two periods, the size of the bio-geographic population as well as the proportion of the bio-geographic population wintering in the Baltic Sea 2007-2009 and 1992-1993.

\begin{tabular}{lrrrrrr}
\hline Species & $\begin{array}{r}\text { Baltic total } \\
\mathbf{1 9 9 3}\end{array}$ & $\begin{array}{r}\text { Baltic total } \\
\mathbf{2 0 0 9}\end{array}$ & $\begin{array}{r}\text { \% } \\
\text { change }\end{array}$ & $\begin{array}{r}\text { Bio- } \\
\text { geographic } \\
\text { population }\end{array}$ & $\begin{array}{r}\text { \%993 } \\
\mathbf{2 0 0 9}\end{array}$ \\
\hline Red-throated/Black-throated Diver & & & & & \\
Great Crested Grebe & 56,500 & 8,575 & -84.8 & 400,000 & 14.1 & 2.1 \\
Red-necked Grebe & 11,325 & 8,300 & -26.7 & 290,000 & 3.9 & 2.9 \\
Slavonian Grebe & 5,500 & 770 & -86.0 & 42,000 & 13.1 & 1.8 \\
Great Cormorant & 1,800 & 2,890 & 60.6 & 18,800 & 9.6 & 15.4 \\
Mute Swan & 19,400 & 54,000 & 178.4 & 500,000 & 3.9 & 10.8 \\
Mallard & 108,000 & 132,000 & 22.2 & 292,000 & 37.0 & 45.2 \\
Common Pochard & 227,000 & 254,000 & 11.9 & $4,500,000$ & 4.4 & 5.6 \\
Tufted Duck & 31,000 & 30,450 & -1.8 & 350,000 & 8.9 & 8.7 \\
Greater Scaup & 319,000 & 476,000 & 49.2 & $1,200,000$ & 26.6 & 39.7 \\
Common Eider & 146,000 & 127,000 & -13.0 & 310,000 & 47.1 & 41.0 \\
Steller's Eider & $1,048,000$ & 515,000 & -50.9 & $1,820,000$ & 35.0 & 28.3 \\
Long-tailed Duck & 6,845 & 2,300 & -66.4 & 10,000 & 45.6 & 23.0 \\
Common Scoter & $4,272,000$ & $1,486,000$ & -65.2 & $4,700,000$ & 90.9 & 31.6 \\
Velvet Scoter & 783,000 & 412,000 & -47.4 & $1,600,000$ & 48.9 & 25.8 \\
Common Goldeneye & 933,000 & 373,000 & -60.0 & $1,000,000$ & 93.3 & 37.3 \\
Smew & 123,000 & 174,000 & 41.5 & $1,000,000$ & 12.3 & 17.4 \\
Red-breasted Merganser & 17,000 & 12,600 & -25.9 & 40,000 & 42.5 & 31.5 \\
Goosander & 44,000 & 25,700 & -41.6 & 170,000 & 25.9 & 15.1 \\
Common Coot & 73,000 & 66,000 & -9.6 & 266,000 & 27.4 & 24.8 \\
& 212,000 & 248,000 & 17.0 & $1,750,000$ & 12.1 & 14.2 \\
\hline
\end{tabular}




\section{Interactions between human activities and waterbirds in the Baltic Sea}

As reported in Chapter 6 and 7 large-scale declines (> 30\%) are documented for 7 out of 20 species of waterbirds since 1993. Moderate declines are documented for three species, stable populations are documented for two species, moderate increases for three species and largescale increases for four species. Thus, the overall picture which has emerged from SOWBAS is that the majority of the wintering waterbird species currently show decreasing trends. A range of potential pressures behind these declines has been suggested, including climate change, oil pollution and incidental bycatch (Rönkä et al. 2005, Skov 2007, Lehikoinen et al. 2008, Nilsson 2008, Hario et al. 2009a, Zydelis et al. 2009). In the following, the available information on relevant regional pressures in relation to wintering waterbirds in the Baltic Sea will be reviewed. The reviews are presented pressure by pressure and focus on recent (after 2000) data and references, and include trends for selected pressures to ease comparisons with the trends in waterbird numbers. At the end of the chapter results of correlations between trends in selected pressures and numbers of wintering waterbirds are presented, and key pressures are identified for the main ecological guilds present in the wintering waterbird community.

While the pressure-specific reviews provide an insight into the linkages between recent trends in relevant environmental conditions in the Baltic Sea and trends in numbers of wintering waterbirds it should be stressed that the multiple interactions between pressures could not be dealt with within the framework of SOWBAS. It is expected that the causes behind the declines in wintering waterbird community are complex and often poorly investigated. Hopefully, the reviews can provide the basis for focused research and studies at species level, both in relation to the reproductive succes of species and populations and studies on feeding ecology and energetics of the species concerned. As the reviews focus on the environmental conditions in the Baltic Sea it should be stressed that integration of knowledge about the conditions in the breeding areas is essential to tease out the relative importance of the different pressures in the Baltic Sea. 


\subsection{Climate change}

Climate change is predicted to become a major driver of large-scale changes in marine ecosystems, including the Baltic Sea, in the immediate future. Already today, trends in the marine ecosystem of the Baltic Sea can be attributed to the long-term increase in water temperature (BACC 2008). Climate change may influence waterbirds wintering in the Baltic Sea by introducing changes in:

- Distribution range

- Total, regional and local abundance

- Traits and habitat affinities

- Migratory routes and stopover sites

- Timing of spring and autumn migration

- Migratory tendency within species/populations

In Figure 21 the trends in surface and mid water sea temperatures are depicted for four regions of the Baltic Sea during the period from 1987 to 2008. The graphs indicate increasing trends in mid water temperatures in the Kattegat and the Straits over the period, while trends in the Baltic Proper and the Gulf of Riga are less obvious. In addition, no trends in surface temperatures can be observed.

The observed trends in wintering waterbirds have only indicated slight range changes or range margin shifts. However, it can not be ruled out, that if undertaken surveys in the northern-most parts of the Baltic Sea (Bothnian Bay, Bothnian Sea, Inner Gulf of Finland) might have revealed northward shifts in the wintering ranges of some species. Both extension of range and range margin shift are expected to require a surplus of recruits in species where breeders show high site fidelity (Møller et al. 2004, Crick 2004). In the earlier warming period (in Fennoscandia in 1870-1940) many range shifts in birds were observed, both of the northern and the southern border (Lehikoinen \& Skov 2008).

Rather than changes in wintering ranges of waterbirds this report has documented changes in the distribution for many species in the Baltic Sea. Generally a northward shift in the distribution has been observed between 1988-1993 and 2007-2009. Obviously, these changes have had consequences for both regional and local densities, as well as for the habitat affinities of the species concerned. Changes in the distribution may be coupled to or at least related to changes in abundance. The understanding of the reasons and linkages between long term changes in abundance of waterbirds and climate changes is still very limited, and limited documentation of such changes exist. In Table 28 an overview of the waterbird species showing a northward shift in their winter range in the Baltic Sea is provided along with information on documented overall change in abundance. 

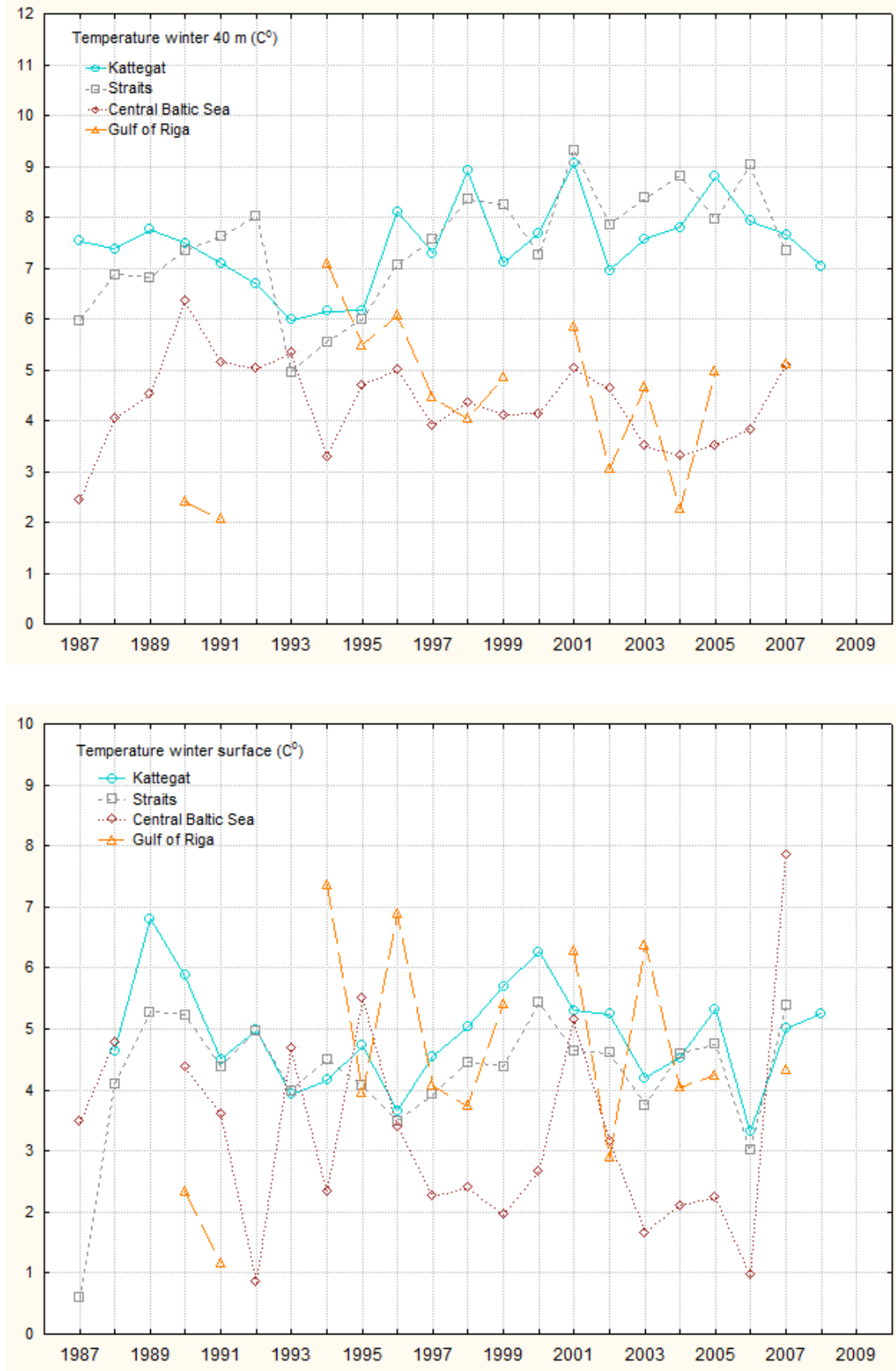

Figure 21. Trends in average surface and mid water (40 $\mathrm{m}$ depth) temperature (degrees Celcius) recorded during winter 1987-2008 in the Kattegat, the Straits, the Central Baltic Sea and Gulf of Riga (Source: ICES Oceanographic Database/HELCOM). 
Table 28. Overview of distribution changes in wintering waterbirds in the Baltic Sea between 1988-1993 and 2007-2009.

\begin{tabular}{lrr}
\hline Species & Northward shift & Population change \\
\hline Divers & + & - - \\
Great Crested Grebe & & - \\
Red-necked Grebe & + & +- \\
Slavonian Grebe & & ++ \\
Great Cormorant & + & + \\
Mute Swan & ++ & + \\
Mallard & + & ++ \\
Common Pochard & & - \\
Tufted Duck & + & - \\
Greater Scaup & + & - \\
Common Eider & & - \\
Long-tailed Duck & ++ & + \\
Common Scoter & + & - \\
Velvet Scoter & + & - \\
Sommon Goldeneye & & - \\
Goosander & & + \\
Red-breasted Merganser & + \\
Common Coot & & + \\
\hline
\end{tabular}

The degree of distribution change towards the north is indicated by a single (moderate change) or two (major change) plus signs. Changes in in total winter abundance of the species in the Baltic Sea are also indicated.

Table 28 outlines major northward shifts in 2 waterbird species, moderate shift in 7 other species and no obvious shifts in ten species. Although the species showing a marked shift in their distribution towards the north display a wide range of ecotypes, species with a diet composed to a large degree of benthic invertebrates and an inshore distribution dominate the list. On the other hand, no obvious shifts are seen in carnivorous species with an offshore distribution or in herbivorous species. The possibility exists that the increase in the proportion of coastal carnivorous in the northern Baltic as compared to 1988-1993 has been caused by differences in the availability of freshwater habitats frequently used by these species. However, as elucidated by the trend analyses the two coastal species which displayed northward shifts did not only change relative proportions between northern and southern areas of the Baltic, but the total numbers recorded also increased in the northern areas over the period, so this effect is likely to be slight. For the Common Goldeneye the northward shift is further elucidated by the appreciable numbers in the coastal areas of Bothnian Sea (normally ice-covered), and higher than normal proportion wintering inland (L. Nilsson pers. comm.).

As several other potentially important pressures may impact the abundance of wintering waterbirds negatively climate change alone is unlikely to be the only cause for these population developments. In fact, the northward shift in distribution may have provided some species with more optimal time windows as the distance between breeding and wintering areas reduces, and the length of suitable breeding period may increase. It has been generally expected, that the length of suitable breeding period increases, but this need not necessarily be the case. Interactions between temperature and precipitation may lead to impacts 
on food availability, which may be more important than the expected longer breeding periods (Lehikoinen \& Skov 2008).

Monitoring of breeding colonies in the principal recruitment areas for waterbirds wintering in the Baltic Sea in western Russia has only been carried out to a limited degree. As a consequence, hardly any studies have been made attempting to link trends to climate changes. Direct influences on breeding waterbird populations are generally of limited significance as compared to indirect influences. The direct influences on breeding waterbird populations include reduced available food supplies due to rising sea levels, increased mortality of chicks in low-lying colonies due to rising sea levels, reduced development of the embryo due to low temperatures, abnormal development or death of the embryo due to excessive exposure to high temperatures and increased chick mortality due to overheating and dehydration during periods of warmer climate. The first of these influences impact on the survival rate, while the following influences impact on the bird's breeding success. Rising sea states in coastal areas may reduce the available food supplies for benthic-feeding waterbirds like swans and geese, by decreasing the area of shallow water, where they are able to reach the bottom vegetation from the surface.

Direct effects of global warming processes are much more likely to affect migrating and wintering birds in the Baltic, as reflected by this study. Extreme winter temperatures have long been documented to influence waterbird mortality in the Baltic Sea, and winter conditions in the Baltic Basin are known to determine the range of several species (Nilsson 1972). Although the migratory and wintering bird fauna of the Baltic Sea represents a wide range of groups and ecotypes the large populations of wintering waterbirds are probably the most susceptible component of the Baltic bird fauna to changes in winter conditions. Documented trends in the winter distribution of wintering waterbirds suggest a close relationship between waterbird winter populations and winter climate (ICES 2003, HELCOM Habitat 2004). The shift of the winter distribution of several waterbird species in the Baltic currently experienced will affect the stocks of the prime food resources. As the major part of the wintering fauna experiencing a northward shift is composed of coastal benthic carnivores the stocks of benthic invertebrates in coastal areas of the northern Baltic may have been altered.

The Eurasian tundra environment has been identified as one of the most susceptible regions to global warming, and as potentially subject of significant environmental alterations which may induce large-scale declines in populations of several species of waterbirds (ICIA 2004). However, this potential has not been confirmed by modeling work or links to trends in numbers of migrating and wintering waterbirds. As the major waterbird species wintering in the Baltic are recruited from the breeding grounds of the Siberian Arctic, sub-Arctic and tundra regions the observed changes in numbers of wintering waterbirds in the Baltic may be a direct or indirect effect of climate changes in the breeding areas in 
northern Fennoscandia and Russia. Indeed, recent monitoring of the Arctic migration in Estonia has revealed ubiquitous low proportions of juveniles among Arctic and tundra species of waterbirds (Ellermaa et al. 2009). The proportions of juvenile birds were about $1.0 \%$ for Common Scoter, 3\% for Long-tailed Duck, 5.5\% for Brent Goose, 6.0\% for Velvet Scoter, $8.5 \%$ for Red-throated Diver and $16.0 \%$ for Black-throated Diver. Species with a more southern range had reproduced more efficiently (Ellermaa et al. 2009). The reproduction success of arctic ducks and geese has been known to fluctuate in three-year cycles. Monitoring of the lemming cycles in Arctic Russia indicate that the short-term cycles in lemming abundance have ceased since 1995 (Hario et al. 2009a). Thus, it is not unlikely that the current breeding failures may implicate a longterm climate-induced alteration of the conditions in the breeding areas.

Although the recent changes in the distribution of wintering waterbirds in the Baltic Sea seem to be driven by decennial climate changes the long-term changes of the Baltic waterbird populations are very hard to predict. The relationship between the warming of the winter climate and the tendency for more waterbirds wintering in the northern parts act as a good example of the uncertainties regarding future waterbird scenarios (ICES 2003, HELCOM Habitat 2004). Although it seems likely that more waterbirds will concentrate in the north with the intensification of the rate of a warmer winter climate, the variations in the tendency for a northward shift in the winter distribution shows that the prediction may depend on the availability of a surplus of food. The limited degree of northward shifts in the distribution of wintering seaducks feeding in offshore areas is an indication of limitation in the available supply of food in these habitats in the northern Baltic. There is little doubt that the ubiquituous reproductive failures in waterbirds breeding in the Arctic tundra has played an important role in the declines of species like Red-throated and Black-throated Diver and Long-tailed Duck which have their core breeding areas in the tundra.

\subsection{Meso-scale oceanographic oscillations}

Coupled to climatic effects are anomalous oceanographic conditions that change the distribution and abundance of prey, especially fish, to seabirds (Harris \& Wanless 1996, Piatt \& Pelt 1997). Changes in the availability of benthic prey for waterbirds as a result of anomalous oceanographic conditions have not been found in the Baltic Sea or neighboring waters. Prey alterations as a result of climatic variability constitute a well-known factor controlling the breeding success of seabirds outside the Baltic Sea, as in the case of Capelin in Newfoundland and the Barents Sea (Nakashima 1996, Regehr \& Rodway 1999), Herring in Northern Norway (AnkerNielssen 1992, Anker-Nielssen \& Aarvak 2002) and Sandeel in the west- 
ern North Sea (Rindorf 2000). The same prey alterations that affect breeding success may also affect the survival rate of adult birds. Mass mortality as a result of potentially climate-induced large-scale fluctuations of prey has been reported in piscivorous seabirds feeding on schooling fish in the Barents Sea (Barrett \& Krasnov 1996), the Bering Sea (Baduini et al. 2001) and the North Sea (Blake 1984), but have yet not been observed for the Baltic Sea. Trends in surface and mid-water salinity in the Baltic Sea show influences from the cold winter in 1987 in southern parts (lower salinities due to ice conditions) and from the large-scale intrusion of high-saline water masses in at depth in 1993 (Figure 22).
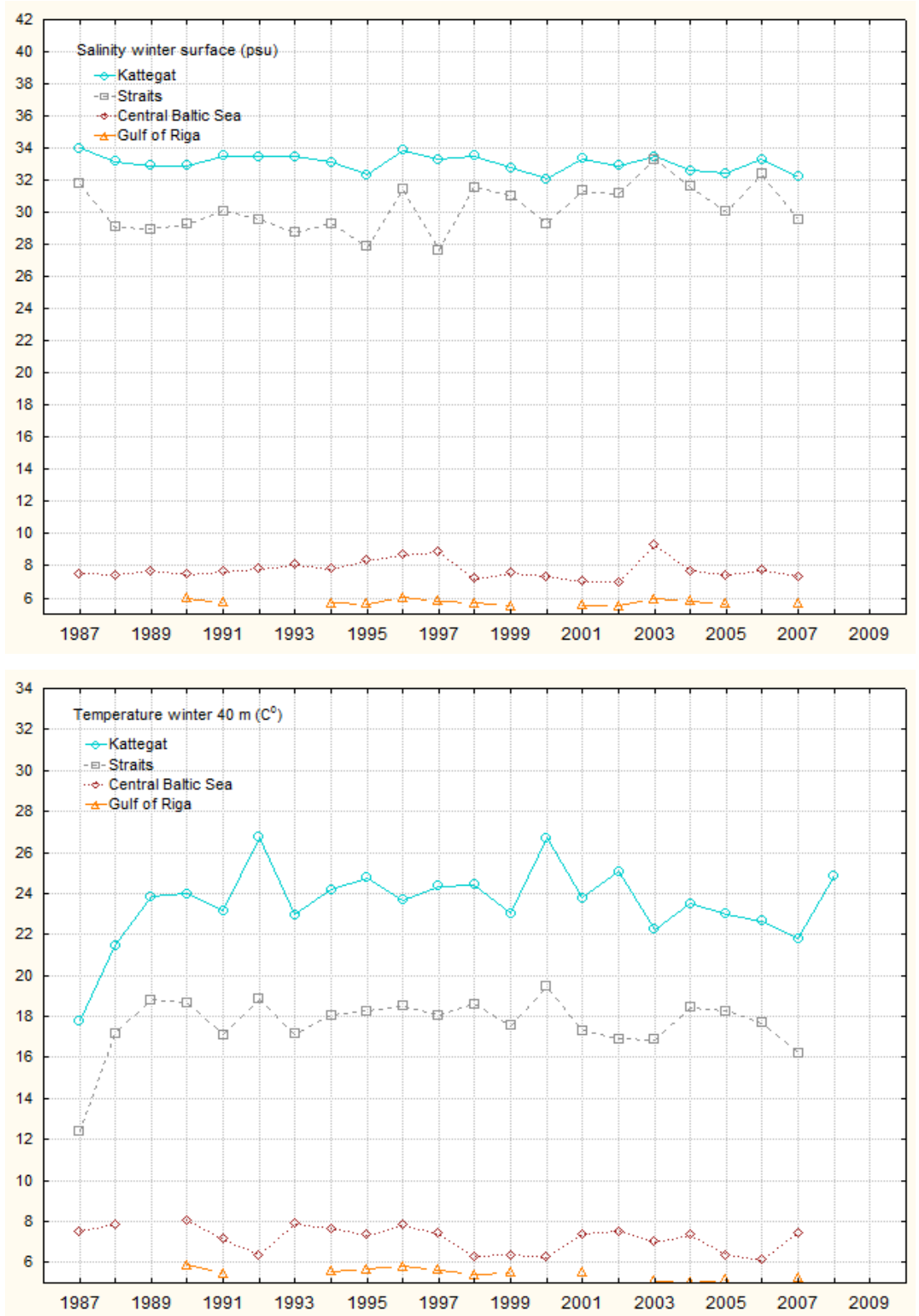

Figure 22. Trends in average surface and mid water ( $40 \mathrm{~m}$ depth) salinity (parts per thousand) recorded during winter 1987-2008 in the Kattegat, the Straits, the Central Baltic Sea and Gulf of Riga (Source: ICES Oceanographic Database/HELCOM). 


\subsection{Eutrophication}

For this review data and time series were retrieved from the recent assessment of the status of eutrophication in the Baltic Sea (HELCOM 2009), which analysed time series of nutrient concentrations in surface $(0-10 \mathrm{~m})$ and bottom waters $(>100 \mathrm{~m})$ to derive both winter (December-March) and annual (January-December) means using the statistical approach from Carstensen et al. (2006). In this report, winter means of inorganic nutrients in the surface layer of coastal and open waters are shown, as they have been found to relate most directly to the potential benthic carrying capacity. Additional time series plots are presented in HELCOM (2009).

In the Bothnian Bay and Sea both total nitrate and phosphorous concentrations (TN and TP) and dissolved inorganic nitrogen and phosphorous (DIN and DIP) in the coastal zone as well as in the open sea have shown increases from the early 1970s to the mid-1980s, with a stabilization or small decrease since then. Lower DIN levels were recorded in the open sea, while lower DIP levels were recorded in the coastal zone. Nitrogen levels in the open Bothnian Sea were only moderately correlated to local loads, while in the coastal zone they were positively, but not significantly, correlated with loads from land. In the Gulf of Finland both TN and DIN concentrations increased by almost $10 \mu \mathrm{mol} l-1$ from 1970 to the mid-1980s, followed by a down-up trend. TP concentrations were low in the 1970s, jumping to higher levels in the 1980s, followed by a decreasing trend and then increasing since 1990. DIP concentrations similarly reached a low around 1990, rising to higher values most recently.

Data on concentrations of nutrients in the Gulf of Riga are more limited as compared to the other regions. TN concentrations in both open and coastal waters have declined by $20-40 \%$ since the mid-1980s, attaining levels presumably present in the early 1970s. DIN concentrations have similarly declined since the mid-1980s in the open sea, but the tendency is not clear for coastal waters owing to a lack of data. Recent $\mathrm{N}$ levels in coastal waters are almost twice as high as levels in the open sea, indicating strong $\mathrm{N}$ gradients towards land. This is also supported by the fact that $\mathrm{N}$ levels in both the coastal zone and open sea were strongly related to $\mathrm{N}$ loads from land. TP concentrations gradually increased from the 1970s up to 1990 and then rapidly declined to almost half the maximum levels for both coastal and open waters. DIP levels also increased until around 1990 and then declined by almost $50 \%$, most pronounced in the coastal zone.

In the Baltic Proper nitrogen fixation seem to have affected the annual TN trends in the open sea. The winter DIN concentrations are more reliable and show and almost 100\% increase from 1970 to the mid 1980s and then a steady decline back to around $3 \mu \mathrm{mol} l-1$. The uplift of the halocline after the major saltwater inflows in 1993 and 2003 result- 
ed in a mixing of waters containing low DIN concentrations through the halocline (Nausch et al. 2003). In the coastal zone, the trends of DIN and TN were more comparable with increasing trends up to the mid-1980s, followed by declines. Significant correlations were obtained between N loads from land and $\mathrm{N}$ levels in the coastal zone. TP and DIP concentrations in the open sea of the Baltic Proper steadily increased from 1970 up to 1990 , followed by a drop in the early 1990s, and then increased again recently. These trends correspond to the dynamics of the deep water renewal in the Baltic Proper (Conley et al. 2002). The major inflows to the Baltic Proper in 1993 and 2003 caused a halocline uplift, increasing the potential for entraining large pools of DIP into the surface layer. DIP and TP concentrations in the coastal zone were considerably higher than the levels in the open sea in the 1970s and 1980s, but they have been more comparable with levels in open waters in the past two decades with regard to both magnitude and trends. This suggests that $P$ levels before 1990 may have been affected by land-based loads, whereas more recent $\mathrm{P}$ levels appear linked to the dynamics of the open sea.

In the Straits TN and DIN concentrations in the open sea increased from the early 1970s to the mid-1980s. Action plans in the region to reduce nutrient loads (Carstensen et al. 2006) have contributed to reduce TN levels further in most recent years to levels comparable to those in the 1970 s. N levels in coastal waters of the Straits in the 1980s were the highest in the Baltic Sea, and 3-4 times higher than the levels in the open sea, indicating the large influence of land-based sources. Since the mid-1980s, $\mathrm{N}$ levels in coastal waters have decreased to approximately half. Significant relationships between loading and concentrations (Carstensen et al. 2006) document a strong link to land-based loads on a year-to-year basis due to the low retention times. DIP and TP concentrations in the open sea of the Straits also increased from 1970 to the mid-1980s, with subsequent declines reaching levels that are now below the levels in 1970. P levels in coastal waters were also the highest of all regions in the mid-1980s, but DIP levels are now comparable to those in open waters and TP levels are only slightly above. The significant declines in P levels primarily result from deliberate management actions to reduce loads from point sources (Carstensen et al. 2006), and P levels are significantly related to the loads for both coastal and open waters.

Although the nutrient literature abounds with studies identifying eutrophication and alterations of benthic animal populations among the dominant changes in estuarine systems, including the Baltic Sea (Pearson \& Rosenberg 1978, Cloern 2001, Bonsdorff et al. 2002, HELCOM 2009), studies are lacking on responses by carnivorous benthivores among waterbirds to these changes. Most of our knowledge of eutrophication effects on waterbirds stem from studies in freshwater habitats focused on herbivores (Yallop et al. 2004, Clausen 2006) and studies focused on breeding performance (Rönkä et al. 2005), - studies which 
have demonstrated negative direct and indirect impacts of increased levels of eutrophication. In addition, several studies have been undertaken on eutrophication caused by waterbirds' allochthonous input of nutrients in lake ecosystems (Linnman 2004).

However, the most significant element of the avifauna of the estuarine system in the Baltic Sea is the concentrations of bivalve-feeding waterbirds during the non-breeding season. With more than $80 \%$ of the waterbirds wintering in the Baltic Sea being species specialized in foraging on bivalves (Durinck et al. 1994) there is a great potential for eutrophication induced effects on the available food supply to waterbirds. Current eutrophication impacts on bivalve populations are not well known, and may differ between the different coastal regions of the Baltic Sea, and even within regions impacts may show a diversity of trends (Lundberg 2005). Thus, conceptual models showing responses of bivalve-feeding waterbirds to nutrient enrichment in coastal areas of the Baltic Sea may ideally represent a dome-shaped response reflecting both the impoverished benthic conditions and hypoxia in enclosed areas with mixing constraints and even in more exposed areas during extreme events of oxygen deficiency, and positive relations between eutrophication and the growth of bivalve stocks found in more exposed areas (Cloern 2001, Wolowicz et al. 2006). Areas which are consistently oxygen-depleted will suffer mortality of benthic organisms, and also more mobile species such as fish will die if unable to escape the oxygen-depleted area. The lowest oxygen concentrations occur in late August to October when bacteria via an oxygen-consuming process decompose organic matter. In the Kattegat, the Danish Straits and the Western Baltic Sea oxygen depletion is a seasonal phenomenon, while in the deeper basin in the Baltic proper it is of a permanent character (AlHamdani \& Reker 2007).

The obvious parallelism between the reported declining trends in winter DIN and DIP concentrations in the southern part of the Baltic Sea and the observed trends in benthic carnivorous waterbirds feeding offshore since 1993 provides a strong indication of a high level of eutrophication control. In fact, over the period the proportion of seaducks in the Baltic waterbird community has declined from $83 \%$ to $63 \%$. Eutrophication control has also been suggested as the main mechanism behind the significant reductions in abundance and number of individuals of several species of benthic invertebrates in the Inner Danish waters after 1995 (Hjorth \& Josefson 2010). In chapter 8.9, the relationship between trends in eutrophication and waterbird densities will be further explored and quantified. 

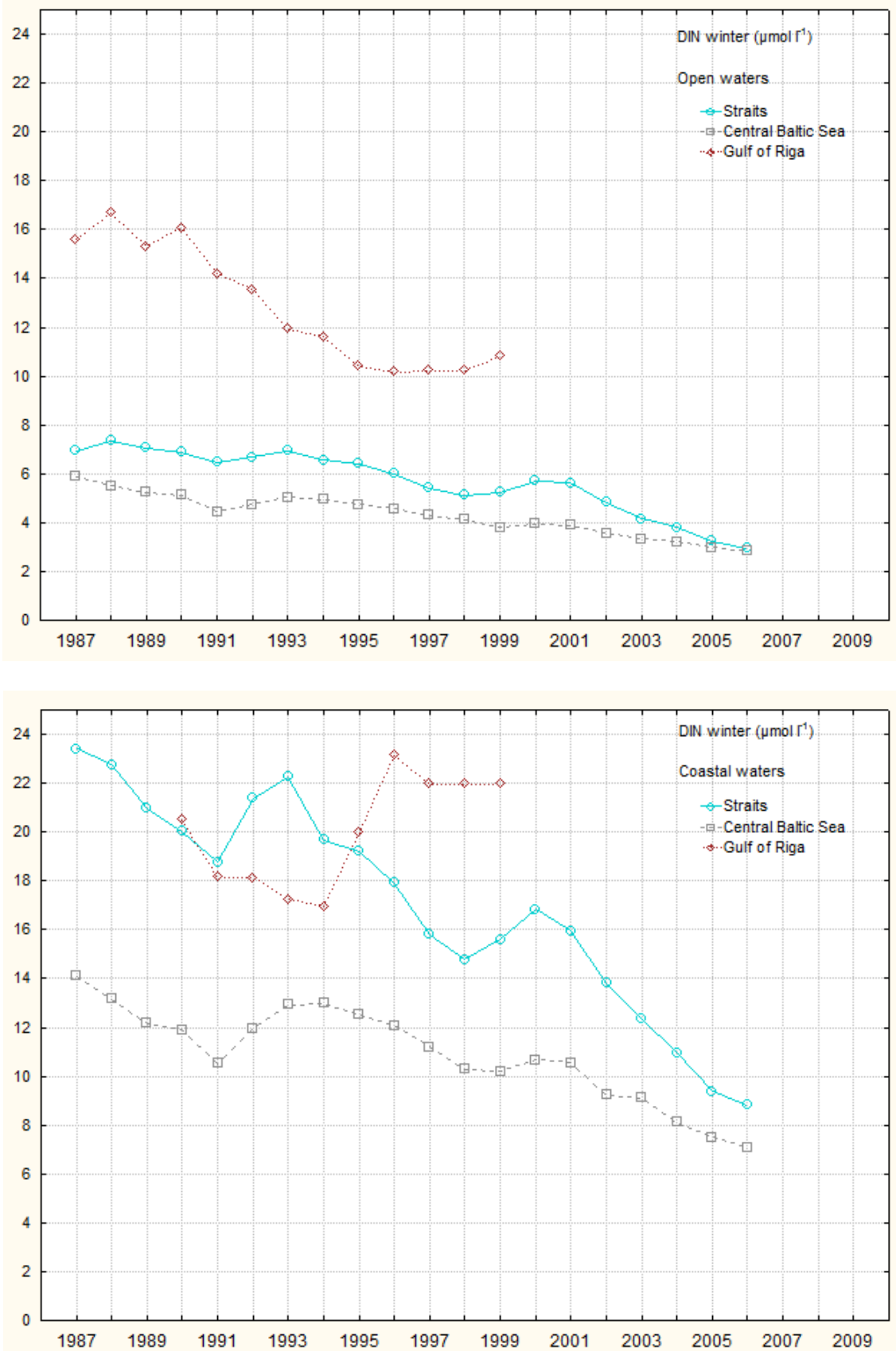

Figure 23. Trends (5-year running means) in DIN concentrations recorded during winter 1987-2008 in the Straits, the Central Baltic Sea and Gulf of Riga (Source: ICES Oceanographic Database/HELCOM). 

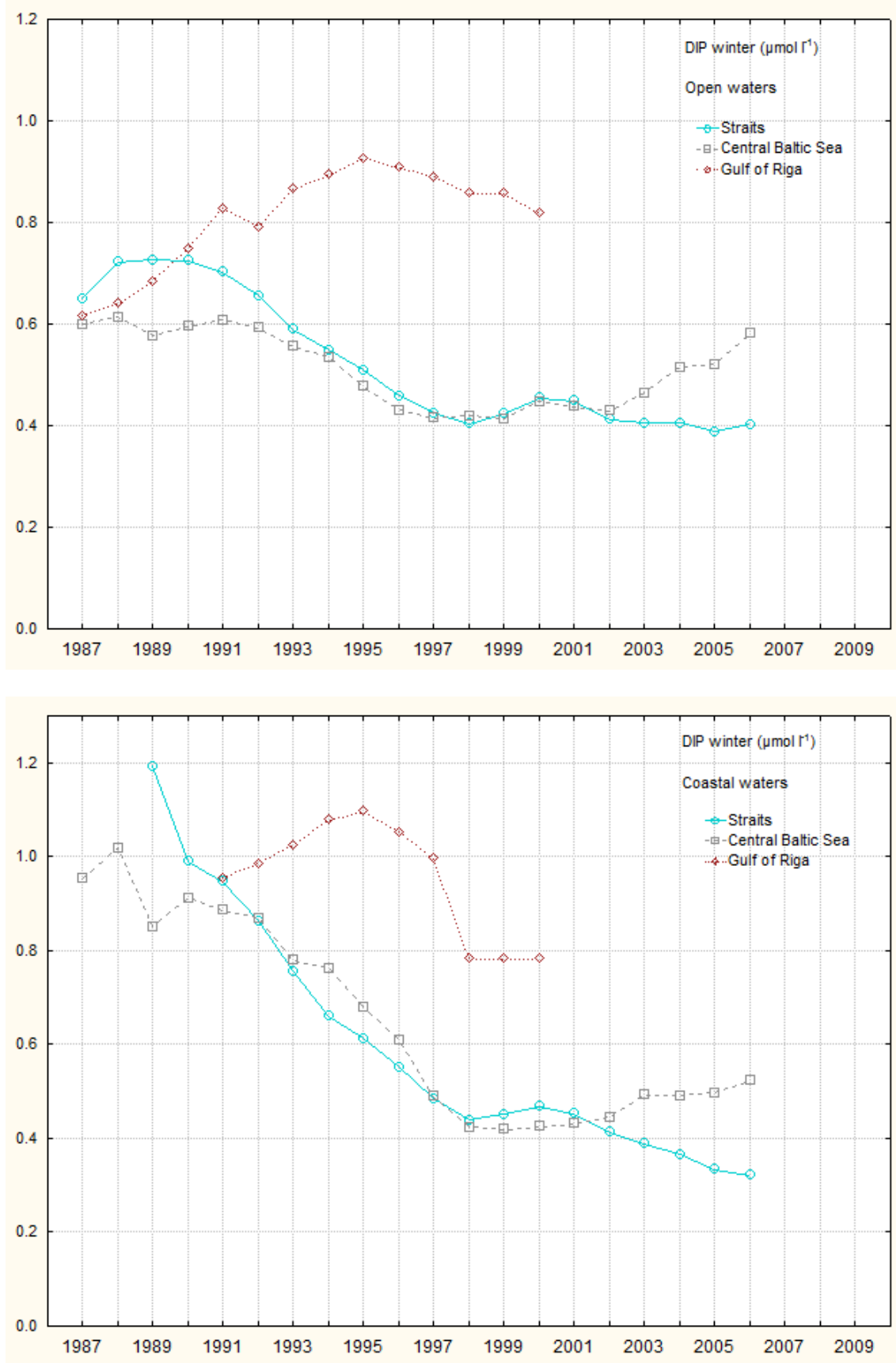

Figure 24. Trends (5-year running means) in DIP concentrations recorded during winter 1987-2008 in the Straits, the Central Baltic Sea and Gulf of Riga (Source: ICES Oceanographic Database/HELCOM). 

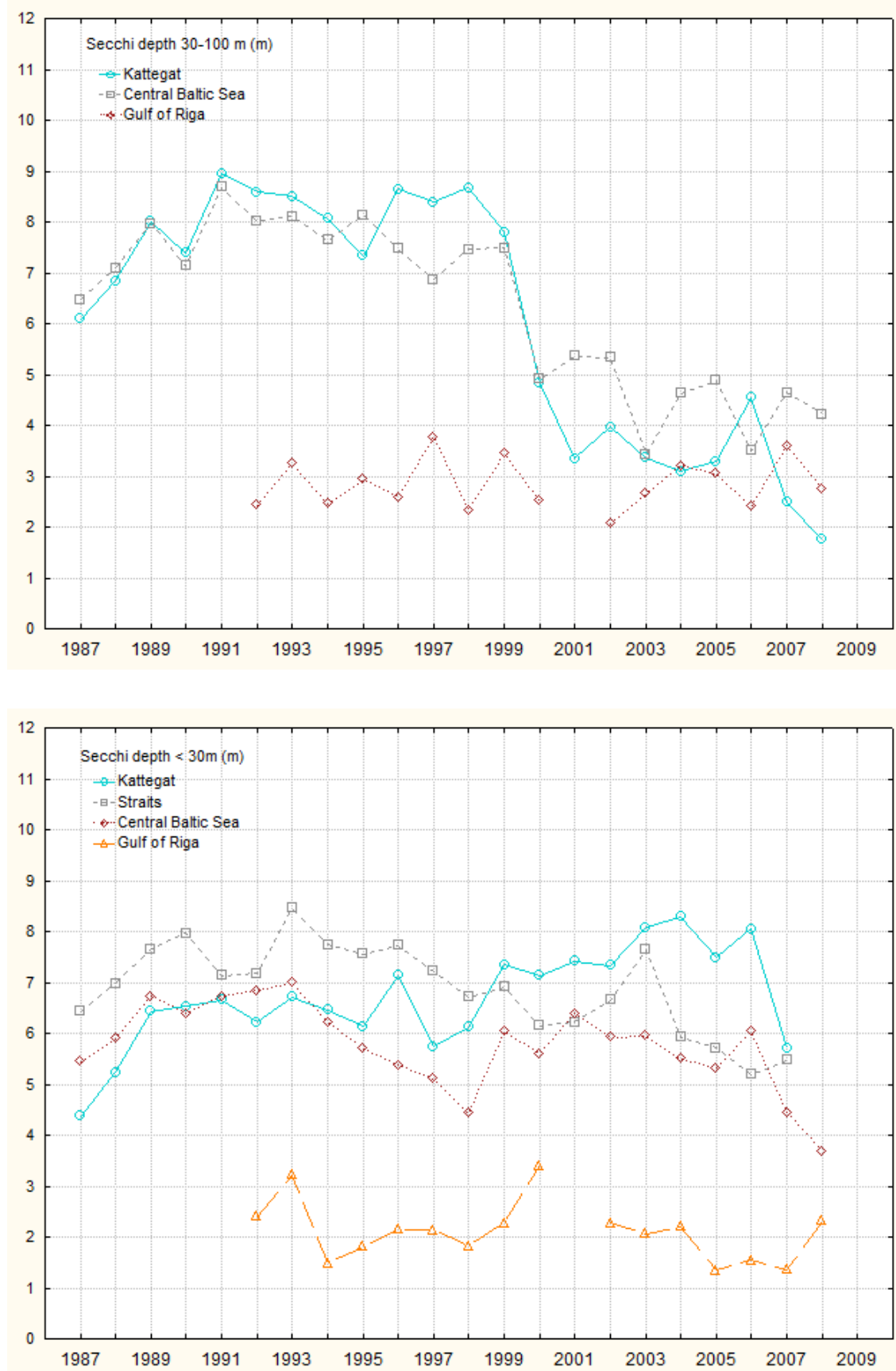

Figure 25. Trends in average secchi depths (m) recorded during winter 19872008 in shallow and deeper waters in the Kattegat, Straits, the Central Baltic Sea and Gulf of Riga (Source: ICES Oceanographic Database/HELCOM). 


\subsection{Oil pollution/shipping}

The medium term prognosis for shipping traffic through the Baltic estimated a 100\% increase between 2002 and 2015 (Rytkönen et al. 2002). Despite this increase in shipping traffic the number of recorded oil pollutions has decreased since 1995, indicating a general improvement of the pollution load from oil spills and accidents. On the other hand, HELCOM's monitoring of the concentrations of TPHS (Total Petroleum Hydrocarbons) in the water column does not indicate a descrease in the load from chronic oil pollution. In the central Baltic Sea there has even been an increase recorded since 2001 (Figure 26). Accordingly, the situation with marine oil pollution in the Baltic Sea is still unsatisfactory, and the level of pollution should be regarded as high in several areas. Whether the high loads of chronic oil pollution is due to changed behaviour of polluters (illegal discharges in periods and areas of limited oil pollution surveillance activities), or whether it is due a change in the sources and amounts of oil being discharges is not known.

Beached bird surveys have traditionally been used to assess the level of offshore oil pollution. The statistical power of these measures has recently been demonstrated, indicating that even minor trends in the level of oil pollution can be detected with operational/acceptable certainty (Camphuysen 1995). The sensitivity of beached bird surveys has been demonstrated in a number of North Sea case studies, in which the effects of measures to reduce oil pollution were instantly observed on nearby beaches (Averbeck 1991, Heubeck 1991). Similar regional monitoring studies are missing in the Baltic Sea, although plans for coordinated beached bird surveys have been designed according to an internationally harmonised standard methodology (Camphuysen \& van Franeker 1992, Heubeck \& Camphuysen 1992). Currently, national or regional beached bird surveys are undertaken in Poland, Russia (Kaliningrad region), Germany and Denmark. Yet, updated trends in the oil rates recorded from these surveys have not yet bee published.

On the basis of beached bird surveys Zydelis and Dagys (1997) considered oil pollution due to ship traffic as the most important threat to wintering seabirds and waterbirds in the coastal zone of Lithuania. Further evidence of the continued serious situation in the Central Baltic Sea with respect to oil pollution from ships stem from recent investigations of oil residues on Long-tailed Ducks caught in fishing gear on Hoburgs Bank (Larsson \& Tydén 2005, 2009). The investigations showed that a high proportion of the birds had oil residues on the feathers. Of a total of 998 analysed birds $11.8 \%$ had oil on the feathers. The proportion of live birds seen at sea with oil on the feathers was even higher. As the high proportion of drowned birds with oil was recorded in 4 of 11 net samples the results can not be explained by a single incident. 

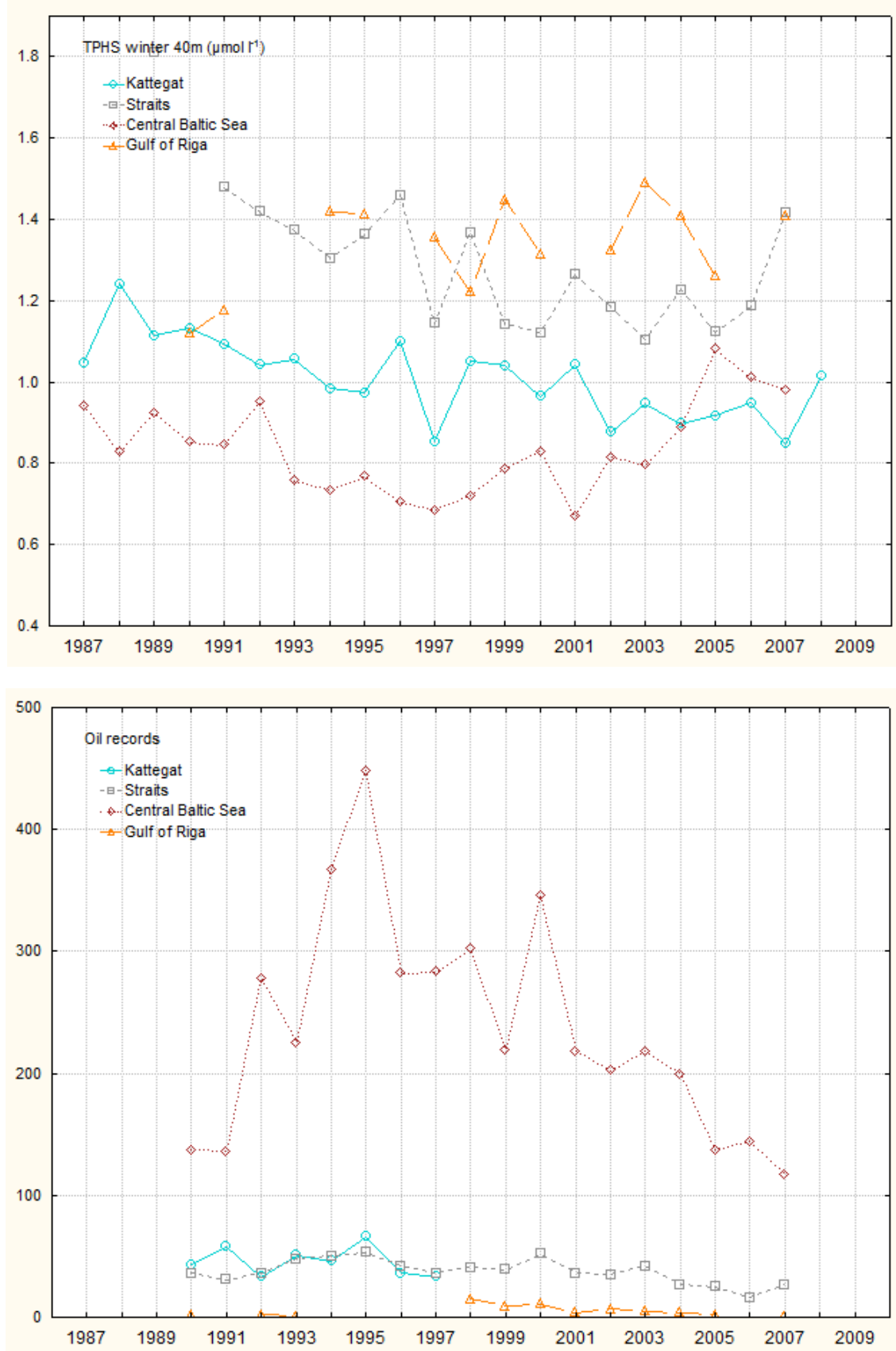

Figure 26. Trends in oil pollution records and average TPHS (Total Petroleum Hydrocarbons) concentrations recorded in midwater during winter 1987-2008 in the Kattegat, Straits, the Central Baltic Sea and Gulf of Riga (Source: Deutsches Ozeanographisches Datenzentrum/ICES Oceanographic Database). 


\subsection{Hazardous substances}

Hazardous substances are here excluding oil compounds. During 19992007, the Baltic Sea was an area with high contamination by hazardous substances, as shown by the Integrated Thematic Assessment of Hazardous Substances in the Baltic Sea (HELCOM 2010a). All open-sea areas of the Baltic Sea except the western Kattegat were classified as being 'disturbed by hazardous substances'. Similarly, 98 of the 104 coastal assessment units were classified as being 'disturbed by hazardous substances'. Altogether, only seven out of the 144 assessment units were considered to be 'undisturbed by hazardous substances'. The main basin of the Baltic Sea (Northern Baltic Proper, Western and Eastern Gotland Basins) together with certain parts of the Kiel and Mecklenburg Bights were the areas most disturbed by hazardous substances. Although status classifications of coastal areas were highly variable, there was a certain tendency for the waters near larger cities to be classified as having a 'moderate', 'poor' or sometimes even 'bad' status. In the main basin, the eight open-sea areas with 'bad' or 'poor' status were most contaminated with PCBs, TBT, lead, cadmium and octylphenol (HELCOM 2010a).

The recent trends in hazardous substances show decreases in persistent organic pollutants (POPs) related to bans or restrictions on the production or use of the substances. Dioxins levels in Common guillemot eggs from Stora Karlsö estern Gotland Basin have been decreasing since the end of the 1960s. The temporal trend of DDE, a degradation product of DDT, measured in herring muscle has been declining since the end of the 1970s. PCBs show significant declining trends for herring, perch and blue mussels in several regions in the Baltic Sea and TBT, which has entered the marine environment primarily due to its use in anti-fouling paints on ship hulls, has declined at least in Danish and German waters (HELCOM 2010a). Lead poisoning in breeding eider females has been established in the Gulf of Finland, and lead exposure is considered as one of the potential factors in the declines of breeding eider populations in that region (Franson et al. 2002).

Despite the declining trends of POPs, their concentrations in the marine environment are still of concern. PCBs are clearly the most widespread and problematic group of pollutants in the Baltic Sea (HELCOM 2010a). TBT levels in sediments and blue mussels are still of concern in most areas of the Baltic Sea. The concentrations of dioxins and furans also still exceed the safety criteria for seafood in the northern and northeastern parts of the Baltic Sea, although the levels in the more southern areas were classified as being 'good' according to environmental standards. Exceedances of the threshold values for cadmium and mercury concentrations in fish and mussels were found in almost all areas of the Baltic Sea (HELCOM 2010a). 
There are also signs of increasing concentrations of some hazardous substances. The concentration of a brominated substance, hexabromocyclododecane (HBCDD) which is used, for example, as a flame retardant in polystyrene-based insulation products in the building and construction industry, has increased approximately $3 \%$ per year in guillemot eggs from Stora Karlsö between the late 1960s and 2007, and is already now of high concern in many of the western Baltic Sea areas. Perfluorooctane sulphonate (PFOS) concentrations have also been found to increase in eggs of the common guillemot since 1968 without signs of levelling off (HELCOM 2010a). There are also indications of an increase in heavy metal concentrations (e.g., nickel, copper, arsenic, chrome) in sediments in the Baltic Sea during the 2000s. Cadmium and mercury concentrations in biota do not show any consistent temporal trends in the Baltic Sea area; both increasing and decreasing trends have been found.

Although the health of fish-eating seabirds seems to be improving there are no signs of improvement in fish health and lower trophic levels are also still impacted by hazardous substances (HELCOM 2010a). Fish populations of the coastal areas seem to suffer more from pollution than those of the open-sea sites, with indications of exposure to compounds such as dioxins, PCBs and PAHs observed on the Swedish east coast. The poorer status of the coastal sites was confirmed with other indicators. Even though there are encouraging signs of decreasing trends of certain substances and improving health status of fish-eating seabirds, it can be concluded that the health of fish-eating birds in the coastal areas is uncertain, and that inputs that primarily took place decades ago are still obvious in the Baltic Sea, as is demonstrated by undesirable concentrations of PCBs, DDT/DDE and TBT.

\subsection{Fishing pressure}

This status report did only cover fish-eating waterbirds in the coastal zone, and the status of fish-eating seabirds such as gulls and auks in offshore waters has not been included. There are promising signs that the abundance of some fish-eating top predators like seals and cormorants is increasing in the Baltic Sea following cessation of hunting pressures and the high fishing pressure on cod, which has caused populations of small fish to increase significantly over the last decade. As the fishing pressure has now been reduced to a sustainable level with the EU longterm management plan for cod (Anon. 2007) it is expected that the cod stocks will recover in the near future. Whether the subsequent expected reduction in the available supply of small fish will create a cascading effect on fish-eating seabirds and marine mammals is unknown, but not unlikely. After 2005, the spawning stock biomass of cod has been in- 
creasing in parallel to a decrease in the spawning stock biomass of sprat (Figures 27, 29).

Probably as a result of the extraordinary low number of top predators the Baltic pelagic food web has shown clear signs of a lack of resilience towards changes in the populations of top predators, and (mis)management of fisheries coupled to eutrophication and climate change has caused a complex series of changes in the Baltic Sea over the last 30 years (HELCOM 2010). As many as three regime shifts seem to have occurred in the Baltic Sea during the $20^{\text {th }}$ century (Österblom et al. 2007). With the prospects of more large-scale changes to the pelagic ecosystem of the Baltic future co-ordinated census activities should include fish-eating species in the entire region.

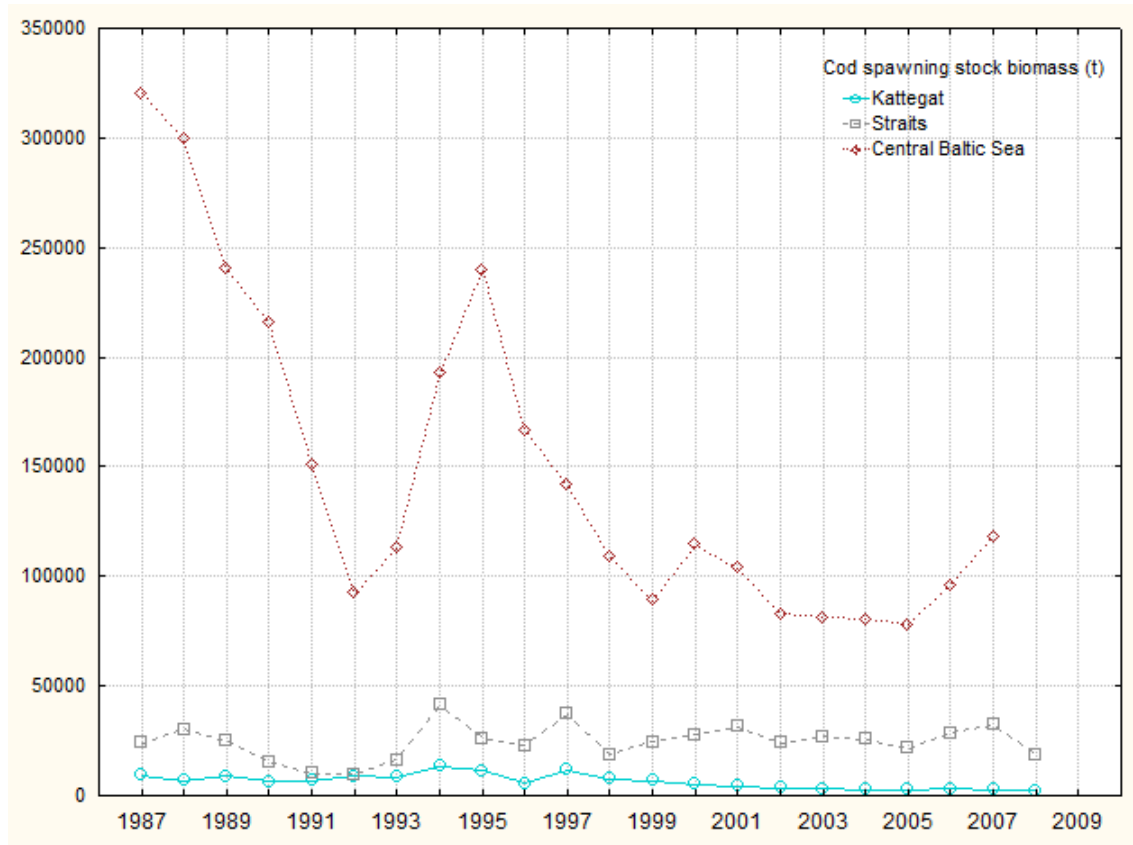

Figure 27. Trends in the spawning stock biomass of cod recorded in the Kattegat, Straits and the Central Baltic Sea 1987-2008. 


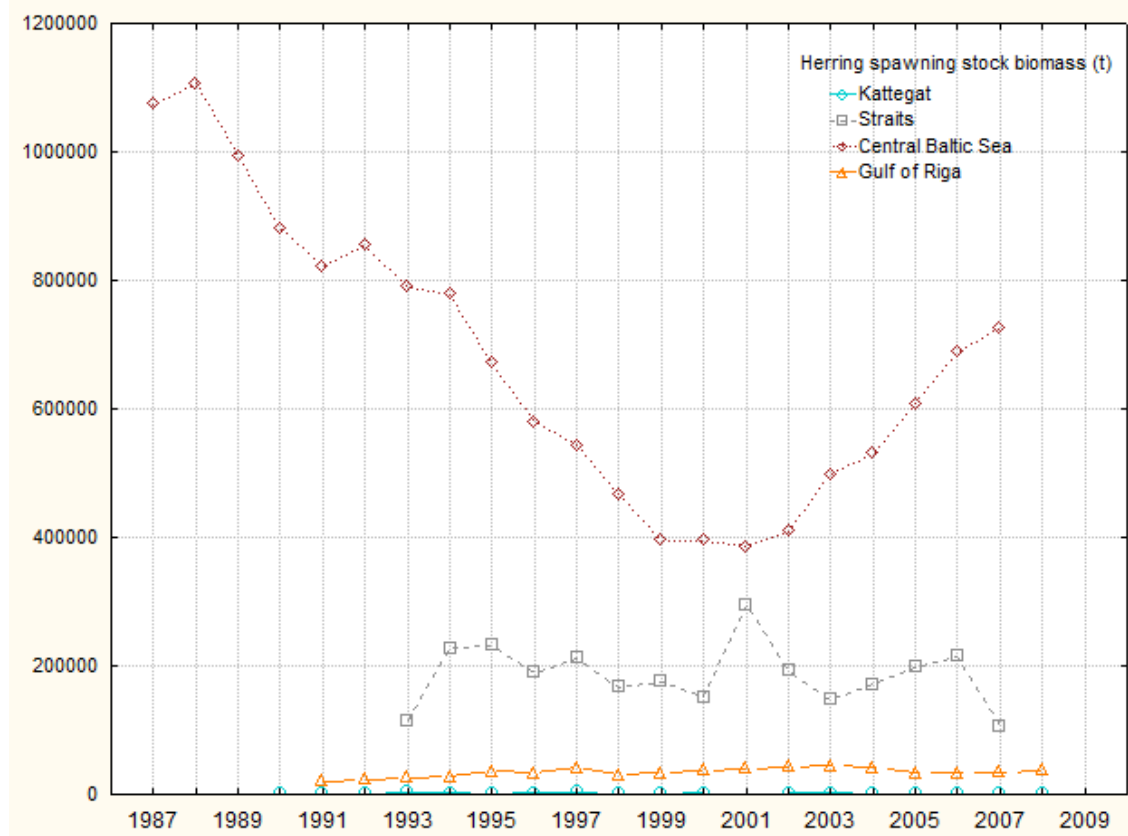

Figure 28. Trends in the spawning stock biomass of herring recorded in the Kattegat, Straits, the Central Baltic Sea and the Gulf of Riga 1987-2008. For Kattegat the catch rate from February IBTS surveys is shown.

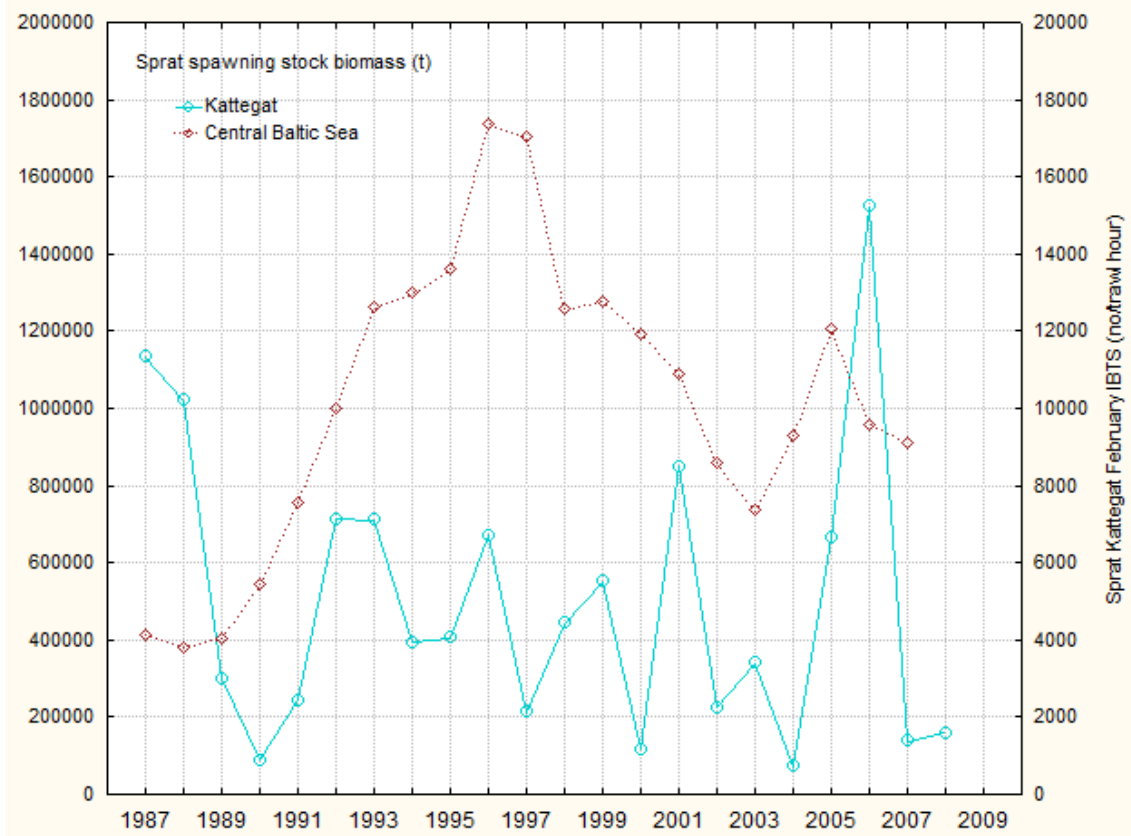

Figure 29. Trends in the spawning stock biomass of sprat recorded in the Central Baltic Sea 1987-2008. The catch rate from February IBTS surveys is shown for the Kattegat. 


\subsection{By-catch}

Incidental bird mortality in fishing gear is a phenomenon that has been recorded in all countries around the Baltic Sea. Gillnets is the main type of fishing gear in which birds are getting killed as they entangle while diving, and consequently drown. Gillnet fishing commonly takes place in shallow coastal waters, and often in the same areas which are favoured by wintering birds. Benthivorous (seaducks, diving ducks) and diving piscivorous species (divers, grebes, auks) are most susceptible to entanglement in fishing nets, while surface foragers (gulls, dabbling ducks) are generally unaffected (Dagys \& Žydelis 2002).

In a recent review on bird bycatch in northern Europe, Žydelis et al. (2009) identified over 20 unique studies reporting bird bycatch in fishing nets in the Baltic Sea. By simple summing reported numbers of caught birds, the authors suggested that at least 76,000 birds are being killed in the Baltic Sea annually (Fig. 2 in Žydelis et al. 2009). This number was assumed as being almost certainly an underestimate, as large areas of the Baltic Sea have not been surveyed for fisheries bycatch (Denmark, large sections of the German coast) or at least such information has not been reported internationally.

Information about coastal gillnet fishing effort is not available in a summarized form for the Baltic Sea, but it is evident that gillnet fisheries remain intensive in many countries (ICES 2007). Considering recent declines of many waterbird populations in the Baltic, current bird bycatch rates might have also consequently decreased compared to the ones reported earlier (reviewed in Žydelis et al. 2009), however bird bycatch is not an object of continuous environmental monitoring in countries around the Baltic and bycatch trends are not established. Still, the latest studies indicate that thousands of birds continue to drown in fishing nets annually (Dagys et al. 2009; Bellebaum 2011). Bycatch mortality, perhaps not being the main cause of population declines, is undoubtedly a contributing factor to rhe unfavourable status of affected species. For instance, Long-tailed Duck is the most frequent victim in fishing nets in the eastern and south-eastern Baltic (Stempniewicz 1994, Urtans \& Priednieks 2000, Dagys \& Žydelis 2002; Schirmeister 2003, Dagys et al. 2009), and this species has already been identified as potentially vulnerable to additive mortality originating from bycatch, hunting and oil pollution (Žydelis et al. 2009). Considering updated Long-tailed Duck population size and declining trend, effects of hunting and fisheries-induced mortality should be regarded as issues of concern. Likewise, impacts of additive mortalities should be reviewed for other species exhibiting population declines.

Proper assessment of additive mortality effects would require application of population demographic models, where detailed demographic and life history information of populations in question is needed. Unfortunately, such data are rare or unavailable for many waterbird species in 
the Baltic. Therefore, it would be most feasible to use the Potential Biological Removal approach, which allows assessment of additive mortality on population dynamics while having only minimum demographic information (Niel \& Lebreton 2005, Dillingham \& Fletcher 2008).

\subsection{Hunting}

A recent review on waterbird use in EU countries suggested that Common Eider and Goldeneye are species experiencing the highest hunting mortality among seaducks with the annual bag of each species exceeding 100,000 birds (Mooij 2005). Seaduck hunting traditions are especially strong in Scandinavian countries, particularly Denmark. Common Eider is highly prized quarry in Denmark, where more than 100,000 birds used to be shot annually until mid-1990s, but the bag has declined lately levelling at about 60,000 birds (Fig. 30, Noer et al. 2009). Similar declining trends took place in Sweden and Finland as well, where numbers of shot eiders per year declined several times from combined total of 3040,000 in late 1980 to 4-5,000 recently (Fig. 30). Common Eider represents well general declining trends in bag size of most other seaduck species. For instance 30-80,000 Long-tailed ducks used to be shot annually in Finland in late 1980s and early 1990s and the current bag stabilized at less than 10,000 birds (Fig. 31).

Similarly, the bag of Long-tailed duck has declined from about 9,000 to 1,000-4,000 annually in Denmark over the same period (Noer et al. 2009). In contrast to other seaduck species, size of Goldeneye annual bag remained relatively stable in Denmark averaging at about 12,000 during the last two decades (Noer et al. 2009), but declined approximately twice in Sweden and Finland (Fig. 29). Recent bag size of seaducks in countries around the Baltic is summarized in Table 29. Seaducks are not hunted in marine waters of Lithuania, Poland, and Germany and numbers shot in Estonia and Latvia are very low (Table 29; Viksne et al. 2008).

The decline in seaduck hunting bags is generally a response of game management authorities in the respective countries to observed local population declines or application of a precautionary principle if population status is unclear (Bregnballe et al. 2007, Noer et al. 2009). 


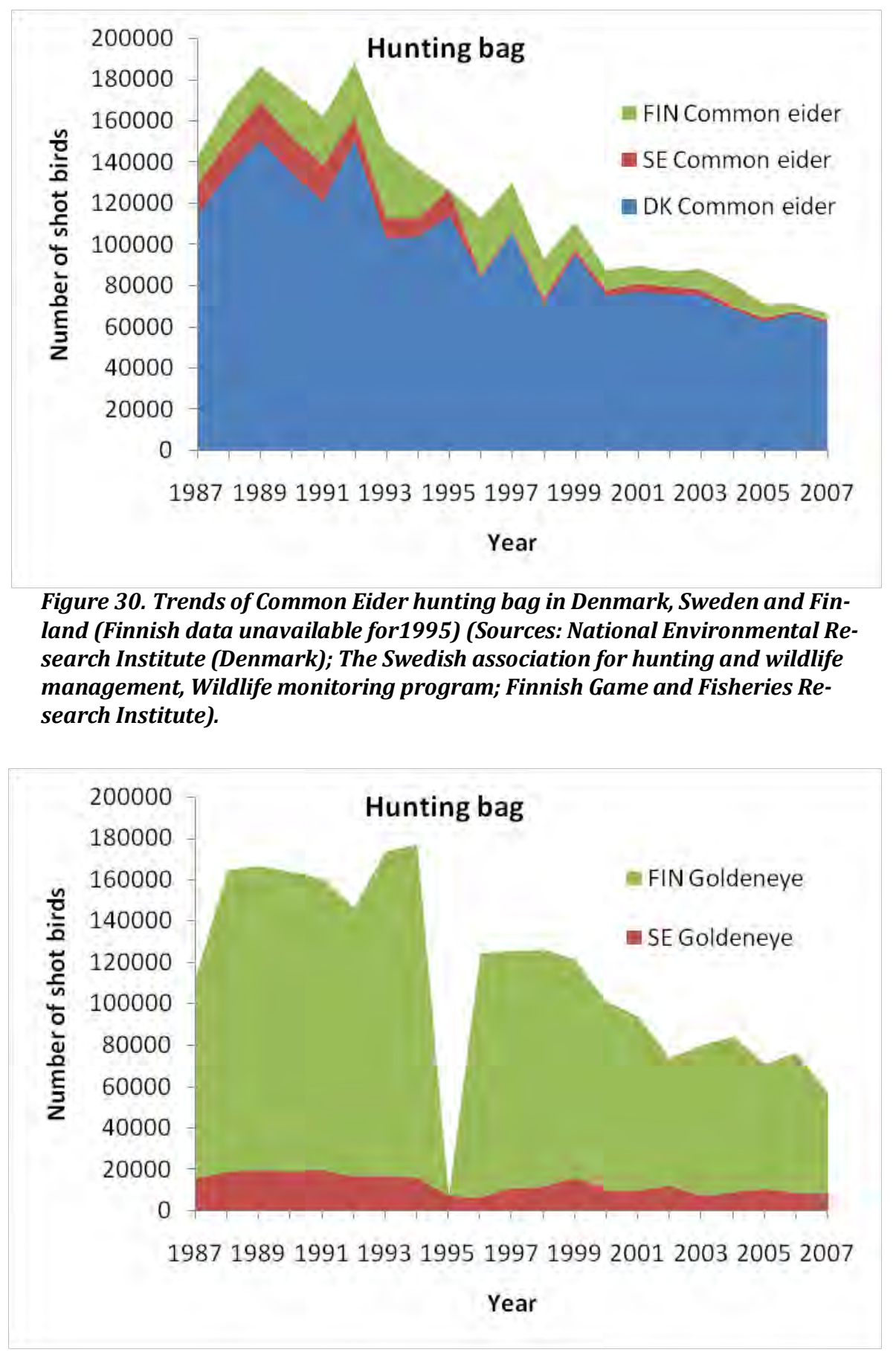




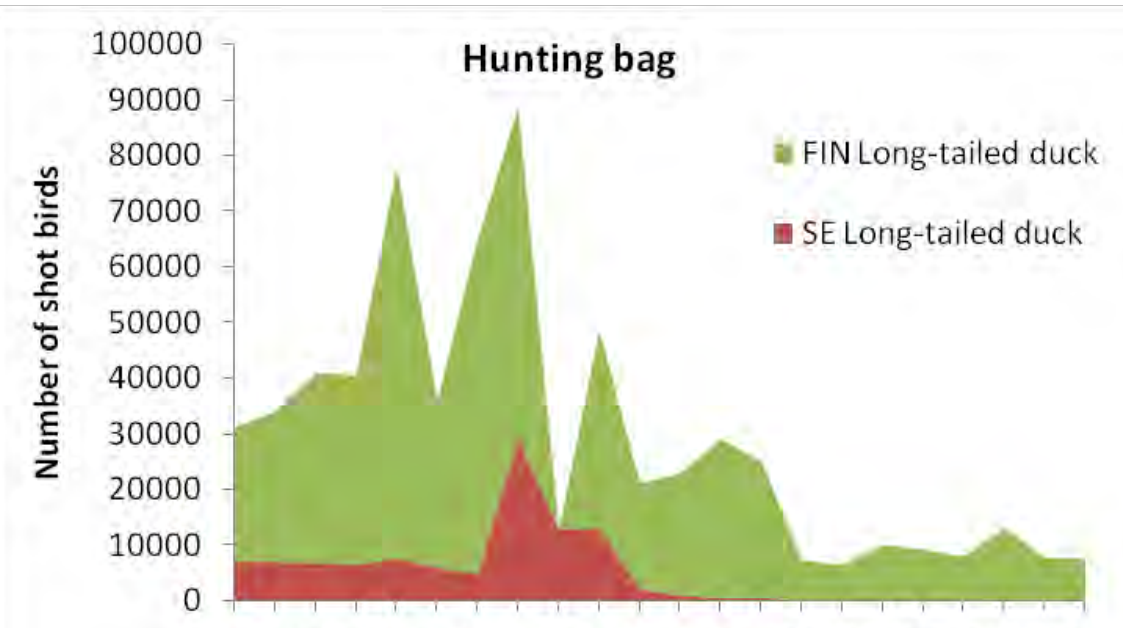

19871989199119931995199719992001200320052007

Year

Figure 31. Trends of Long-tailed Duck and Goldeneye hunting bag in Sweden and Finland (Finnish data unavailable for1995; peak numbers of Long-tailed Ducks shot in Sweden include birds that have been deliberately shot after oil spill incidents) (Sources: The Swedish association for hunting and wildlife management, Wildlife monitoring program; Finnish Game and Fisheries Research Institute).

Table 29. Numbers of seaduck and selected waterbird species shot in Denmark, Sweden, Finland and Estonia in 2007

\begin{tabular}{|c|c|c|c|c|}
\hline Species & Denmark & Sweden & Finland & Estonia \\
\hline Cormorant & 5,100 & 3,526 & & 345 \\
\hline Common Pochard & 1,500 & & 700 & 6 \\
\hline Tufted Duck & 9,000 & & 6,000 & 43 \\
\hline Greater Scaup & 300 & & & 0 \\
\hline Common Eider & 61,800 & 1,948 & 2,600 & 0 \\
\hline Long-tailed Duck & 1,500 & 130 & 7,700 & 7 \\
\hline Common Scoter & 5,000 & 0 & & 1 \\
\hline Velvet Scoter & 2,000 & 0 & & \\
\hline Common Goldeneye & 12,000 & 8,413 & 48,600 & 92 \\
\hline Goosander & 1,000 & 1,394 & 4,600 & \\
\hline Red-breasted Merganser & 2,000 & & 2,100 & \\
\hline
\end{tabular}

(Sources: National Environmental Research Institute (Denmark), Noer et al. 2009; The Swedish association for hunting and wildlife management, Wild life monitoring program; Finnish Game and Fisheries Research Institute; Estonian Ministry of the Environment).

\subsection{Fisheries discards}

Scavenging on discards and offal is a widespread phenomenon in the Baltic Sea as it is in other shelf areas of Europe, but the number of bird species involved is generally lower and strongly biased towards gulls, especially Herring Gulls (Garthe \& Scherp 2003). As this status report did not cover the gull species it is not known to what extent the drop in fishing effort after the mid 1990'es has affected the distribution and abundance of gulls in the Baltic Sea. Herring gulls are the most numerous scavenging species in all areas of the Baltic during winter, followed 
by Great Black-backed Gulls and Mew Gulls. Experimental discarding from fishing boats have shown that high percentages of discarded gadids (cod, whiting), clupeids (herring, sprat), scad, rockling and offal are consumed by seabirds, whereas percentages of flatfish consumed are extremely low (Garthe \& Scherp 2003). By combining official discard and offal statistics and experimental discarding, Garthe \& Scherp (2003) estimated that $6,500 \mathrm{t}$ of fish discards and $16,000 \mathrm{t}$ of offal were consumed annually by seabirds in the Baltic Sea. The proportion of discards in Herring Gull pellets was on average 1.6\% (range: $0-4.5 \%$ ) and $17.5 \%$ (range: 9.4-25.5\%), respectively, at two study sites in the southwestern Baltic Sea. Even if these percentages are not extremely high it seems likely that herring gulls in particular but also great black-backed gulls in winter should have benefited from this surplus food.

\subsection{Predation by native and introduced predators}

Predation by mammalian ground predators is one of the main reasons for declines in breeding gulls and terns (as well as shorebirds) along the Baltic Sea coasts. Different predators are involved, native (e.g. red fox Vulpes vulpes) as well as introduced (e.g. American mink Mustela vison) species. In addition to other local factors, predation and disturbance by American minks has been one the main factors responsible for the decline of Black-headed Gulls in Latvia (e.g., Viksne \& Janaus 1993, Viksne et al. 1996) and Black Guillemot in Sweden (Andersson \& Staav 1990). Mew gulls in Schleswig-Holstein (northern Germany) suffer from repeated breeding failure due to intense predation above all from red foxes (Kubetzki 2001). Further east along the German Baltic Sea coast, foxes and some other mammals caused severe reduction in breeding success and breeding populations of many coastal species (Dierschke et al. 1995, Hartmann \& Stier 2003).

Large-scale losses of breeding habitats such as small islands which are hardly accessible to predators have strongly enhanced the predation pressure on the remaining breeding colonies. These colonies are usually easily accessible for predators (Kubetzki 2001). After the experimental removal of minks from islands in SW Finland the smaller waterfowl and seabirds returned to their former breeding sites whereas mink predation had no effect on larger species like Common Eiders (Nordström et al. 2003). However, removal of native species is a much bigger issue at least for most of the southern Baltic Sea coast (Garthe et al. 2003). 


\subsection{Coastal development}

Many coastal zones of the Baltic Sea have been developed extensively so that most natural habitats have been destroyed. This is most obvious in countries where economic development occurred earlier. Protected areas are often the only places where breeding seabirds and also coastal birds can still reproduce though indirect effects such as predation pressure can be very intense. Herring Gulls and Mew Gulls seem to circumvent the problem of lacking natural breeding habitats by founding new colonies on buildings with flat-roofs, basically doing that in the muchexploited western part of Germany and hardly so in the less-exploited eastern part (Kubetzki 2001, Garthe et al. 2003). Most other breeding species respond simply by decreasing in population sizes along with the disappearing breeding habitats.

\subsection{Wind energy}

Plans for extensive development of offshore wind farms exist in all countries surrounding the Baltic Sea. However, only one large-scale offshore wind farm has so far been built in the Baltic Sea; the Nysted wind farm in the Fehmarn Belt. Thus, experiences concerning impacts on waterbirds from windfarms stem mainly from the impacts and monitoring programme associated with Nysted (Petersen et al. 2006b). The general experience from all offshore wind farm projects is that by far the highest impacts on wintering waterbirds are associated with the operation phase due to the long-term duration of habitat displacement. The evidence gathered from existing monitoring programmes at offshore wind farms indicate that specific responses of waterbirds to wind farms are highly variable, both as a function of specific disturbance stimuli and site-specific characteristics. In addition, adaptations to the turbines and rotor blades are observed, which make accurate assessment of the scale of habitat displacement rather difficult, especially over the long term. A further complication is the fact that habitat displacement impacts as documented during the monitoring programmes of existing offshore wind farms may not have taken (natural) changes in food supply into consideration. Despite these uncertainties, experiences with habitat displacement at the Nysted wind farm point at the strongest responses in seaducks (Table 30). Similar experiences were made at Lillgrund in the Öresund, where marked changes were found for Red-breasted Mergansers and Common Eiders (Nilsson \& Green in prep.). 
Table 30. Reported habitat displacement effects on waterbirds within a distance of $\mathbf{2} \mathbf{~ k m}$ from the Nysted offshore wind farm (Petersen et al. 2006b).

\begin{tabular}{ll}
\hline Species & Response type \\
\hline Red-throated/Black-throated Diver & Some displacement to $2 \mathrm{~km}$, yet not significant \\
Common Eider & No or moderate displacement \\
Long-tailed Duck & Complete displacement to $2 \mathrm{~km}$ distance \\
Red-breasted Merganser & No displacement \\
Herring Gull (Larus argentatus) & No displacement \\
\hline
\end{tabular}

\subsection{Sand and gravel extraction}

Sand and gravel extraction is carried out at some locations in the Baltic Sea with plans for many more sites to be exploited. No information is available so far as how such activities may influence seabirds. However, there is at least some overlap between major sea duck (and other seabird) concentrations and extraction sites so that at least food availability for benthivorous seabirds might possibly be affected. The observed longterm trend for Baltic Sea seabirds is nevertheless unlikely to have been caused by the current level of sand and gravel extraction.

\subsection{Identification of key pressures}

\subsubsection{Herbivores}

Negative correlations with nutrient concentrations are documented directly for Mallards in Estonia and Mute Swans in the Straits and in the German Central Baltic Coast, and indirectly by the positive relationship between Mallards and secchi depth in the German Central Baltic Coast and the same for Common Coot in the Straits (Figure 32, Tables 31-34). In addition, positive correlations with water temperature and BSI index are seen in all three species in the central and southern regions. 

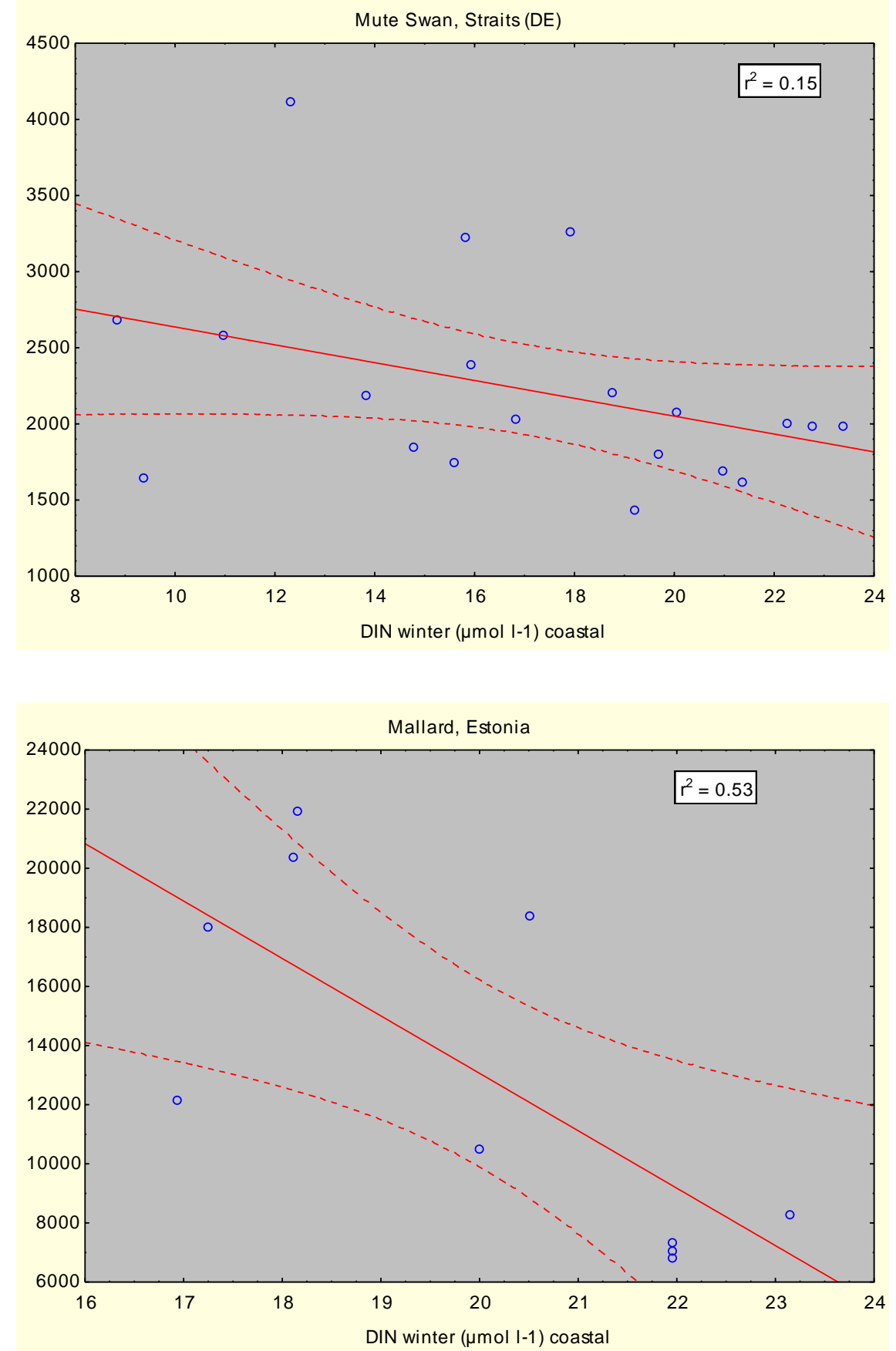

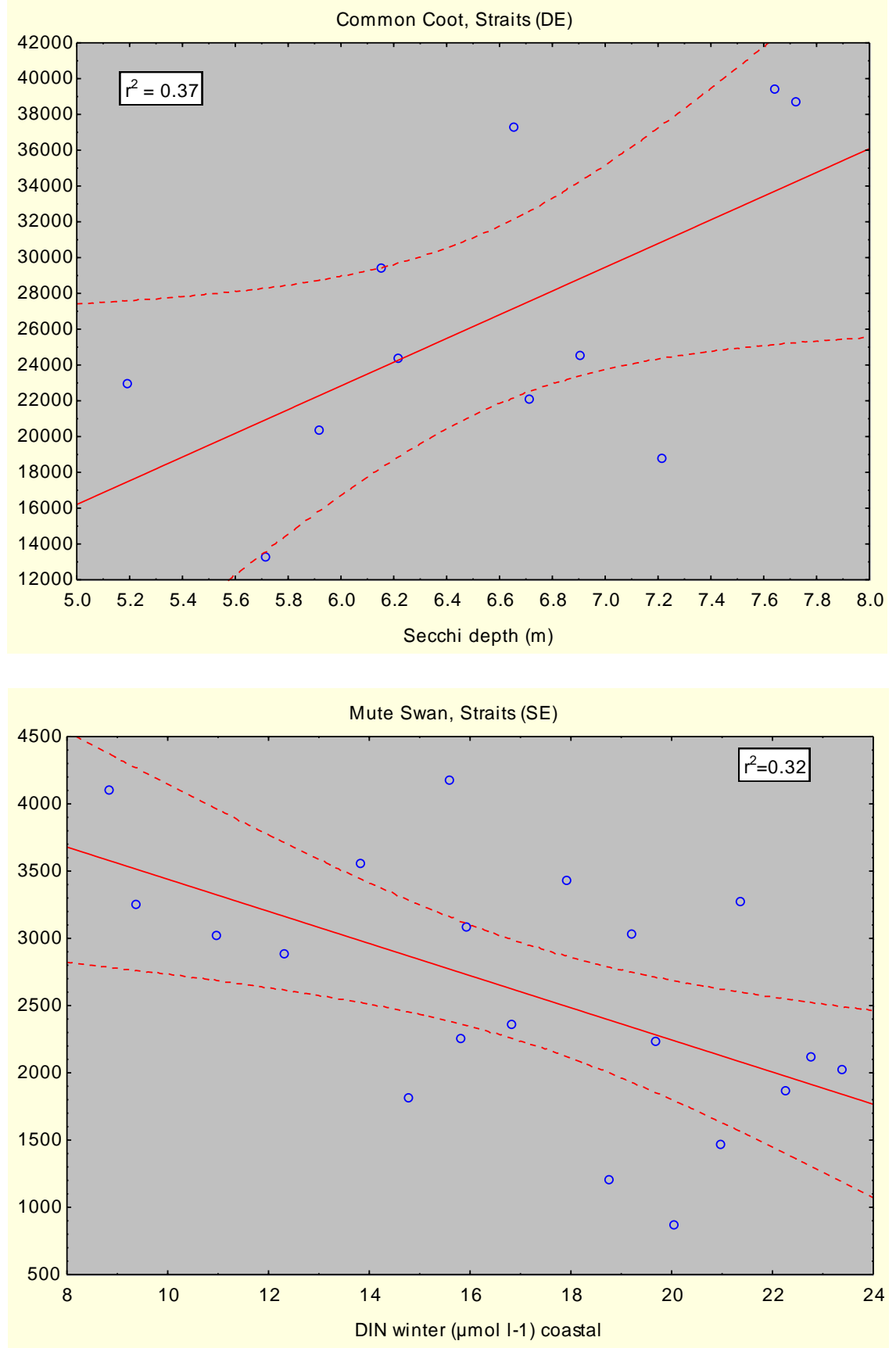

Figure 32. Plots of relationship between selected species (regions) of herbivores and pressures. Linear fit (solid line) and 95\% confidence intervals (hatched lines) are indicated. 
Table 31. Significant correlation coefficients (Pearson, $p<0.05$ ) between waterbirds and selected pressures in the Kattegat and the Straits.

\begin{tabular}{|c|c|c|c|c|c|c|c|c|c|c|c|c|c|c|c|c|c|c|c|c|}
\hline Pressure/ Species & Region & Mallard & $\begin{array}{l}\text { Mute } \\
\text { Swan }\end{array}$ & $\begin{array}{l}\text { Common } \\
\text { coot }\end{array}$ & $\begin{array}{l}\text { Tufted } \\
\text { Duck }\end{array}$ & $\begin{array}{l}\text { Common } \\
\text { Pochard }\end{array}$ & $\begin{array}{l}\text { Greater } \\
\text { Scaup }\end{array}$ & $\begin{array}{l}\text { Common } \\
\text { Goldeneye }\end{array}$ & Smew & $\begin{array}{l}\text { Red- } \\
\text { breasted } \\
\text { Merganser }\end{array}$ & Goosander & $\begin{array}{l}\text { Longtai- } \\
\text { led Duck }\end{array}$ & $\begin{array}{l}\text { Velvet } \\
\text { Scoter }\end{array}$ & $\begin{array}{l}\text { Common } \\
\text { Scoter }\end{array}$ & $\begin{array}{l}\text { Common } \\
\text { Eider }\end{array}$ & Divers & $\begin{array}{l}\text { Slavonian } \\
\text { Grebe }\end{array}$ & $\begin{array}{l}\text { Great } \\
\text { Crested } \\
\text { Grebe }\end{array}$ & $\begin{array}{l}\text { Red- } \\
\text { necked } \\
\text { Grebe }\end{array}$ & $\begin{array}{l}\text { Great } \\
\text { Cormo- } \\
\text { rant }\end{array}$ \\
\hline \multirow{3}{*}{$\begin{array}{l}\text { DIN winter concentrati- } \\
\text { on }\end{array}$} & Kattegat & & & & & & & & & & & & & & & & & & & \\
\hline & Straits (SE) & & & & & & -0.76 & & & & & & & & -0.68 & & & -0.61 & & \\
\hline & Straits (DE) & & & & & & & & & 0.70 & & & & & & & & & & -0.67 \\
\hline \multicolumn{21}{|c|}{ DIP winter concentration } \\
\hline & Straits (SE) & & & & & & -0.74 & & 0.64 & & & & & & -0.63 & & & & & \\
\hline & Straits (DE) & & & & & & & & & 0.74 & & & & & & & & & & -0.61 \\
\hline \multirow[t]{2}{*}{ TPHS } & Kattegat & & & & & & & & & & & & & & & & & & & \\
\hline & Straits (DE) & & & & & & & & & & & & & & & & & & & \\
\hline \multirow[t]{3}{*}{ Bottom oxygen } & Kattegat & & & & & & & & & & & & & & & & & & & \\
\hline & Straits (SE) & & & -0.86 & & & -0.69 & & & & & & & & & & & & & \\
\hline & Straits (DE) & & & -0.68 & & & & & & & & & & & & & & & & \\
\hline \multirow[t]{3}{*}{ Oil records } & Kattegat & & & & & & & & & & & & & & & & & & & \\
\hline & Straits (SE) & & & & & & -0.61 & & & & & & & & & & & -0.65 & & \\
\hline & Straits (DE) & & & & & & & & & & & & & & & & & & & -0.65 \\
\hline \multirow[t]{3}{*}{ Bottom salinity } & Kattegat & & & & & & & & & & & & & & & & & & -0.79 & \\
\hline & Straits (SE) & & & & & & & & & & & & & & -0.75 & & & & & \\
\hline & Straits (DE) & & & & & & & & & & & & & & & & & & & \\
\hline Bottom temperature & Kattegat & & & 0.75 & & & & & & & & & & -0.84 & -0.85 & & & & & -0.58 \\
\hline \multicolumn{21}{|l|}{ Secchi depth } \\
\hline & Kattegat & & & & & & & & & & & & & & & & & & -0.79 & \\
\hline & Straits (SE) & & & & & & -0.65 & & & & & & & & & & & -0.61 & & \\
\hline & Straits (DE) & & & 0.59 & & & & & & & & & & & & & & & & \\
\hline
\end{tabular}


Table 32. Significant correlation coefficients (Pearson, $p<0.05$ ) between waterbirds and selected pressures in the German, Polish and Swedish parts of the Central Baltic Sea.

\begin{tabular}{|c|c|c|c|c|c|c|c|c|c|c|c|c|c|c|c|c|c|c|c|c|}
\hline Pressure/ Species & Region & Mallard & $\begin{array}{l}\text { Mute } \\
\text { Swan }\end{array}$ & $\begin{array}{l}\text { Common } \\
\text { coot }\end{array}$ & $\begin{array}{l}\text { Tufted } \\
\text { Duck }\end{array}$ & $\begin{array}{l}\text { Common } \\
\text { Pochard }\end{array}$ & $\begin{array}{l}\text { Greater } \\
\text { scaup }\end{array}$ & $\begin{array}{l}\text { Common } \\
\text { Goldeneye }\end{array}$ & Smew & $\begin{array}{l}\text { Red- } \\
\text { breasted } \\
\text { Merganser }\end{array}$ & Goosander & $\begin{array}{l}\text { Long- } \\
\text { tailed } \\
\text { Duck }\end{array}$ & $\begin{array}{l}\text { Velvet } \\
\text { Scoter }\end{array}$ & $\begin{array}{l}\text { Common } \\
\text { Scoter }\end{array}$ & $\begin{array}{l}\text { Common } \\
\text { Eider }\end{array}$ & Divers & $\begin{array}{l}\text { Slavonian } \\
\text { Grebe }\end{array}$ & $\begin{array}{l}\text { Great } \\
\text { Crested } \\
\text { Grebe }\end{array}$ & $\begin{array}{l}\text { Red- } \\
\text { necked } \\
\text { Grebe }\end{array}$ & Cormorant \\
\hline \multirow[t]{2}{*}{ DIN winter concentration } & $\mathrm{DE}$ & & -0.52 & & & & & & & & -0.81 & & & & & & & & & -0.71 \\
\hline & POL & & & & & & & & & & & & & & & & & & & \\
\hline \multirow[t]{3}{*}{ DIP winter concentration } & DE & & & & & & 0.55 & & & & -0.6 & & & & & & & & & \\
\hline & $\mathrm{POL}$ & & & & & & & & & & & & & & & & & & & \\
\hline & SE & & & & & & & & & & & & & & & & & & & \\
\hline \multirow[t]{2}{*}{ TPHS } & DE & & & & & & & & & & & & & & & & & & & \\
\hline & POL & & & & & & & & & & & & & & & & & & & \\
\hline \multirow[t]{3}{*}{ Bottom oxygen } & $\mathrm{DE}$ & & & & & & & & & & & & & & & & & & & \\
\hline & $\mathrm{POL}$ & & & & & & & & & & & & & & & & & & & \\
\hline & SE & & & & & & & & & & & & & & & & & & & \\
\hline \multirow[t]{3}{*}{ Baltic Sea Index } & $\mathrm{DE}$ & & & & & & & & & & & & & & & & & & & \\
\hline & $\mathrm{POL}$ & & & & & & & & & & & & & & & & & & & \\
\hline & $\mathrm{SE}$ & & 0.96 & & & & & & & & & & & & & & & & & \\
\hline \multirow[t]{3}{*}{ Bottom salinity } & DE & & & & & & & & & -0.5 & & & & & & & & & & \\
\hline & $\mathrm{POL}$ & & & & & & -0.98 & & & & & & & & & & & -0.96 & & \\
\hline & SE & & & & & & & & & -0.96 & & & & & & & & & & \\
\hline \multirow[t]{2}{*}{ Bottom temperature } & DE & 0.53 & & 0.49 & 0.62 & 0.72 & & & & 0.49 & & & & & & & & & & \\
\hline & $\mathrm{POL}$ & & & & & & & & & & & & & & & & & & & \\
\hline \multirow{2}{*}{ Secchi depth } & DE & 0.55 & & & & 0.53 & 0.76 & & & 0.47 & & & & & & & & & & \\
\hline & POL & & & & & & & & & & & & & & & & & & & \\
\hline
\end{tabular}

Table 33. Significant correlation coefficients (Pearson, $p<0.05$ ) between waterbirds and selected pressures in the Finnish part of the Central Baltic Sea.

\begin{tabular}{|c|c|c|c|c|c|c|c|c|c|c|c|c|c|c|c|c|c|c|c|c|}
\hline Pressure/ Species & Region & Mallard & $\begin{array}{l}\text { Mute } \\
\text { Swan }\end{array}$ & $\begin{array}{l}\text { Common } \\
\text { coot }\end{array}$ & $\begin{array}{l}\text { Tufted } \\
\text { Duck }\end{array}$ & $\begin{array}{l}\text { Common } \\
\text { Pochard }\end{array}$ & $\begin{array}{l}\text { Greater } \\
\text { Scaup }\end{array}$ & $\begin{array}{l}\text { Common } \\
\text { Goldeneye }\end{array}$ & Smew & $\begin{array}{l}\text { Red- } \\
\text { breasted } \\
\text { Merganser }\end{array}$ & Goosander & $\begin{array}{l}\text { Long- } \\
\text { tailed } \\
\text { Duck }\end{array}$ & $\begin{array}{l}\text { Velvet } \\
\text { Scoter }\end{array}$ & $\begin{array}{l}\text { Common } \\
\text { Scoter }\end{array}$ & $\begin{array}{l}\text { Common } \\
\text { Eider }\end{array}$ & Divers & $\begin{array}{l}\text { Slavonian } \\
\text { Grebe }\end{array}$ & $\begin{array}{l}\text { Great } \\
\text { Crested } \\
\text { Grebe }\end{array}$ & $\begin{array}{l}\text { Red- } \\
\text { necked } \\
\text { Grebe }\end{array}$ & Cormorant \\
\hline DIN winter concentration & & & & & & & & & & & & & & & & & & & & \\
\hline $\begin{array}{l}\text { DIP winter concentration } \\
\text { TPHS }\end{array}$ & & & & & & & & & & & & -0.97 & 0.98 & & & & & & & -0.73 \\
\hline Bottom oxygen & & -0.96 & & & & & & & & & & 0.96 & -0.96 & & & & & & & \\
\hline Baltic Sea Index & & & & & & & & & & & & 0.99 & -0.95 & & & & & & & \\
\hline $\begin{array}{l}\text { Bottom salinity } \\
\text { Bottom temperature }\end{array}$ & & & & & & & & & & & & & & & & -0.96 & & & & \\
\hline Secchi depth & & & & & & & & -0.99 & & -0.97 & & & & & & & & & & -0.98 \\
\hline
\end{tabular}


Table 34. Significant correlation coefficients (Pearson, $p<0.05$ ) between waterbirds and selected pressures in Estonia.

\begin{tabular}{|c|c|c|c|c|c|c|c|c|c|c|c|c|c|c|c|c|c|c|c|}
\hline Pressure/ Species & Region & Mallard & $\begin{array}{l}\text { Mute } \\
\text { Swan }\end{array}$ & $\begin{array}{l}\text { Common } \\
\text { Coot }\end{array}$ & $\begin{array}{l}\text { Tufted } \\
\text { Duck }\end{array}$ & $\begin{array}{l}\text { Common } \\
\text { Pochard }\end{array}$ & $\begin{array}{l}\text { Greater } \\
\text { Scaup }\end{array}$ & $\begin{array}{l}\text { Common } \\
\text { Goldeneye }\end{array}$ & Smew & $\begin{array}{l}\text { Red- } \\
\text { breasted } \\
\text { Merganser }\end{array}$ & Goosander & $\begin{array}{l}\text { Long- } \\
\text { tailed } \\
\text { Duck }\end{array}$ & $\begin{array}{l}\text { Velvet } \\
\text { Scoter }\end{array}$ & $\begin{array}{l}\text { Common } \\
\text { Scoter }\end{array}$ & $\begin{array}{l}\text { Common Divers } \\
\text { Eider }\end{array}$ & $\begin{array}{l}\text { Slavonian } \\
\text { Grebe }\end{array}$ & $\begin{array}{l}\text { Great } \\
\text { Crested } \\
\text { Grebe }\end{array}$ & $\begin{array}{l}\text { Red- } \\
\text { necked } \\
\text { Grebe }\end{array}$ & Cormorant \\
\hline DIN winter concentration & & -0.73 & & & 0.66 & & & 0.81 & & & & & & & & & & & \\
\hline $\begin{array}{l}\text { DIP winter concentration } \\
\text { TPHS }\end{array}$ & & & & & & & & & & & -0.83 & & & & & & -0.68 & -0.59 & \\
\hline Bottom oxygen & & & & & & & & -0.83 & & & & & & & & & & & \\
\hline Bottom salinity & & & & & & & & & & & & & -0.65 & & & & & & \\
\hline $\begin{array}{l}\text { Bottom temperature } \\
\text { Secchi depth }\end{array}$ & & -0.83 & & & 0.87 & & & 0.85 & & & & & & & & & & & \\
\hline
\end{tabular}




\subsubsection{Benthic carnivores}

The surveys and trend analyses documented that benthic carnivores in coastal and offshore habitat have experienced different population developments since 1993. While benthic carnivores with a coastal distribution have either shown moderate declines, stable populations or increases seaducks and mergansers with an offshore distribution have all declined seriously. Unfortunately, long time series of the abundance of seaducks and mergansers in the offshore parts of the Baltic Sea have not been available. Accordingly, despite steep declines in DIN and DIP which have coincided with the declines in all seaduck species and in Redbreasted Mergansers the correlations with nutrient concentrations are generally weak (Figures 31-32, Tables 31-24). Red-breasted Mergansers displayed correlations with nutrient concentrations in the Straits. Positive correlations with water temperature are seen throughout the Baltic for ducks of Aythya genus and Goldeneye. These linkages are most likely caused by indirect and direct mortality coupled to severe winter conditions. No effects of water temperature is seen on offshore species of seaducks, which is in line with Hario et al. (2009b), who reported that the Baltic Sea winter climate, as measured with winter NAO index, had no effect on female eider survival in a 48-year-long time series on capture-recapture data from the Gulf of Finland.

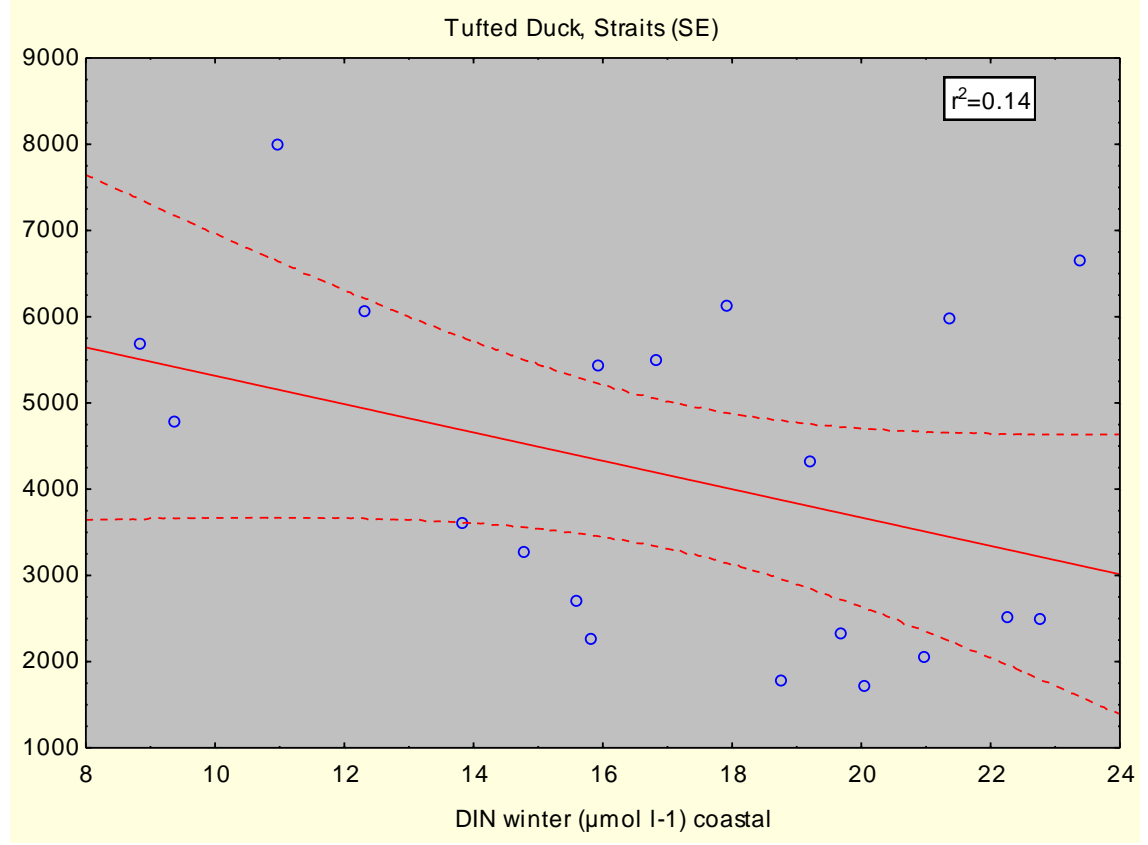



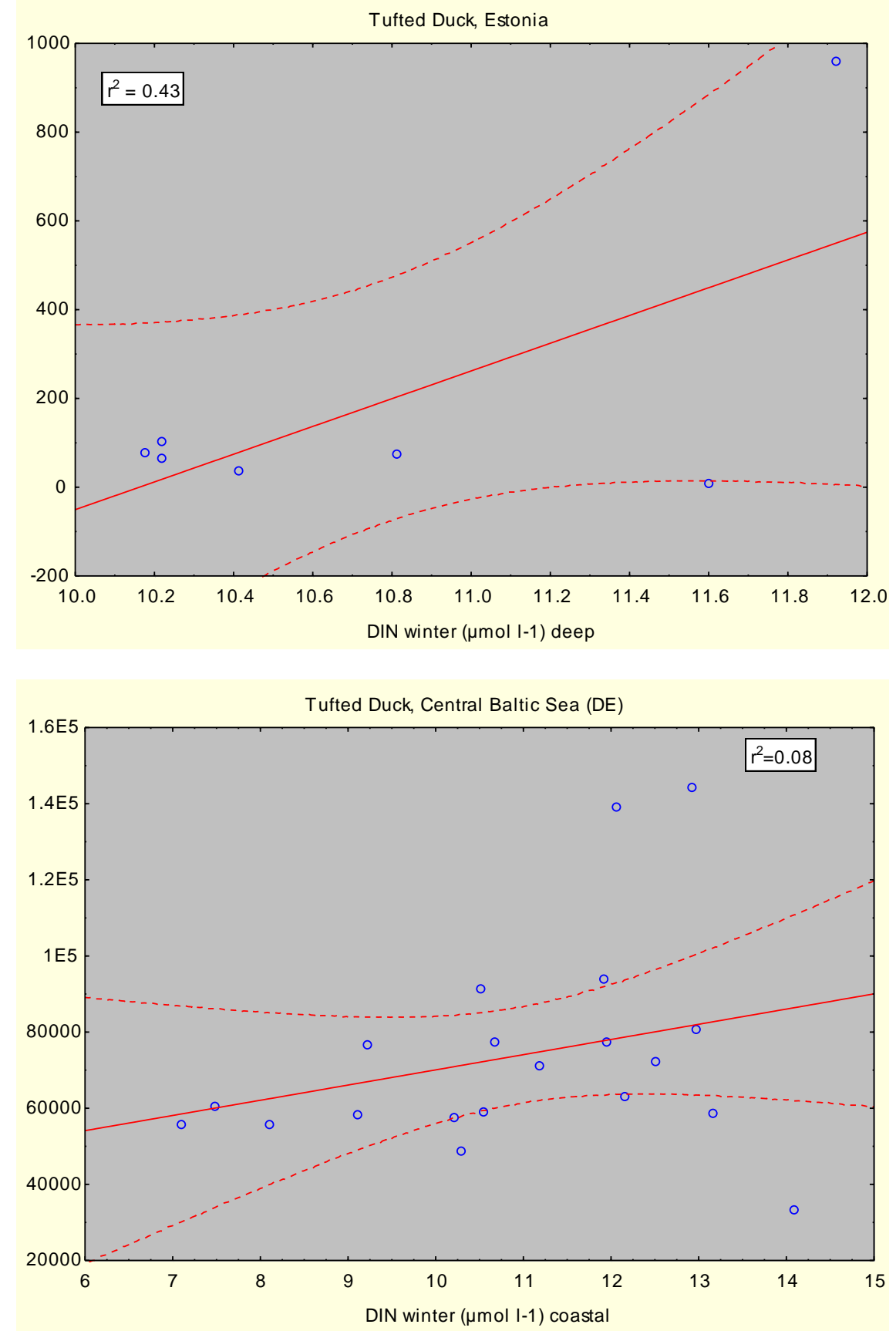

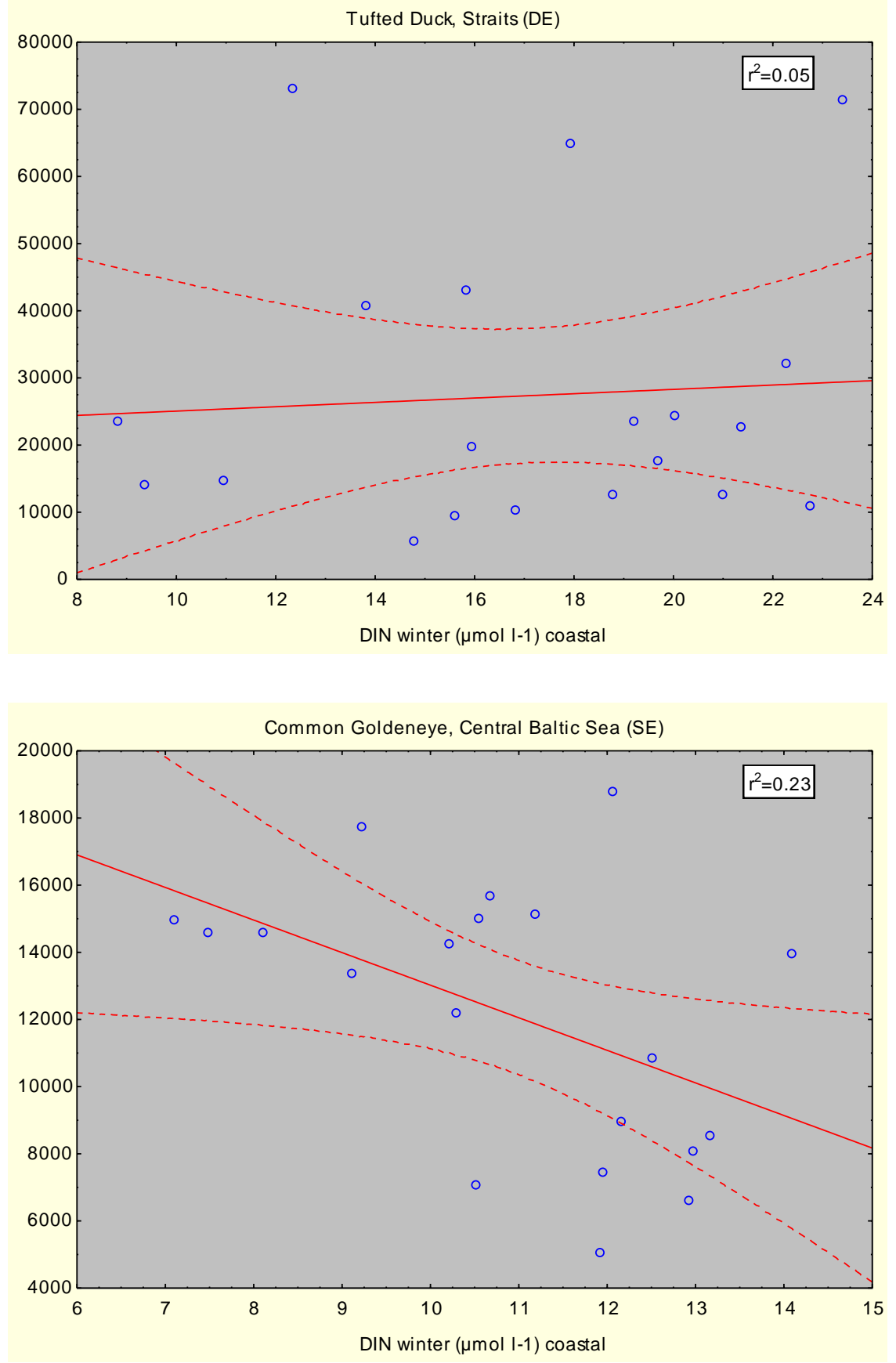


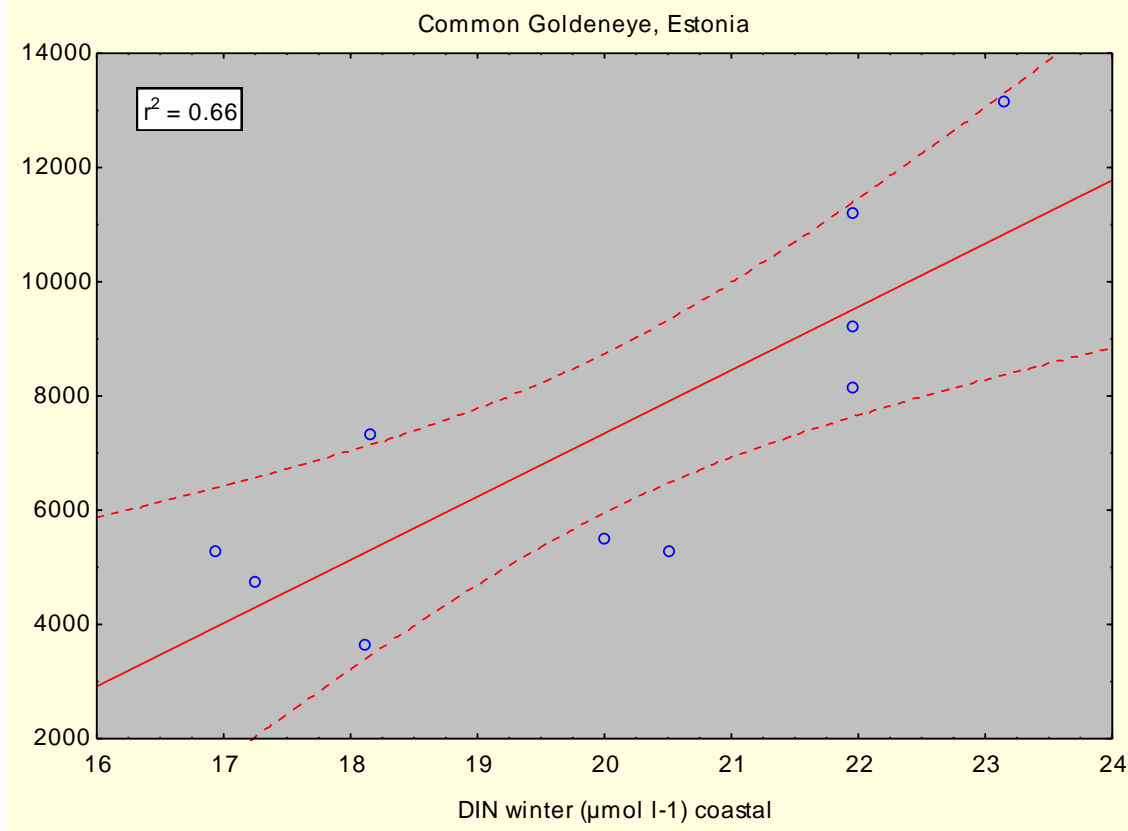

Figure 31. Plots of relationship between selected species (regions) of coastal ducks and pressures. Linear fit (solid line) and 95\% confidence intervals (hatched lines) are indicated.

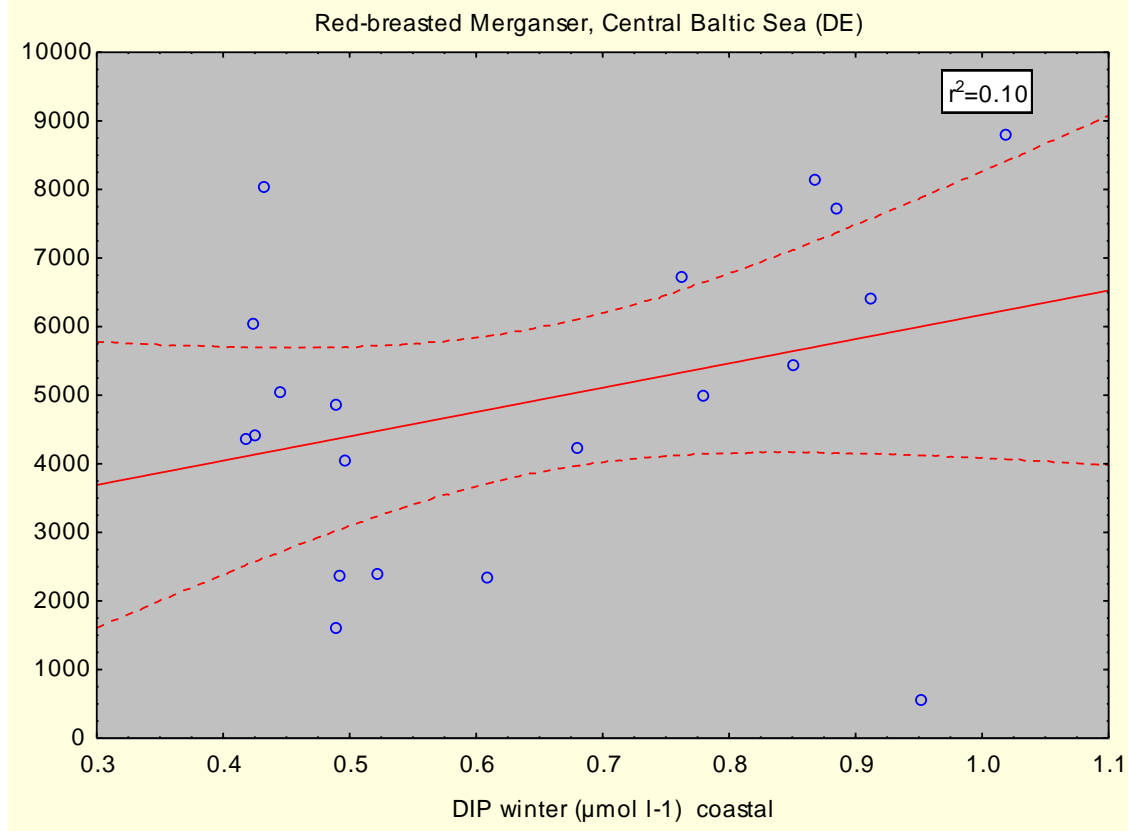



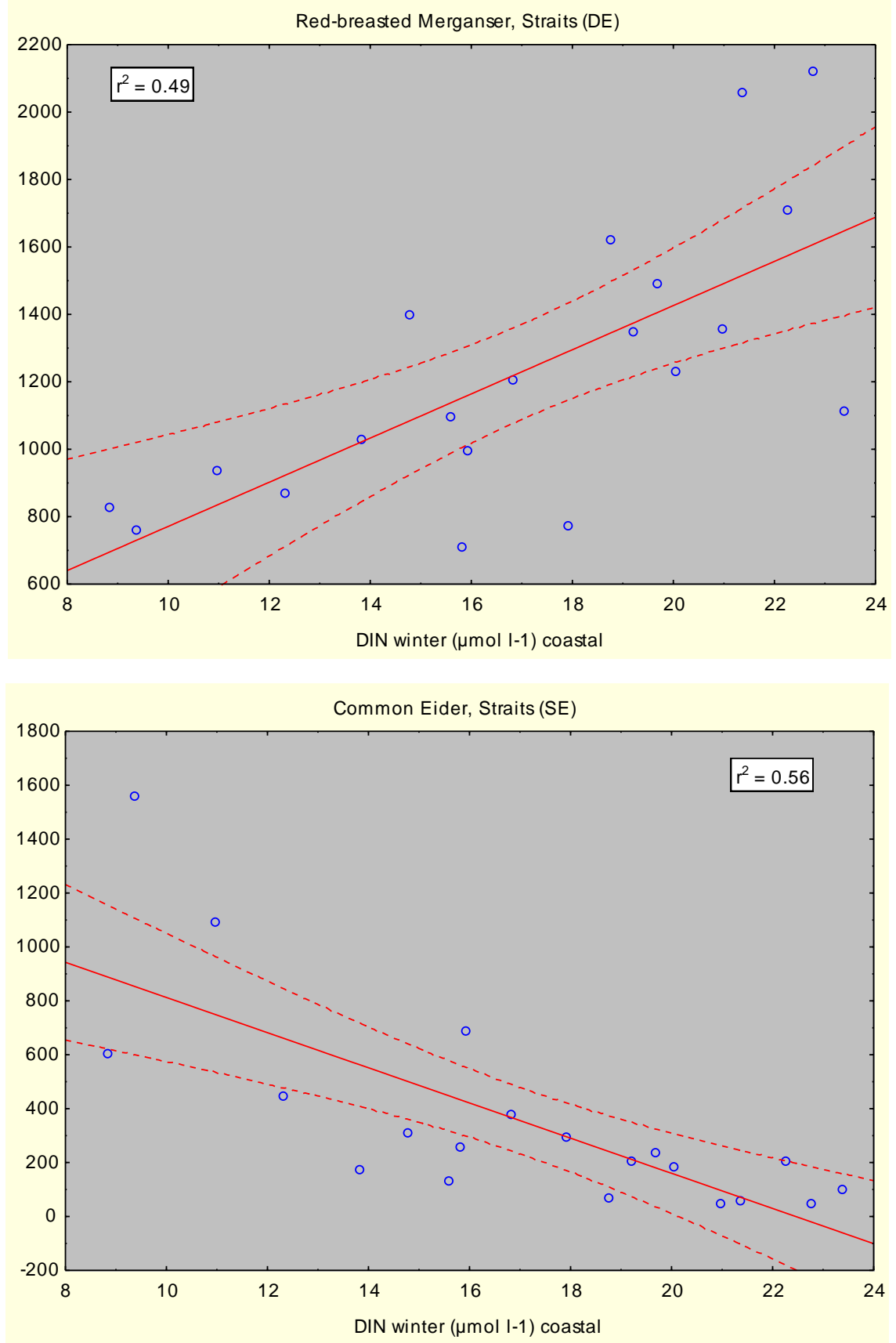


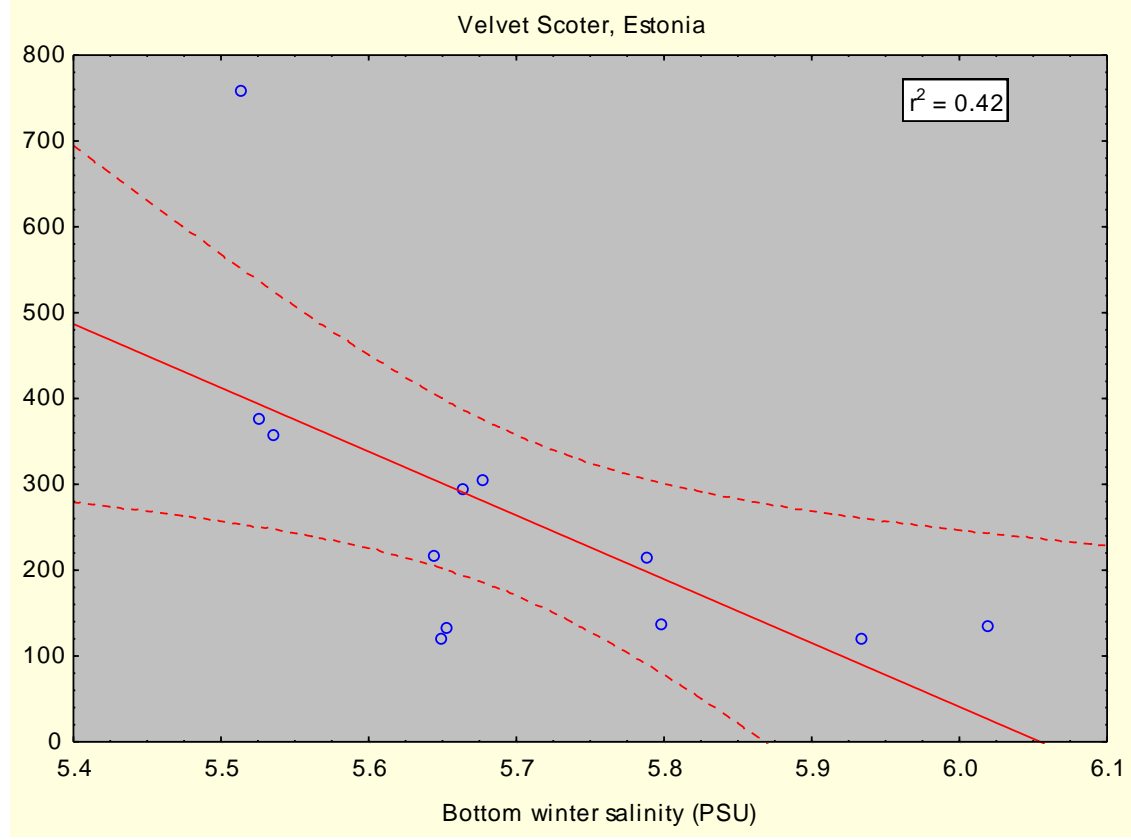

Figure 32. Plots of relationship between selected species (regions) of mergansers, seaducks and pressures. Linear fit (solid line) and 95\% confidence intervals (hatched lines) are indicated.

\subsubsection{Piscivores}

Negative correlations with nutrient concentrations were documented in the number of both Red-necked Grebe and Great Crested Grebe recorded in Estonia and the numbers of Cormorants recorded in Finland indicating that the north-ward shift in their distribution may not only be governed by climate change, but also by reductions in nutrient loads and improvements in water quality (Figure 33, Tables 33-34). In the Kattegat, where Great Cormorants have decreased since 1993, the numbers of cormorants displayed a negative relationship with bottom winter temperatures. 

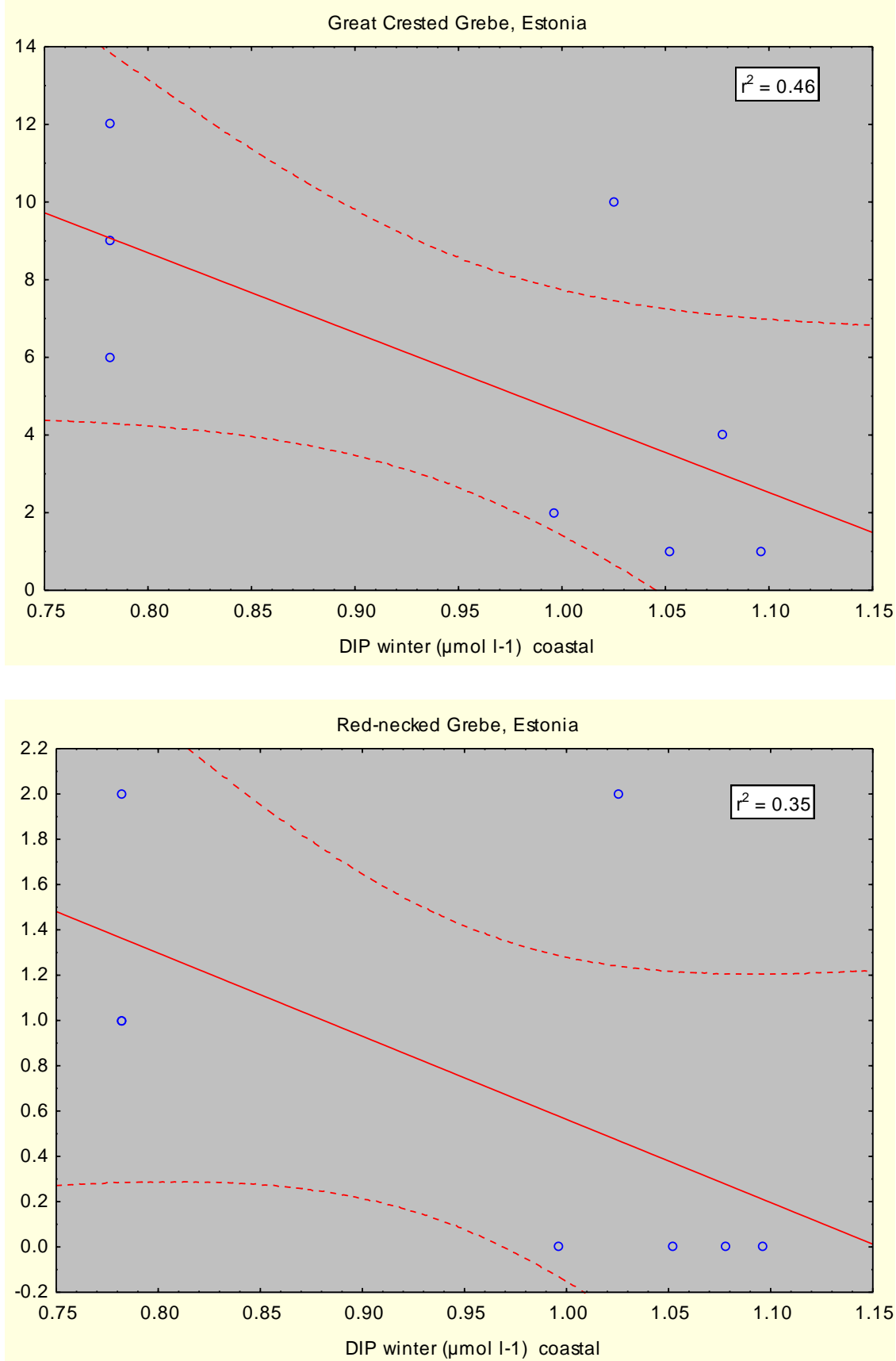

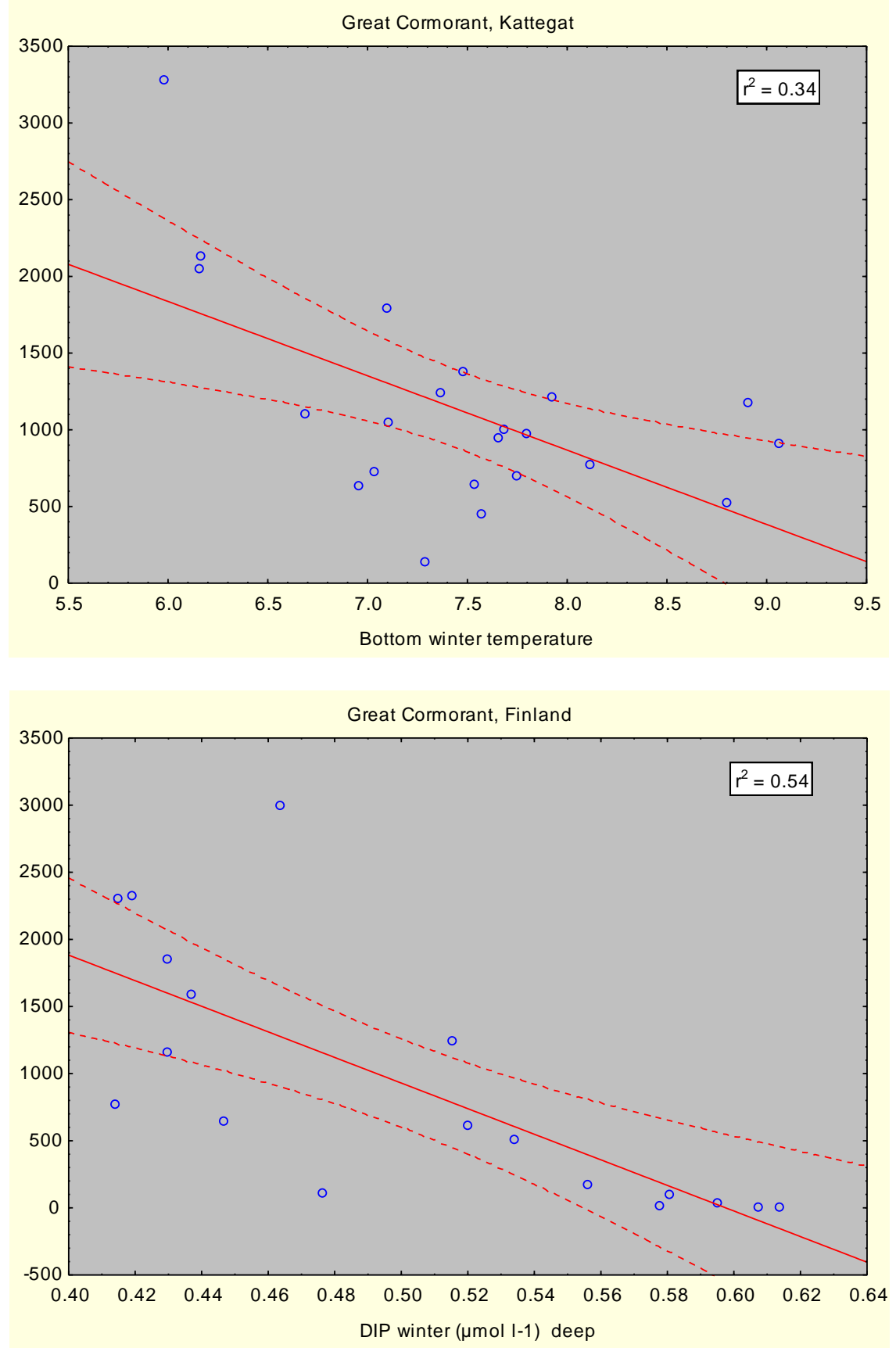

Figure 33. Plots of relationship between selected species (regions) of piscivores and pressures. 



\section{Guidelines for management and monitoring}

In chapter 8, a qualitative and quantitative assessment was made of the impact of the different anthropogenic pressures on current population numbers of waterbirds in the Baltic Sea. In this chapter, an attempt will be made to synthesize the results of the individual assessments into recommendations for indicators. Indicators are here interpreted as both priority species for conservation and species which may be used as performance indicators in relation to the international and national actions taken to reduce the anthropogenic pressures in the Baltic Sea. As documented in chapter 8 , multiple pressures can be identified as playing an important (either negative or positive) role in the development of populations and distributions of most species of waterbirds. Teasing out the relative influence of each pressure on the health and conservation status of each species will require more detailed statistical analyses, which are outside the scope of this report. Thus, the suggested indicators should be seen as a first step in the direction of including targets and indicators for wintering waterbirds into the Baltic Sea Action Plan (BSAP). The goal of BSAP is to restore good ecological status of the Baltic marine environment by 2021, i.e. the Baltic Sea should be unaffected by eutrophication, life in the sea should be undisturbed by hazardous substances, maritime activities in the Baltic Sea should be carried out in an environmentally friendly way and the Baltic Sea biodiversity should have a favourable conservation status.

With the current developlement of Baltic waterbird populations this goal seems unachievable unless the available scientific knowledge on key waterbird pressures is being used to include waterbird indicators in the preliminary pool of biological indicators in the HELCOM biodiversity assessment. The BSAP is based on a clear set of 'ecological objectives' defined to reflect a jointly agreed vision of "a healthy Baltic Sea environment". Each of the objectives has been designed to reflect and further specify one of the four Strategic Goals. The Ecological Objectives for eutrophication are:

- Clear water

- Concentrations of nutrients close to natural levels

- Natural level of algal blooms

- Natural distribution and occurrence of plants and animals

- Natural oxygen levels 
The objectives with regard to hazardous substances are:

- Concentrations of hazardous substances close to natural levels

- All fish safe to eat

- Healthy wildlife

- Radioactivity at pre-Chernobyl level

The objectives with regard to maritime activities are managementoriented. They are:

- Enforcement of international regulations - No illegal discharges

- Safe maritime traffic without accidental pollution

- Efficient emergency and response capability

- Minimum sewage pollution from ships

- No introductions of alien species from ships

- Minimum air pollution from ships

- Zero discharges from offshore platforms

- Minimum threats from offshore installations

The objectives with regard to biodiversity are:

- Natural marine and coastal landscapes

- Thriving and balanced communities of plants and animals

- Viable populations of species

The biodiversity objectives can be characterized as being 'downstream' and thus integrating the cumulative effects from eutrophication, inputs of hazardous substances and maritime activities. Obviously, the results of this status report on wintering waterbirds indicate that the objectives for eutrophication and biodiversity may be diverging, and at least in the sublittoral parts of the Baltic Sea largely conflicting. Monitoring the future development of wintering waterbirds in the Baltic Sea is a priority if the goal of the BSAP shall be reached in 10 years from now. The plan for a future Baltic-wide monitoring programme focused on waterbirds within HELCOM (HELCOM HABITAT 2004) should be implemented in the short term. The results of this report provide a comprehensive baseline for a future waterbird monitoring programme. As shown by the trend analyses the counts of wintering waterbirds in the littoral zone of the Baltic Sea should be regarded as adequate to resolve time trends for most regions and countries for coastal waterbird species and habitats, including most ice-free lagoons, fjords and coastal areas. However, the almost complete lack of monitoring programmes for waterbirds wintering in sub-littoral areas will make it very difficult to track changes in populations of wintering seaducks, the numerically most important group of waterbirds in the Baltic Sea. Thus, opportunities to integrate monitoring of seaduck populations within the Cooperative Monitoring in the Baltic Marine Environment (COMBINE) programme should be pursued. 
- The main purpose of the waterbird monitoring programme as described by HELCOM NATURE (2004) and Skov (2007) is to provide a framework for assessments of ecosystem health by analysing observations of waterbirds from population to community levels. One of the reasons why the inclusion of waterbird monitoring in HELCOM COMBINE will constitute a major step towards ecosystem-based monitoring of the Baltic Sea is the fact that long-standing waterbird monitoring programmes exist for representative areas of all coastal regions and that waterbirds are comparatively visible organisms which can be counted with only minor bias. The programme is composed of monitoring of breeding and non-breeding waterbirds, monitoring of Arctic migration of waterbirds and beached bird surveys of oil pollution (Figure 34). An important advantage of capitalising on the existing long-term monitoring programmes for breeding and wintering waterbirds as well as on beached bird surveys will be the fact that the baseline year can be set as far back as 1987.

Waterbirds are migratory, hence the variability of non-breeding concentrations are not only related to wintering grounds but also related to ecosystem conditions over large parts of Russia and Fennoscandia. Breeding success and numbers of breeding pairs, however, provide information on environmental effects at smaller scale, and typically in coastal waters of more complicated pressures. Although it is not the responsibility of the waterbird monitoring programme to provide indepth understanding of the relationship between observed patterns (abundance, community structure) and ecosystem changes and pressures the monitoring should provide a synthesis of observed changes to verify whether or not changes are relevant and related to anthropogenic or natural stress. When changes are detected but their relevance is unclear, this should lead to a priori designed analytical follow-up studies addressing the cause of the change and its further ecological significance. The objectives of the waterbird monitoring programme are set to:

- Monitor long-term trends of waterbird numbers and species composition at different scales from specific areas (BSPAs, SPAs, IBAs) to communities (lagoons, coastal, offshore, deep water, banks etc.) and populations (basins, countries, Baltic);

- Provide in situ data on key environmental variables and stressors for comprehensive and integrated interpretations of waterbird distribution and abundance;

- Provide data on natural variations in Baltic waterbird populations;

- Estimate the response of measures taken to increase ecosystem health and reduce negative impacts from fisheries;

- Provide data for development and implementation of Ecological Quality Objectives; 
- Provide information for HELCOM's periodic assessments on biodiversity;

- Provide reference data for local monitoring

- Assess the existing level of chronic oil and chemical pollution in the maritime area

- Assess the effectiveness of measures taken for the reduction of chronic oil pollution (using oiled beached birds as indicators);

- Assess the effect of oil incidents on coastal birds and seabirds.

\section{HELCOM Waterbird Monitoring Programme}

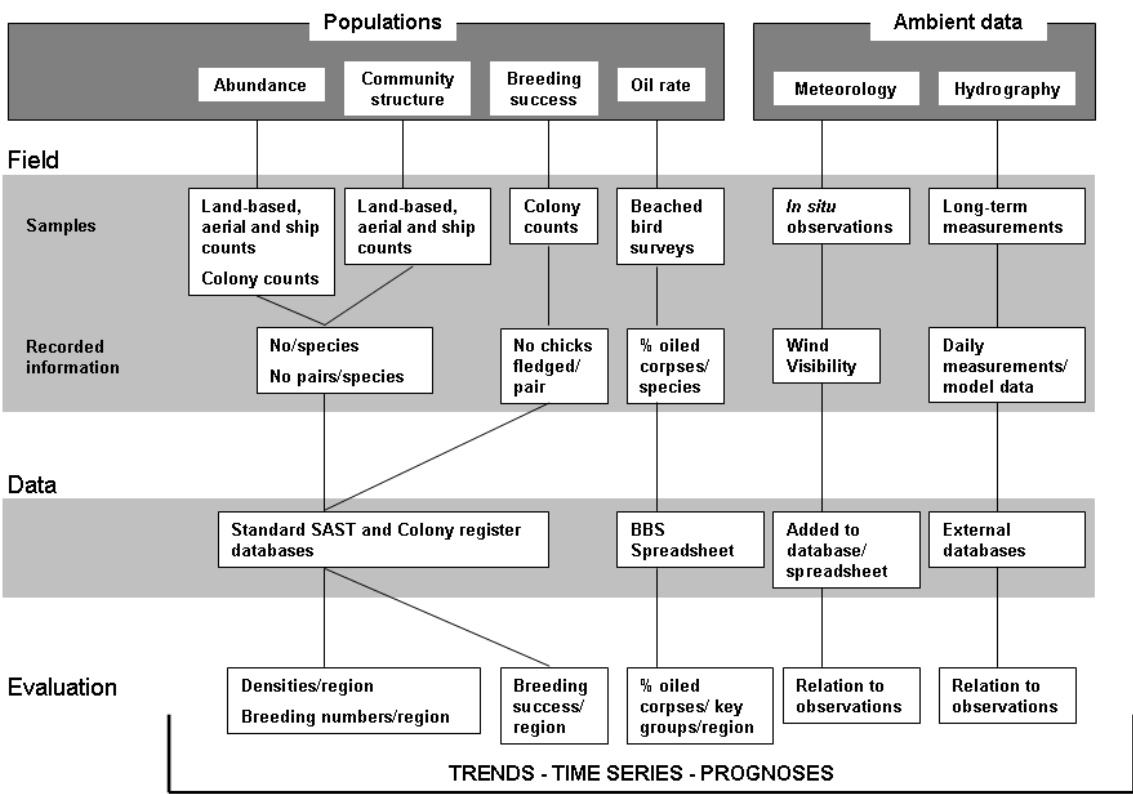

Figure 34. Sketch of the planned HELCOM Waterbird Monitoring Programme (Skov 2007)

As agreed with HELCOM the final selection of waterbird indicators should await the results of the SOWBAS project. In the following draft indicators for wintering waterbirds are listed both in terms of priority species for conservation and species which may be used as performance indicators in relation to international and national actions taken to reduce anthropogenic pressures. Further work on the development of waterbird indicators is expected in the short term within the HELCOM CORESET project http://www.helcom.fi/projects/on_going/en_GB/coreset/, the MARMONI http://marmoni.balticseaportal.net and HARMONY Projects . 


\subsection{Priority species for conservation}

A Baltic-wide monitoring programme for non-breeding waterbirds should include priority species for conservation selected on the basis of an unfavourable conservation status (SPEC 2 and 3, Tucker \& Heath 1997), on the basis of being listed on Annex I to the EU Birds Directive (EU Birds Directive 1979) or on the basis of the importance of the Baltic Sea to the relevant bio-geographic population. With respect to the latter, species for which the Baltic Sea is of global significance in relation to the reference bio-geographic population ( $\geq 25 \%$, Table 27 ), have been selected.

Table 35. Species for which representative parts of the non-breeding Baltic populations should be covered by the waterbird monitoring programme.

\begin{tabular}{lll}
\hline Species & & Prey type \\
\hline Red-/Black-throated Diver & Gavia stellata/arctica & Fish \\
Red-necked Grebe & Podiceps grisegena & Fish and invertebrates \\
Slavonian Grebe & Podiceps auritus & Fish and invertebrates \\
Mute Swan & Cygnus olor & Benthic vegetation \\
Tufted Duck & Aythya fuligula & Benthic invertebrates \\
Scaup & Aythya marila & Benthic invertebrates \\
Eider & Somateria mollissima & Benthic invertebrates \\
Steller's Eider & Polysticta stelleri & Benthic invertebrates \\
Long-tailed Duck & Clangula hyemalis & Benthic invertebrates \\
Common Scoter & Melanitta nigra & Benthic invertebrates \\
Velvet Scoter & Melanitta fusca & Benthic invertebrates and fish \\
Goldeneye & Bucephala clangula & Benthic invertebrates \\
Smew & Mergus albellus & Benthic invertebrates \\
Red-breasted Merganser & Mergus serrator & Coastal fish \\
Goosander & Mergus merganser & Benthic invertebrates and fish \\
Black Guillemot & Cepphus g. grylle & Benthic invertebrates and fish \\
\hline
\end{tabular}

The list shows species with an unfavourable conservation status (SPEC 2 and 3, Tucker \& Heath 1997), species listed in Annex I to the Birds Directive (EU Birds Directive 1979) and species for which the Baltic Sea is considered of global importance. The main category of prey taken by the species is indicated.

\subsection{Performance indicators}

\subsubsection{Climate change}

Although the BSAP does not yet cover objectives related to climate changes it is worth noting that ubiquitous north-ward shifts in the distribution of wintering waterbirds have taken place over the last 15 years. The majority of northward distribution shifts may be coupled to reductions in ecosystem capacity in the southern Baltic as well as to increases in water temperature and the related increased availability of open water areas. Despite a lack of distributional change the trends of Mute swan, Mallard and Common Coot are also positively correlated with rising water temperatures in the Baltic Sea. This relationship is not surprising given the sensitivity of these species to cold winter and extensive ice cover. Accordingly, a wide range of waterbird ecotypes (herbivores, omnivores, molluscivores) may be used as indicators of climate change (Table 36). 
Table 36. List of indicator waterbird species in relation to climate change based on documented responses to rising winter temperatures and northward distribution shifts.

\begin{tabular}{ll}
\hline Species & Response to climate change \\
\hline Great Crested Grebe & Northward distributional shift \\
Cormorant & Northward distribution shift \\
Mute swan & Increasing winter population \\
Mallard & Increasing winter population \\
Common Pochard & Northward distribution shift \\
Tufted Duck & Northward distribution shift \\
Greater Scaup & Northward distribution shift \\
Common Scoter & Northward distribution shift \\
Common Goldeneye & Northward distribution shift \\
Smew & Northward distribution shift \\
Goosander & Northward distribution shift \\
Common Coot & Increasing winter population \\
\hline
\end{tabular}

\subsubsection{Eutrophication}

The long-term reduction in loads of nitrogen and phosphorous in the southern and central Baltic may be coupled to wide-spread declines since 1993 in almost all species feeding on benthic invertebrates and fish in sublittoral environments. The results of this study stress the importance of eutrophication as a key driving factor for the spatiotemporal variability in food supply for and abundance of bivalve-eating seaducks and fish-eating mergansers in the Baltic Sea. Further studies are needed to investigate the geographical and habitat specific responses of bivalve-feeding and fish-eating waterbirds to variable levels of reductions in nutrient load to the Baltic ecosystem. At this stage, however, large-scale declines in the number of wintering seaducks and mergansers have been observed in parallel to similar declines in nutrient loads of coastal waters of the southern and central Baltic Sea.

Table 37. List of indicator waterbird species in relation to eutrophication based on documented responses to levels of eutrophication.

\begin{tabular}{ll}
\hline Species & Response to eutrophication \\
\hline Great Crested Grebe & Decreasing winter population \\
Cormorant & Decreasing winter population \\
Mute swan & Decreasing winter population \\
Mallard & Decreasing winter population \\
Common Eider & Increasing winter population \\
Long-tailed Duck & Increasing winter population \\
Common Scoter & Increasing winter population \\
Velvet Scoter & Increasing winter population \\
Red-breasted Merganser & Increasing winter population \\
Common Coot & Decreasing winter population \\
\hline
\end{tabular}

\subsubsection{Oil pollution/shipping}

Illegal discharges of oil pollution from ship traffic introduce significant extra mortality to wintering waterbirds in offshore Baltic waters. The scale and significance of the problem can not currently be assessed for all areas, but for Swedish offshore waters current mortality rates and proportions of oiled birds indicate that oil pollution possesses one of the most important threats to waterbirds, particularly to Long-tailed Ducks and 
Black Guillemots. Indicators of oil pollution level can be developed from beached bird surveys and samples of net-drowned birds.

Table 38. List of indicator waterbird species in relation to oil pollution based on current levels of oil-induced mortality.

\begin{tabular}{ll}
\hline Species & Response/Level of oil-induced mortality \\
\hline Long-tailed Duck & High \\
Black Guillemot & High \\
Multiple vulnerable waterbird species, beached & Increasing oil rates with increasing level of oil pollu- \\
birds & tion \\
\hline
\end{tabular}

\subsubsection{By-catch}

Despite the current lack of national or international monitoring programmes on incidental by-catches of waterbirds in the Baltic Sea bycatches have been reported in several areas and for several fisheries/waterbird scenarios in the Baltic Sea. In general, all diving species today experience extra-mortality due to by-catches in gill-nets. Without dedicated monitoring activities no reliable estimates of the scale of the problem can be obtained. 



\section{References}

Al-Hamdani, Z. \& Reker, J. (eds.). 2007. Towards marine landscapes in the Baltic Sea. BALANCE interim report \#10. Available at http://balance-eu.org/.

Andersson, Å. \& R. Staav. 1980. Den häckande kustfågelfaunan i Stockholms län 1974-75. Stockholms läns landsting. Regionplanekontoret. Nacka.

Anker-Nielssen, T. 1992. Food-supply as a determinant of reproduction and population development in Norwegian Puffins Fratercula arctica. Ph. D. Thesis, University of Trodnheim, Department of Zoology, Trondheim, Norway.

Anker-Nielssen, T. \& Aarvak, T. 2002. The population ecology of Puffins at Røst. Status after the breeding season 2001. NINA Oppdragsmelding 736: 1-40.

Anon. 2007. Council Regulation (EC) No 1098/2007 of 18 September 2007 establishing a multiannual plan for the cod stocks in the Baltic Sea and the fisheries exploiting those stocks, amending Regulation (EEC) No 2847/93 and repealing Regulation (EC) No 779/97. Official Journal of the European Union, L 248/1, 22.9.2007.

Austin, M.P. 2002. Spatial prediction of species distribution: an interface between ecological theory and statistical modelling. Ecological Modelling, 157, 101-118.

Averbeck, C. 1991. Ergebnisse des 'Beached Bird Survey’ der Bundesrepublik Deutschland im Februar 1990. NNA Mitt. 3/91: 50-52.

Barrett, R. \& Krasnov, Y. 1996. Recent responses to changes in stocks of prey species by seabirds breeding in the southern Barents Sea. ICES Journal iof Marine Science 53: 713-722.

Barry, S.C. and Welsh, A.H. 2002. Generalized additive modelling and zero inflated count data. Ecological Modelling, 157, 179-188.

BACC Author Team. 2008. Assessment of Climate Change for the Baltic Sea Basin. Series: Regional Climate Studies. Springer Verlag, Heidelberg. 474 p.

Baduini, C., Hyrenbach, K., Coyle, K., Pinchuk, a., Menenhall, V. \& Hunt G. 2001. Massmortality of short-tailed shearwaters in the south-eastern Bering Sea during summer 1997. Fisheries Oceanography 10: 117-130.

Bellebaum, J. 2011. Untersuchung und Bewertung des Beifangs von Seevögeln durch die passive Meeresfischerei in der Ostsee. BfN-Skripten 295. Bundesamt für Naturschutz. Vilm.

Bivand, R. 2009. Spatial dependencies: weighting schemes, statistics and models. R package version $0.4-34$.

Blake, B.F. 1984. Diet and fish stock availability as possible factors in the mass death of auks in the North Sea. Journal of Experimental Marine Biology and Ecology 76: 89-103.

Bregnballe, T., Noer, H., Christensen, T.K., Clausen, P., Asferg, T., Fox, A.D. \& Delany, S. 2006. Sustainable hunting of migratory waterbirds: the Danish approach. Waterbirds around the world. Eds. G.C. Boere, C.A. Galbraith \& D.A. Stroud. The Stationery Office, Edinburgh, UK. pp. 854-860.

Buckland, S.T., Anderson, D.R., Burnham, K.P. \& Laake, J.L. 1993. Distance sampling: estimating abundance of biological populations. Chapman \& Hall. London.

Camphuysen, C.J., 1995. Project 'Beached Bird Survey': de waarde van tellingen van olie slachtoffers op het strand bij het inschatten van veranderingen in de de vervuiling van de zee door olie. Final report DGSM contract 2835(70/4/127), CSR Report 92-02, DLO Instituut voor Bosen Natuuronderzoek, Wageningen.

Camphuysen, C.J. and van Franeker, J.A. 1992. The value of beached bird surveys in monitoring marine oil pollution. Techn. Rapport Vogelbescherming 10, Vogelbescherming Nederland, Zeist, 191 pp. 
Camphuysen, K. J., Fox, A. D., Leopold, M. F. and Petersen, I. K. 2004. Towards standardised seabirds at sea census techniques in connection with environmental impact assessments for offshore wind farms in the U.K.: a comparison of ship and aerial sampling methods for marine birds, and their applicability to offshore wind farm assessments (PDF, $2.7 \mathrm{mb}$ ), NIOZ report to COWRIE (BAM - 02-2002). Texel. 37pp.

Carstensen, J., D.J. Conley, J.H. Andersen \& G. Ertebjerg. 2006. Coastal eutrophication and trend reversal: A Danish case study. Limnology \& Oceanology 51: 398-408.

Clausen, P. 2006. Negative effects of eutrophication on food resources for herbivorous water-birds in four Danish wetlands - and its potential negative influence on their present conservation status. Research and Management of Eutrophication in Coastal Ecosystems, Ny-borg, Denmark, 20-23 June 2006.

Cloern, J.E., 2001. Our evolving conceptual model of the coastal eutrophication model. Mar. Ecol. Prog. Ser. 210: 223-253.

Conley, D.J., C. Humborg, L. Rahm, O.P. Savchuk \& F. Wulff. 2002. Hypoxia in the Baltic Sea and Basin-Scale changes in phosphorous and biogeochemistry. Environmental Science \& Technology 36: 5315-5320.

Crick, H. 2004. The impact of climate change on birds. Ibis 146(Suppl.):48-56.

Dagys, M., Žydelis, R. 2002. Bird bycatch in fishing nets in Lithuanian coastal waters in wintering season 2001-2002. Acta Zoologica Lituanica 12 (3), 276-282.

Dagys, M., Ložys, L., Žydelis, R., Stipniece, A., Minde, A., Vetemaa, M. 2009. Action C1 Assessing and reducing impact of fishery by-catch on species of community interest. LIFE Nature project "Marine Protected Areas in the Eastern Baltic Sea” Reference number: LIFE 05 NAT/LV/000100. Final Report.

Delany, S., \& D. Scott, eds. 2006. Waterbird Population Estimates - Fourth Edition. Wetlands International, Wagingen, The Netherlands.

Dillingham, P.W., Fletcher, D., 2008. Estimating the ability of birds to sustain additional human-caused mortalities using a simple decision rule and allometric relationships. Biological Conservation 141, 1783-1792.

Dierschke, V., Helbig, A.J., and Barth, R. 1995. Ornithologischer Jahresbericht 1994 für Hiddensee und Umgebung. Berichte Vogelwarte Hiddensee, 12: 41-96.

Durinck, J., Skov, H., Jensen, F.P. \& Pihl, S. 1994. Important Marine Areas for Wintering Birds in the Baltic Sea. EU DG XI research contract no. 2242/90-09-01. Ornis Consult report.

Ellermaa, M., Pettay, T. \& Könönen, J. 2010. Sügisränne Põõsaspeal 2009. Aastal. Hirundo 23: 21-46.

EU Birds Directive. 1979. Council Directive of 2 April 1979 on the conservation of wild birds (79/409/EEC). Official Journal of the European Communities No. L103, 25-04-1979.

Fielding, A.H. \& Bell, J.F. 1997. A review of methods for the assessment of prediction errors in conservation presence/absence models. Environ. Conserv., 24, 38-49.

Franson, J.C., Holmén, T., Hario, M., Kilpi, M. \& D.L. Finley. 2002. Lead and deltaaminolevulinic acid dehydratase in blood of Common Eiders (Somateria mollissi$m a$ ) from the Finnish archipelago. Ornis Fennica 79: 87-91.

Garthe, S. \& Scherp, B. 2003. Utilization of discards and offal from commercial fisheries by seabirds in the Baltic Sea. ICES Journal of Marine Science 60: 980-989.

Garthe, S., Ullrich, N., Weichler, T., Dierschke, V., Kubetzki, U., Kotzerka, J., Krüger, T., Sonntag, N., Helbig, A.J. 2003. See- und Wasservögel der deutschen Ostsee - Verbreitung, Gefährdung und Schutz. Report to the Federal Agency for Nature Conservation, Bonn.

Hario, M., Rintala, J. \& Nordenswan, G. 2009. Allin aallonpohjat Itämerellä - taustalla öljyvahingot, sopulisyklit vai metsästys? Suomen Riista 55: 83-96.

Hario, M., Mazerolle, M. J. \& Saurola, P. 2009. Survival of female common eiders Somateria m. mollissima in a declining population of the northern Baltic Sea. Oecologia 159: 747-756. 
Harris, M. \& Wanless, S. 1996. Differential responses of Guillemots (Uria aalge) and Shag (Phalacrocorax aristotelis) to a late winter wreck. Bird Study: 43: 220-230.

Hartmann, E., and Stier, N. 2003. Raubsäuger in Küstenvogelschutzgebieten Mecklenburg-Vorpommerns - einer Gefahr für Bodenbrüter? Vogelkundliche Berichtung Niedersachsen, 35: 83-90.

Hastie, T.J. \& Tibshirani, R.J., 1990. Generalised Additive Models. Chapman and Hall, London. 335pp.

HELCOM HABITAT. 2004. Minutes of the 6th meeting of HELCOM Habitat. Sgt. Petersburg, Russia. Helsinki Commission.

HELCOM. 2007. HELCOM Baltic Sea Action Plan. Helsinki. 100 pp.

HELCOM. 2009. Eutrophication in the Baltic Sea - An integrated thematic assessment of the effects of nutrient enrichment in the Baltic Sea region. Baltic Sea Environment Proceedings 115B.

HELCOM. 2010. Hazardous substances in the Baltic Sea - An integrated thematic assessment of hazardous substances in the Baltic Sea. Baltic Sea Environment Proceedings $120 \mathrm{~B}$.

HELCOM. 2010. Ecosystem Health of the Baltic Sea 2003-2007: HELCOM Initial Holistic Assessment. Balt. Sea Environ. Proc. No. 122.

Heubeck, M. and Camphuysen, C.J. 1992. European beached bird survey schemes. Seabird Group Newsletter 62: 35.

Heubeck, M. 1991. Oil Pollution around Orkney and Shetland, 1976-1983. In: Camphuysen, C.J. and van Franeker, J.A. (eds). Oil pollution, Beached Bird Surveys and Policy: towards a more effective approach to an old problem. Sula 5 (special issue): 6-11.

Hjorth, M. \& Josefson, A.B. (red.) 2010: Marine områder 2008. NOVANA. Tilstand og udvikling i miljø- og naturkvaliteten. Danmarks Miljøundersøgelser, Aarhus Universitet. $136 \mathrm{~s}$.

ICES. 2003. A review of the status and trends of seabirds in the Baltic Sea. ICES CM 2003/C: 03. Copenhagen.

ICES, 2007. Report of the Baltic Fisheries Assessment Working Group (WGBFAS), 17-26 April 2007, ICES Headquarters, Copenhagen, Denmark. ICES CM 2007/ACFM:15.

ICIA. 2004. Impacts of a warming Arctic. Cambridge University Press. Cambridge Jørgensen, B. 1997. Theory of Dispersion Models. Chapman and Hall, London.

Kubetzki, U. 2001. Zum Bestandsrückgang der Sturmmöwe (Larus canus) an der schleswig-holsteinischen Ostseeküste - Ausmaß, Ursachen und Schutzkonzepte. Corax, 18: 301-323.

Laake, J.L., Buckland, S.T., Anderson, D.R. \& Burnham, K.P. 1991. DISTANCE User's Guide V2.0. Colorado Cooperative Fish \& Wildlife Research Unit. Colorado State University. Fort Collins. CO.

Larsson, K. och Tydén, L. 2005. Effects of oil spills on wintering Long-tailed Ducks Clangula hyemalis at Hoburgs bank in central Baltic Sea between 1996/97 and 2003/2004. Ornis Svecica 15:161-171.

Larsson, K. och Tydén, L. 2009. Inventeringar av oljeskadad alfågel längs Gotlands sydkust under perioden 1996/97 till 2008/09. Rapport Högskolan på Gotland.

Lehikoinen, E. \& H. Skov 2008. Climate related ecosystem change - Seabirds. In: BACC Author Team: Assessment of Climate Change for the Baltic Sea Basin. Series: Regional Climate Studies. Springer Verlag, Heidelberg. 474 p.

Lehikoinen, E., Ekroos, J., Jaatinen, K., Lehikoinen, P., Lindén, A., Piha, M., Vattulainen A. \& Vähätalo, A.2008. Bird population trends based on the data of Hanko Bird Observatory (Finland) during 1979-2007 (in Finnish). Tringa 4/2008: 146-209.

Linnman, G. 1983. Seasonal eutrophication by wildfowl in basins isolating from the sea. Hydrobiologia: 103-1.

Lundberg, C., 2005. Eutrophication in the Baltic Sea. Åbo Akademi University. 
Mooij, J.H. 2005. Protection and use of waterbirds in the European Union. Beiträge zur Jagd- und Wildforschung 30, 49-76.

Møller, A., Fiedler, W. \& Berthold, P. (editors) 2004. Birds and Climate Change. Advances in Ecological Research 35:1-259.

Nakashima, B. 1996. The relationship between oceanographic conditions in the 1990s and changes in spawning behaviour, growth and early life history of capelin (Mallotus villosus). NAFO Scientific Council Research Document 94/74: 18.

Nausch, G., W. Mätthäus \& R. Feistel. 2003. Hydrographic and hydrochemical conditions in the Gotland Deep area between 1992 and 2003. Oceanology 45:557-569.

Niel, C., Lebreton, J.-D., 2005. Using demographic invariants to detect overharvested bird populations from incomplete data. Conservation Biology 19, 826-835.

Nilsson, L. 1972. Habitat selection, food choice, and feeding habits of diving ducks in coastal waters of south Sweden during the non-breeding season. Ornis Scand. 3: $55-78$.

Nilsson, L. 2008. Changes in numbers and distribution of wintering waterfowl in Sweden during forty years, 1967-2006. Ornis Svecica 18: 135-226.

Nilsson, L. \& Green, M. In prep. Monitoring of birds at the Lilgrund wind farm in Öresund. Report to Vattenfall. University of Lund.

Noer, H., Asferg, T., Clausen, P., Olesen, C.R., Bregnballe, T., Laursen, K., Kahlert, J., Teilmann, J., Christensen, T.K. \& Haugaard, L. 2009: Vildtbestande og jagttider i Danmark: Det biologiske grundlag for jagttidsrevisionen 2010. Danmarks Miljøundersøgelser, Aarhus Universitet. 288 p. - Faglig rapport fra DMU nr. 742. http://www.dmu.dk/Pub/FR742.pdf

Nordic Council of Ministers. 2005. Environmental Action Plan 2005-2008. Copenhagen. $35 \mathrm{pp}$.

Nordic Council of Ministers. 2008. Environmental Action Plan 2009-2012. Copenhagen. $37 \mathrm{pp}$.

Nordström, M., Högmander, J., Laine, J., Nummelin, J., Laanetu, N., Korpimäki, E. 2003. Effects of feral mink removal on seabirds, waders and passerines on small islands in the Baltic Sea. Biological Conservation, 109: 359-368.

Österblom, H., S. Hansson, U. Larsson, O. Hjerne, F. Wulff, R. Elmgren \& C. Folke. 2007. Human induced trophic cascades and ecological regime shifts in the Baltic Sea. Ecosystems 10: 877-889.

Pearson,T. \& R. Rosenberg. 1978. Macrobenthic succession in relation to organic enrichment and pollution of the marine environment, Oceanogr. Mar. Biol. Ann. Rev. 16: 229-311.

Petersen, I.K., Pihl, S., Hounisen, J.P., Holm, T.E., Clausen, P., Therkildsen, O.R., Christensen, T.K. 2006. Landsdækkende optællinger af vandfugle, januar og februar 2004. - Danmarks Miljøundersøgelser. Faglig rapport fra DMU, nr. 606. 76 s.

Petersen et al. 2006. Final results of bird studies at the offshore wind farms at Nysted and Horns Rev, Denmark. Report request. Commissioned by DONG energy and Vattenfall A/S. National Environmental Research Institute. Ministry of the Environment, Denmark.

Piatt, J. \& Pelt, T. 1997. Mass-mortality of Guillemots (Uria aalge) in the Gulf of Alaska in 1993. Marine Pollution Bulletin 34: 656-662.

Pihl S. \& Frikke J. 1992, Counting birds from aeroplane. Pp. 8-21 in: J. Komdeur. J. Bertelsen \& G. Cracknell (Eds.). Manual for Aeroplane and Ship Surveys of Waterfowl and Seabirds. IWRB Special Publications No. 19.

Pihl S., Webb A., Frikke J. \& Durinck J. 1992. The importance of monitoring waterfowl and seabirds. Pp. 6-8 in: Komdeur. J. J. Bertelsen \& G. Cracknell (Eds.), Manual for aeroplane and Ship Surveys of Waterfowl and Seabirds. IWRB S ecial Publication No. 19.

Potts, J.M. \& Elith, J. 2006. Comparing species abundance models. Ecological Modelling, 199, 153-163. 
R Development Core Team . 2004. A language and environment for statistical computing. R Foundation for Statistical Computing, Vienna, Austria. http://www.Rproject.org.

Regehr, H. \& Rodway, M. 1999. Seabird breeding performance during two years of delayed Capelin arrival in the Northwest Atlantic: a multi-species comparison. Waterbirds 22: 60-67.

Rindorf, A., Wanless, S., Harris, M.P. 2000. Effects of changes in sandeel availability on the reproductive output of seabirds. Marine Ecology Progress Series 202: 241-252.

Rytkönen, J., Siitonen, L., Riipi, T., Sassi, J. \& Sukselainen. 2002. Statistical Analyses of the Baltic Maritime Traffic. Research report. No VAL34-012344. VTT Technical Research Centre of Finland. 153 sidor.

Rönkä, M., L. Saari, E. Lehikoinen, Suomela, J. \& Häkkilä, K.. 2005. Environmental changes and population trends of breeding waterfowl in the northern Baltic Sea. Ann. Zool. Fennici 42: 587-602.

Schirmeister, B., 2003. Verluste von Wasservögeln in Stellnetzen der Küstenfischerei - das Beispiel der Insel Usedom. Meer und Museum 17, 160-166.

Schneider, D.C. \& Duffy, D.C. 1985. Scale-dependent variability in seabird abundance. Mar. Ecol. Prog. Ser. 25: 211-218.

Segurado, PAGE, Araújo, M.B. \& Kunin, W.E. 2006. Consequence of spatial autocorrelation for niche-based models. Journal of Applied Ecology, 43, 433-444.

Skov, H. 2007. Helcom waterbird monitoring programme. Implementation 20052007. Report to HELCOM. DHI Report.

Skov, H. (Ed.) et al. In press. Modelling of the potential coverage of habitat-forming species and development of tools to evaluate the conservation status of the marine Annex I habitats (MOPODECO). TemaNord Series 2011.

Stefánsson, G. 1996. Analysis of groundfish survey abundance data: combining the GLM and delta approaches. ICES Journal of Marine Science, 53, 577-588.

Stempniewicz, L., 1994. Marine birds drowning in fishing nets in the Gulf of Gdansk (southern Baltic): numbers, species composition, age and sex structure. Ornis Svecica 4, 123-132.

Tasker, M.L., Jones, P.H., Dixon, D.J. \& Blake, B.F. 1984. Counting seabirds at sea from ships: a review of methods employed and a suggestion for a standardized approach. Auk 101: 567-577.

Tucker, G. M. and M.F. Heath. 1997. Birds in Europe: their conservation status. Cambridge, UK. BirdLife International.

Calcutta: Indian Statistical Institute.

Urtans, E., Priednieks, J., 2000. The present status of seabird by-catch in Latvian coastal fishery of the Baltic Sea. ICES CM 2000/J:14, pp. 1-8.

Viksne, J., \& Janaus, M. 1993. What is going on with the Black-headed Gull (Larus ridibundus) at the eastern coast of the Baltic? Ring 15: 154-158.

Viksne, J., Janaus, M., Stipniece, A. 1996. Recent trends of the Black-headed Gull (Larus ridibundus L.) population in Latvia. Ornis Svecica 6: 39-44.

Vīksne J., Janaus M., Stīpnieks A. 2008. Ūdensputnu medības Kaṇiera ezerā 1993.2005. gadā - dabas resursu nenoplicinošas izmantošanas piemērs. In Auniņš A. (red.) Aktuālā savval̦as sugu un biotopu apsaimniekošanas problemātika Latvijā. Latvijas Universitāte, Rīga, pp. 143-162.

Webb, A. \& Durinck, J. 1992. Counting birds from ship. In: Komdeur. J. J. Bertelsen \& G. Cracknell (Eds.), Manual for aeroplane and Ship Surveys of Waterfowl and Seabirds. IWRB S ecial Publication No. 19.

Wintle, B.A., Elith, J. and Potts, J.M. 2005. Fauna habitat modelling and mapping: A review and case study in the Lower Central Coast Region of NSW. Austral Ecology, 30, 719-738.

Wolowicz, M., A. Sokolowski, A.S. Bawazir, \& R. Lasota. 2006. Effect of eutrophication on the distribution and ecophysiology of the mussel Mytilus trossulus (Bivalvia) in 
southern Baltic Sea (the Gulf of Gdansk). Limnology and Oceanography 51 2-1: 580-590.

Wood, S.N. 2006. The mgcv package. R statistical group.

Wood, S.N. 2006. Generalised Additive Models - An Introduction with R. Chapman and Hall/CRS, Boca Raton, Florida.

Wood, S.N. and Augustin, N.H. 2002. GAMs with integrated model selection using penalized regression splines and applications to environmental modelling. Ecological Modelling, 157, 157-177.

Žydelis, R., Lorentsen, S-H., Fox, A.D., Kureso, A., Krasnov, Y., Goryaev, Y., Bustnes, J.O., Hario, M. Nilsson, L. \& Stipniece, A. 2006. Recent changes in the status of Steller's Eider Polysticta stelleri wintering in Europe: a decline or redistribution? Bird Conservation International 16:217-236.

Žydelis, R., Bellebaum, J., Österblom, H., Vetemaa, M., Schirmeister, B., Stipniece, A., Dagys, M., van Eerden, M., Garthe, S. 2009. Bycatch in gillnet fisheries - an overlooked threat to waterbird populations. Biological Conservation 142, 1269-1281.

Žydelis, R. \& Dagys, M. 1997. Winter period ornithological impact assessment of oil related activities and sea transportation in Lithuanian inshore waters of the Baltic Sea and in the Kursiu Lagoon. Acta Zoologica Lituanica, Ornithologia, 6: 45-65.

Yallop M., M. O'Connell \& R. Bullock, 2004. Waterbird herbivory on a newly created wetland complex: potential implications for site management and habitat creation. Wetlands Ecology and Management 12-5: 395-408. 


\section{Appendices}

\subsection{Appendix I Diagnostics of distribution models}

\subsubsection{Red-throated Diver Gavia stellata and Black- throated Diver Gavia arctica}

Approximate significance of smooth terms (Chi square and $F$ values) of variables in the distribution model for Red-throated Diver/Blackthroated Diver. Values for both model parts are presented on separate panels. The model was evaluated by fitting the model on $70 \%$ of the data set and testing the model on $30 \%$. Evaluation results are presented as area under the receiver operator characteristic curve (AUC) for the presence/absence part and Spearman's correlation coefficient for the combined model. Deviance explained for both model parts are shown. The presence-absence part was fitted by a binomial distribution, and the positive part by a gamma distribution.

\begin{tabular}{llcll}
\hline Variable & \multicolumn{2}{c}{ Precense/absence } & Positive part \\
\cline { 2 - 5 } & Chi sq. & $\mathrm{P}$ & $\mathrm{F}$ & $\mathrm{P}$ \\
\hline Bathymetry & 23.36 & $<0.01$ & 10.68 & $<0.01$ \\
Distance to land & 9.18 & $<0.01$ & - & - \\
Distance to shipping & 18.01 & $<0.01$ & 10.55 & $<0.01$ \\
Salinity & 11.47 & $<0.01$ & - & - \\
Current V & - & - & 3.85 & $<0.01$ \\
Current W & 5.457 & 0.02 & 4.03 & $<0.01$ \\
XY (coordinates) & 227.26 & $<0.01$ & 15.23 & $<0.01$ \\
Model performance & & & & \\
AUC & & 0.75 & & $50.2 \%$ \\
Deviance explained & $11.2 \%$ & & \\
Correlation (combined) & \multicolumn{2}{c}{$0.12(\mathrm{P}<2.2 \mathrm{e}-16)$} & \\
\hline
\end{tabular}



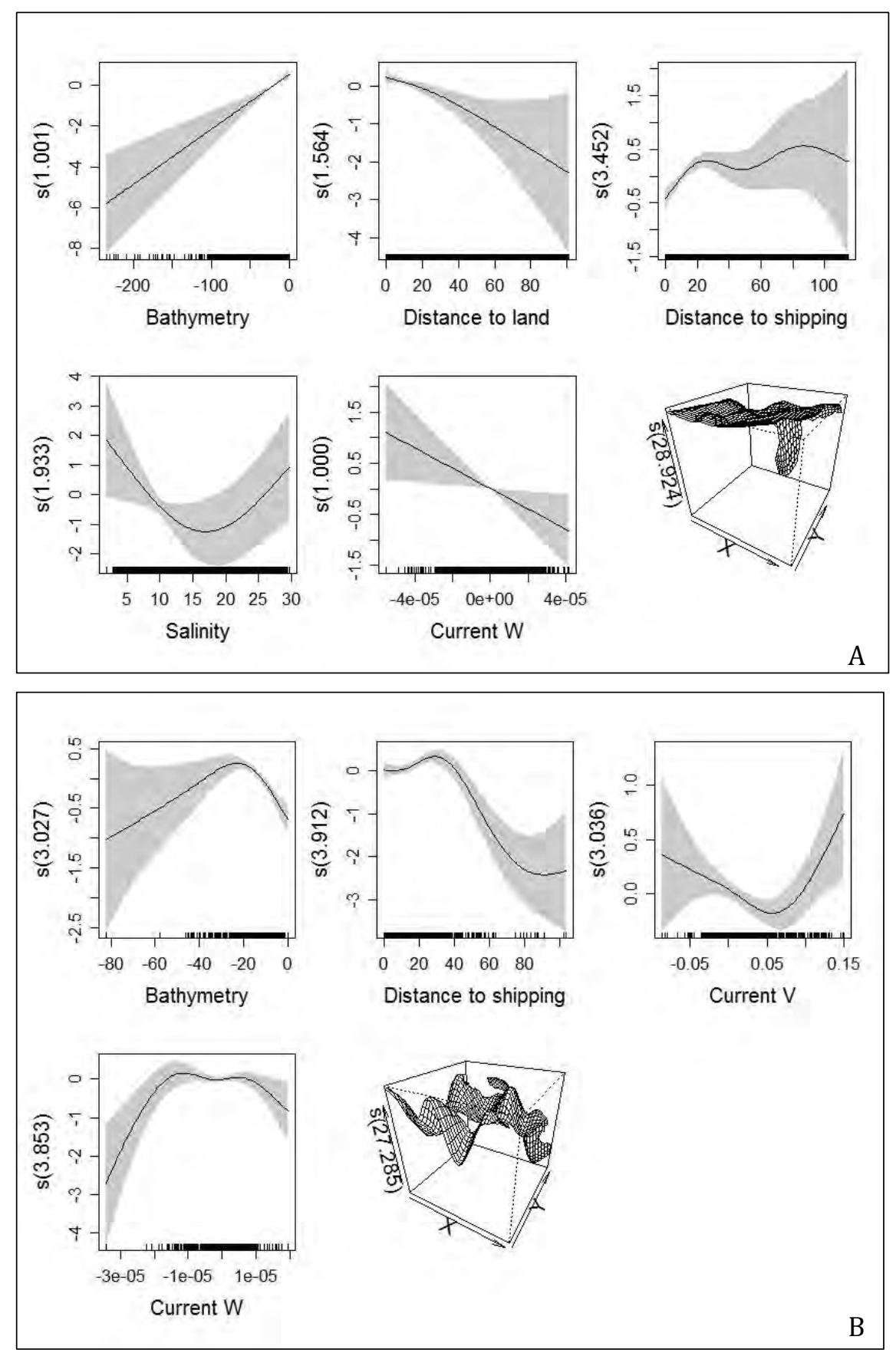

Response curves of the two-part GAM for the Red-throated Diver/Black-throated Diver ( $A$ = binomial part of the model and $B=$ positive part of the model). The values of the environmental predictor are shown on the $X$-axis and the probability on the $Y$-axis in logit scale. The degree of smoothing is indicated in the title of the $Y$-axis. The shaded areas and the dotted lines show \pm 1 standard errors. For the 2-d term $(X, Y)$ a perspective plot is shown, with the degree of smoothing indicated as a label to the Z-axis. 
Resids vs. linear pred.

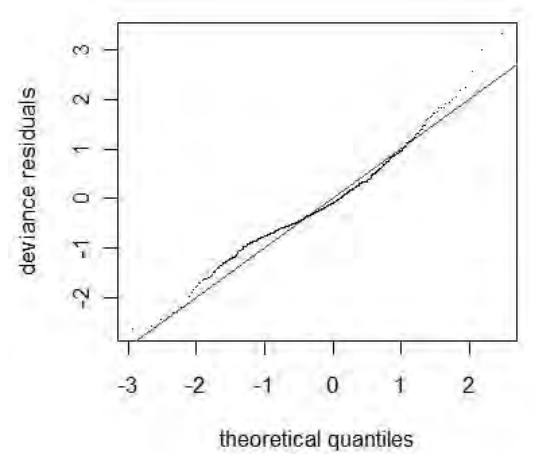

Histogram of residuals

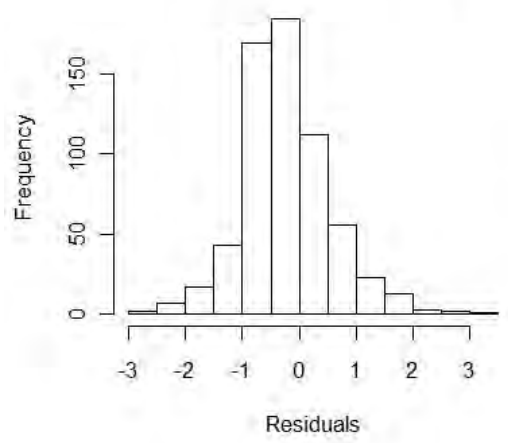

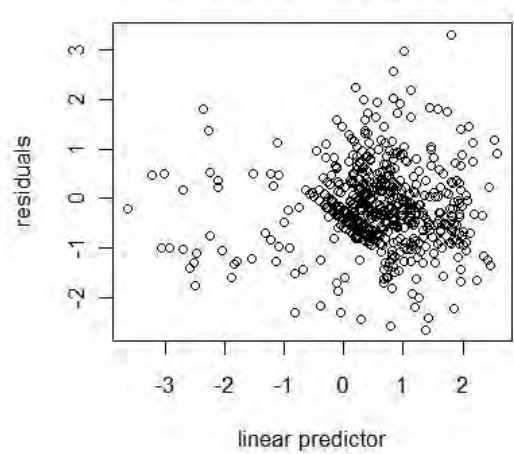

Response vs. Fitted Values

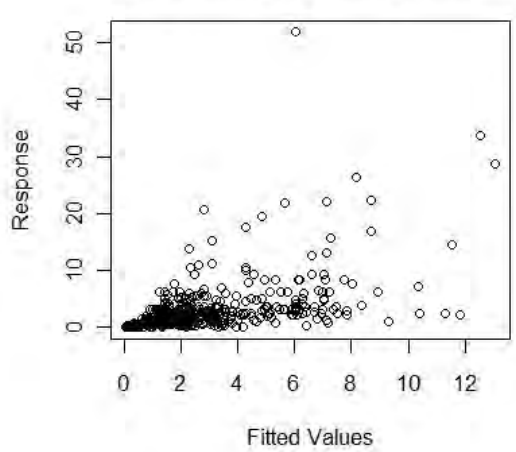

Diagnostic plots for the positive part of the two-part GAM for the Red-throated Diver/Black-throated Diver. Normality of the residuals is displayed in a $Q-Q$ plot (upper left) and in a histogram (lower left). The spread of the residuals is displayed in the upper right plot whereas the predicted against the observed values are plotted in the lower right plot.
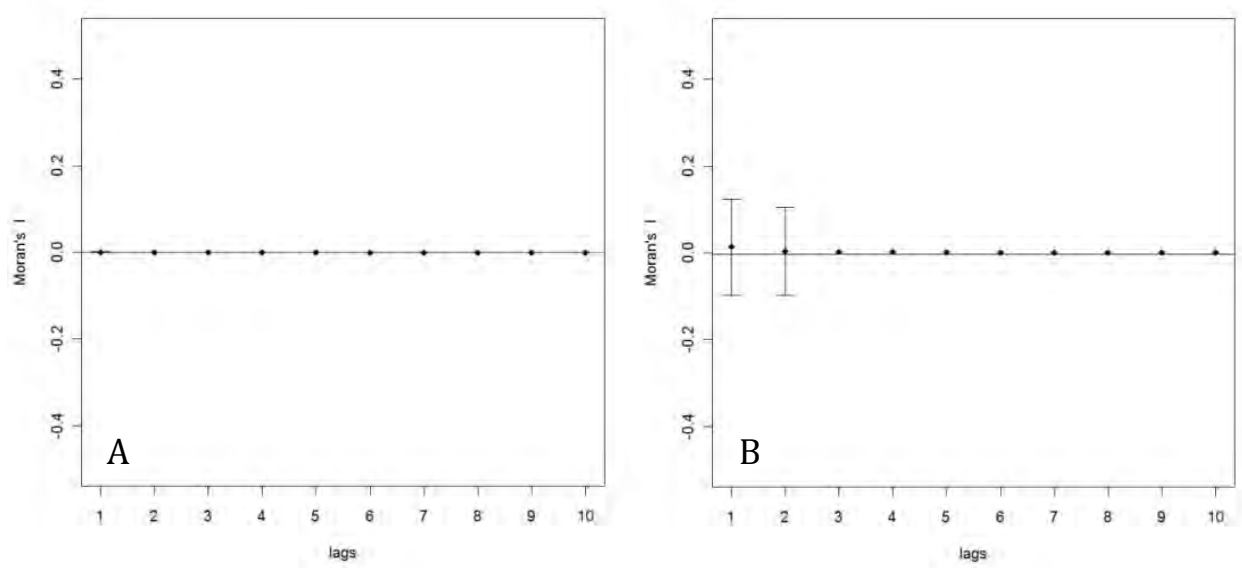

Spatial correlograms displaying the spatial autocorrelation over 10 lags in the residuals for the two-part GAM model for the Red-throated Diver/Black-throated Diver ( $A=$ binomial part, $B=$ positive part). The dots indicate the estimated Moran's I value and the bars show twice the square root of the variance from the estimated Moran's I value. 1 lag equals the defined nearest neighborhood of 3000 meters No significant spatial autocorrelation was found in the model residuals. 


\subsubsection{Great Crested Grebe Podiceps cristatus}

Approximate significance of smooth terms (Chi square and $F$ values) of variables in the distribution model for the Great Crested Grebe. Values for both model parts are presented on separate panels. The model was evaluated by fitting the model on $70 \%$ of the data set and testing the model on 30\%. Evaluation results are presented as area under the receiver operator characteristic curve (AUC) for the presence/absence part and Spearman's correlation coefficient for the combined model. Deviance explained for both model parts are shown. The presenceabsence part was fitted by a binomial distribution, and the positive part by a gamma distribution.

\begin{tabular}{lllll}
\hline Variable & Precense/absence & Positive part & & \\
& Chi sq. & P & F & P \\
\hline Bathymetry & 25.50 & $<0.01$ & - & - \\
Bottom slope & 5.54 & 0.02 & 6.171 & 0.01 \\
Distance to land & 25.443 & $<0.01$ & - & - \\
Distance to shipping & 3.14 & $<0.01$ & - & - \\
Salinity & 10.03 & $<0.01$ & - & - \\
Current V & 5.39 & 0.13 & 4.36 & $<0.01$ \\
Current W & 8.80 & 0.03 & 5.53 & $<0.01$ \\
XY (coordinates) & 237.63 & $<0.01$ & 15.69 & $<0.01$ \\
Model performance & & & & \\
AUC & & 0.92 & & \\
Deviance explained & & $39.5 \%$ & $0.22(\mathrm{P}<2.2 \mathrm{e}-16)$ & \\
Correlation (combined) & & & \\
\hline
\end{tabular}



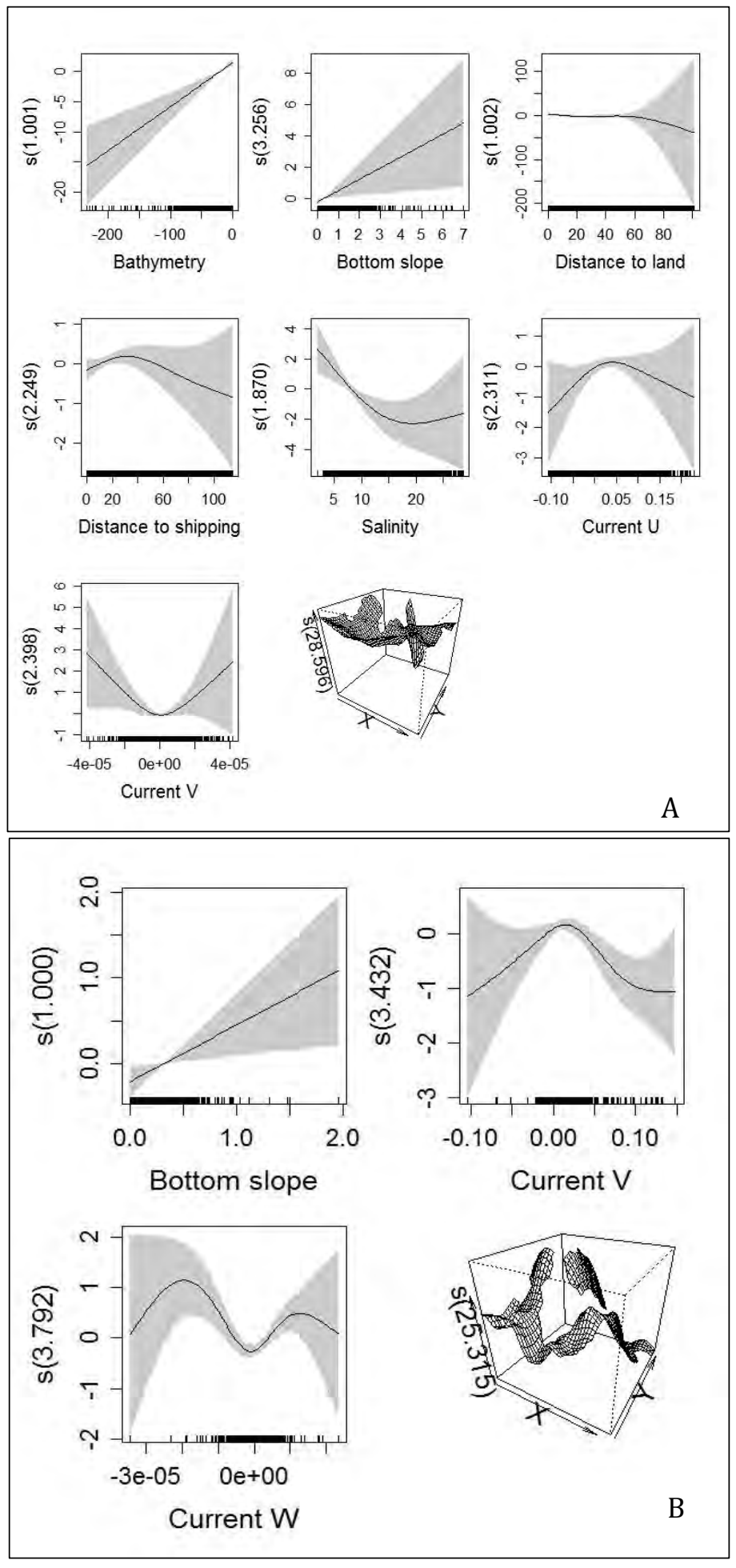

Response curves of the two-part GAM for the Great Crested Grebe (A = binomial part of the model and $B=$ positive part of the model). The values of the environmental predictor are shown on the $X$-axis and the probability on the $Y$-axis in logit scale. The degree of smoothing is indicated in the title of the $Y$-axis. The shaded areas and the dotted lines show \pm 1 standard errors. For the 2-d term $(X, Y)$ a perspective plot is shown, with the degree of smoothing indicated as a label to the Z-axis. 


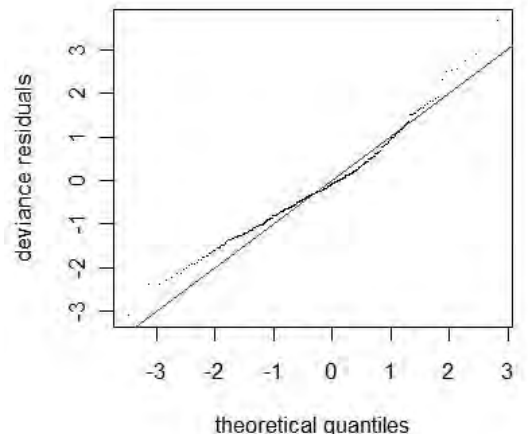

Histogram of residuals

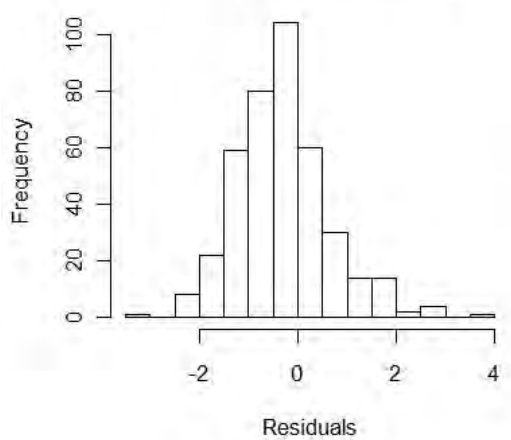

Resids vs. linear pred.

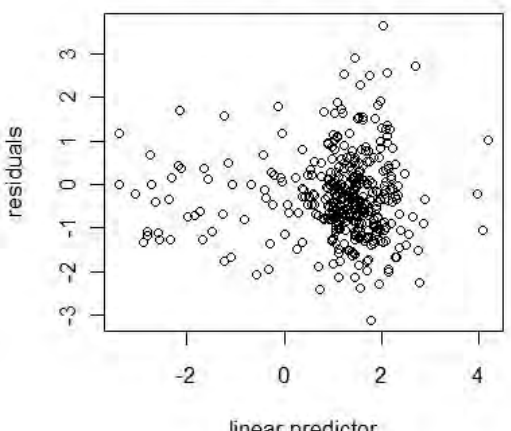

Response vs. Fitted Values

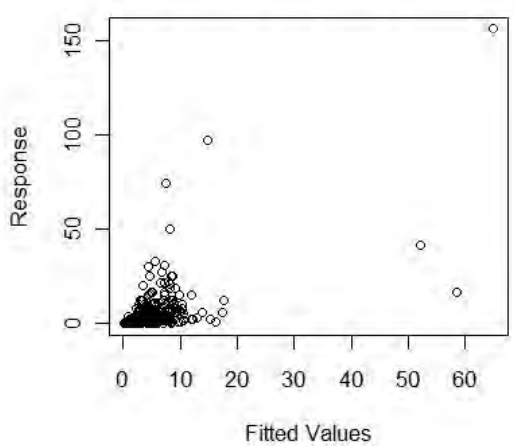

Diagnostic plots for the positive part of the two-part GAM for the Great Crested Grebe. Normality of the residuals is displayed in a Q-Q plot (upper left) and in a histogram (lower left). The spread of the residuals is displayed in the upper right plot whereas the predicted against the observed values are plotted in the lower right plot.
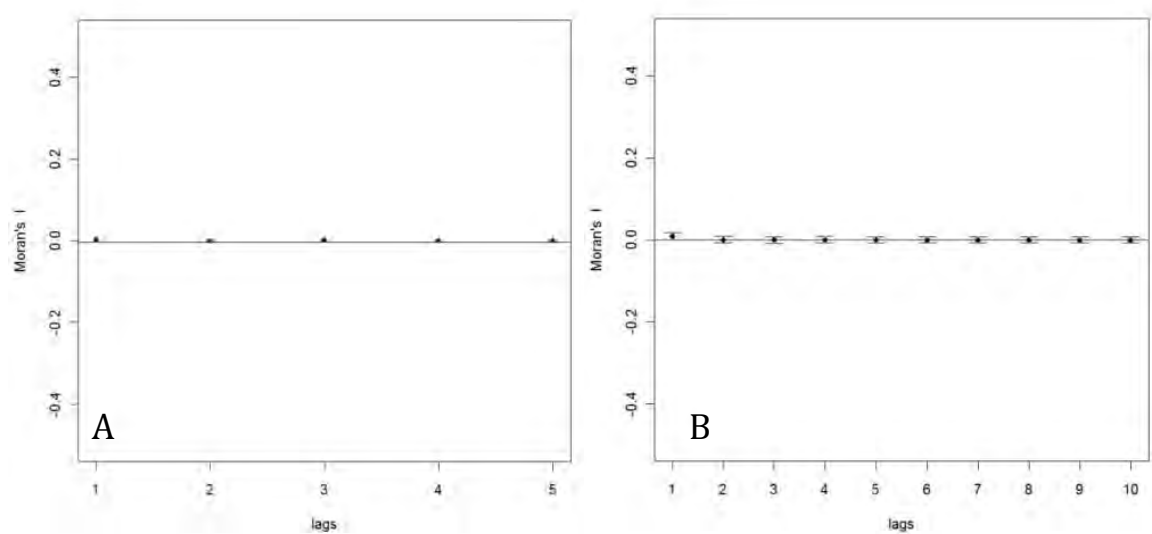

Spatial correlograms displaying the spatial autocorrelation over 10 lags (only 5 lags were valid in the positive part) in the residuals for the two-part GAM model for the Great Crested Grebe ( $A=$ binomial part, $B=$ positive part). The dots indicate the estimated Moran's I value and the bars show twice the square root of the variance from the estimated Moran's I value. 1 lag equals the defined nearest neighborhood of 3000. No significant meters spatial autocorrelation was found in the model residuals. 


\subsubsection{Red-necked Grebe Podiceps grisegena}

Approximate significance of smooth terms (Chi square and $F$ values) of variables in the distribution model for the Red-necked Grebe. Values for both model parts are presented on separate panels. The model was evaluated by fitting the model on $70 \%$ of the data set and testing the model on $30 \%$. Evaluation results are presented as area under the receiver operator characteristic curve (AUC) for the presence/absence part and Spearman's correlation coefficient for the combined model. Deviance explained for both model parts are shown. The presenceabsence part was fitted by a binomial distribution, and the positive part by a gamma distribution.

\begin{tabular}{|c|c|c|c|c|}
\hline \multirow[t]{2}{*}{ Variable } & \multicolumn{2}{|c|}{ Precense/absence } & \multicolumn{2}{|c|}{ Positive part } \\
\hline & Chi sq. & $\mathbf{P}$ & $\mathbf{F}$ & $\mathbf{P}$ \\
\hline Bathymetry & 7.48 & $<0.01$ & - & - \\
\hline Bottom slope & 2.05 & 0.15 & - & - \\
\hline Distance to shipping & 1.53 & 0.22 & - & - \\
\hline Temperature & 8.10 & $<0.01$ & 3.83 & 0.03 \\
\hline Salinity & - & - & 4.02 & 0.05 \\
\hline Current U & 6.19 & 0.09 & 7.25 & $<0.01$ \\
\hline Current V & 4.28 & 0.15 & - & - \\
\hline Current W & - & - & 3.53 & 0.06 \\
\hline XY (coordinates) & 60.70 & $<0.01$ & 5.50 & $<0.01$ \\
\hline \multicolumn{5}{|l|}{ Model performance } \\
\hline AUC & \multicolumn{2}{|c|}{0.90} & \multirow{3}{*}{\multicolumn{2}{|c|}{$60.3 \%$}} \\
\hline Deviance explained & \multicolumn{2}{|c|}{$32.4 \%$} & & \\
\hline Correlation (combined) & \multicolumn{2}{|c|}{$0.15(\mathrm{P}<2.2 \mathrm{e}-16)$} & & \\
\hline
\end{tabular}



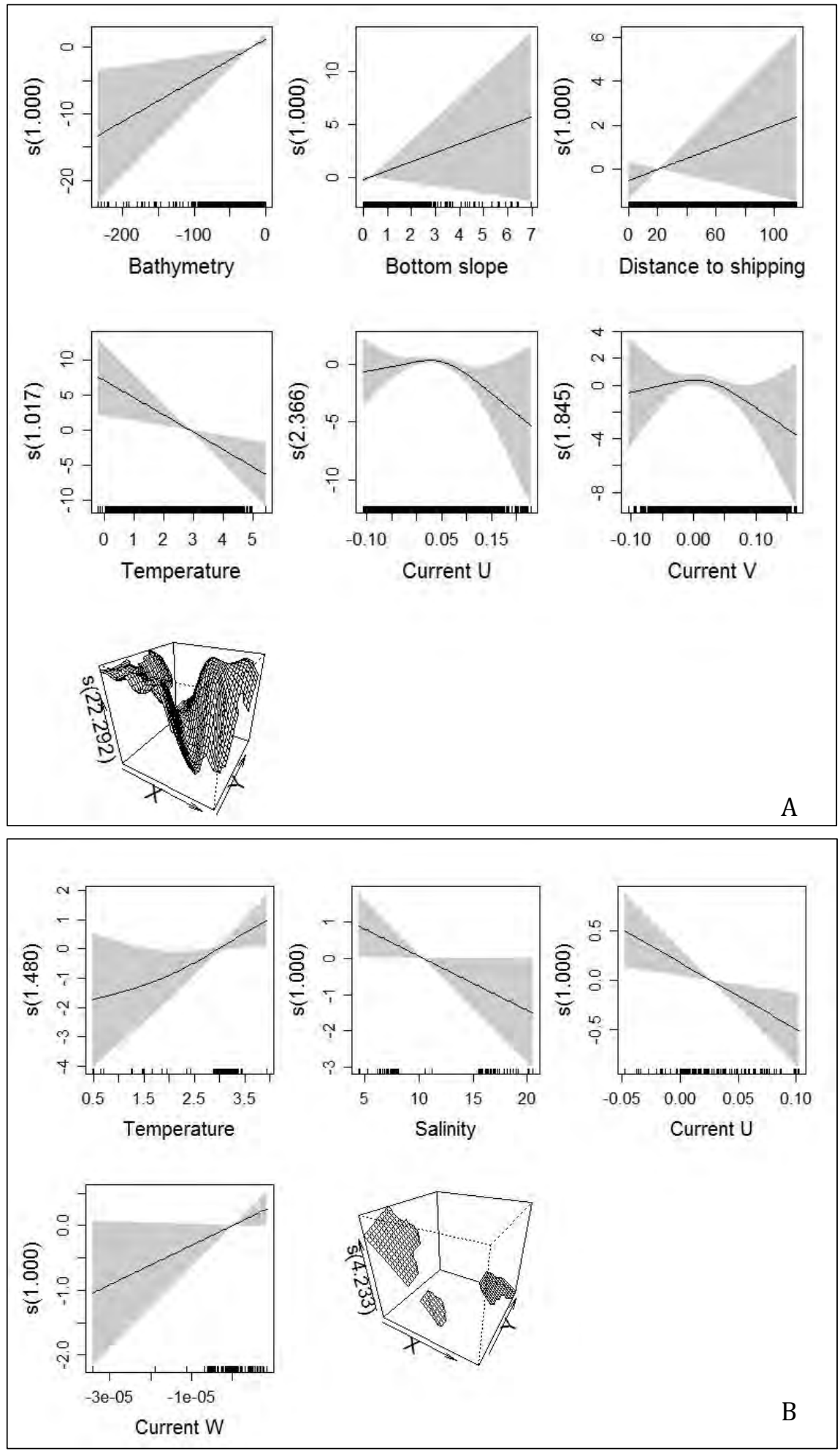

Response curves of the two-part GAM for the Red-necked Grebe (A = binomial part of the model and $B=$ positive part of the model). The values of the environmental predictor are shown on the $X$-axis and the probability on the $Y$-axis in logit scale. The degree of smoothing is indicated in the title of the $Y$-axis. The shaded areas and the dotted lines show \pm 1 standard errors. For the 2 -d term $(X, Y)$ a perspective plot is shown, with the degree of smoothing indicated as a label to the Z-axis. No significant spatial autocorrelation was found in the model residuals. 
Resids vs. linear pred.

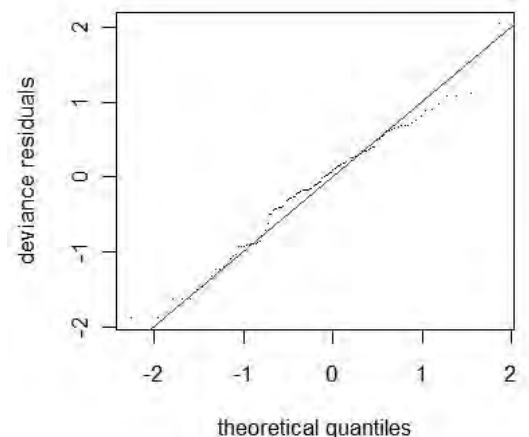

Histogram of residuals

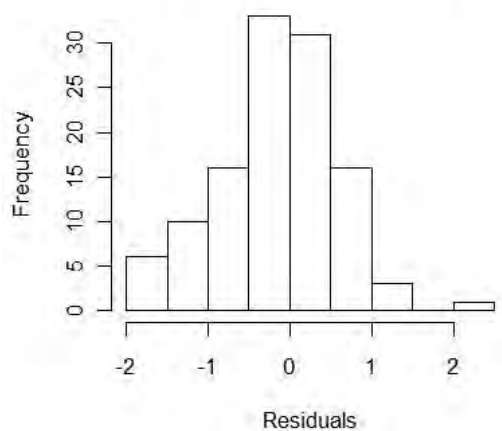

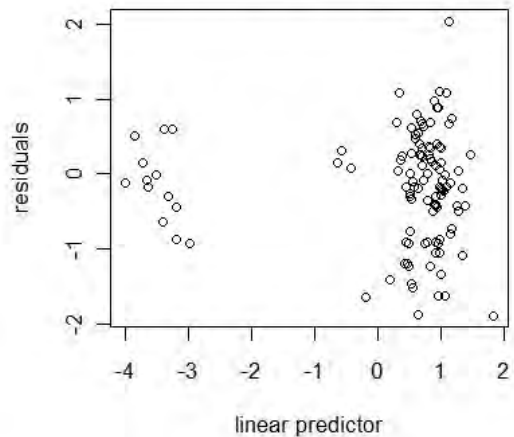

Response vs. Fitted Values

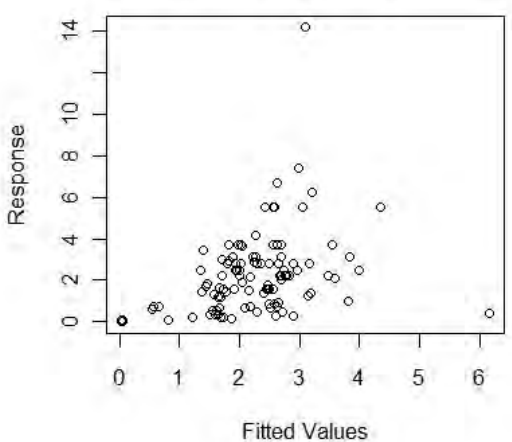

Diagnostic plots for the positive part of the two-part GAM for the Red-necked Grebe. Normality of the residuals is displayed in a $Q-Q$ plot (upper left) and in a histogram (lower left). The spread of the residuals is displayed in the upper right plot whereas the predicted against the observed values are plotted in the lower right plot.
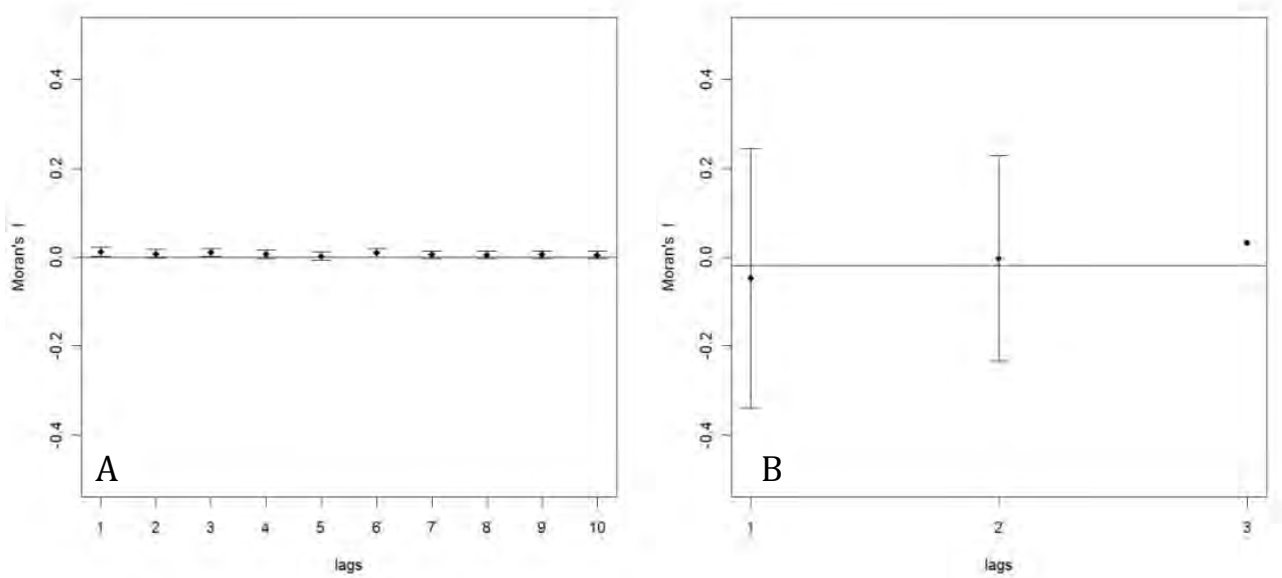

Spatial correlograms displaying the spatial autocorrelation over 10 lags (only 3 lags were valid in the positive part) in the residuals for the two-part GAM model for the Red-necked Grebe ( $A$ = binomial part, $B=$ positive part). The dots indicate the estimated Moran's I value and the bars show twice the square root of the variance from the estimated Moran's I value. 1 lag equals the defined nearest neighborhood of 3000 meters. No significant spatial autocorrelation was found in the model residuals.. 


\subsubsection{Slavonian Grebe Podiceps auritus}

Approximate significance of smooth terms (Chi square and $\mathrm{F}$ values) of variables in the distribution model for the Slavonian Grebe. Values for both model parts are presented on separate panels. The model was evaluated by fitting the model on $70 \%$ of the data set and testing the model on 30\%. Evaluation results are presented as area under the receiver operator characteristic curve (AUC) for the presence/absence part and Spearman's correlation coefficient for the combined model. Deviance explained for both model parts are shown. The presenceabsence part was fitted by a binomial distribution, and the positive part by a gamma distribution.

\begin{tabular}{|c|c|c|c|c|c|}
\hline \multirow[t]{2}{*}{ Variable } & \multicolumn{3}{|c|}{ Precense/absence } & \multicolumn{2}{|c|}{ Positive part } \\
\hline & Chi sq. & & $\mathbf{P}$ & $\mathbf{F}$ & $\mathbf{P}$ \\
\hline Bathymetry & 16.52 & & $<0.01$ & 2.17 & 0.08 \\
\hline Distance to land & 8.38 & & 0.08 & 13.00 & $<0.01$ \\
\hline Salinity & 12.42 & & 0.01 & - & - \\
\hline Current U & 6.24 & & 0.08 & - & - \\
\hline Current W & - & & - & 4.71 & 0.03 \\
\hline XY (coordinates) & 46.11 & & $<0.01$ & 2.86 & 0.06 \\
\hline \multicolumn{6}{|l|}{ Model performance } \\
\hline AUC & \multicolumn{3}{|c|}{0.86} & \multirow{3}{*}{\multicolumn{2}{|c|}{$23.9 \%$}} \\
\hline Deviance explained & \multicolumn{3}{|c|}{$36.7 \%$} & & \\
\hline Correlation (combined) & & & $0.32(\mathrm{P}<2.2 \mathrm{e}-16)$ & & \\
\hline
\end{tabular}



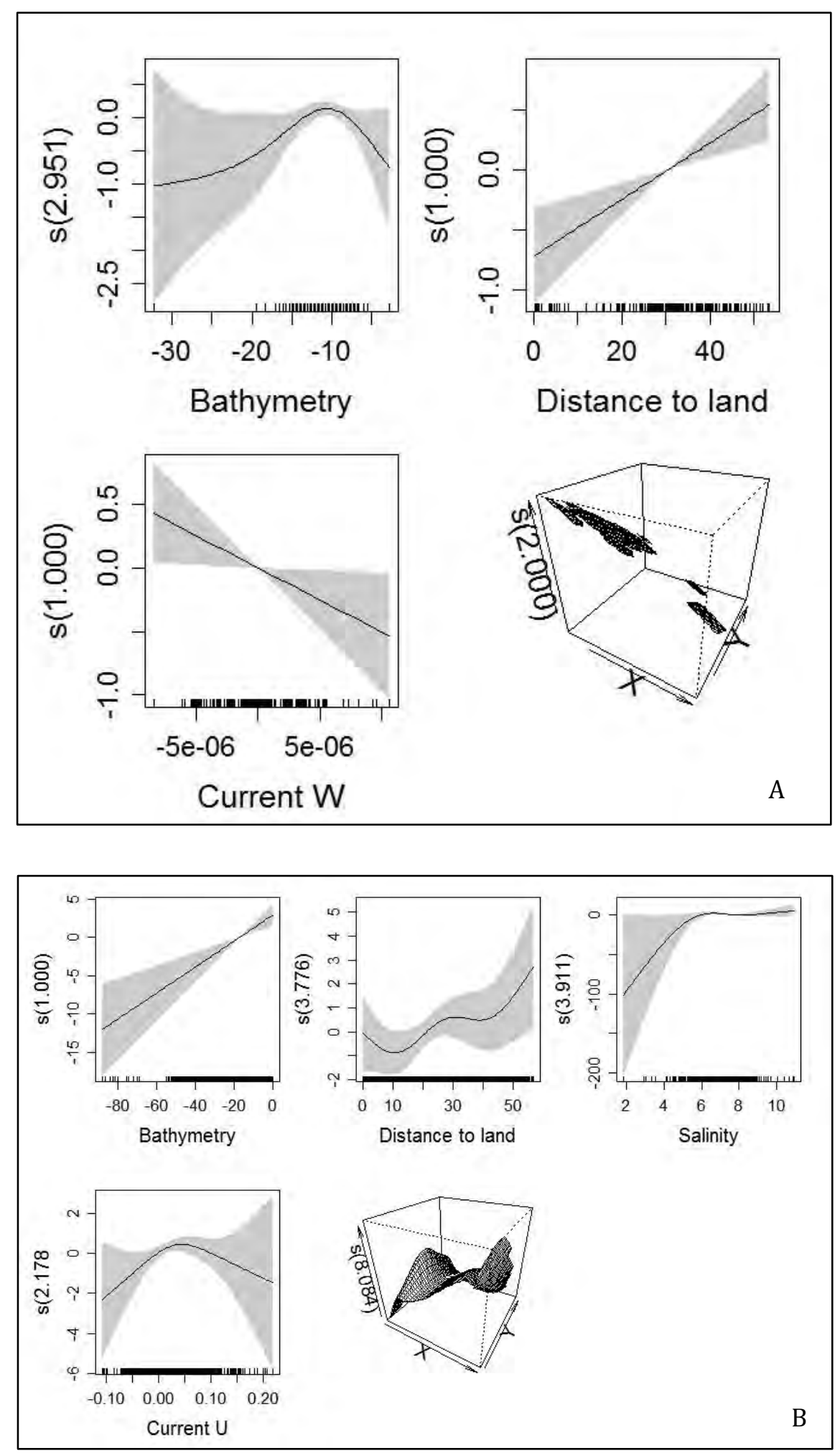

Response curves of the two-part GAM for the Slavonian Grebe ( $A=$ binomial part of the model and $B=$ positive part of the model). The values of the environmental predictor are shown on the $X$-axis and the probability on the $Y$-axis in logit scale. The degree of smoothing is indicated in the title of the Y-axis. The shaded areas and the dotted lines show \pm 1 standard errors. For the 2-d term $(X, Y)$ a perspective plot is shown, with the degree of smoothing indicated as a label to the Z-axis. 


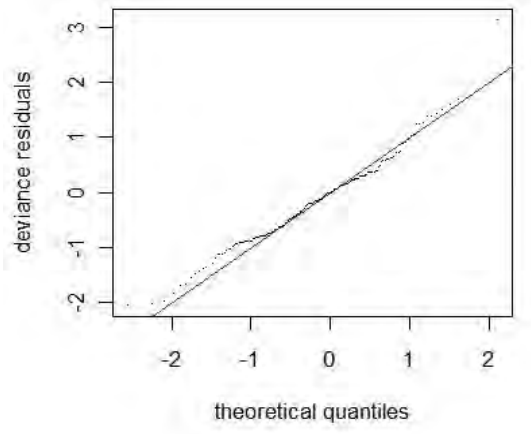

Histogram of residuals

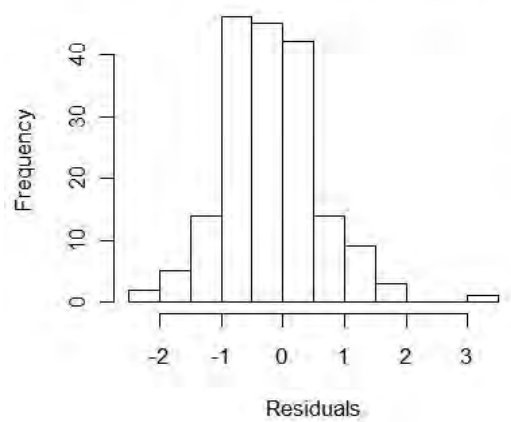

Resids vs. linear pred.

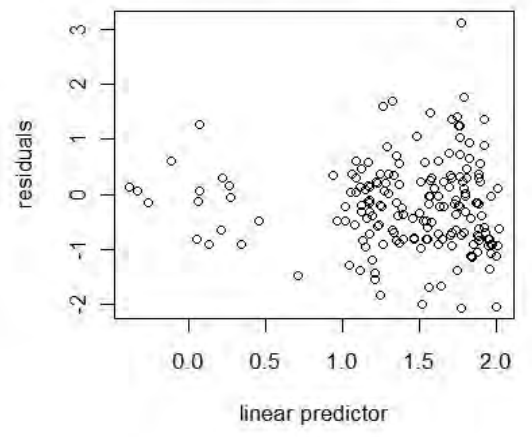

Response vs. Fitted Values

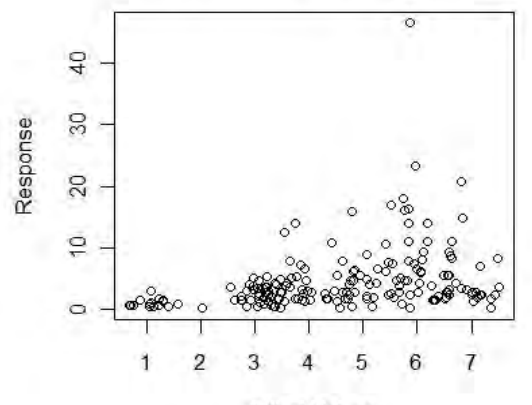

Fitted Values

Diagnostic plots for the positive part of the two-part GAM for the Slavonian Grebe. Normality of the residuals is displayed in a Q-Q plot (upper left) and in a histogram (lower left). The spread of the residuals is displayed in the upper right plot whereas the predicted against the observed values are plotted in the lower right plot.
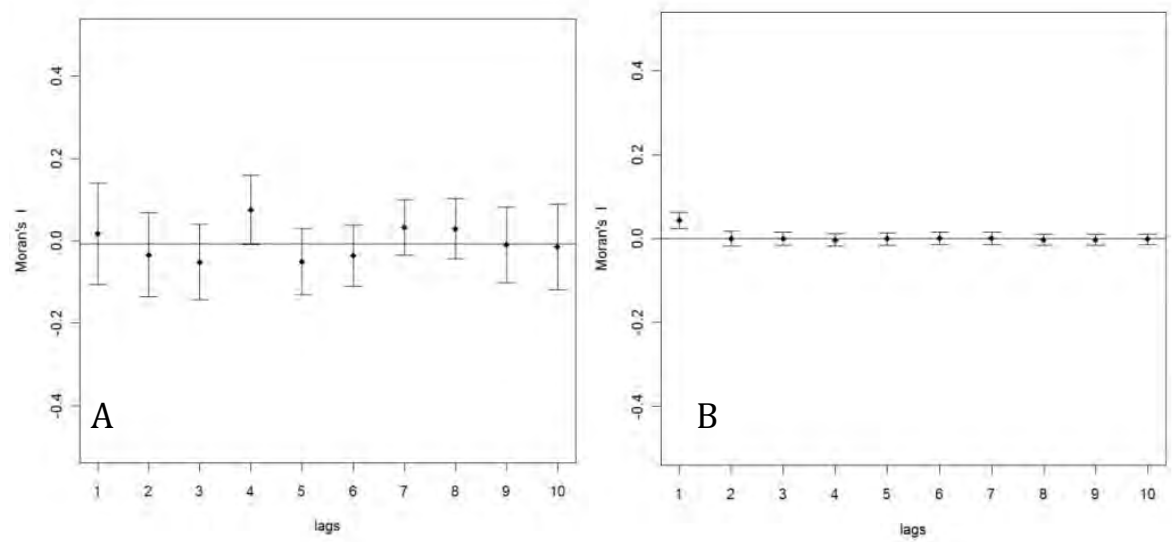

Spatial correlograms displaying the spatial autocorrelation over 10 lags in the residuals for the two-part GAM model for the Slavonian Grebe ( $A=$ binomial part, $B$ = positive part). The dots indicate the estimated Moran's I value and the bars show twice the square root of the variance from the estimated Moran's I value. 1 lag equals the defined nearest neighborhood of 3000 meters. Significant spatial autocorrelation was found in model residuals in the first lag of the presence/absence part of the model. The Moran's I value was very low however, indicating weak spatial autocorrelation. 


\subsubsection{Common Eider Somateria mollissima}

Approximate significance of smooth terms (Chi square and $\mathrm{F}$ values) of variables in the distribution model for the Common Eider. Values for both model parts are presented on separate panels. The model was evaluated by fitting the model on $70 \%$ of the data set and testing the model on $30 \%$. Evaluation results are presented as area under the receiver operator characteristic curve (AUC) for the presence/absence part and Spearman's correlation coefficient for the combined model. Deviance explained for both model parts are shown. The presenceabsence part was fitted by a binomial distribution, and the positive part by a gamma distribution.

\begin{tabular}{llccc}
\hline \multirow{2}{*}{ Variable } & \multicolumn{3}{c}{ Precense/absence } & \multicolumn{2}{c}{ Positive part } \\
\cline { 2 - 5 } & Chi sq. & P & F & P \\
\hline Bathymetry & 394.29 & $<0.01$ & 89.44 & $<0.01$ \\
Bottom slope & - & - & 14.24 & $<0.01$ \\
Distance to land & 80.66 & $<0.01$ & 8.21 & $<0.01$ \\
Salinity & 18.71 & $<0.01$ & 37.7 & $<0.01$ \\
Filter-feeder index & 115.19 & $<0.01$ & 6.98 & $<0.01$ \\
XY (coordinates) & 502.16 & $<0.01$ & 70.74 & $<0.01$ \\
Model performance & & & & \\
AUC & & 0.92 & & 21.5 \\
Deviance explained & $41.4 \%$ & & \\
Correlation (combined) & & & $0.51(\mathrm{P}<2.2 \mathrm{e}-16)$ & \\
\hline
\end{tabular}



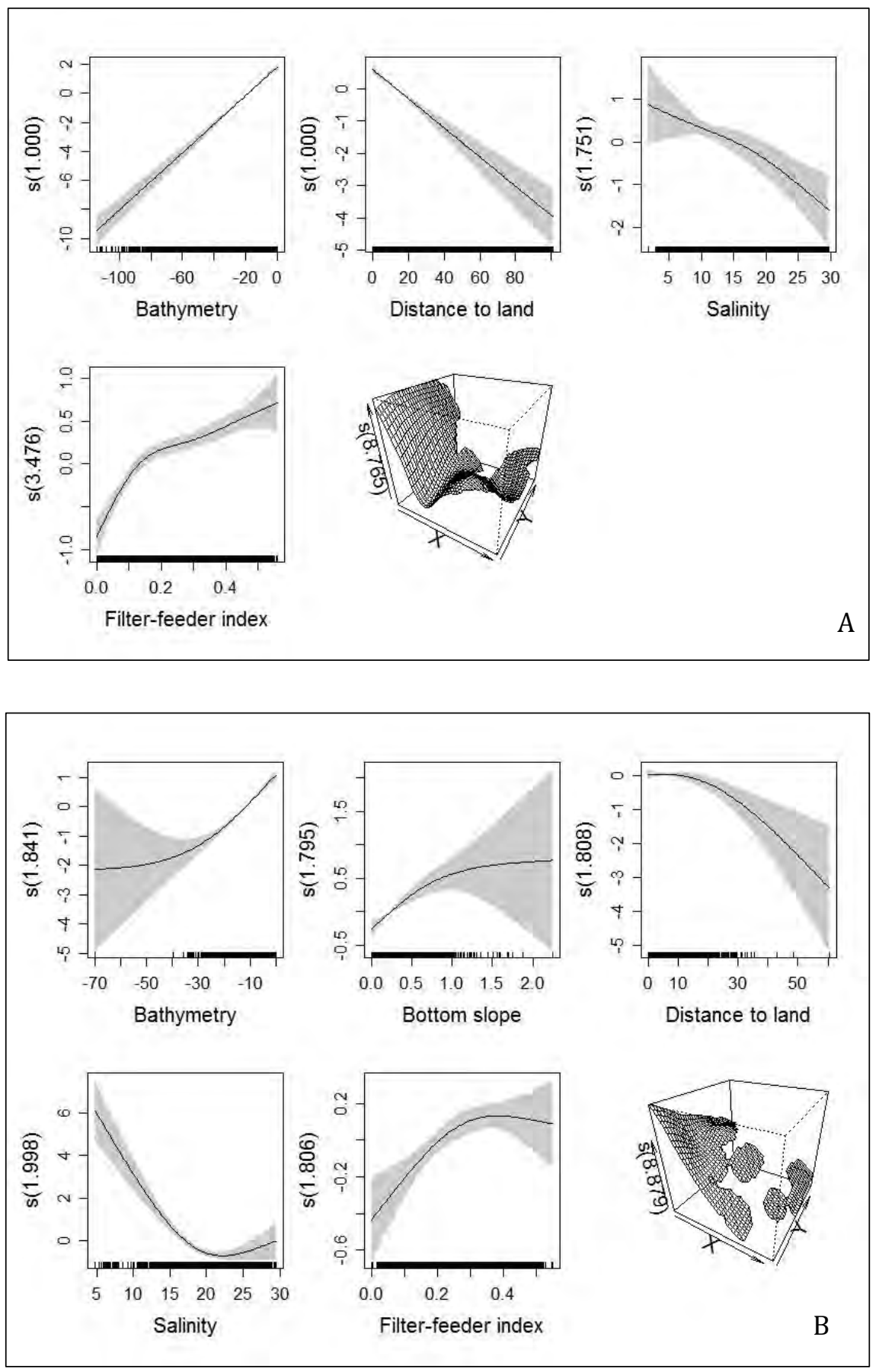

Response curves of the two-part GAM for the Common Eider $(A=$ binomial part of the model and $B$ = positive part of the model). The values of the environmental predictor are shown on the $X$-axis and the probability on the $Y$-axis in logit scale. The degree of smoothing is indicated in the title of the $Y$-axis. The shaded areas and the dotted lines show \pm 1 standard errors. For the 2-d term $(X, Y)$ a perspective plot is shown, with the degree of smoothing indicated as a label to the Z-axis. 
Resids vs. linear pred.
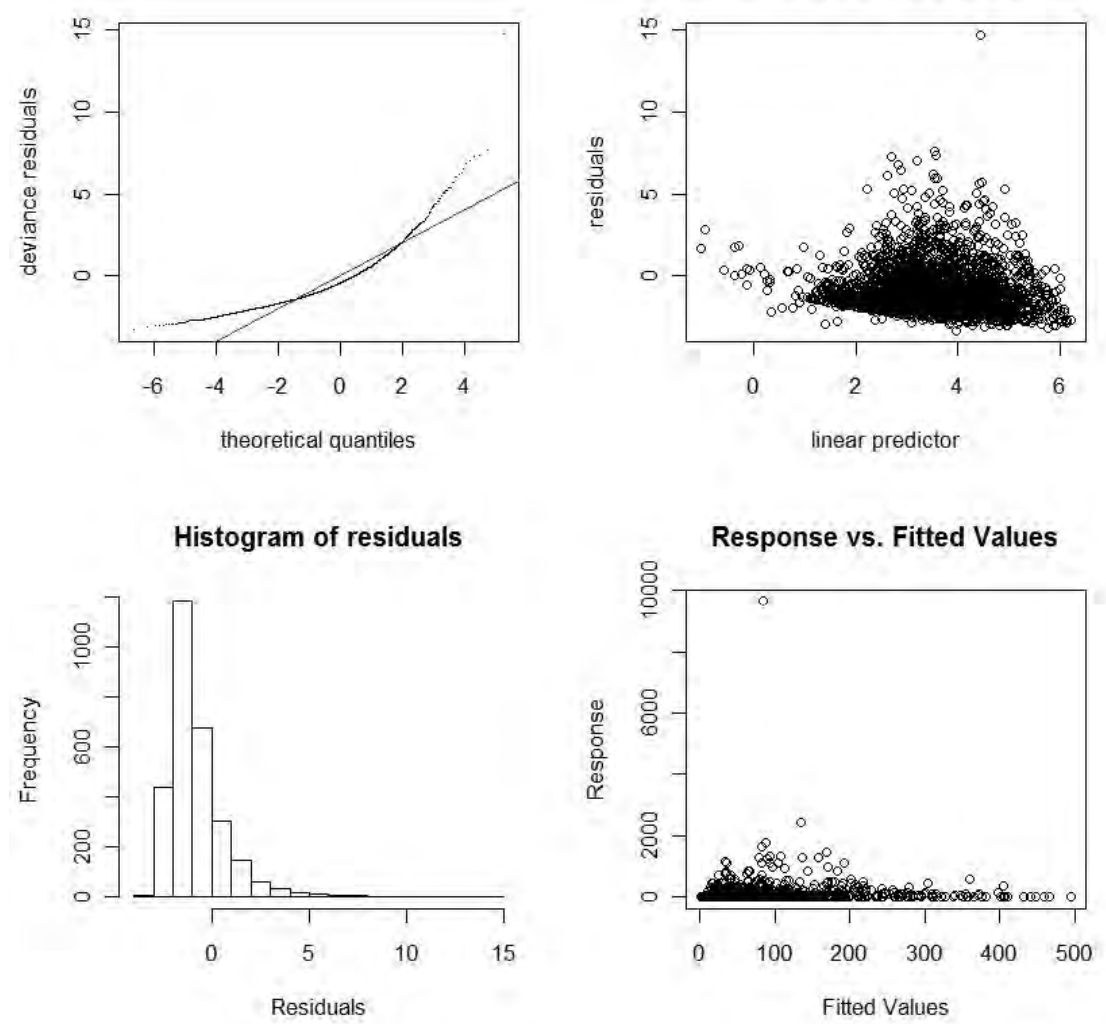

Diagnostic plots for the positive part of the two-part GAM for the Common Eider. Normality of the residuals is displayed in a Q-Q plot (upper left) and in a histogram (lower left). The spread of the residuals is displayed in the upper right plot whereas the predicted against the observed values are plotted in the lower right plot.
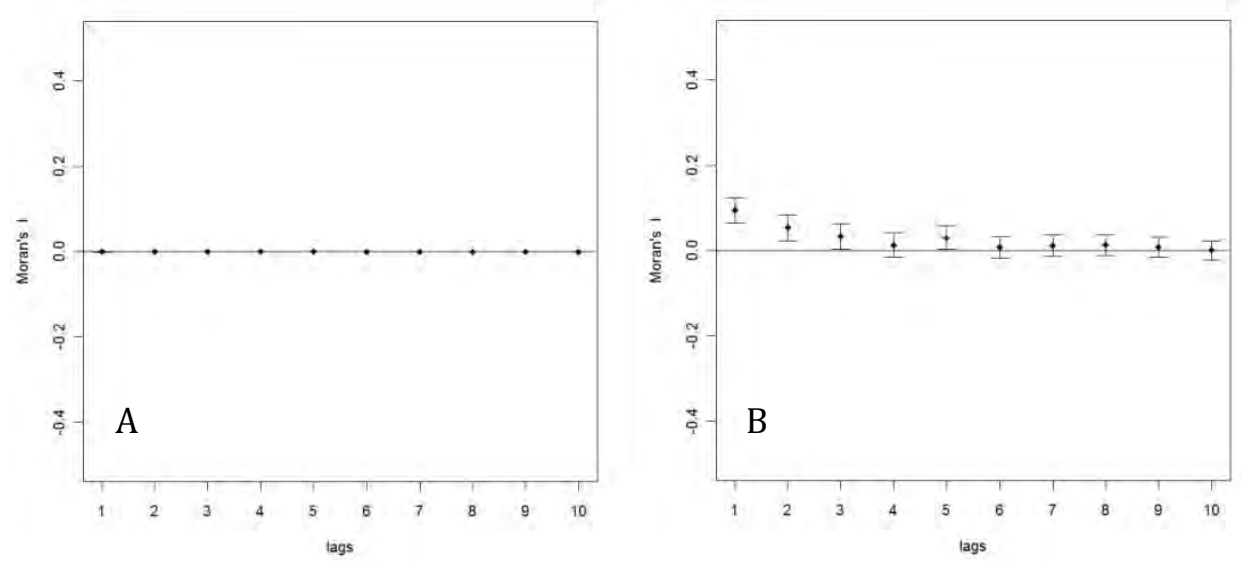

Spatial correlograms displaying the spatial autocorrelation over 10 lags in the residuals for the two-part GAM model for the Common Eider ( $A=$ binomial part, $B=$ positive part). The dots indicate the estimated Moran's I value and the bars show twice the square root of the variance from the estimated Moran's I value. 1 lag equals the defined nearest neighborhood of 3000 meters. Significant but low spatial autocorrelation was found in model residuals of the positive part of the model (two first lags) indicating weak spatial autocorrelation. 


\subsubsection{Long-tailed Duck Clangula hyemalis}

Approximate significance of smooth terms (Chi square and $\mathrm{F}$ values) of variables in the distribution model for the Long-tailed Duck. Values for both model parts are presented on separate panels. The model was evaluated by fitting the model on $70 \%$ of the data set and testing the model on 30\%. Evaluation results are presented as area under the receiver operator characteristic curve (AUC) for the presence/absence part and Spearman's correlation coefficient for the combined model. Deviance explained for both model parts are shown. The presenceabsence part was fitted by a binomial distribution, and the positive part by a gamma distribution.

\begin{tabular}{|c|c|c|c|c|}
\hline \multirow[t]{2}{*}{ Variable } & \multicolumn{2}{|c|}{ Precense/absence } & \multicolumn{2}{|c|}{ Positive part } \\
\hline & Chi sq. & $\mathbf{P}$ & $\mathbf{F}$ & $\mathbf{P}$ \\
\hline Bathymetry & 582.63 & $<0.01$ & 16.98 & $<0.01$ \\
\hline Bottom slope & 95.56 & $<0.01$ & - & - \\
\hline Distance to land & 325.84 & $<0.01$ & 54.12 & $<0.01$ \\
\hline Distance to shipping & 11.51 & $<0.01$ & - & - \\
\hline Salinity & - & - & 15.00 & $<0.01$ \\
\hline Filter-feeder index & 42.99 & $<0.01$ & 9.70 & $<0.01$ \\
\hline XY (coordinates) & 1967.89 & $<0.01$ & 13.62 & $<0.01$ \\
\hline \multicolumn{5}{|l|}{ Model performance } \\
\hline AUC & \multicolumn{2}{|c|}{0.84} & & \\
\hline Deviance explained & \multicolumn{2}{|c|}{$25.4 \%$} & \multicolumn{2}{|c|}{$28.6 \%$} \\
\hline Correlation (combined) & \multicolumn{4}{|c|}{$0.43(\mathrm{P}<2.2 \mathrm{e}-16)$} \\
\hline
\end{tabular}



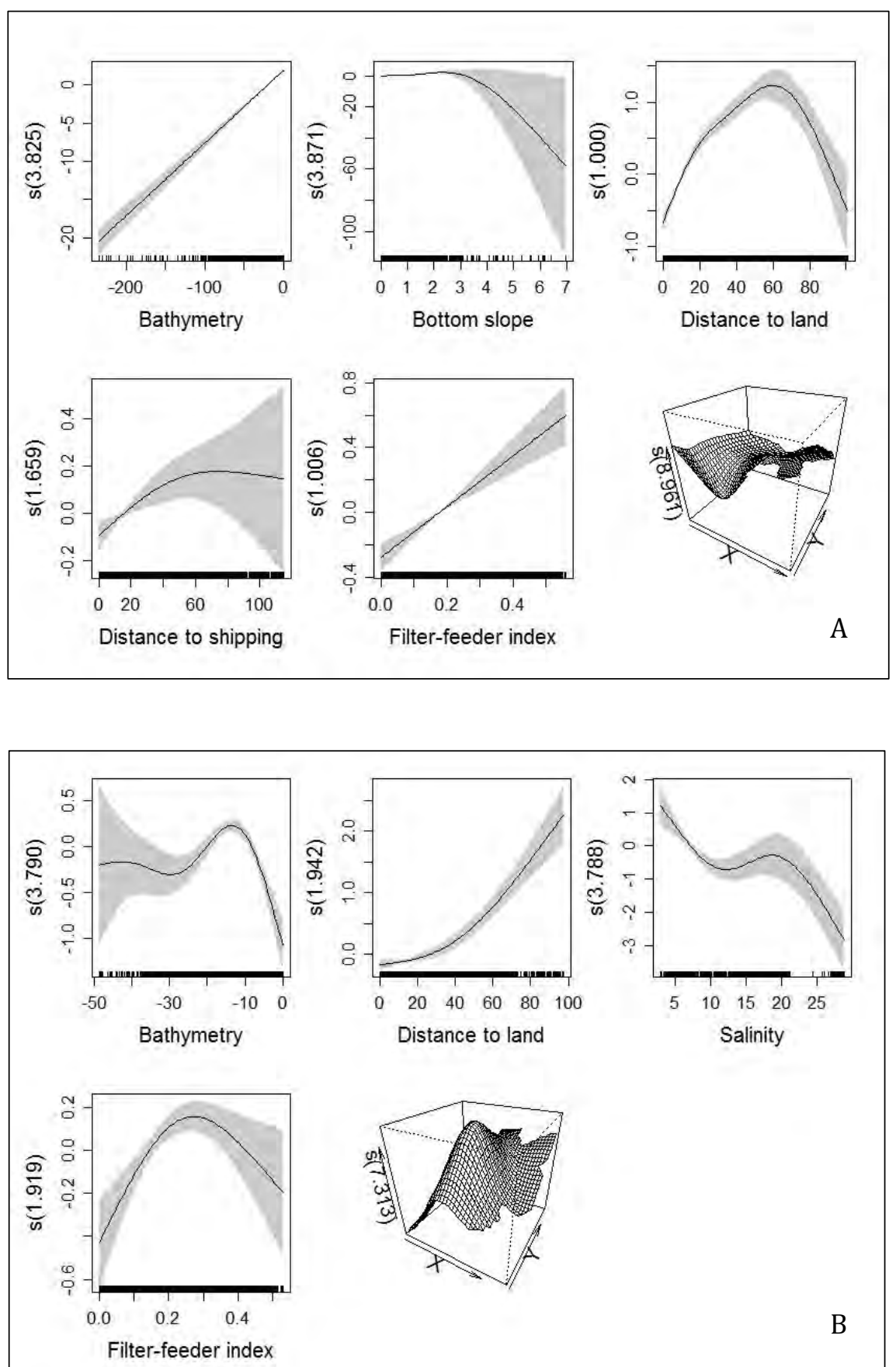

Response curves of the two-part GAM for the Long-tailed Duck ( $A$ = binomial part of the model and $B=$ positive part of the model). The values of the environmental predictor are shown on the $X$-axis and the probability on the $Y$-axis in logit scale. The degree of smoothing is indicated in the title of the $Y$-axis. The shaded areas and the dotted lines show \pm 1 standard errors. For the 2-d term $(X, Y)$ a perspective plot is shown, with the degree of smoothing indicated as a label to the Z-axis. 


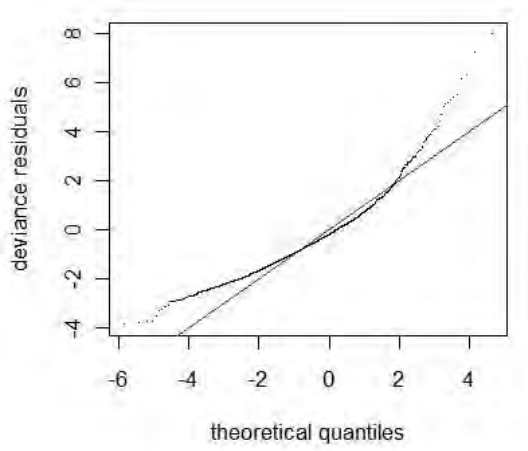

Histogram of residuals

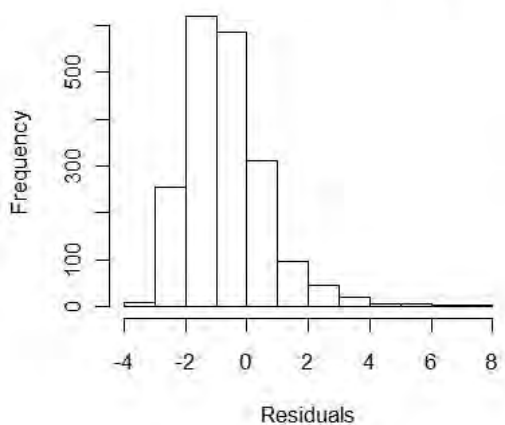

Resids vs. linear pred.

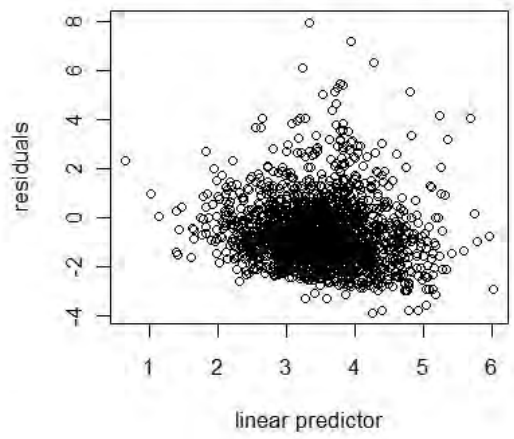

Response vs. Fitted Values

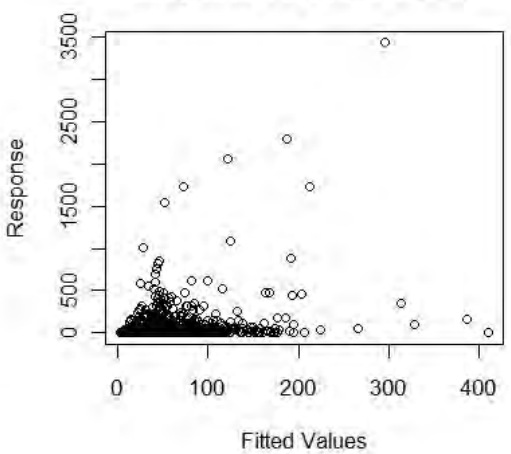

Diagnostic plots for the positive part of the two-part GAM for the Long-tailed Duck. Normality of the residuals is displayed in a Q-Q plot (upper left) and in a histogram (lower left). The spread of the residuals is displayed in the upper right plot whereas the predicted against the observed values are plotted in the lower right plot.
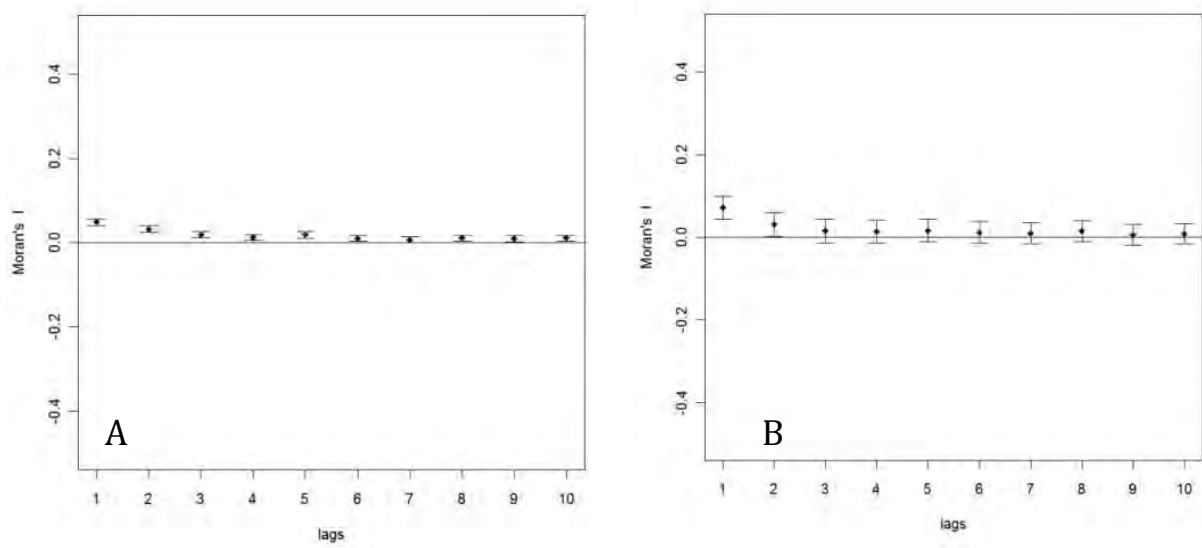

Spatial correlograms displaying the spatial autocorrelation over 10 lags in the residuals for the two-part GAM model for the Long-tailed Duck ( $A=$ binomial part, $B=$ positive part). The dots indicate the estimated Moran's I value and the bars show twice the square root of the variance from the estimated Moran's I value. 1 lag equals the defined nearest neighborhood of 3000 meters. Significant but very low spatial autocorrelation was found in model residuals of both model parts indicating weak spatial autocorrelation. 


\subsubsection{Common Scoter Melanitta nigra}

Two models were fitted for the Common Scoter; a "global" model for the whole Baltic and a regional model for the westernmost parts of the Baltic (region 1, see map below), as a single "global" Baltic model could not produce as good predictions as a regional model for the South western parts of the study area. The resulting predictions from both models were thereafter "mosaicked" together in ArcGIS by choosing the values from region 1 as first option. For remaining areas the predictions from the "global" Baltic model were used.

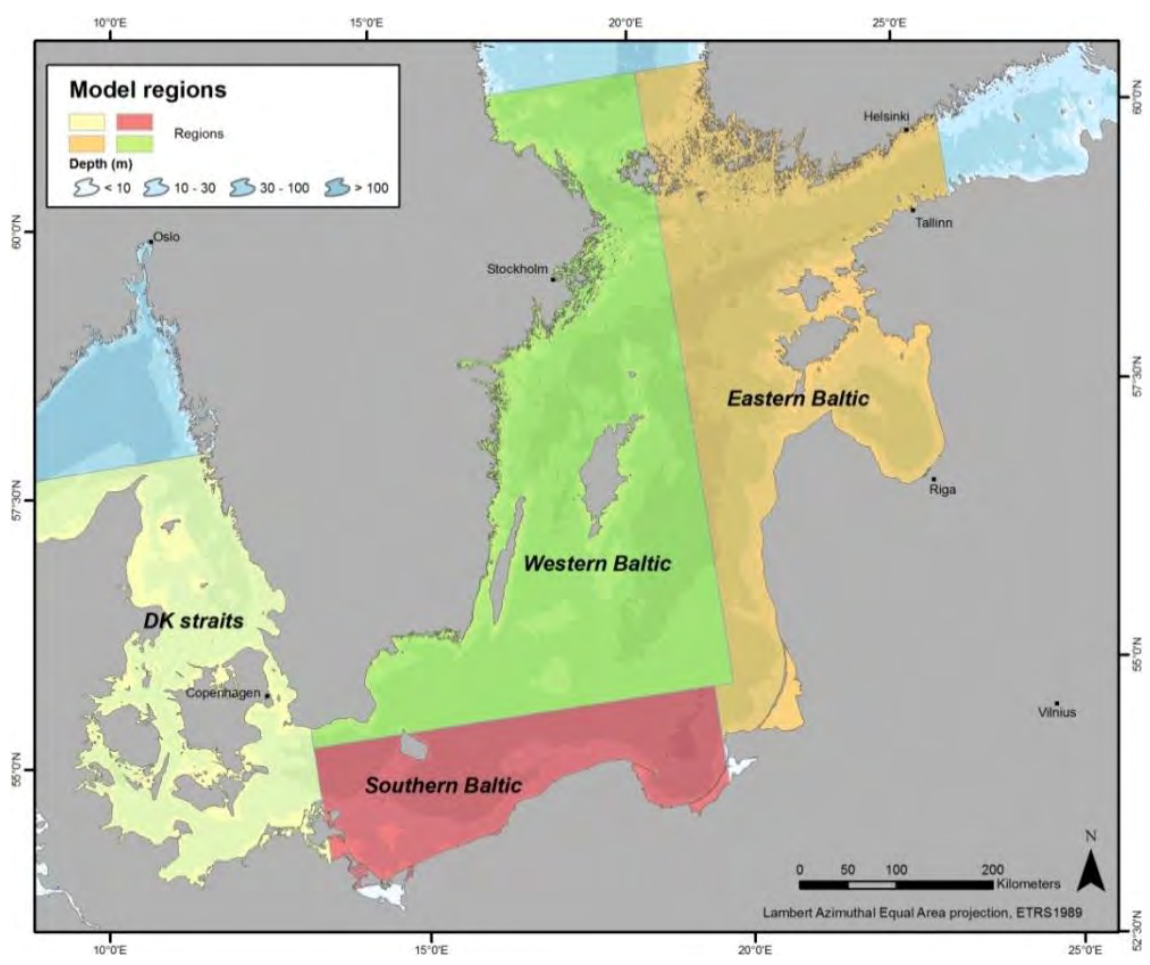

Map showing different regions of the Baltic Sea. The westernmost part defined as DK straits (Region 1) was modelled separately for the Common Scoter

\subsubsection{Region 1 for Common Scoter}

Approximate significance of smooth terms (Chi square and $\mathrm{F}$ values) of variables in the distribution model for Common Scoter in region 1. Values for both model parts are presented on separate panels. The model was evaluated by fitting the model on $70 \%$ of the data set and testing the model on 30\%. Evaluation results are presented as area under the receiver operator characteristic curve (AUC) for the presence/absence part and Spearman's correlation coefficient for the combined model. Deviance explained for both model parts are shown. The presence-absence part was fitted by a binomial distribution, and the positive part by a gamma distribution. 


\begin{tabular}{|c|c|c|c|c|c|}
\hline \multirow[t]{2}{*}{ Variable } & \multicolumn{2}{|c|}{ Precense/absence } & \multicolumn{2}{|c|}{ Positive part } & \\
\hline & Chi sq. & $\mathbf{P}$ & $\mathbf{F}$ & $\mathbf{P}$ & \\
\hline Bathymetry & & 138.56 & $<0.01$ & 64.88 & $<0.01$ \\
\hline Bottom slope & - & - & 6.39 & $<0.01$ & \\
\hline Distance to land & 100.11 & $<0.01$ & 9.27 & $<0.01$ & \\
\hline Distance to shipping & 37.03 & $<0.01$ & - & - & \\
\hline Salinity & 9.39 & $<0.01$ & - & - & \\
\hline Filter-feeder index & & 14.01 & $<0.01$ & 3.24 & 0.03 \\
\hline XY (coordinates) & 560.15 & $<0.01$ & 15.16 & $<0.01$ & \\
\hline \multicolumn{6}{|l|}{ Model performance } \\
\hline AUC & \multicolumn{2}{|c|}{0.91} & & & \\
\hline Deviance explained & \multicolumn{2}{|c|}{$42.1 \%$} & \multicolumn{2}{|c|}{$35.5 \%$} & \\
\hline Correlation (combined) & \multicolumn{4}{|c|}{$0.46(\mathrm{P}<2.2 \mathrm{e}-16)$} & \\
\hline
\end{tabular}



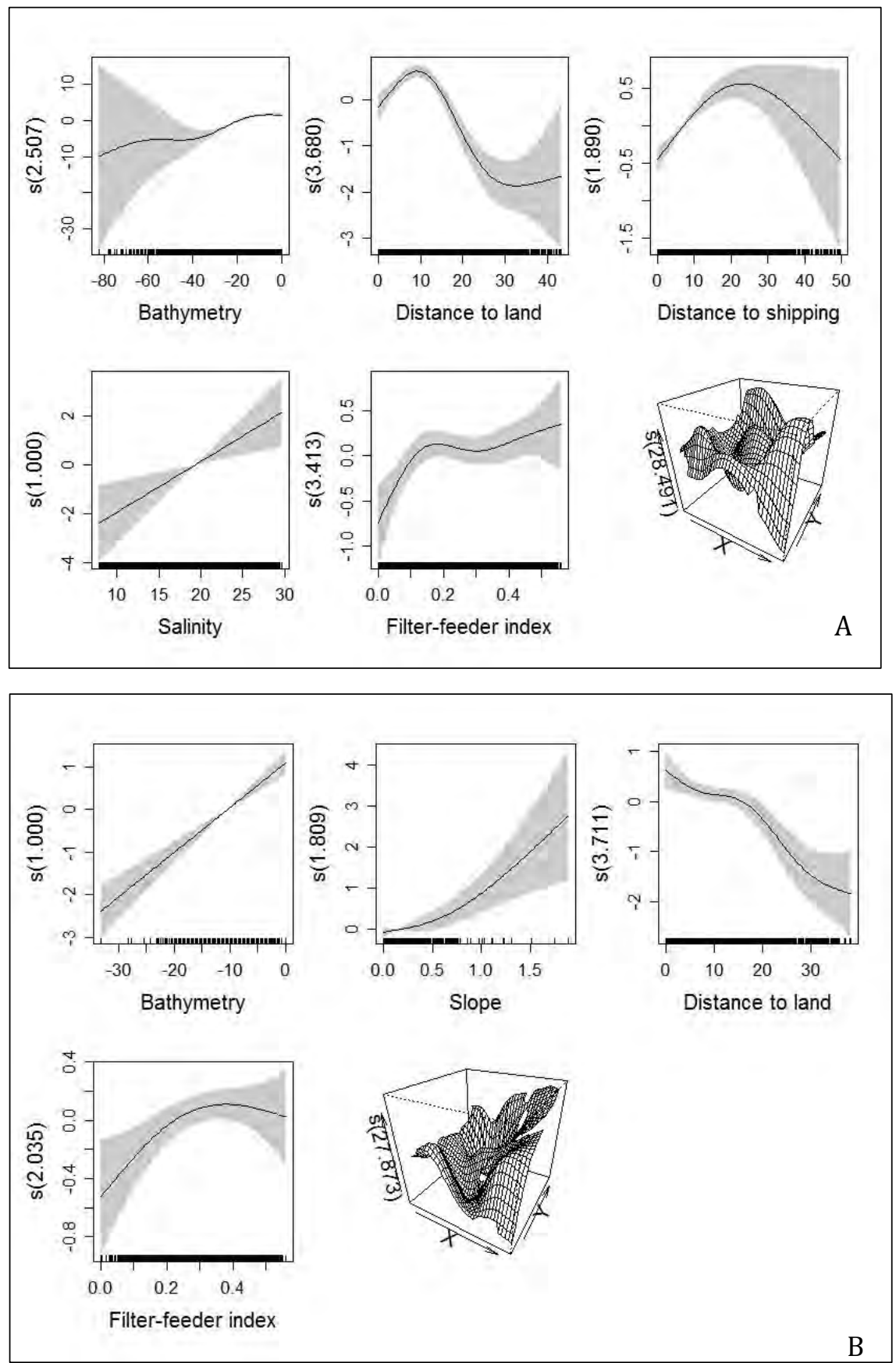

Response curves of the two-part GAM for the Common Scoter in region 1 ( $A=$ binomial part of the model and $B=$ positive part of the model). The values of the environmental predictor are shown on the $X$-axis and the probability on the $Y$ axis in logit scale. The degree of smoothing is indicated in the title of the Y-axis. The shaded areas and the dotted lines show \pm 1 standard errors. For the 2 -d term $(X, Y)$ a perspective plot is shown, with the degree of smoothing indicated as a label to the Z-axis. 

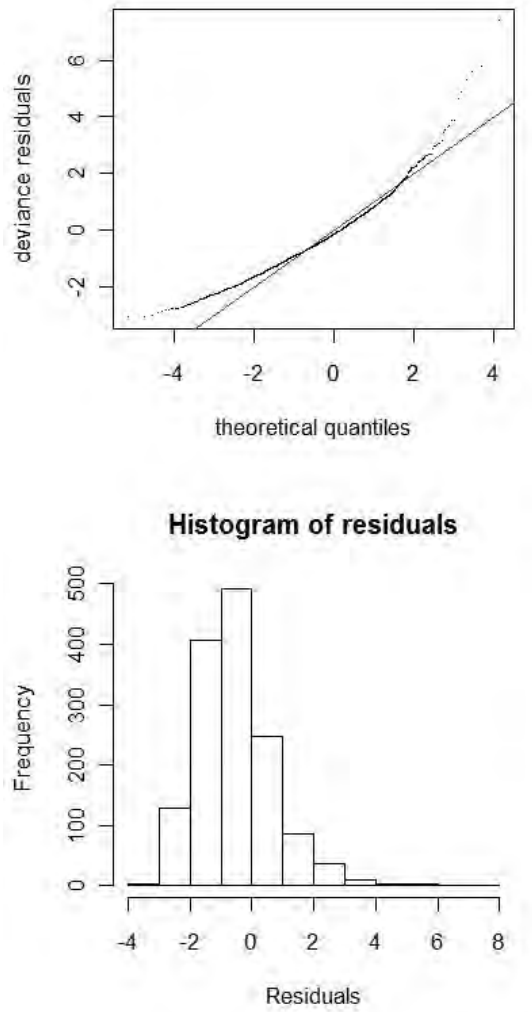

Resids vs. linear pred.

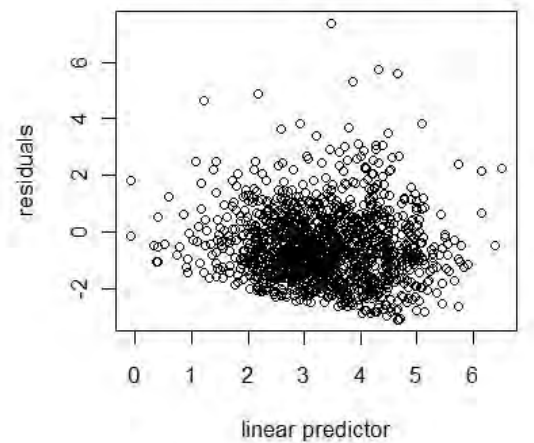

Response vs. Fitted Values

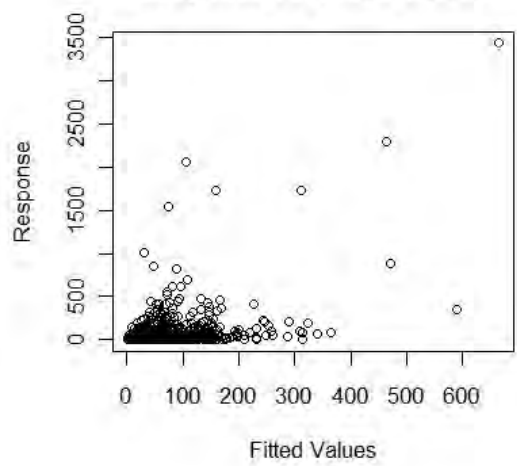

Diagnostic plots for the positive part of the two-part GAM for the Common Scoter in region 1. Normality of the residuals is displayed in a $Q-Q$ plot (upper left) and in a histogram (lower left). The spread of the residuals is displayed in the upper right plot whereas the predicted against the observed values are plotted in the lower right plot.
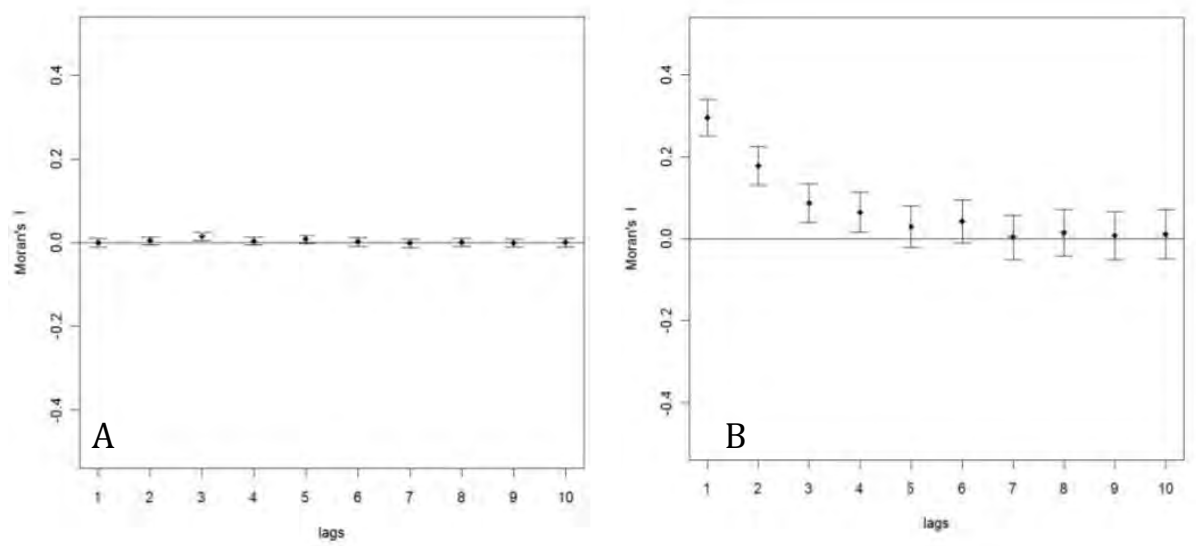

Spatial correlograms displaying the spatial autocorrelation over 10 lags in the residuals for the two-part GAM model for the Common Scoter in region 1 ( $A=$ binomial part, $B=$ positive part). The dots indicate the estimated Moran's I value and the bars show twice the square root of the variance from the estimated Moran's I value. 1 lag equals the defined nearest neighborhood of 3000 meters. Significant spatial autocorrelation was found in model residuals. In the presence/absence part weak Moran's I was only found in the third lag. Relatively strong spatial autocorrelation was found in the two first lags of the positive part and weaker in the two following lags. 


\subsection{9 "Global" Baltic model for Common Scoter}

Approximate significance of smooth terms (Chi square and $\mathrm{F}$ values) of variables in the distribution model for the Common Scoter in the "global" Baltic model. Values for both model parts are presented on separate panels. The model was evaluated by fitting the model on $70 \%$ of the data set and testing the model on $30 \%$. Evaluation results are presented as area under the receiver operator characteristic curve (AUC) for the presence/absence part and Spearman's correlation coefficient for the combined model. Deviance explained for both model parts are shown. The presence-absence part was fitted by a binomial distribution, and the positive part by a gamma distribution.

\begin{tabular}{|c|c|c|c|c|}
\hline \multirow[t]{2}{*}{ Variable } & \multicolumn{2}{|c|}{ Precense/absence } & \multicolumn{2}{|c|}{ Positive part } \\
\hline & Chi sq. & $\mathbf{P}$ & $\mathbf{F}$ & $\mathbf{P}$ \\
\hline Bathymetry & 310.91 & $<0.01$ & 58.22 & $<0.01$ \\
\hline Bottom slope & - & - & 6.97 & $<0.01$ \\
\hline Distance to land & 96.08 & $<0.01$ & 39.35 & $<0.01$ \\
\hline Distance to shipping & 119.48 & $<0.01$ & & \\
\hline Salinity & 85.89 & $<0.01$ & 5.14 & $<0.01$ \\
\hline Filter-feeder index & 121.86 & $<0.01$ & & \\
\hline XY (coordinates) & 966.32 & $<0.01$ & 15.68 & $<0.01$ \\
\hline Model performance & & & & \\
\hline AUC & \multicolumn{2}{|c|}{0.90} & & \\
\hline Deviance explained & \multicolumn{2}{|c|}{$38.7 \%$} & \multicolumn{2}{|c|}{$19.8 \%$} \\
\hline Correlation (combined) & \multicolumn{4}{|c|}{$0.37(\mathrm{P}<2.2 \mathrm{e}-16)$} \\
\hline
\end{tabular}



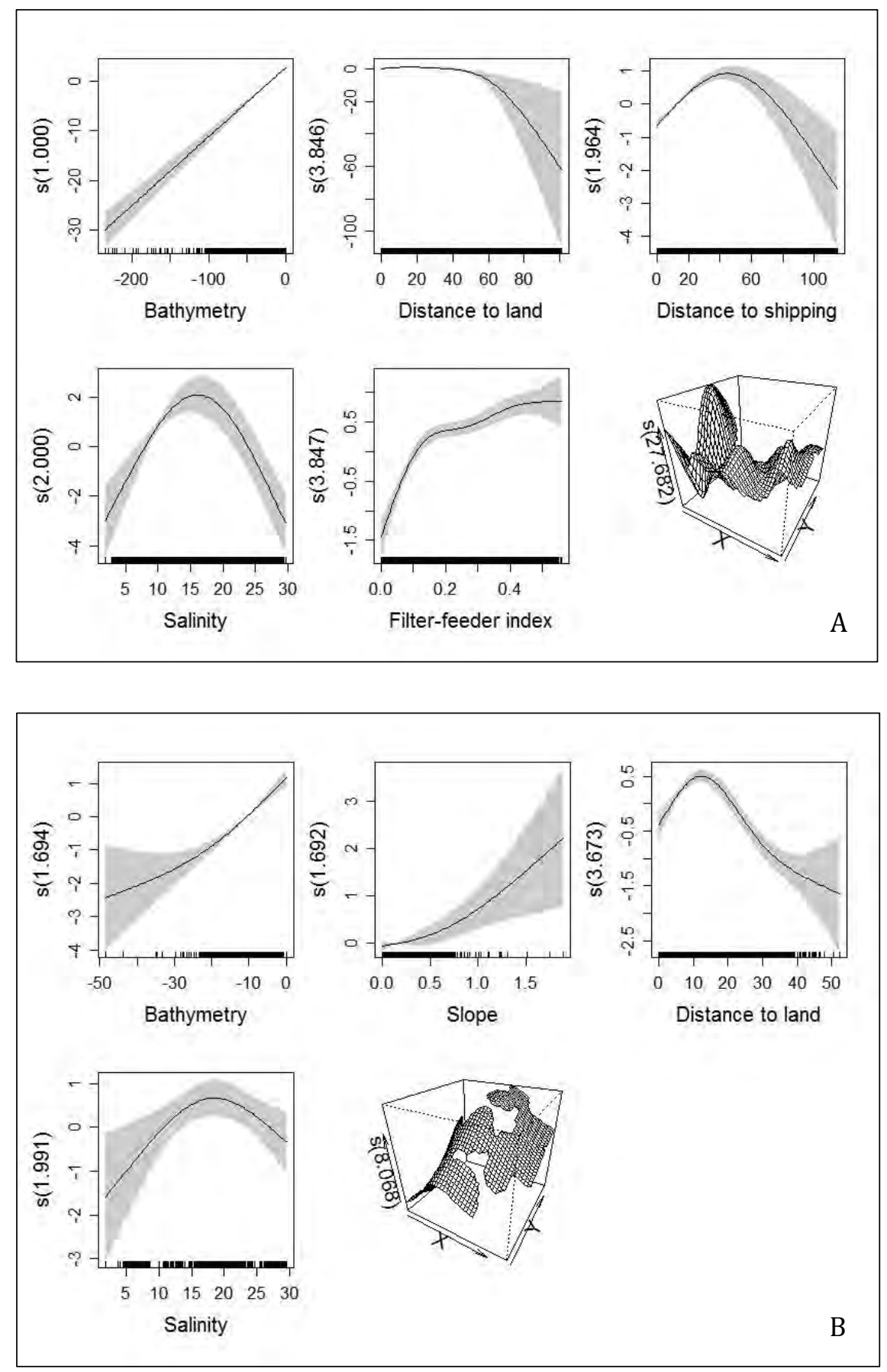

Response curves of the two-part GAM for the Common Scoter in the "global" Baltic model ( $A=$ binomial part of the model and $B=$ positive part of the model). The values of the environmental predictor are shown on the $X$-axis and the probability on the $Y$-axis in logit scale. The degree of smoothing is indicated in the title of the $Y$-axis. The shaded areas and the dotted lines show \pm 1 standard errors. For the 2-d term $(X, Y)$ a perspective plot is shown, with the degree of smoothing indicated as a label to the Z-axis. 
Resids vs. linear pred.
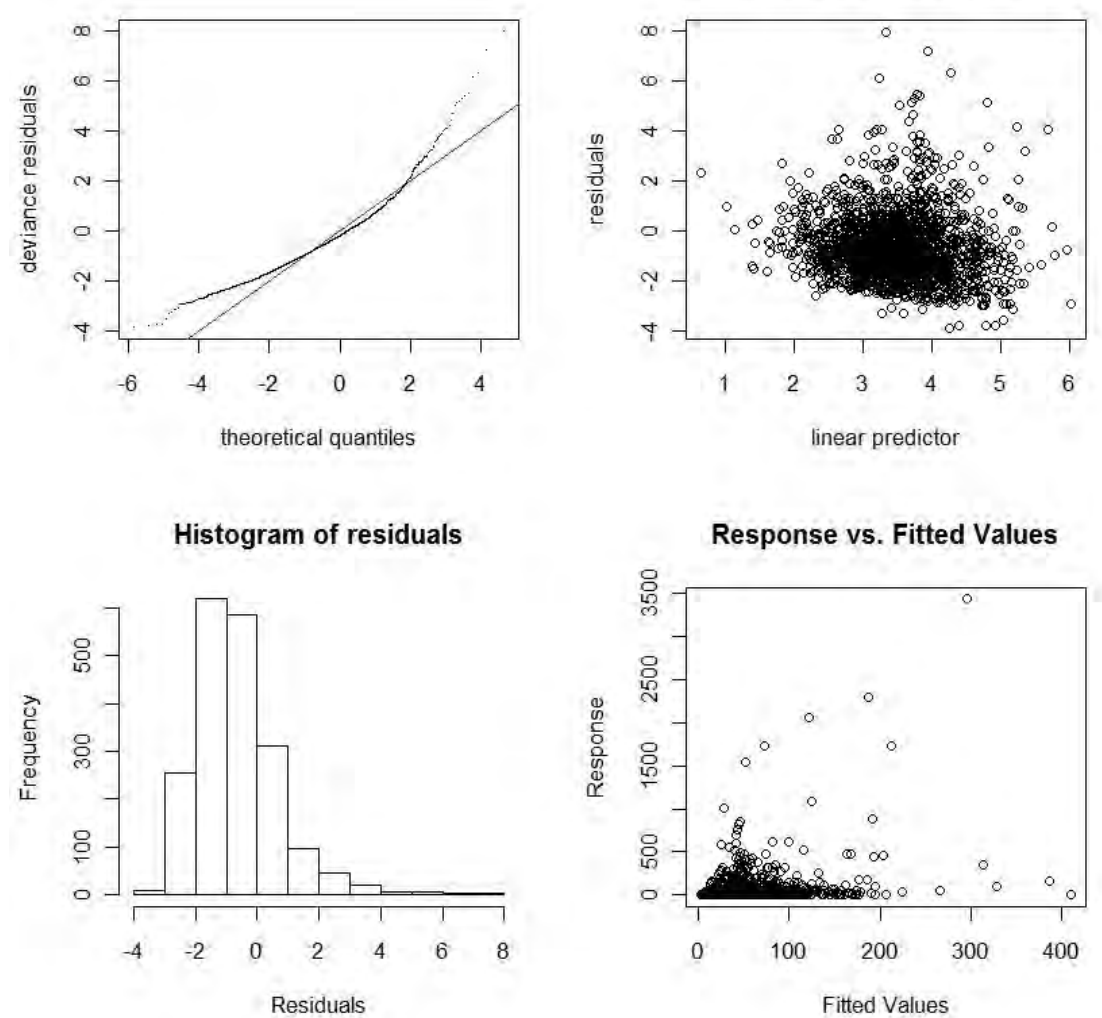

Diagnostic plots for the positive part of the two-part GAM for the Common Scoter in the "global" Baltic model. Normality of the residuals is displayed in a $Q-Q$ plot (upper left) and in a histogram (lower left). The spread of the residuals is displayed in the upper right plot whereas the predicted against the observed values are plotted in the lower right plot.
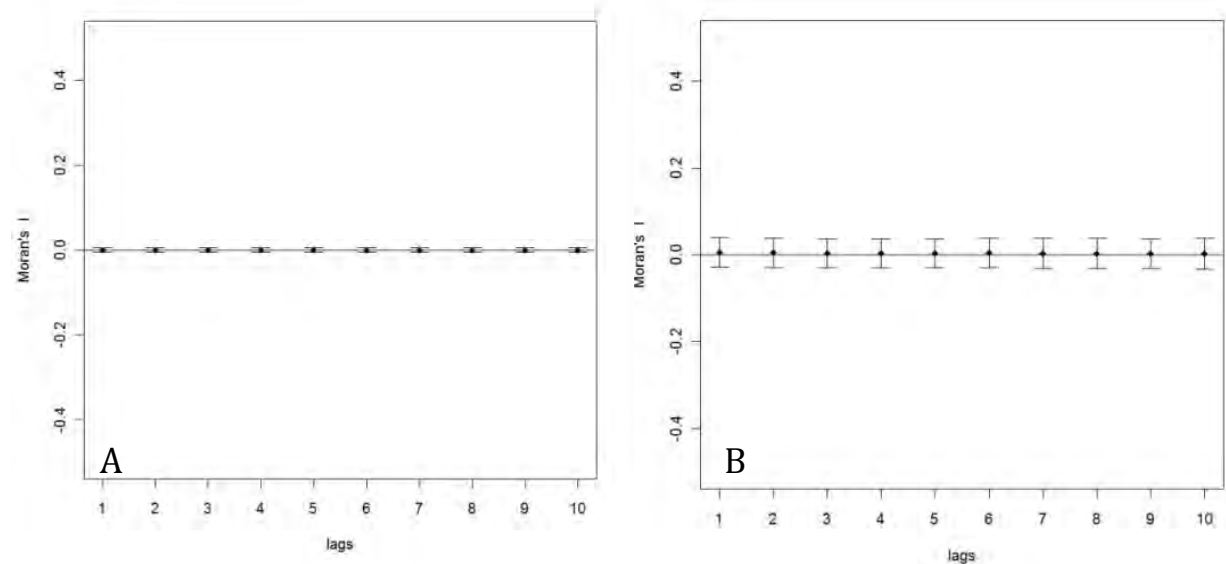

Spatial correlograms displaying the spatial autocorrelation over 10 lags in the residuals for the two-part GAM model for the Common Scoter in the "global" Baltic model ( $A$ = binomial part, $B=$ positive part). The dots indicate the estimated Moran's I value and the bars show twice the square root of the variance from the estimated Moran's I value. 1 lag equals the defined nearest neighborhood of 3000 meters. Significant spatial autocorrelation was not found in model residuals. 


\subsubsection{Velvet Scoter Melanitta fusca}

Approximate significance of smooth terms (Chi square and $\mathrm{F}$ values) of variables in the distribution model for the Velvet Scoter. Values for both model parts are presented on separate panels. The model was evaluated by fitting the model on $70 \%$ of the data set and testing the model on $30 \%$. Evaluation results are presented as area under the receiver operator characteristic curve (AUC) for the presence/absence part and Spearman's correlation coefficient for the combined model. Deviance explained for both model parts are shown. The presence-absence part was fitted by a binomial distribution, and the positive part by a gamma distribution.

\begin{tabular}{lcccc}
\hline Variable & \multicolumn{2}{c}{ Precense/absence } & Positive part \\
\cline { 2 - 5 } & Chi sq. & P & F & P \\
\hline Bathymetry & 8.27 & 0.04 & 8.26 & $<0.01$ \\
Distance to land & 93.19 & $<0.01$ & 5.47 & $<0.01$ \\
Distance to shipping & 29.97 & $<0.01$ & & 0.07 \\
Salinity & 6.68 & $<0.01$ & 2.14 & $<0.01$ \\
XY (coordinates) & 844.12 & $<0.01$ & 9.22 & \\
Model performance & & & $25.3 \%$ \\
AUC & & 0.94 & $(\mathrm{P}<2.2 \mathrm{e}-16)$ \\
Deviance explained & \multicolumn{2}{c}{$0.7 \%$} & & \\
Correlation (combined) & & 0.35 & & \\
\hline
\end{tabular}



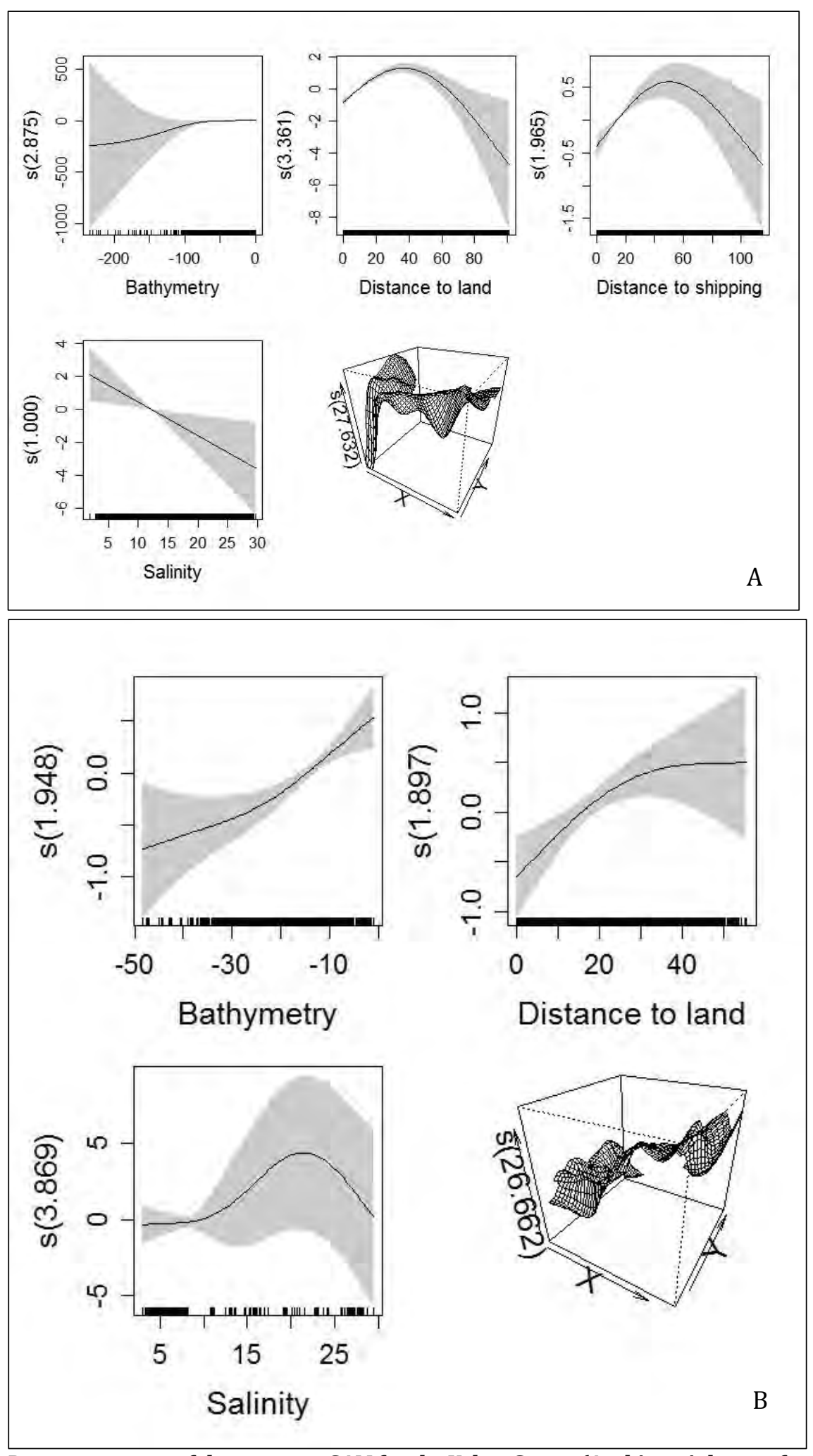

Response curves of the two-part GAM for the Velvet Scoter $(A=$ binomial part of the model and $B=$ positive part of the model). The values of the environmental predictor are shown on the $X$-axis and the probability on the Y-axis in logit scale. The degree of smoothing is indicated in the title of the $Y$-axis. The shaded areas and the dotted lines show \pm 1 standard errors. For the $2-d$ term $(X, Y)$ a perspective plot is shown, with the degree of smoothing indicated as a label to the Z-axis. 
Resids vs. linear pred.

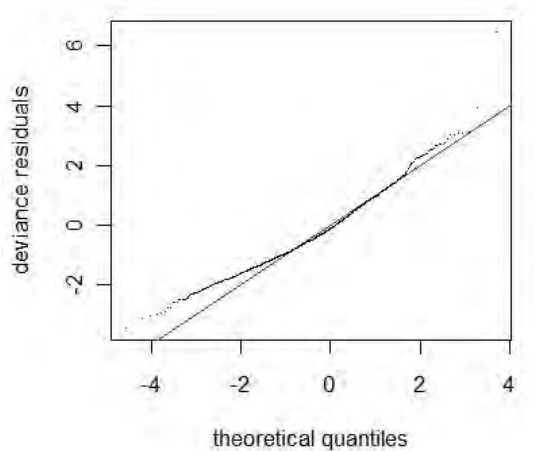

Histogram of residuals

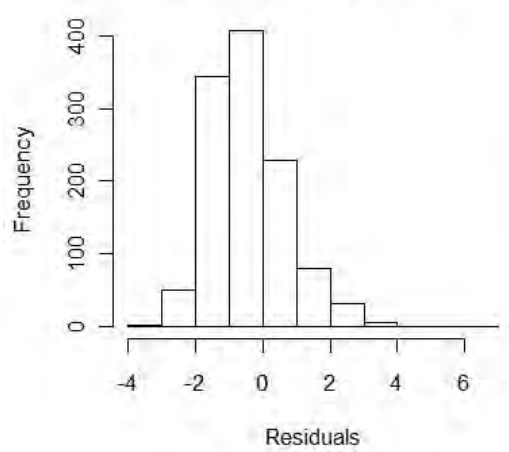

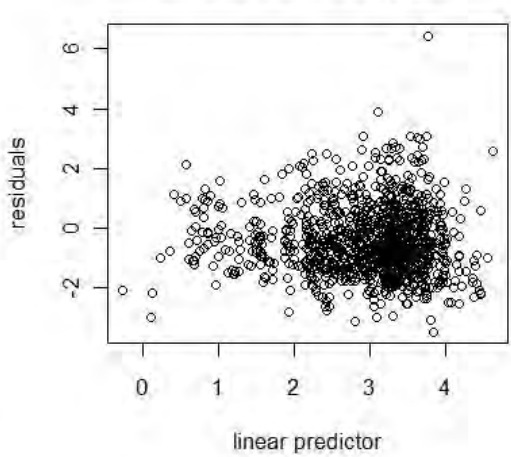

Response vs. Fitted Values

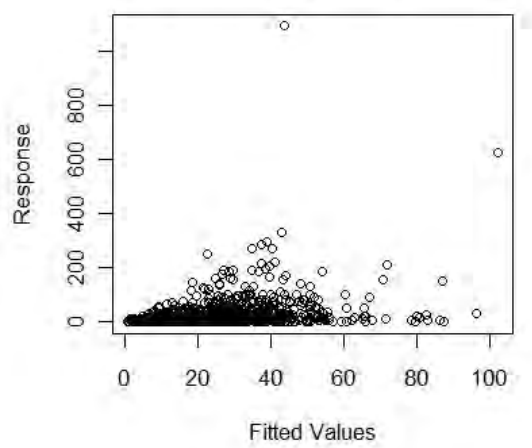

Diagnostic plots for the positive part of the two-part GAM for the Velvet Scoter. Normality of the residuals is displayed in a Q-Q plot (upper left) and in a histogram (lower left). The spread of the residuals is displayed in the upper right plot whereas the predicted against the observed values are plotted in the lower right plot.
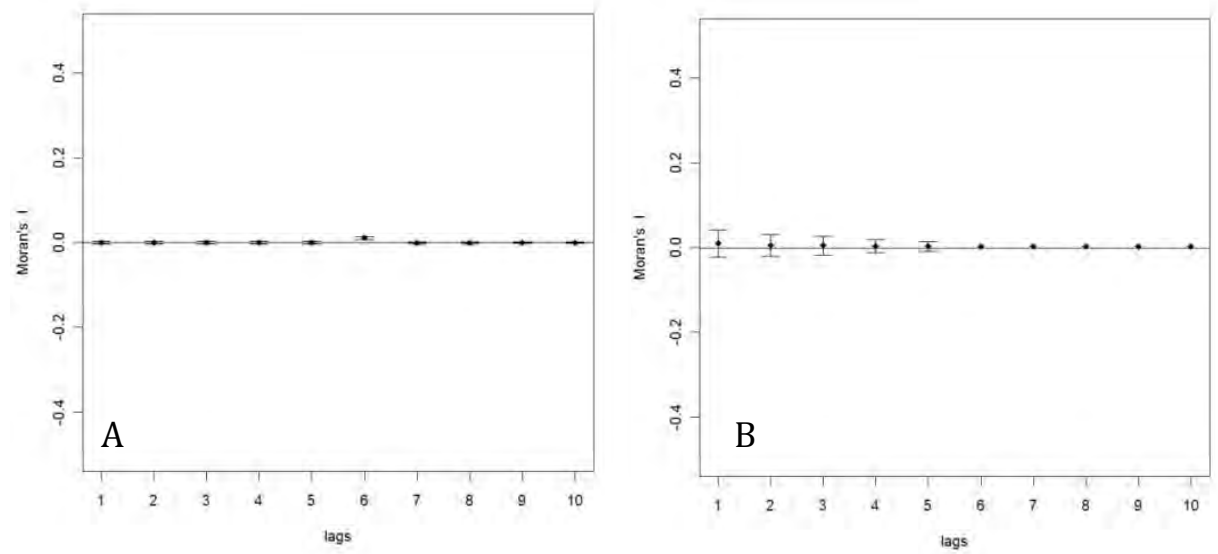

Spatial correlograms displaying the spatial autocorrelation over 10 lags in the residuals for the two-part GAM model for the Velevet Scoter $(A=$ binomial part, $B$ = positive part). The dots indicate the estimated Moran's I value and the bars show twice the square root of the variance from the estimated Moran's I value. 1 lag equals the defined nearest neighborhood of 3000 meters. Significant but very low spatial autocorrelation was found in model residuals of the presence/absence part (6th lag). 


\subsection{Appendix II Bansai 3 model complex}

Several numerical 3D flow models have been established within DHI's MIKE modelling framework covering the North Sea and the Baltic Sea. Each of these models has individual strengths. With the purpose of water quality modelling in the Baltic Sea, the so-called BANSAI model was chosen as it has been running operationally since 2001 . The model provides input data with regard to the flow field and water quality, and consists of two parts:

- A hydrodynamic module for calculating the evolution in water levels, currents, salinity, and water temperature.

- An ecological module that calculates the spreading of nutrients, the primary production, the biomass, and other ecological parameters.

The main objective of this integrated model system is to calculate the environmental status in the ecosystems of the North and Baltic Seas. This includes source apportioning, transport, dispersion, transformation and removal in the coastal and open sea marine waters of nutrients inputs to the North and Baltic Seas. Originally the BANSAI model was created in a collaboration between the Swedish Meteorological and Hydrological Institute (SMHI, Sweden), Finnish Institute of Marine Research (FIMR) and DHI.

The model is using DHI's 3-dimensional model system MIKE3 Classic, which is a fully three-dimensional, non-hydrostatic, primitive equation model (Rasmussen 1991). It is based on the Reynolds-averaged NavierStokes equations and the conservation of mass, salinity and temperature. The prognostic variables are fluid pressure, the three velocity components and the two scalar quantities salt and temperature. In the waters nearest Denmark (the eastern part of the North Sea, Skagerrak, Kattegat, the Belts and the western Baltic) a 3 nautical miles grid is used while a 9 nautical miles grid is used in the North Sea and in the eastern Baltic Sea. The local model applied has this resolution in the outer mesh but by use of the nesting technique this is downscaled by a factor 9 to a resolution of app. $600 \mathrm{~m}$ in the area of interest where the wind mills are located. The distance between the wind mills is $600 \mathrm{~m}-700 \mathrm{~m}$ which means that there will be approximately one wind turbine in each cell in the model area.

The model represents the water column with a $2 \mathrm{~m}$ resolution. The model is operational and based on:

- Meteorology

- Tide, salinity-, temperature and nutrients on the edge of the Atlantic (tide from tidal constituents, salinity and temperature from monthly climatology (ICES), nutrients from climatology supplied with national monitoring data from Denmark and Germany 
- Runoff and nutrient loadings from land (runoff from monthly climatology from HELCOM, OSPAR, national monitoring data) and nutrient loadings from climatology supplied with national monitoring data

The model was first calibrated based on measurements from the year 2000 and has been continuously improved since then.

\subsubsection{Ecological model}

The ecological model consists of an eutrophication model describing the pelagic system with 13 state variables, and seven state variables describing the exchangeable Nitrogen and Phosphorous pools in the sediment (Rasmussen et al. 2009). The pelagic system includes phytoplankton, described in terms of their concentration of carbon (C), nitrogen (N) and phosphorus (P), chlorophyll-a, zooplankton, detritus (C, N \& P), inorganic nutrients (dissolved inorganic nitrogen-DIN \& PO4-P), total N and P nutrients (including dissolved organic $\mathrm{N}$ and $\mathrm{P}$ compounds) and dissolved Oxygen (DO). Due to the depth in the wind farm development areas benthic vegetation (i.e. macroalgae) is poorly developed or not existing, and accordingly benthic vegetation is not included in the model.

In addition to state variables a large suite of derived variables such as water transparency and secchi depth is modelled and stored during the modelling process. Benthic organisms are not modelled explicitly, but are included as a forcing in the water quality model. Filter-feeding bivalves constitute on average $93 \%$ of the entire biomass of benthic invertebrates in the areas, and their filtering activity can exert a significant grazing loss on phytoplankton. Their effect is included in the model by imposing a filtration loss on phytoplankton and detritus in the near bed model layer according to the filtration capacity calculated from length distribution and total biomass of the different species. Because bivalves are not included as a state-variable they do not participate directly in nutrient cycling and accordingly, $50 \%$ of filtered algae $(\mathrm{C}, \mathrm{N}, \mathrm{P})$ are returned as inorganic solutes to the near-bed layer and $50 \%$ are entered into the detritus pool subject to sedimentation and remineralisation. The figure below shows the state variables and processes for carbon (C) for the pelagic system. 


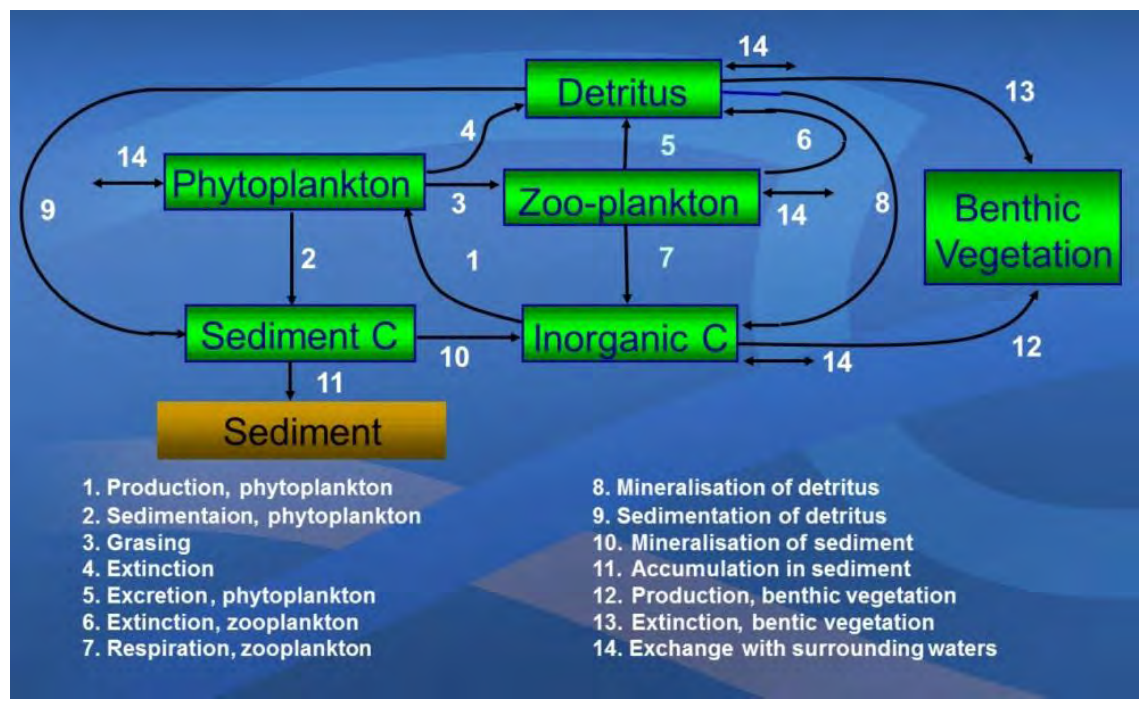

Schematic diagram showing state variables and processes for carbon in the ecological model established to simulate water quality.

The ecological model was built using the generic equation solver ECOLab that functions as a module in the MIKE 3 simulation software, and ECOLab is linked to the advection-dispersion term of the hydrodynamic flow model, enabling transport mechanisms based on advectiondispersion to be seamlessly integrated into the ECO Lab simulation. Forcings and boundary conditions of the water quality model follows the line of the forcings and boundaries of the hydrodynamic model, but in addition values for all pelagic state variables at boundaries and nutrient concentrations in freshwater loads (monthly basis) in addition to atmospheric loads are included. Boundary values are forced with water quality data extracted from the BANSAI model.

\subsubsection{Filter-feeder model}

Carrying capacity models for filter-feeders (FF) were established for epibenthic filter-feeding bivalves exemplified by Mytilus edulis using the output from the hydrodynamic and water quality models. The FF models build on the same concept by combining a physiology-based growth and survival model for a standard individual with an advection term that replenish the food ingested by filter-feeders. On a large scale benthic FF for filter-feeders depends on the local primary production and on smaller scale current speed plays an increasing role for FF.

The energy balance of a filter-feeding bivalve can be expressed as: $I=$ $P+R_{t}+F$, where $I=$ ingestion; $P=$ growth, $R_{t}=$ total respiration (sum of maintenance respiration, $R_{m}$, and respiratory cost of growth, $R_{g}$ ), and $F=$ excretion. Rearranging, growth is expressed as $P=I \times A E-\left(R_{m}+R_{g}\right)$ or $P$ $=(F \times C \times A E)-\left(R_{m}+R_{g}\right)$, where $A E=(I-F) / I=$ assimilation efficiency, $F$ $=$ filtration rate, and $C=$ algal concentration. In the individual bivalve growth depends on the quantity (C) and quality of suspended food parti- 
cles including different species of algae, ciliates and zooplankton organisms along with suspended inorganic material (silt). The maintenance food concentration (which just is sufficient for zero growth) and the maximum growth rate for a standard-sized bivalve differs between species and between populations within species as result of adaptation to local composition and concentration of food (Kiørboe \& Møhlenberg 1981). Energetic growth models are available for many filter-feeders, including Spisula subtruncata (Kiørboe et al. 1980) and Mytilus edulis (Møhlenerg \& Kiørboe 1981, Kiørboe et al. 1981).

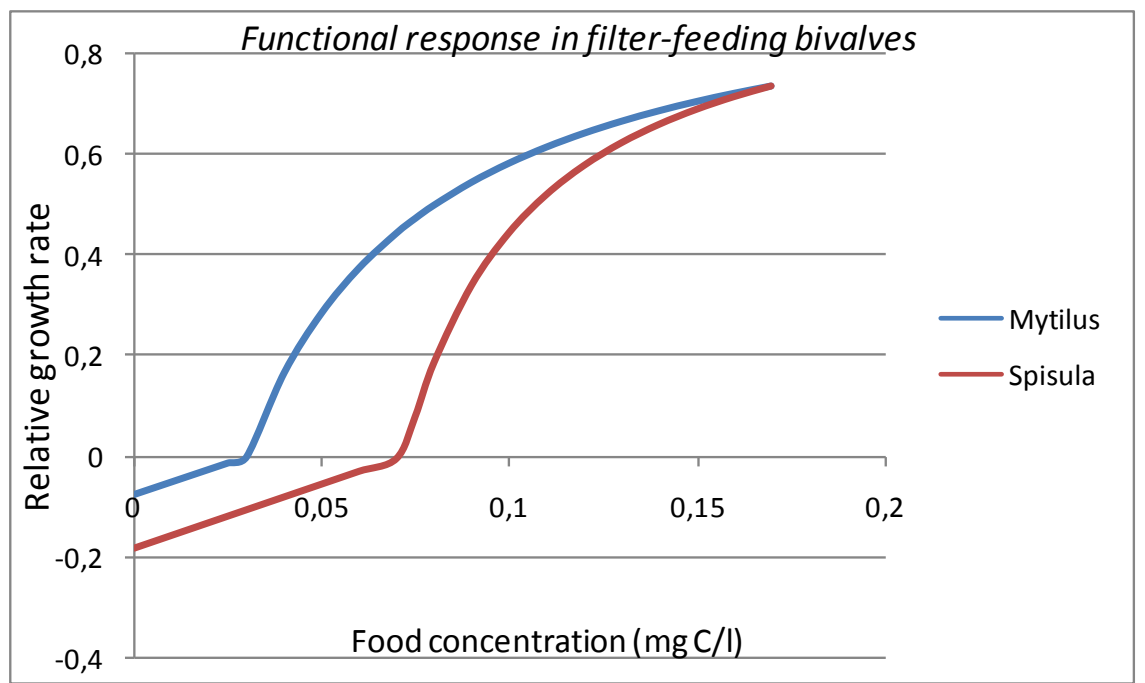

Comparison of functional response in Spisula subtruncata and Mytilus edulis.

Important documented evidence for food requirements for Spisula subtruncata (Figure 2) includes a rather high maintenance food concentration of $0.072 \mathrm{mgC} / \mathrm{l}$, and that suspended bottom material (i.e. detritus) can constitute up to $30 \%$ of assimilated food (Kiørboe et al. 1981). Based on the modelled detritus concentration in the model areas $5 \%$ of detritus was assumed to be available for assimilation, hence a growth equation fitted to observed data was developed using non-linear curvefitting:

- For food concentration (PC $+0.05^{*} \mathrm{DC}$ ) less than $0.072 \mathrm{mg} \mathrm{C} / \mathrm{l}$ :

- $\mathrm{Gf}=2.55 *(\mathrm{PC}+0.05 * \mathrm{DC}-0.1833)$

- For food concentration (PC $+0.05^{*} \mathrm{DC}$ ) above $0.072 \mathrm{mg} \mathrm{C} / \mathrm{l}$ :

- $\left.\mathrm{Gf}=\left(\mathrm{PC}+0.05^{*} \mathrm{DC}-0.072\right) /(\mathrm{PC}+0.05 * \mathrm{DC}-0.057)\right)$

The growth functions described above relate to individual bivalves surrounded by food at constant concentrations. In nature, filter-feeding bivalves aggregate in dense assemblages if current speeds are high, e.g. in tidal areas such as in the Wadden Sea. In low-current environments plankton algae removed by filtration are only slowly replenished and such environments cannot sustain dense populations. Therefore, the growth func- 
tions need to be supplemented by an equation that describes the replenishment of food. In Mytilus the in situ growth rate increases with current speed (Riisgård et al., 1994) and wind-induced turbulence (Sand-Jensen et al., 1994). As bivalves in benthic environments consisting of erodible substrate such as sand cannot maintain their position at current speeds larger than $0.6-1.0 \mathrm{~m} \mathrm{~s}^{-1}$ a bell-shaped current function with an optimum speed at $0.3 \mathrm{~m} \mathrm{~s}^{-1}$ was constructed (Figure 4 ).

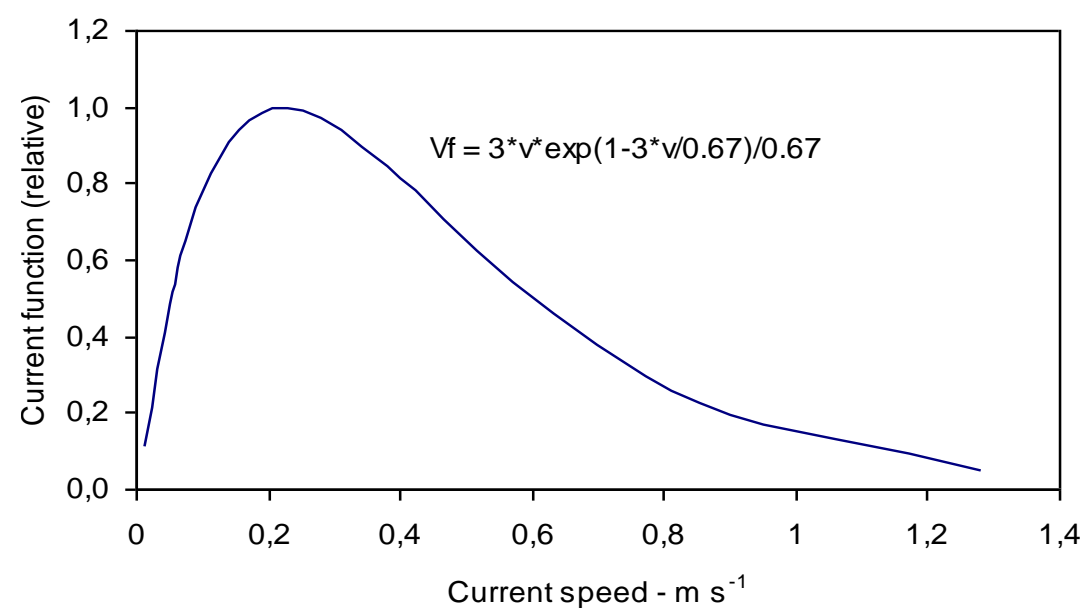

Current function to describe food replenishment and physical stress in filterfeeding bivalves.

The individual growth function can then be combined with the current function to a 'carrying capacity' index reflecting both individual growth conditions and the density of bivalves that can be sustained:

- 'CC'-index $=\mathrm{Gf} * \mathrm{Vf}$

Controlled experiments of the effects of current speed on growth have only been carried out on oysters, which showed an increase until an optimal current speed of $15 \mathrm{~cm} \mathrm{~s}^{-1}$, after which the growth started decreasing. Other bivalve species such as blue mussels increase growth in the field with increasing current speed and wind-induced turbulence until a plateau. This is generally interpreted as a consequence of increasing food availability. Mussels which are settled on substrate like cliffs, stones and foundations may survive and grow in even very energy rich environments (e.g. in current speeds $>60-80 \mathrm{~cm} \mathrm{~s}^{-1}$ ), while blue mussels on sandy sediments are unable to establish long-living populations at current speeds exceeding 40-50 $\mathrm{cm} \mathrm{s}^{-1}$, probably as a result of erosion.

Extended periods with low oxygen concentration can reduce growth and increase mortality in benthic invertebrates including filter-feeders. Such information is included numerically by multiplying the CC-index with a factor (0.8-0.9) for each day oxygen concentration is below $2 \mathrm{mg}$ $\mathrm{O}_{2} / \mathrm{l}$ but starting the reduction at day 7 with low oxygen. Also a salinitydependent function (species-specific) is included in the combined index: 
- FF-Index=CC index* SF*OF

- SF denotes a species dependent salinity index and OF denotes a species independent oxygen index. SF attains values below 1 at salinities less than 20 psu.

The final mean index for Mytilus edulis in the Baltic Sea is shown below for the period between 2000 and 2006. In general, the index is rather high in the shallow areas at depths less than 12-13 m, whereas at depths larger than $15 \mathrm{~m}$, i.e. where the seabed is located below the pycnocline, the index is rather low due to lower chlorophyll concentrations and lower current speeds. The time series documents striking patterns of benthic productivity in the shallow areas of southern and central Baltic Sea. The modelled benthic productivity provided a solid basis for the assessment of the importance of different parts of the Baltic Sea to waterbirds.

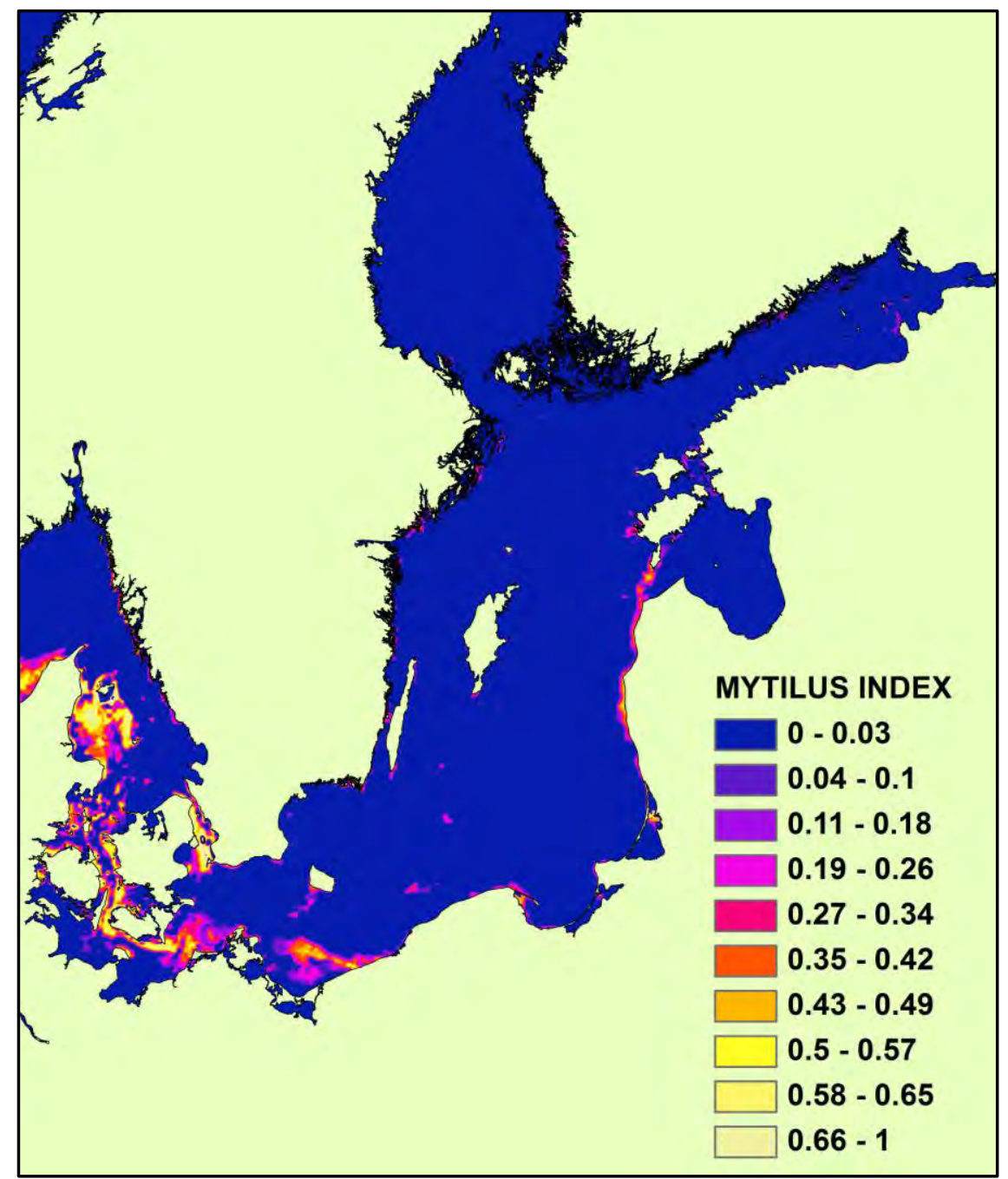

Mean modelled filter-feeder index for Mytilus in the Baltic Sea 2000-2006. 


\section{Resumé}

Denne rapport beskriver resultaterne af de koordinerede optællinger af vandfugle i Østersøen 2007-2009, som blev gennemført i forbindelse med SOWBAS-projektet (Status of wintering Waterbird populations in the Baltic Sea). Den internationale koordination og analyse af vandfugletællingerne blev gennemført med støtte fra Nordisk Ministerråd, medens tællingerne var støttet af de regionale og nationale myndigheder, og blev organiseret af de involverede institutter.

Den hidtil eneste samlede optælling af størrelsen af de overvintrende vandfuglebestande blev gennemført 1992-1993, og dokumenterede bestande på ni millioner fugle, som regelmæssigt anvender området. Selvom resultaterne af denne optælling har vist sig at udgøre et vigtigt grundlag for udpegningen af marine Natura 2000 områder i hele Østersøen, har kendskabet til den nuværende status for de overvintrende bestande været utilstrækkelig til at beskrive arternes beskyttelsesstatus, og integrere vandfuglebeskyttelsen i den bredere forvaltning på regionalt og nationalt plan.

Den manglende information har degraderet potentialet for implementering af marine naturbeskyttelsesmål, som beskrevet i HELCOM's handlingsplan for Østersøen og Nordisk Ministerråd's handlingsplan for 20052008 og 2009-2012, specielt med hensyn til økosystem-baseret forvaltning af de åbne farvande i Østersøen, og med hensyn til vurderingerne af effekterne af eutrofieringen, antropogene stoffer, fiskeriaktiviteter og klimaændringer på de større biodiversitetsværdier i regionen. Som et resultat af dette indeholder de økologiske mål for Østersøhandlingsplanen (BSAP), som tilstræber at re-etablere god økologisk status i Østersøen 2021, ikke målsætninger og indikatorer for overvintrende vandfugle.

Rapporten tilstræber at udfylde disse huller i vores viden om status og recente trends i bestandene af ovevintrende vandfugle i Østersøen. Habitater og områder dækket af denne rapport er stort set identiske med dem, der blev dækket under optællingen 1992-1993 (Durinck et al. 1994). Ligesom den tidligere optælling dækkede optællingen i 20072009 ikke ferskvandshabitater. Rapporten er opdelt i et metodeafsnit og fem afsnit, der omhandler resultaterne. Sammenlignet med rapporten, der dækkede resultaterne fra 1992-1993, er resultaterne for offshore arterne i denne rapport fremkommet på baggrund af rumlig modelering snarere end ved interpolation. Selvom begge metoder kun blev anvendt for de faktisk optalte områder bør interpolation betragtes som en mindre robust metode end rumlig modellering, da den i modsætning til denne ignorerer udbredelsen af fysiske og biologiske faktorer. 
Den første del af resultaterne omhandler den opdaterede status for vandfuglenes udbredelse, antal og habitat. For hver art vurderes betydningen af Østersøen for den berørte fly-way bestand, de vigtigste områder og udbredelsen i Østersøen, inklusiv sammenligninger med situationen i 1992-93. I det andet afsnit "Changes in wintering populations of waterbirds in the Baltic Sea” gennemgås ændringerne i bestandsstørrelse og udbredelse mere detaljeret ved trends fra udvalgte områder, der er dækket intensivt over den 23-årige periode fra 1987 til 2009, og ved sammenligninger af udbredelsen mellem 1992-93 og 2007-2009. Det tredje afsnit "Conservation status of wintering waterbirds in the Baltic Sea" opsummerer resultaterne af de artsspecifikke bestandsvurderinger. I det fjerde afsnit beskrives samspillet mellem de nuværende menneskelige aktiviteter og vandfugle i Østersøen, og inkluderer oversigter over de regionale trends i potentiale presfaktorer for vandfugle, og analyser af koblinger mellem individuelle vandfuglearter og presfaktorer, og identifikation af de vigtigste presfaktorer pr. art. Det femte og konkluderende afsnit giver retningslinier for forvaltning og overvågning, inklusiv en foreløbig udvælgelse af indikator for vandfugle for hele Østersøen.

Af de 20 vandfuglearter, der er omfattet af denne rapport, er bestandene for de 11 arter gået tilbage i løbet af perioden mellem de to optællinger; 7 af disse er gået stærkt tilbage med mere end $30 \%$ over 16 år. De estimerede totalantal af overvintrende vandfugle i perioden 2007-2009 var 4.41 millioner sammenlignet med 7.44 millioner under 1992-1993; en tilbagegang på omkring $41 \%$. Summen af andelene af de bio-geografiske bestande kan anvendes som en indikation på den totale beskyttelsesstatus. En sammenligning mellem de to perioder viser en reduktion i den totale beskyttelsesstatus for Østersøen's vandfugle på $30 \%$.

På trods af de gennemgående store tilbagegange $\mathrm{i}$ bestandene af overvintrende vandfugle i Østersøen viser resulterne af tællingerne variationer i det generelle billede. Såvel optællingsresultaterne og trendanalyserne indikerer stabile eller stigende bestande for Knopsvane, Gråand og Blishøne i stort set alle områder siden 1993. Trendanalyserne afslørede, at antallet af knopsvaner i Kattegat faktisk er gået tilbage årligt med $3 \%$ siden 1995, hvorimod antallet i den centrale del af Østers $\emptyset$ en generelt er steget årligt med 2-4\%, og i den nordlige Østersø med 6 \%. På trods af en gennemgående positive bestandsudvikling har Gråand og Blishøne været i tilbagegang i Schleswig-Holstein, Finland og Estland. Negative korrelationer med nærinsstofkoncentrationer er dokumenteret for Gråand i Estland og Knopsvane i de danske stræder og i den tyske del af den central Østersø, og inddirekte ved den positive kobling mellem Gråand og secchi dybde i den tyske del af den Centrale Østersø og Blishøne i de danske stræder. Den generelle positive status for de herbivore vandfugle i Østersøen kan derfor betragtes som en respons på den generelle forbedring af vandkvaliteten drevet af den koordinerede implementering siden 1993 af politiske handlingsplaner til bekæmpelse af eutrofiering. Derudover observeres der positive korrelationer med hav- 
temperaturen om vinteren og det såkaldte Østersøindeks hos alle tre arter i den centrale og sydlige del af Østersøen.

Optællinger og trend-analyser dokumenterede, at bentiske karnivore arter i kystnære og marine habitater generelt har vist forskellige bestandsudviklinger siden 1993. Hvor bentiske karnivore med en kystnær udbredelse har haft relativt stabile bestande så har dykænder og skalleslugere, som er udbredt længere offshore, alle udvist store tilbagegange. Desværre har lange tidsserier på skalleslugere og dykænder ikke været til rådighed fra offshore-områderne i Østersøen. Af den grund er korrelationer med næringsstofkoncentrationerne generelt svage på trods af store og parallele reduktioner i næringsstofbelastning, bentisk produktivitet og i antallet af overvintrende dykænder. Tilbagegangen i bestandene af overvintrende Ederfugl, Fløjlsand og Havlit ligger generelt på over $45 \%$, med lidt kraftigere tilbagegang i den sydlige og vestlige del. Eftersom der ikke er observeret et skift mod nord i udbredelsen af disse arter kan udbredelsen af havdykænderne i Østersøen generelt siges nu at være mere koncentreret. De indsamlede data på Havlit viser tilbegange på omkring $65 \%$ af denne den mest talrige af de overvintrende vandfugle i Østersøen. Tilsvarende tilbagegange dokumenteres for Stellersand og Fløjlsand. Tilbagegangen hos Ederfugl er på 51 \%, hos Sortand $47 \%$ og hos Toppet Skallesluger $42 \%$.

I den kystnære zone og i lagunerne har antallet af Taffeland og Stor Skallesluger været stabilt siden 1993, hvorimod Bjergand og Lille Skallesluger har haft moderate tilbagegange (h.h.v. $25.9 \%$ og $13.0 \%$ ), og alle fire arter har udvist moderate skift mod nord i deres udbredelse.

Troldand og Hvinand har begge udvist store bestandsfremgange, og et signifikant skift i udbredelsen mod nord. De største koncentrationer af begge arter findes nu i skærgårdsområderne langs den svenske østersøkyst. Den kystnære tidsserie for Hvinand viser årlige stigninger på 7-9 $\%$ for Estland og Finland, og $2.8 \%$ for den central del af den svenske østersøkyst, medens Troldand viser en årlig stigning i Estland på $18.9 \%$ og $3.9 \%$ langs den central del af den svenske østersøkyst.

Det nordlige skift i udbredelsen af Aythya ænder og Hvinand kan fortolkes som en respons på klimaændringer, som den reflekteres af positive korrelationer mellem tidsserier for disse arter, havtemperatur og Østersøindekset.

Udviklingen i antallet af overvintrende fiskespisende vandfugle (lommer, lappedykkere og skarver) i Østersøen varierede meget fra art til art. Estimaterne for Rødstrubet/Sortstrubet Lom indikerer en stor bestandsnedgang på $85 \%$ siden 1993. Antallet af Toppet Lappedykker er faldet moderat med $27 \%$, medens den Nordiske Lappedykker nu er mere almindelig i Østersøen om vinteren, og er steget med $61 \%$. Eftersom ingen skibsbaserede surveys blev gennemført i danske farvande er bestandsudviklingen hos Gråstrubet Lappedykker usikker. Med undtagelse af Kattegat, udviser Skarven generelt store bestandsstigninger 
over hele Østersøen. Den største stigning er sket i MecklenburgVorpommern og i Poland (årlige stigninger på 11 \% og $19 \%$ ).

Anbefalinger til indikatorer dækker prioriterede arter i forhold til naturbeskyttelse og arter, som kan anvendes som performance-indikatorer i relation til internationale og nationale handlingsplaner til reduktion af anthropogene presfaktorer i Østersøen. Flere presfaktorer vurderes at spille en vigtig (negative eller positiv) rolle for udviklingen i bestande og udbredelsesmønstre for de fleste vandfuglearter. Kvantifiseringen af den relative effekt af de enkelte presfaktorer på beskyttelsesstatus for de enkelte arter vil kræve mere detaljerede statistiske analyses, som ligger udenfor rammerne for dette projekt. De foreslåede indikatorer skal ses som et første skridt i retning af at inkludere målsætninger og indikatorer for de overvintrende vandfugle i Østersøhandlingsplanen (BSAP).

Listen af prioriterede arter er baseret på arter I Annex I til EF's Fugledirektiv (EC Birds Directive 1979) eller på betydningen af Østersøen i forhold til den relevante bio-geografiske population. Med hensyn til sidstnævnte er arter udvalgt for hvilke Østersøen er af global betydning i relation til den bio-geografiske population ( $\geq 25 \%$ ).

En bred vifte af vandfugle-økotyper (herbivore, omnivore, molluscivore) kan anvendes som indikatorer på klimaændringer. Selvom BSAP ikke endnu indeholder mål relateret til klimaændringer er det værd at bemærke det generelle skift i udbredelsen af overvintrende vandfugle mod nordlige områder, der er sket over de sidste 15 år. Hovedparten af disse udbredelses-skift kan formodentlig kobles til reductioner i kapaciteten af økosystemerne i den sydlige Østersø og til stigningen i havtemperatur og den relaterede stigning i tilgængeligheden af åbne havområder. På trods af at udbredelsen af Knopsvane, Gråand og Blishøne ikke har ændret sig mærkbart viser tidsserier for disse arter positive korrelationer med stigende vandtemperaturer i Østersøen. Denne kobling er ikke overraskende i betragtning af disse arters følsomhed overfor kolde vintre og isdække.

Opfølgende studier er nødvendige for at undersøge de geografiske og habitat-specifikke koblinger mellem muslingespisende havdykænder og varierende niveauer af reduktioner i næringsstoftilførslen til det baltiske $ø$ kosystem. For nærværende kan vi observere, at de gennemgående nedgange i bestandene af havdykænder og skalleslugere er sket parallelt med tilsvarende reduktioner i næringsstofkoncentrationen i kystområderne i den sydlige og centrale Østersø. Resultaterne af undersøgelserne understreger betydningen af eutrofiering som en nøgle pres-faktor i forhold til den spatio-temporale variation i udbuddet af føde for og antallet af vandfugle i Østersøen. Samtidigt skal det understreges, at flere vandfuglearter som er i tilbagegang i Østersøen, rekrutteres fra yngleområderne i Sibirien's arktiske, sub-arktiske og tundra regioner, og derfor kan være genstand for direkte eller indirekte effekter af klimainducerede ændringer i økosystemerne i disse regioner. Nyere monitoringsresultater fra det Arktiske vandfugletræk i Estland har afsløret generelle 
lave andele af ungfugle blandt vandfuglearterne fra Arktis og tundraen (Ellermaa et al. 2009).

Indikatorer på olieforurening kan udvikles ud fra optællinger af strandede fugle og stikprøver af netdrukne fugle. Illegale udslip af olie kan stadig forårsage en stor ekstradødelighed blandt overvintrende vandfugle i de åbne havormåder i Østersøen. Skalaen og betydningen af problemet kan ikke i øjeblikket vurderes for alle farvande, men for lithauiske og svenske farvande indikerer den nuværende dødelighed og andelen af olieforurenede fugle at olieforurening udgør en af de vigtigste trusler for vandfugle, her især Havlit og Lomvie.

På trolds af de manglende nationale og internationale monitoringsprogrammer omkring bifangster af vandfugle i Østersøen rapporteres der om bifangster fra adskillige fiskeri/vandfugle-scenarier i Østersøen. Generelt erfarer alle dykkende arter i dag øget dødelighed på grund af bifangst i fiskenet. Uden dedikerede overvågningsprogrammer vil omfanget af problemet ikke kunne estimeres pålideligt. 


\section{Waterbird Populations and Pressures in the Baltic Sea}

This report outlines the results of the internationally coordinated census of wintering waterbirds in the Baltic Sea 2007-2009 undertaken under the SOWBAS project (Status of wintering Waterbird populations in the Baltic Sea). The estimated total number of wintering waterbirds was 4.41 million compared to 7.44 million during the last co-ordinated census 1992-1993. Despite the general declines stable or increasing populations of herbivorous species were recorded. While benthic carnivores with a coastal distribution have either shown moderate declines, stable or increasing populations seaducks with an offshore distribution have declined seriously. Based on analyses of trends in wintering waterbirds and pressures indicators are suggested as performance indicators in relation to the international and national actions taken to reduce the anthropogenic pressures in the Baltic Sea. 